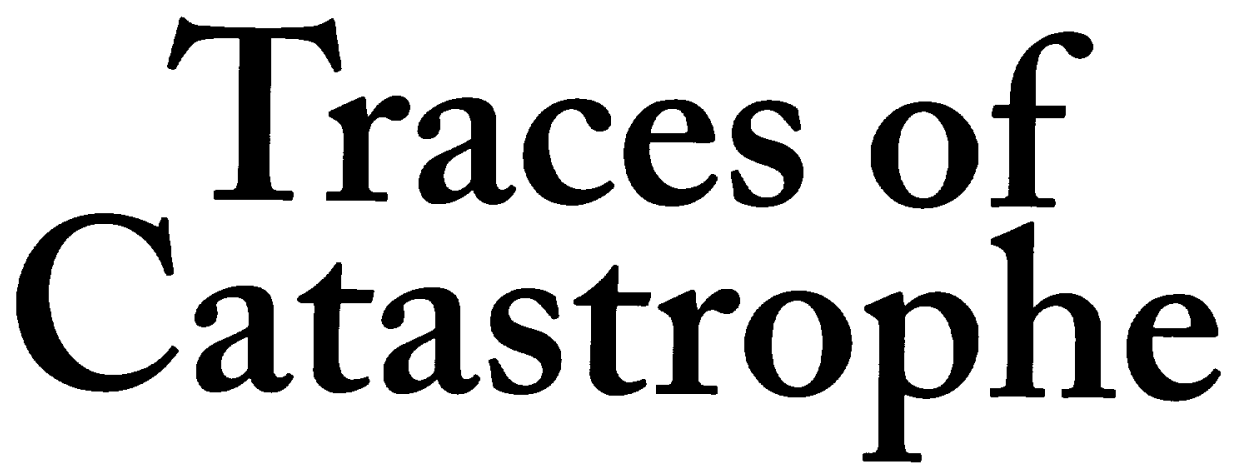

\title{
A Handbook of Shock-Metamorphic Effects in Terrestrial Meteorite Impact Structures
}

\author{
Bevan M. French \\ Research Collaborator \\ Department of Mineral Sciences, MRC-119 \\ Smithsonian Institution \\ Washington DC 20560
}




\section{Copyright (C) 1998 by \\ LUNAR AND PLANETARY IN STITUTE}

The Institute is operated by the Universities Space Research Asso iation under Contract No. NASW-4574 with the National Aeronautics and Space Administration.

Material in this volume may be copied without restraint for libray, abstract service, education, or personal research purposes; however, republication of any portion thereof re fuires the written permission of the Institute as well as the appropriate acknowledgment of this publication.

Figures $3.1,3.2$, and 3.5 used by permission of the publisher, Oxfor 1 University Press, Inc. Figures 3.13, 4.16, $4.28,4.32$, and 4.33 used by permission of the publisher, Springer-Verlag. Figure 4.25 used by permission of the publisher, Yale University. Figure 5.1 used by permission of the publisher, Geological Society of America. See individual captions for reference citations.

This volume may be cited is

French B. M. (1998) Traces of Catastrophe: A Handbook of Shock-i Metamorphic Effects in Terrestrial Meteorite Impact Structures. LPI Contribution No. 954, Lunar and Planetary Institute, Houston. 120 pp.

This volume is distributed by

ORDER DEPARTMEN T

Lunar and Planetary Instit ite 3600 Bay Area Boulevarı!

Houston TX 77058-1113, ISA

Phone: 281-486-2172

Fax: 281-486-2186

E-mail: order@lpi.jsc.nasa.zov

Mail order requestors will be invoiced for the cost ef shipping and bandling.

Cover Art. "One Minute After the End of the Cretaceous." This artist's viev shows the ancestral Gulf of Mexico near the present Yucatán peninsula as it was $65 \mathrm{~m}$.y. ago, just after the impact of an asteroid or comet about $10 \mathrm{~km}$ in diameter began to form the huge Chixculub (Mexico) impact structure. In only a minute after the impact, a transient crater about $100 \mathrm{~km}$ across has been excavated, cutting through the surface ocean water, the underlying carbonate sediments, and the deep-seated crystalline crustal rocks. The edge of the growing transient crater is marked by a curtain of material that is being ejecte $d$ into the atmosphere. Earth's Moon appears as a small dot above and to the left of the ejecta curtain. Painting by William K. Hartmann; used by permission of the artist. 


\section{Preface}

Meteorite impacts are getting plenty of respect these days. The public regards them as the established destroyer of dinosaurs and as the possible destroyer of civilization. The large planetary science community sees impacts as the process that helped form the solar system and is still modifying planets more than 4 b.y. later. Increasing numbers of geoscientists are coming to appreciate the importance of meteorite impact events and the extent of their influence on the geological and biological history of Earth.

However, despite the growing importance of meteorite impact phenomena in terrestrial geology, the topic is still not widely addressed in general geoscience textbooks and references. (Some exceptions are Dence and Robertson, 1989; Philpotts, 1990, Chapter 14-9; Melosh, 1992; and Hibbard, 1995, Chapter 24.) The geoscientist seeking instruction and information about impacts thereforc faces a body of literature that, although large, is both specialized and scattered: isolated review articles (e.g., Grieve, 1991; Grieve and Pesonen, 1992; Grieve and Pilkington, 1996); older volumes on shock waves and cratering mechanics (Roddy et al., 1977; Melosh, 1989) and shock metamorphism (French and Short, 1968); collections of papers in special issues of various journals (Hörz, 1971; Nicolaysen and Reimold, 1990; Pesonen and Henkel, 1992; Glikson, 1996b); and several good histories and memoirs (Hoyt, 1987; Mark, 1987; Alvarez, 1997). The linking of meteorite impacts to at least one extinction cvent (Alvarez et al., 1980) has brought impact processes into the geological mainstream, and this trend is reflected by the appearance of several Special Papers of the Geological Society of America, each one a collection of technical papers involving extinctions (Silver and Schultz, 1982; Sharpton and Ward, 1990; Ryder et al., 1996) and planetary cratering (Dressler et al., 1994; Koeberl and Anderson, 1996a). More recently, several books have given serious consideration to large impact events in the present (Spencer and Mitton, 1995) and to the hazards associated with possible impact events in the future (Chapman and Morrison, 1989; Gebrels, 1994).

It is therefore surprising and unfortunate that no complete and systematic introductory textbook for geoscientists has yet appeared. With this book, I have attempted to fill this gap and provide for geoscientists a detailed introduction and overview of impact processes, crater formation, and shock metamorphism. The book is not intended for a general reader, nor is it aimed primarily at specialists actually working in impact geology. It is intended for geoscientists of all kinds: students who want to learn about the importance of meteorite impact; professors who want to add impact information to their geoscience courses; and professional geologists who may unexpectedly encounter an impact structure in the next field area or in the next drill core.

The book therefore emphasizes terrestrial impact structures, field geology, and particularly the recognition and petrographic study of shock-metamorphic effects in terrestrial rocks. As a result, I have deliberately left out or summarized only briefly many important and exciting aspects of impact geology: shock-wave physics, cratering mechanics, cratering on other planets, ejecta formation and deposits, extinction mechanisms, geochemical and geophysical studies of impact structures, and tektites. However, I have included literature references to get the interested reader started on further exploration in these fields.

Although this book could be used as a textbook, albeit a very focused one, I view it as a combination of sourcebook, laboratory manual, and reference for working geologists. The chapters are designed to be read independently, depending on the background and needs of the reader. Nonspecialists or readers interested in general information can explore the early chapters (Chapters 1 and 2). Geoscientists with backgrounds in structural geology, mineralogy, and petrology may prefer to go directly to the detailed information on cratering mechanics (Chapter 3), shock-metamorphic features (Chapter 4), impactites (Chapter 5), impact melts (Chapter 6), or the detection and identification of new impact structures (Chapter 7). With this presentation, some introductory material is repeated in different chapters, but I hope the arrangement will be useful for a wide range of readers interested in various aspects of impact. 
In any field of science, the fine details of terminology are complicated a nd often controversial. Impact geology is no exception. I have tried to keep things simple, even a the loss of some precision. For example, I use meteorite as a general term for any extraterrestrial obje zt, regardless of size, composition, or source, that is large enough to strike Earth's surface and to make a crater. More specific terms (asteroid, comet, projectile, etc.) are reserved for more specific contexts. Similarly, I use impact crater and impact structure more or less interchangeably, despite the actual differences that exist between them Finally, I have kept the classification of impactites (breccias, impact melts, etc.) as simple as possible. I hope this approach will help communicate information to all $\mathrm{k}$ nds of readers and will also prepare specialists to explore the details as needed.

I owe a great deal to many colleagues, who responded both promptly a id generously to my many requests for samples, photographs, literature references, and other materic I needed for this book. I am especially grateful to those who supplied photographs, particularly Richar 1 Grieve, Glenn Izett, and Dieter Stöffler. The reader will also note my extensive reliance on Jay Melosh's textbook (Melosh, 1989), which, after nearly a decade, still remains an essential sourcebook on the theoretical aspects of cratering mechanics and shock metamorphism. I am equally indebted to other :olleagues who reviewed the various versions of the changing manuscript, and whose criticisms and co nments produced major improvements: Burkhard Dressler, Richard Grieve, Fred Hörz, Christiar Koeberl, Bruce Marsh, Anthony Philpotts, Virgil Sharpton, Richard Wunderman, and Mary-Hil French. Any errors, misstatements, and other flaws that managed to survive are entirely my orn.

I am also grateful to the staff at the Lunar and Planetary Institute, esp :cially Mary Cloud, for their continued interest in this undertaking, for their patience while it was slowly taking shape, and for their usual speed and editorial excellence in the final production. I thank Debr. Rueb and Mary Ann Hager for providing graphics and other resources from the LPI library, and Step zen L. Hokanson and Reneé Dotson for their editorial and digital publishing expertise. Willian K. Hartmann generously provided one of his striking paintings for use on the cover. Finally, I am g ateful for the continued support of the Smithsonian Institution, which allowed me to continue working on this book as a Research Collaborator in the Department of Mineral Sciences since 1994.

The field of impact geology continues to expand in scope and importa ace, as the statistically minded reader can see from the bibliography; the number and variety of articles on the subject published in just the last five years is impressive. Even though approximately 150 terrestrial impact structures are known, several hundred remain to be discovered and studied, perhaps as senuine exercises for students. Beyond the identification of new impact structures, we are just beginning to explore the role of impacts in major geological processes: the actual mechanisms by which extinctions are produced, the recognition of distal ejecta deposits in the geological record, and the role of large impacts in shaping the Precambrian Earth. I hope this book will help in the explorations to com :.

Bevan M. French Chevy Chase, Maryland

September 1998 


\section{Dedicated to}

Ralph B. Baldwin

Robert S. Dietz

Eugene M. Shoemaker

Who were so far abead Of all the rest of us. 



\section{Contents}

\section{Chapter 1: LANDSCAPES WITH CRATERS: METEORITE IMPACTS,}

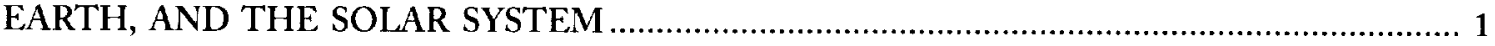

1.1. The New Geology: Meteorite Impacts on the Earth ........................................................................... 1

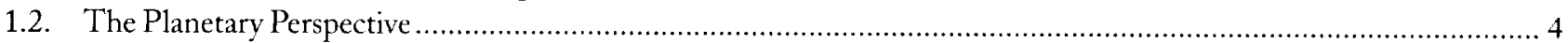

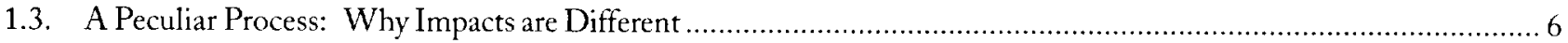

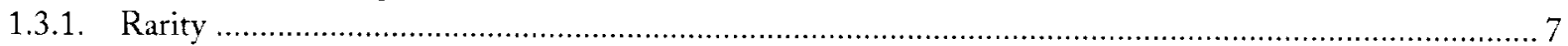

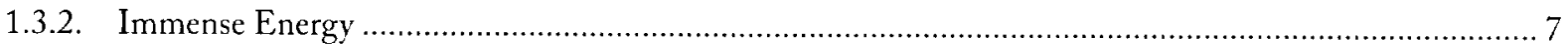

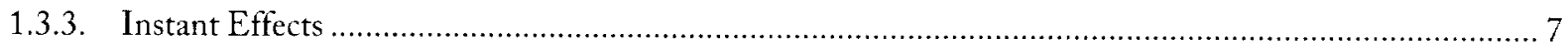

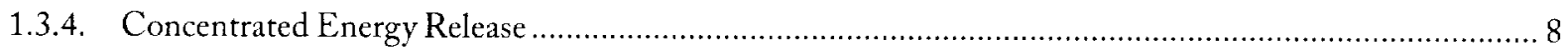

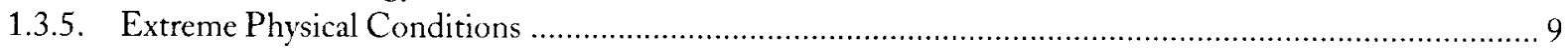

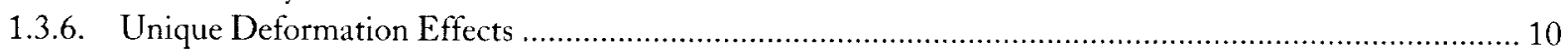

Chapter 2: TARGET EARTH: PRESENT, PAST, AND FUTURE …...................................................... 11

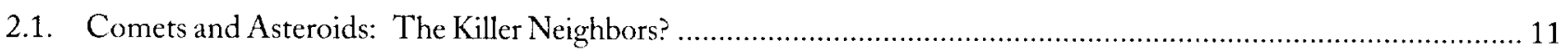

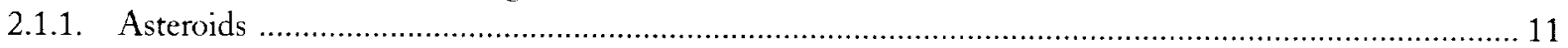

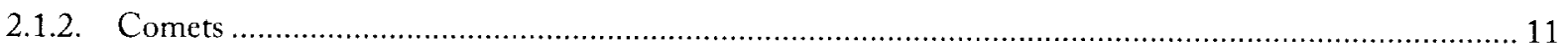

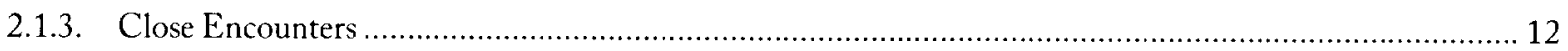

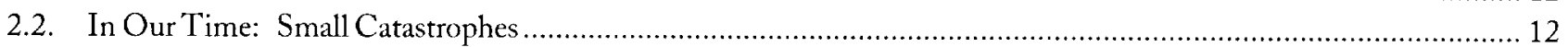

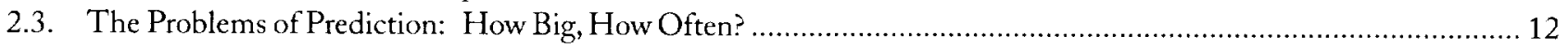

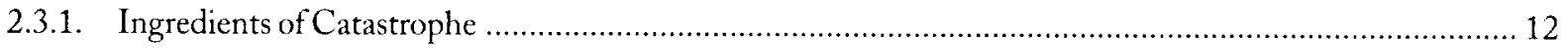

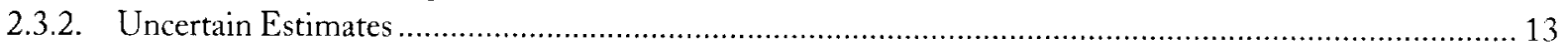

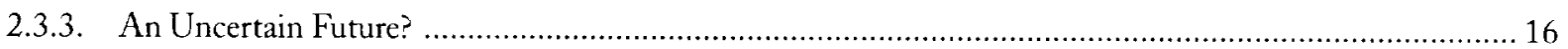

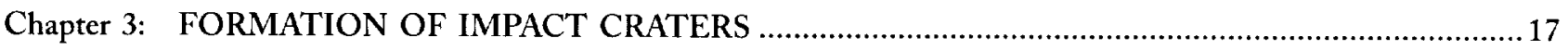

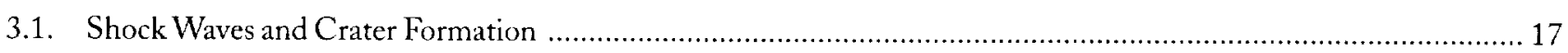

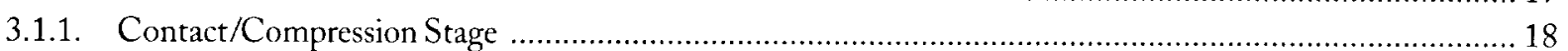

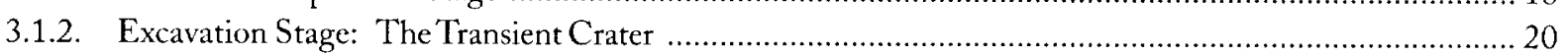

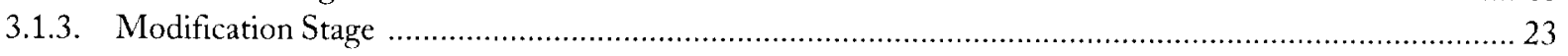

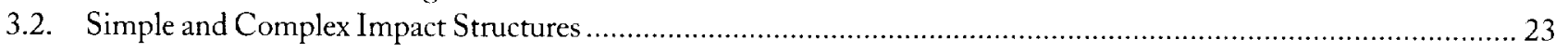

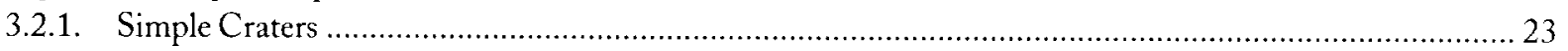

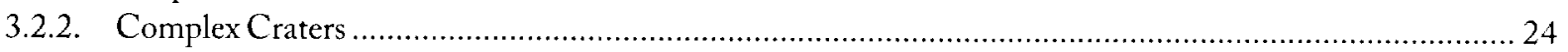

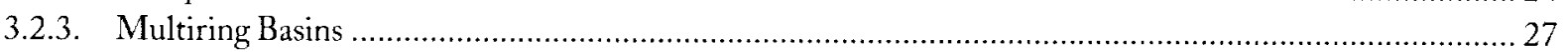

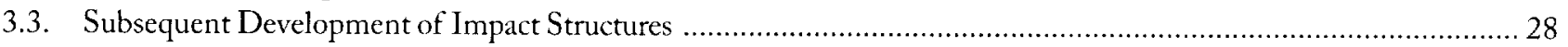

Chapter 4: SHOCK-METAMORPHIC EFFECTS IN ROCKS AND MINERALS .................................... 31

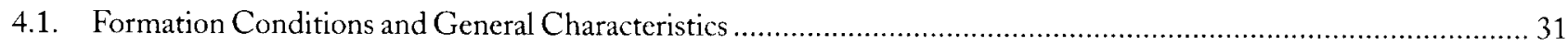

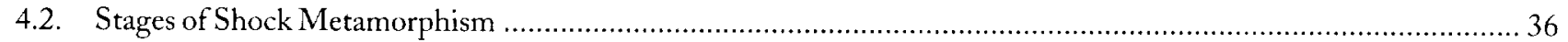

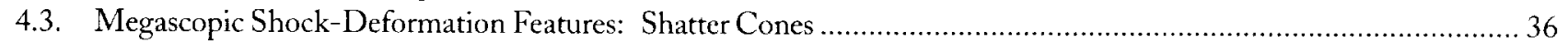

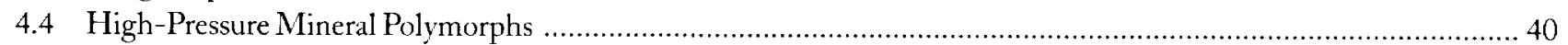

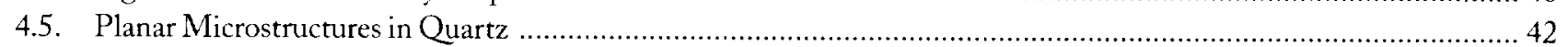

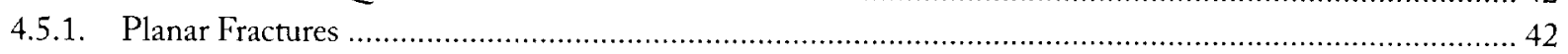

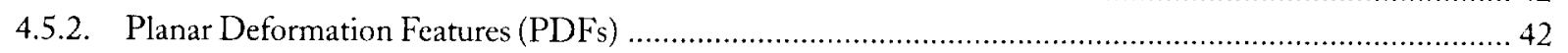

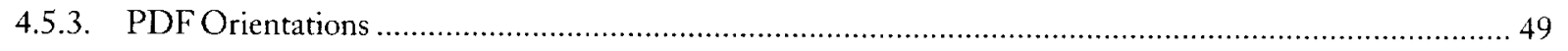

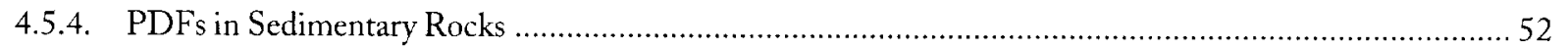

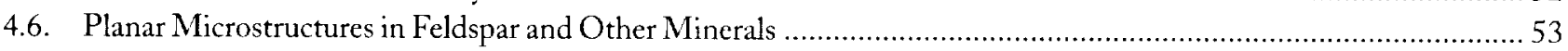

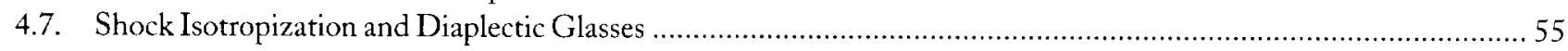

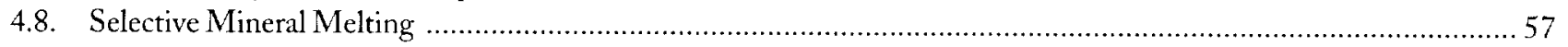




\section{Chapter 5: SHOCK-METAMORPHOSED ROCKS (IMPACTITIS) IN IMPACT STRUCTURES}

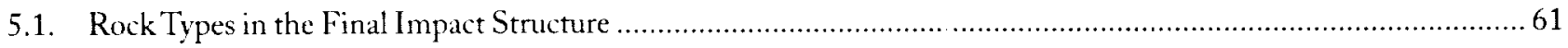

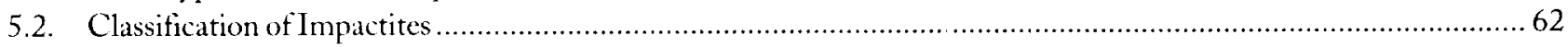

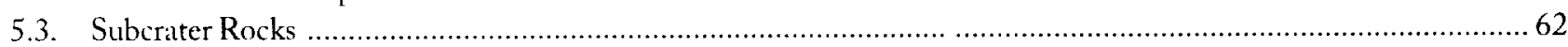

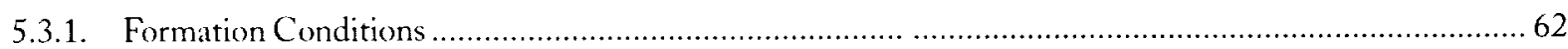

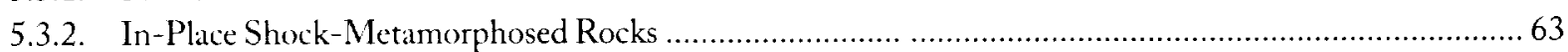

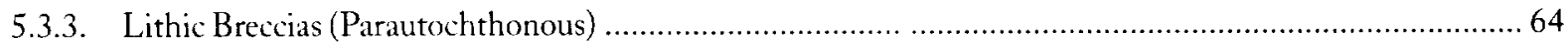

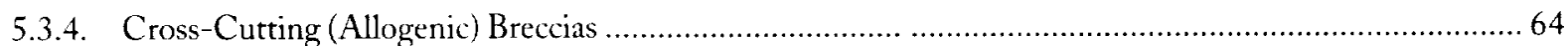

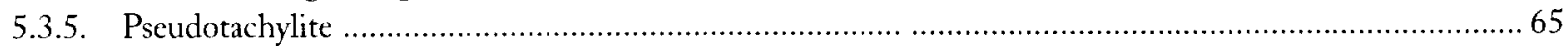

5.4. Crater Interior: Crater-Fill Deposits (Breccias and Melt Rocks) … .............................................................69

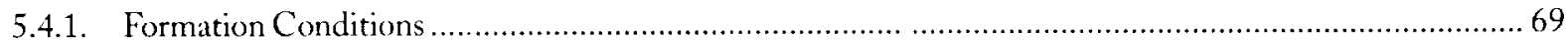

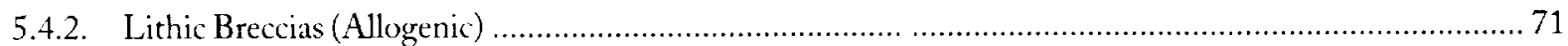

5.4.3. Melt-Fragment Breccias (Allogenic) (Suevites) ............................................................................ 71

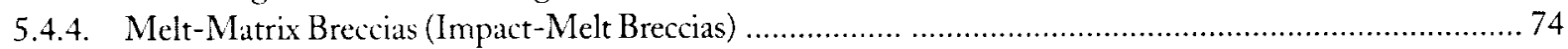

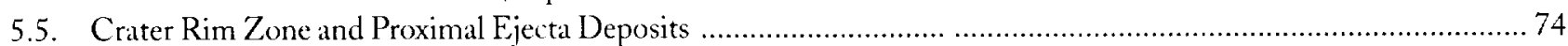

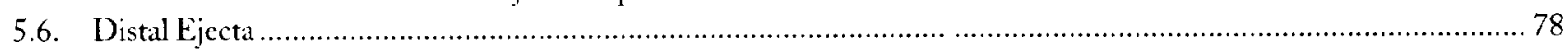

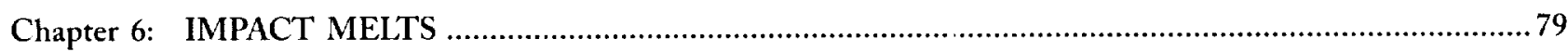

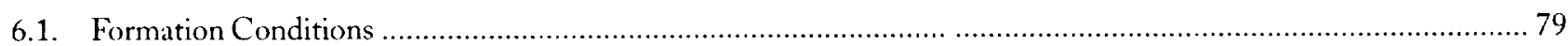

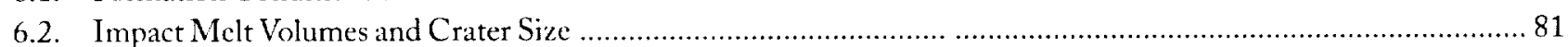

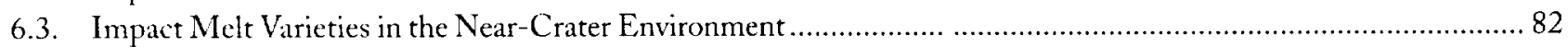

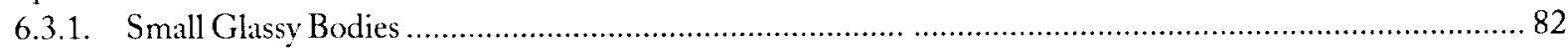

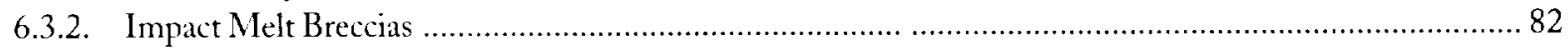

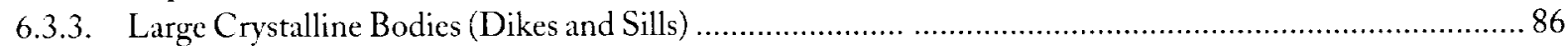

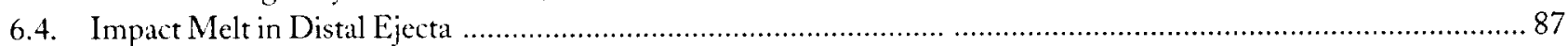

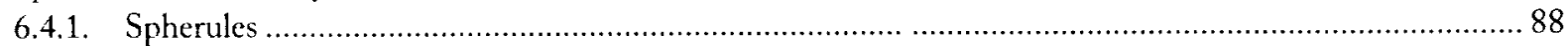

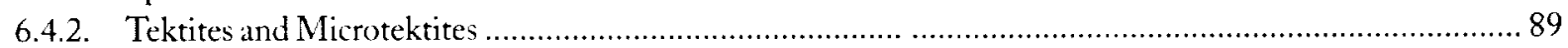

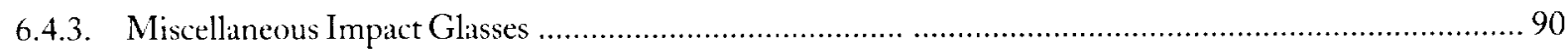

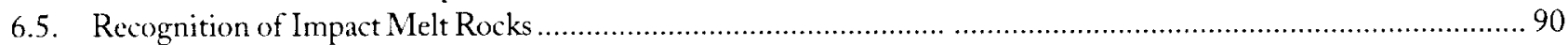

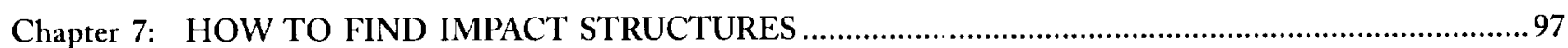

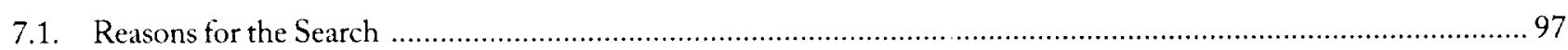

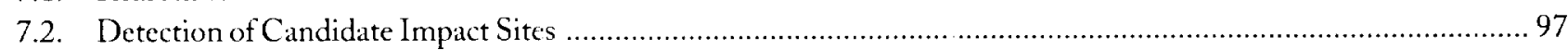

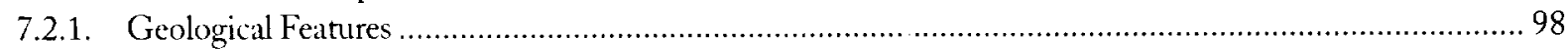

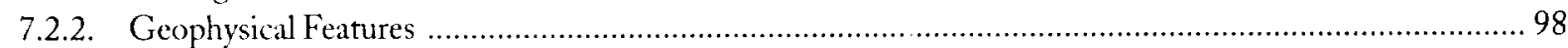

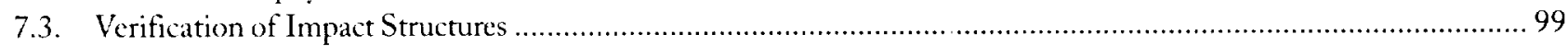

Chapter 8: WHAT NEXT? CURRENT PROBLEMS AND

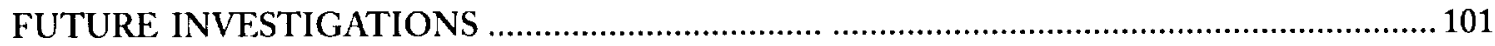

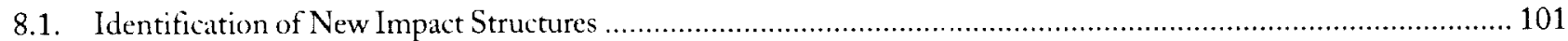

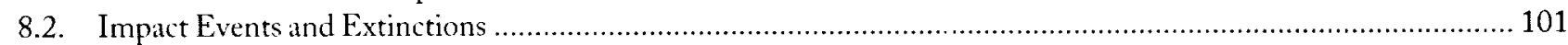

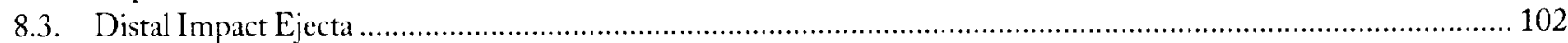

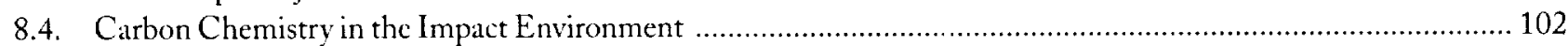

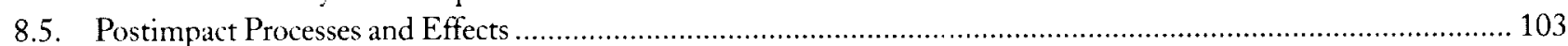

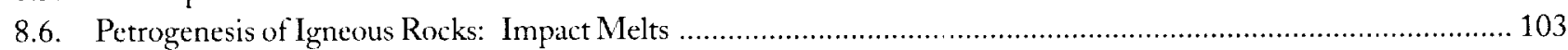

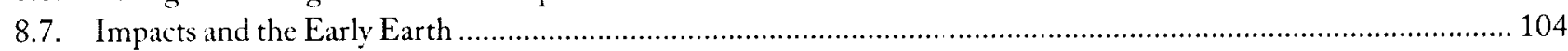

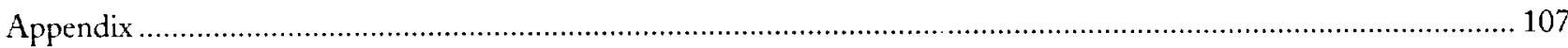

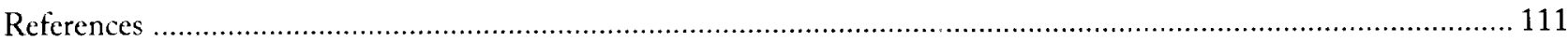




\section{1}

\section{Landscapes with Craters: Meteorite Impacts, Earth, and the Solar System}

\subsection{THE NEW GEOLOGY: METEORITE IMPACTS ONTHE EARTH}

During the last 30 years, there has been an immense and unexpected revolution in our picture of Earth and its place in the solar system. What was once a minor astronomical process has become an important part of the geological mainstream. Impacts of extraterrestrial objects on the Earth, once regarded as an exotic but geologically insignificant process, have now been recognized as a major factor in the geological and biological history of the Earth. Scientists and the public have both come to realize that terrestrial impact structures are more abundant, larger, older, more geologically complex, more economically important, and even more biologically significant than anyone would have predicted a few decades ago. Impact events have generated large crustal disturbances, produced huge volumes of igneous rocks, formed major ore deposits, and participated in at least one major biological extinction.

Before the 1960s, collisions of extraterrestrial objects with the Earth were not considered significant. Geologists did agree (and had agreed since the early 1800s) that pieces of extraterrestrial material did occasionally penetrate the atmosphere and strike Earth's surface, but the only visible results of such collisions were a collection of meteorites to study and display in museums, together with a few small and geologically short-lived meteorite craters, usually located in out-of-the-way desert areas (Fig. 1.1). Almost no one believed that extraterrestrial objects could produce major geological effects or that such projectiles could be any more than a local hazard.

This simple view has changed drastically, and the change reflects two major factors: (1) explorations of the solar system by humans and robotic spacecraft, which have established the importance of impact cratering in shaping all the planets, including Earth (Taylor, 1982, Chapter 3; 1992, Chapter 4); and (2) the ability to definitely identify terrestrial impact structures, especially large or ancient ones, by the presence of unique petrological and geochemical criteria, particularly the distinctive shock-metamorphic effects produced in rocks and minerals by the intense shock waves generated in impact events (French, 1968a; French and Short, 1968).

In the last few decades, geologists have gradually realized that collisions of extraterrestrial objects with Earth - and especially the rare but catastrophic impacts of kilometer-sized asteroids and comets - have significantly shaped Earth's surface, disturbed its crust, and altered its geological history (French, 1968a, 1990b; Shoemaker, 1977; Grieve, 1987, 1990, 1991; Nicolaysen and Reimold, 1990; Pesonen and Henkel, 1992; Dressler et al., 1994).

The record of impacts on Earth is still being deciphered. Approximately 150 individual geological structures have already been identified as the preserved results of such impacts (Grieve, 1991, 1994; Grieve et al., 1995; Grieve and Pesonen, 1992, 1996), and it is estimated that several hundred more impact structures remain to be identified (Trefil and Raup, 1990; Grieve, 1991). The known impact structures (Fig. 1.2) range from small circular bowls only a few kilometers or less in diameter (Fig. 1.1) to large complex structures more than $200 \mathrm{~km}$ in diameter and as old as $2 \mathrm{Ga}$ (Figs. 1.3 and 1.4). Formation of the larger features, such as the Sudbury (Canada) and Vredefort (South Africa) structures, involved widespread disturbances in Earth's crust and major perturbations in the geologic history of the regions where they were formed.

In addition to the geological disturbances involved, impact events have produced several geological structures with actual economic value; a production value of about $\$ 5$ billion per year has been estimated for North American 


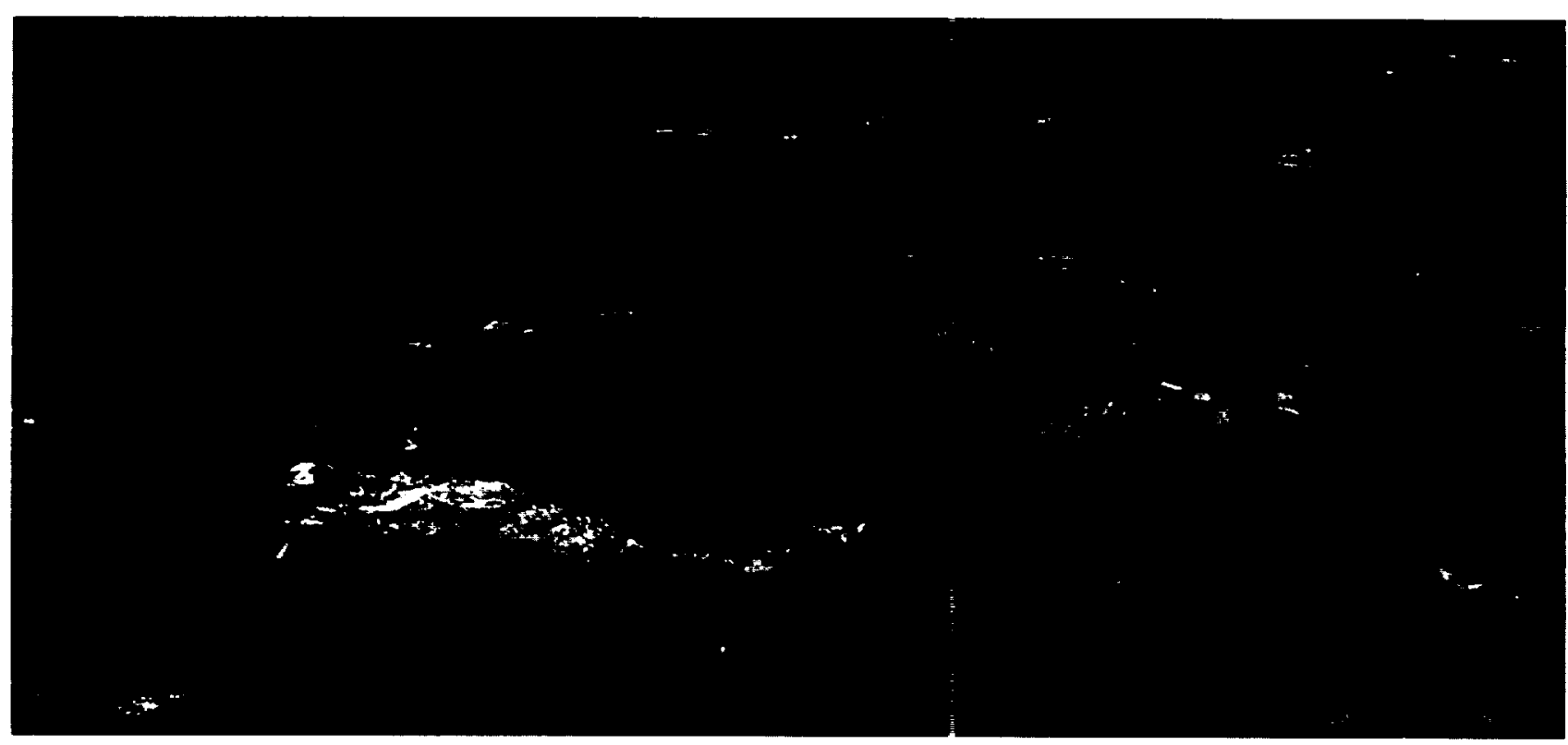

Fig. 1.1. A simple impact crater. Barringer Meteor Crater (Arizona), a young, vell-preserved, and well-known impact crater, $1.2 \mathrm{~km}$ in diameter, has become the type example for small, bowl-shaped impact craters o the simple type. The crater was formed about 50,000 years ago when an iron meteorite approximately $30 \mathrm{~m}$ across struck the horizont il sediments of northern Arizona's Colorado Plateau. After decades of controversy, the impact origin of the crater has been firmly establ shed by the presence of preserved iron meteorites, the recognition of unique shock-metamorphic features in its rocks, and geological stud es that detailed the mechanisms of its formation. This aerial view, looking northwest, shows typical features of young simple impact cratı ss: a well-preserved near-circular outline, an uplifted rim, and hummocky deposits of ejecta just beyond the rim (e.g., white areas at lower left). The uplifted layers of originally horizontal sedimentary target rocks can be seen in the far rim of the crater at the right. (Phot ograph copyright D. J. Roddy; used with permission.)

impact structures alone (Grieve and Masaitis, 1994). The economic products of impact structures include such diverse items as local building stone, diamonds, and uranium. Hydrocarbons (petroleum and gas) are an especially important product from impact structures (Donofrio, 1997; Jobnson and Campbell, 1997). Large impacts crush and shatter the target rocks extensively beneath and around the crater; in a few structures [e.g., Ames (Oklahoma); Red Wing Creek (North Dakota)], the resulting breccia zones have served as traps for oil and gas. Within and around other impact craters, the other kinds of breccias produced by the impact have provided building stone [Ries Crater (Germany); Rochechouart (France)] and industrial limestone [Kentland (Indiana)]. In some cases, the sediments that subsequently fill the crater depressions may contain deposits of such economic materials as oil shale [Boltysh (Ukraine)], diatomite [Ragozinka (Russia)], gypsum [Lake St. Martin (Canada)], and lead-zinc ores [Crooked Creek (Missouri)].

The biggest impact-related bonanza (current production about $\$ 2$ billion per year) is the Sudbury structure (Canada), which contains one of the largest nickel-copper sulfide deposits on Earth (Guy-Bray, 1972; E. G. Pye et al., 1984; Dressler et al., 1994; Lightfoot and Naldrett, 1994). The deposit occurs at the base of a large igneous body (the Sudbury Igneous Complex), which is in turn emplaced in a large, complex, and highly deformed impact basin nearly 2 b.y. old.
Terrest ial life itself has not escaped this cosmic bombardment. During the last 20 years an impressive amount of evidence $r$ as accumulated to show that at least one large impact event about 65 m.y. ago redirected biological evolution on Eirth by producing the major extinction that now marks the boundary between the Cretaceous and Tertiary periods, th e point at which the dinosaurs died and mammals (our : ncestors) became major players in the history of terrestrial ife (Alvarez et al., 1980; Silver and Schultz, 1982; McLaren und Goodfellow, 1990; Sharpton and Ward, 1990; Ryder et al. 1996; Alvarez, 1997). The giant crater produced by that col ision has now been definitely identified, a structure [Chic ulub (Mexico)] at least $180 \mathrm{~km}$ across, completely buried uncler the younger sediments of Mexico's Yucatan Peninsula (Hildebrand et al., 1991; Sharpton et al., 1992; Morgan et 1l., 1997). Active debates continue about how this catastrophic event actually produced the extinction and whether sinilar impacts have caused the other major and minor exti ictions recorded in the geologic record.

Althou ${ }_{i}$ h the recognition of impact events and their effects on $E_{i}$ irth has been marked by debate and controversy (e.g., Dietz, 1963; Bucher, 1963; French, 1968a, 1990b; Sharpton and Grieve, 1990; Nicolaysen and Reimold, 1990), there is no longer any need to demonstrate either the existence or th: importance of such impact events. The young but maturing science of impact geology is turning toward 


\section{A Note on Style}

Metric and standard international (SI) units are used throughout. Length units are meters (m), millimeters (mm), centimeters $(\mathrm{cm})$, decimeters $(\mathrm{dm})$, kilometers $(\mathrm{km})$, and micrometers $(\mu \mathrm{m})$. In planetary discussions, the astronomical unit (AU) is also used; $1 \mathrm{AU}=150 \times 10^{6} \mathrm{~km}$. Mass units are grams $(\mathrm{g})$, milligrams $(\mathrm{mg})$, kilograms $(\mathrm{kg})$, and micrograms $(\mu \mathrm{g})$. Larger masses are given in tons $\left(\mathrm{T}, 1 \mathrm{~T}=10^{6} \mathrm{~kg}\right.$ ), kilotons $\left(\mathrm{kT}\right.$, or $\left.10^{3} \mathrm{~T}\right)$, and megatons (MT, or $\left.10^{6} \mathrm{~T}\right)$.

Ages of stratigraphic units or times of geologic events are given in kilo-annum (ka, $10^{3}$ years before present), Megaannum ( $\mathrm{Ma}, 10^{6}$ years before present), and $\mathrm{Giga-annum}\left(\mathrm{Ga}, 10^{9}\right.$ years before present). ("Present" in this sense refers to 1950 A.D.) Length units of time used are billion years (b.y.), million years (m.y.), years (yr), minutes (min), and seconds (s).

Energies are given in joules $(\mathrm{J})$. Pressures are in gigapascals (GPa); $1 \mathrm{GPa}=10$ kilobars (kbar); $100 \mathrm{GPa}=1 \mathrm{Megabar}$ (Mbar). Other miscellaneous abbreviations used are diameter (D) and Cretaceous-Tertiary (K/T).

Technical terms are highlighted where they are first defined in the text. Terms directly related to cratering and shock metamorphism are shown in boldface; other technical terms are shown in italics. 


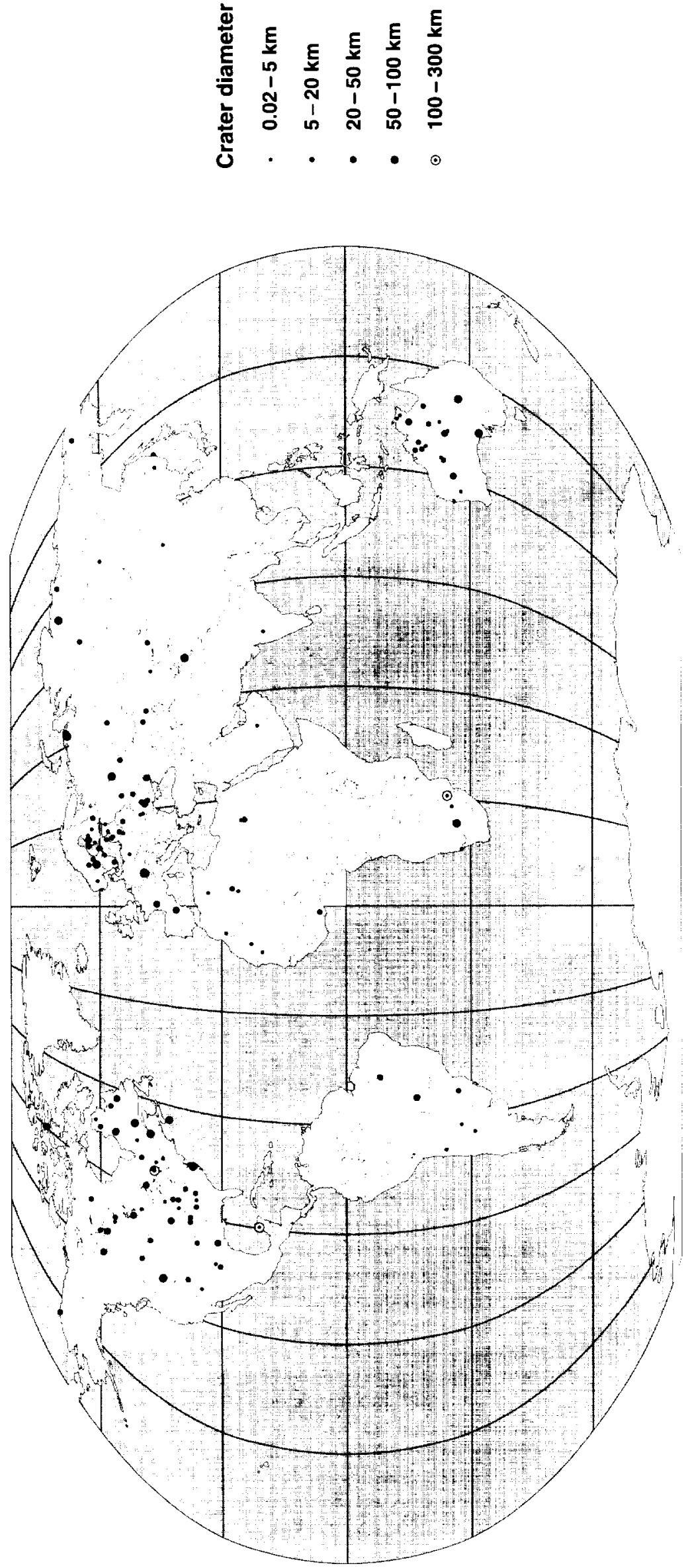

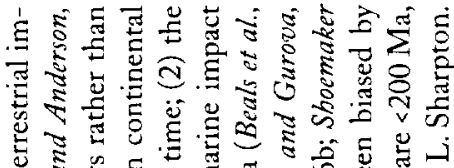

\&

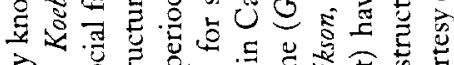

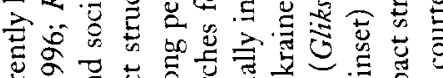

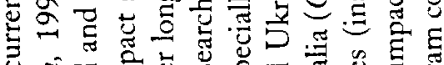

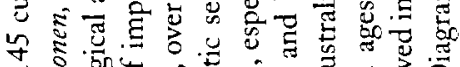

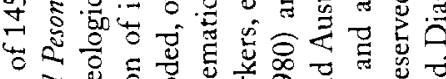

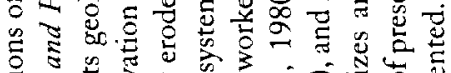
s

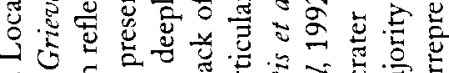

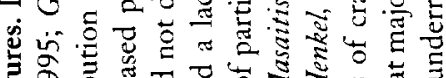

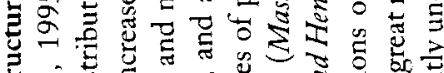

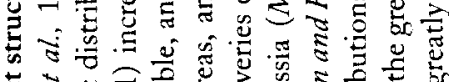

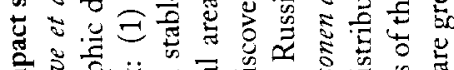

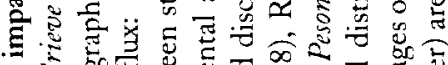

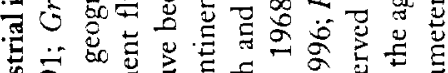

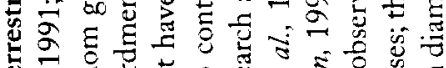

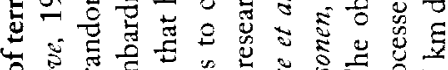

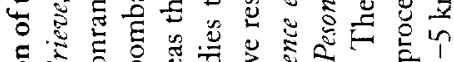

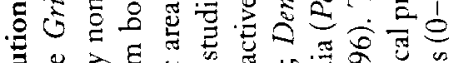

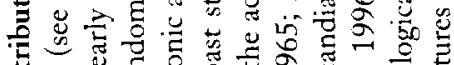

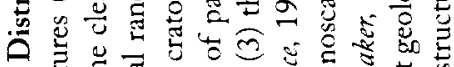

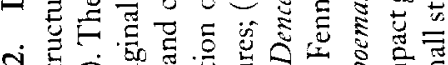
궁

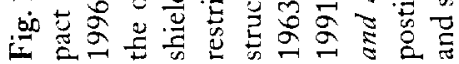

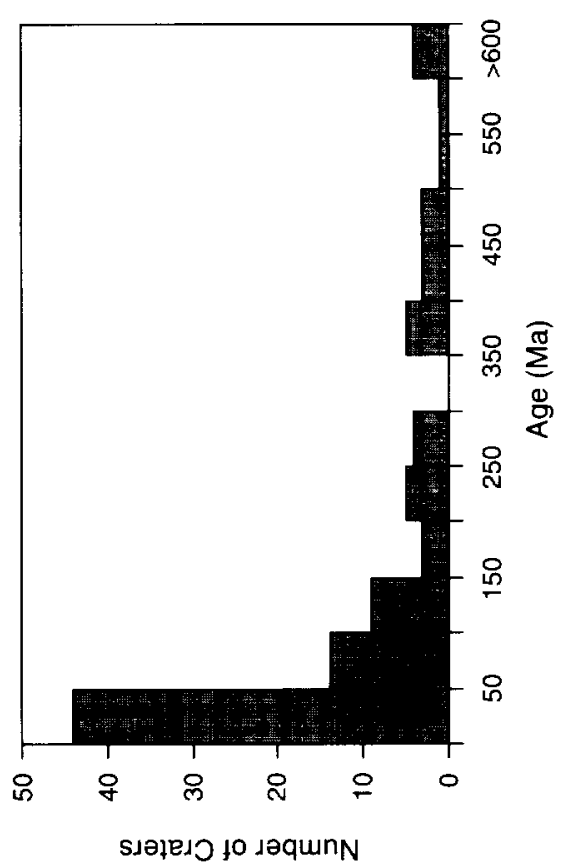




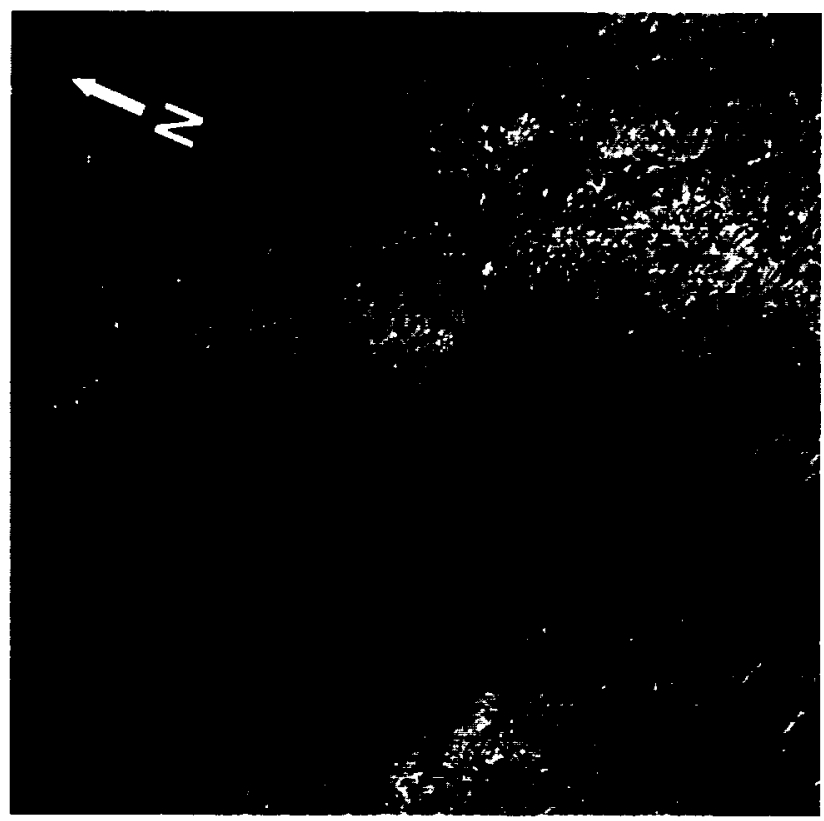

Fig. 1.3. Dual complex impact structures. Clearwater Lakes (Canada), two large, deeply eroded complex impact structures, both with central uplifts, were formed at $\sim 290 \mathrm{Ma}$ by an unusual double impact into the massive crystalline rocks of the Canadian Shield. In the larger structure, Clearwater Lake West $(D=32 \mathrm{~km})$, the central uplift is expressed by a prominent ring of islands about $10 \mathrm{~km}$ in diameter; the islands are capped by units of breccias and impact melt. In the smaller Clearwater Lake East $(\mathrm{D}=$ $22 \mathrm{~km}$ ), the central uplift is covered by the waters of the lake. Northeast is at the top of the picture. (STS 61A image 61A-35-86.)

new problems: finding the hundreds of undiscovered impact structures still preserved on Earth, discovering the full extent of impact effects on Earth, establishing the mechanisms by which large impacts produce geological and biological effects, understanding the puzzling chemical and mineralogical changes that occur in the extreme physical conditions of the impact environment, and using preserved terrestrial impact structures to better define the complex mechanics by which impact structures form on Earth and other planets.

\subsection{THE PLANETARY PERSPECTIVE}

The recognition of the importance of meteorite impacts on Earth has come largely from the study of other planets. Explorations of the Moon and the solar system by astronauts and robotic spacecraft in the 1960s and 1970s demonstrated that impact cratering has been, and still is, a major process in the origin and evolution of all the solid bodies of the solar system, from Mercury to the moons of Neptune (for summaries and references, see Taylor, 1982, Chapter 3; 1992, Chapter 4). The abundant craters on the surface of our Moon (Figs. 1.5 and 1.6) had been known for centuries since the time of Galileo, and their origin (either by impacts or volcanir: activity) had been debated for just as long (for historical eviews, see Hoyt, 1987; Mark, 1987; Wilhelms, 1993). Thr A pollo program provided better views of the lunar surfaci, as well as samples returned by astronauts, and this comb nation gradually but definitely established the impact ori zin of most lunar craters (Wilhelms et al., 1987; Hörz et al. 1991; Taylor, 1992, Chapter 4).

Beyonc the Moon, spacecraft revealed impact craters on every solic planetary surface that we could see: the other terrestrial planets Mercury, Venus (Fig. 1.7), and Mars (Figs. 1.8: ind 1.9); the satellites of the gas-giant planets in the outer s slar system (Figs. 1.10 and 1.11); and even small asteroids ( i. 1.12).

The gesleral acceptance of lunar and planetary craters as the results of impact events (Taylor, 1982, Chapter 3;1992, Chapter 4) was based on several lines of evidence: their abundance on tll solid planetary surfaces, their occurrence on objects of r,reatly differing composition (rocky, icy) and on surfaces of varying ages, the wide range of crater sizes ob-

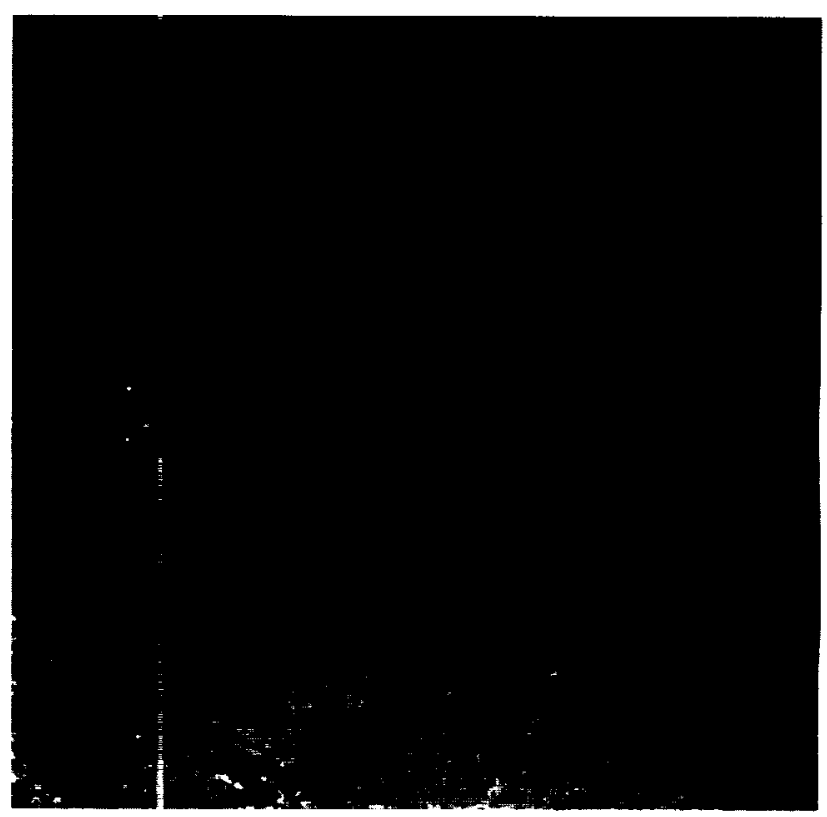

Fig. 1.4. $\triangle$ giant impact structure. One of the largest known terrestrial ir upact structures, Vredefort (South Africa) is located in the centr $r$ of the Witwatersrand Basin, about $100 \mathrm{~km}$ from Johannesbu g. With an age of nearly $2 \mathrm{Ga}$, the structure has been so deeply esoded that only subcrater rocks are still exposed, and the souther I half of the structure has been covered by younger sediments. ' The structure now appears as a central core of uplifted ancient grar itic rocks about $40 \mathrm{~km}$ in diameter (circular light-colored area in center), surrounded by a collar of upturned younger sediments and basalt lavas. This raised central core and collar rocks, about $80 \mathrm{kr}$ in diameter, is now believed to be only the central part of an inpact structure originally $200-300 \mathrm{~km}$ in diameter. Despite the great age and deep erosion, the impact origin of Vredefort his been definitely established by a variety of preserved shock-metamorphic effects: shatter cones, planar deformation features in quartz, and the high-pressure minerals coesite and stishovite. North is approximately at the top. (STS 8 image 0835-1294.) 


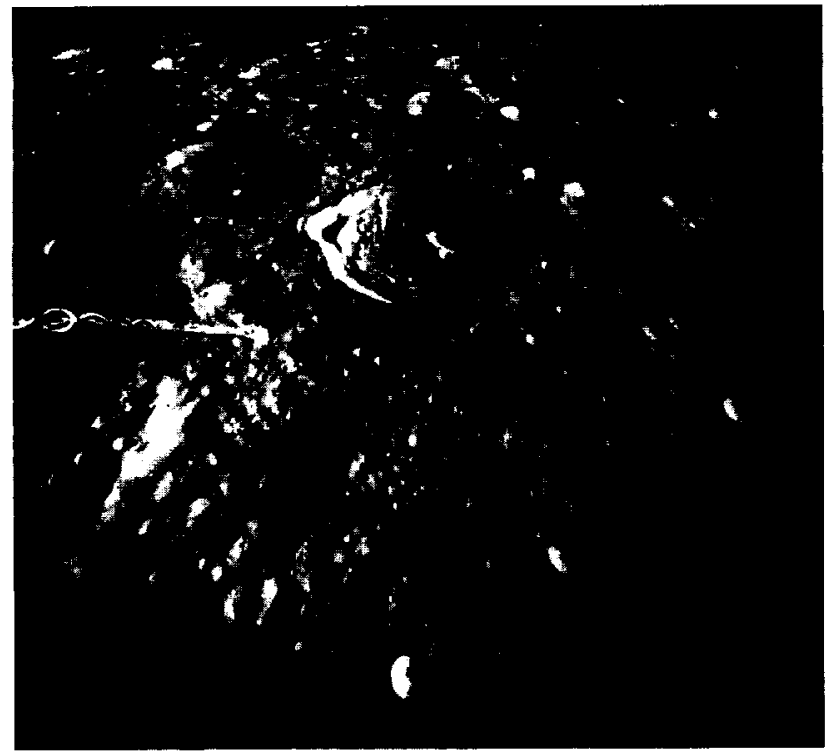

Fig. 1.5. Heavily cratered lunar highlands. The light-colored highland regions of the Moon record an intense and ancient bombardment between about $4.5 \mathrm{Ga}$ and $3.8 \mathrm{Ga}$. During this time, cratering rates were hundreds to thousands of times their present values, and the highland surfaces were saturated with large craters $>10 \mathrm{~km}$ in diameter. This view of the farside highlands, looking south from the lunar equator, shows two large complex impact craters: Green $(\mathrm{D}=90 \mathrm{~km})$ (upper center) and Hartmann $(\mathrm{D}=$ $70 \mathrm{~km}$ ) on its left. These two complex craters, which show typical central uplifts and collapsed terraces in the inner walls, are accompanied by large numbers of smaller craters. The crater Hartmann also cuts the rim of the older impact basin Mendeleev $(D=330 \mathrm{~km})$, part of which can be seen at the left. The spiral-like rod at left center is an instrument boom on the Apollo 16 spacecraft, from which this orbital picture was taken. (Apollo 16 image AS16-M2370.)

served (from tiny microcraters $<1 \mathrm{~mm}$ across on lunar rocks to great ringed basins $>2000 \mathrm{~km}$ in diameter), their consistent and regular morphology, and their presence on tiny bodies (e.g., asteroids) too small to have ever generated internal volcanic activity.

The abundance of well-preserved impact craters on planetary surfaces of all kinds made it possible to use crater frequencies to determine relative geological ages, based on the simple principle that older surfaces accumulate more craters (Shoemaker and Hackman, 1962; Shoemaker et al., 1963). On the Moon, where crater counts could be combined with absolute ages obtained by radiometric dating of returned samples, it became possible to estimate the flux of objects bombarding the Moon (and by implication, Earth as well) over geologic time by counting the craters of different sizes on surfaces of known age. However, application of the lunar data to other planets lacking absolute age data has been a complicated and problematic process (Taylor, 1992, Chapter 4).

Even before the Apollo program, it was recognized that the lunar bombardment rate had not been constant over time and that the ancient, heavily cratered lunar highlands record a bombardment rate thousands of times higher than that recorded by the younger maria (Baldwin, 1949, 1963). The Apollo data confirmed this conclusion and demonstrated that an intense bombardment of the Moon occurred between its formation $(4.5 \mathrm{Ga}$ ) and about $3.8 \mathrm{Ga}$. The bombardment rate was most intense at about $4.5 \mathrm{Ga}$, decreased rapidly until about $3.8 \mathrm{Ga}$, and then leveled off (Fig. 1.13) (Wilhelms et al., 1987; Hörz et al., 1991; Taylor, 1992, Chapter 4). The bombardment rate after $3.8 \mathrm{Ga}$ has been approximately constant (Fig. 1.13), although it has been suggested that variations of perhaps $\pm 2 \times$ have occurred, especially during the Phanerozoic ( $<600 \mathrm{Ma}$ ).

It is now accepted that impact events, especially large ones, have had a major role in the formation and early history of the solar system and the solid objects in it. In current theories of solar system formation, the planets are believed to have formed by the steady accretion (with collisional impacts) of small objects (planetesimals) in an original solar nebula. But newer, post-Apollo theories suggest that large impact events, affecting nearly grown planets, may be responsible for many unexplained problems of planetary motions, compositions, and atmospheres (Taylor; 1992, Chapter 4). Many chemical and dynamical problems concerning the origin of the Moon are explained by the current theory that the Moon formed as the result of a collision be-

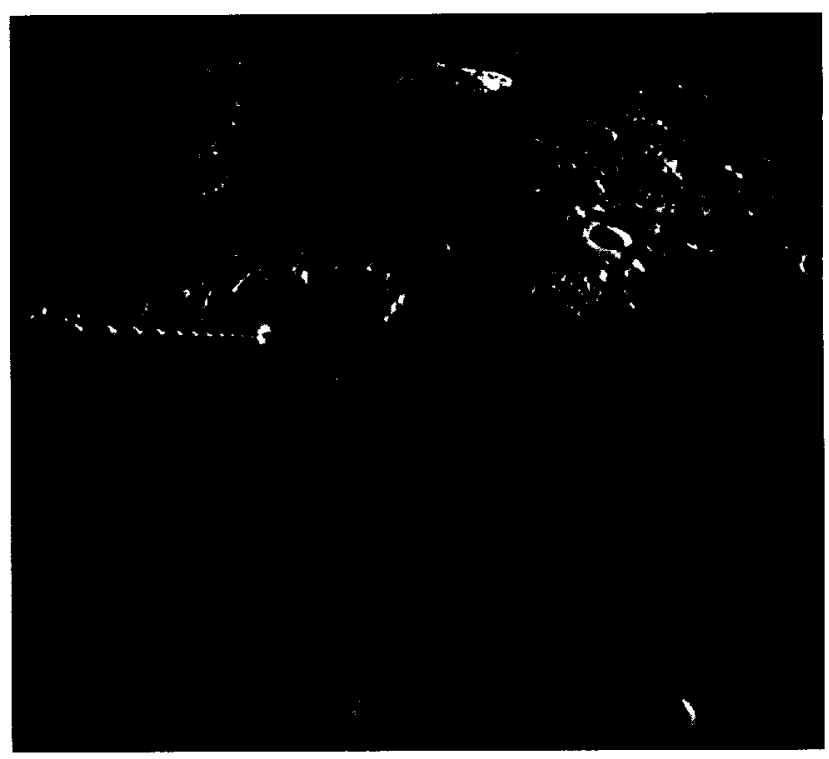

Fig. 1.6. Lightly cratered lunar maria. The much lower bombardment rate on the Moon since $3.8 \mathrm{Ga}$ is clearly reflected in the lightly cratered character of these younger lava flows that fill the lunar maria in the lower half of this image. Craters are scattered and much smaller than those developed in highland areas. This view shows Mare Nubium in the south-central part of the Moon's nearside. The dark lava flows exposed here are relatively young by lunar standards (about 3.2-3.5 Ga). Bullialdus, the large fresh complex crater near the horizon, is about $60 \mathrm{~km}$ in diameter. The spiral-like rod at left center is an instrument boom on the Apollo 16 spacecraft, from which this orbital picture was taken. (Apollo 16 image AS16-M-2492.) 


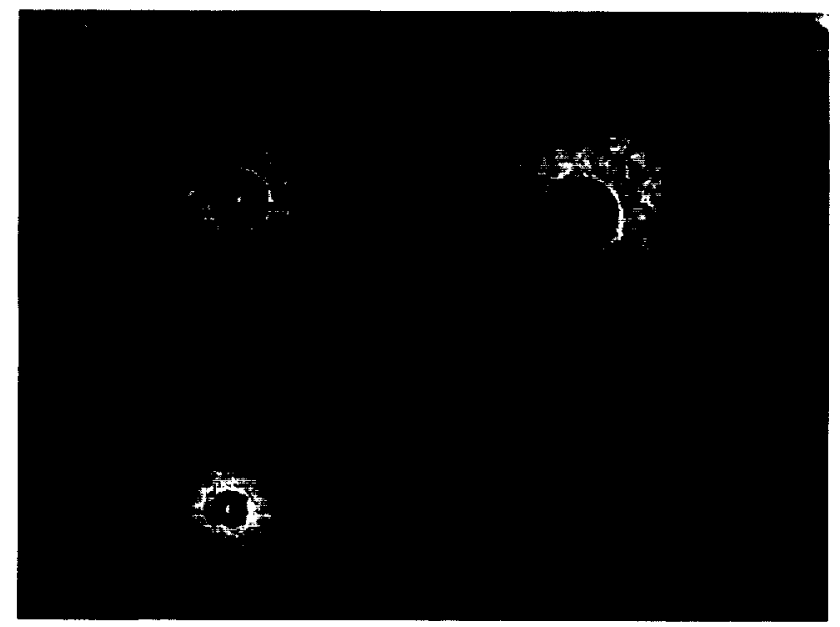

Fig. 1.7. Complex impact craters on Venus. Large, wellpreserved impact craters on the surface of Venus were revealed by the Magellan spacecraft, which used an imaging radar system to penetrate the planet's opaque atmosphere. In this "crater farm" area, three large, well-preserved impact structures have been produced on a low-relief, slightly fractured surface that may consist of basalt lava flows. The "colors" in this picture actually represent different degrees of surface roughness detected by Magellan's radar system; dark surfaces (the target surface and the crater interiors) are smooth, while lighter areas (crater ejecta blankets and linear fractures in the preimpact surface) are rougher. The three largest craters show features typical of complex impact structures: circular outlines, complex central uplifts, and surrounding deposits of lobate ejecta. Aglaonice, the largest crater (center right), is $63 \mathrm{~km}$ in diameter. (Magellan image JPL P-36711.)

tween a Mars-sized object and the larger proto-Earth at about $4.5 \mathrm{Ga}$ (Hartmann et al., 1986). Similar impacts may have stripped off the silicate mantle of the planet Mercury, leaving the present iron-rich object (Benz et al., 1988), may have removed the early primordial atmospheres of the planets (Melosh and Vickery, 1989; Abrens, 1993), and may be responsible for the fact that Uranus' axis of rotation is tilted more than $90^{\circ}$ from the axes of all the other planets. In considering the early solar system, large random impact events have become the method of choice for explaining planetary anomalies, a situation that provides local explanations but makes it more difficult to construct uniform theories for planetary development (Taylor, 1992; Chapter 4).

The planetary perspective is a critical part of the study of terrestrial impact structures. The widespread existence of impact craters throughout the solar system demonstrates that they must have been equally abundant on Earth, and the cratered surfaces of other planets make it possible to estimate the intensity and the effects of impact cratering on Earth. More important, impact craters on Earth and other planets complement each other. On other planets, where erosion and tectonics have not been extensive, we can see the preserved upper levels of craters, the sharply circular form, the widespread ejecta deposits, the lava-like bodies of impact melt, and the cliffs and terraces formed during crater development (Figs. 1.5, 1.7, and 1.8).
In most exposed terrestrial impact structures, such surface featur s have been removed by erosion, and the present surface exp ses deeper levels within or even beneath the original crater. "errestrial structures thus provide a unique third dimension to cratering studies, and their accessibility makes possible a vide range of investigations not possible on other planets. Tet restrial impact structures can be mapped, sampled, drilled, anc analyzed in great detail, and they have provided critical "grsund truth" for understanding impact phenomena on other planets. Many fundamental concepts of cratering mechanics - crater modification, central uplifts, impact melt formation and emplacement - have been established on terrestrial : tructures (Shoemaker, 1963; Dence, 1968, 1971; Milton et al., 1972; Dence et al., 1977; Grieve et al., 1977, 1981; Grieve and Cintala, 1981, 1992) and then applied to craters i lsewhere in the solar system (e.g., Cintala and Grieve, 19! 8).

\subsection{A :ECULIAR PROCESS: WHY IMPACTS ARE DIFFERENT}

Large ir apact events differ in many ways from more familiar geol sgical processes like volcanic explosions, earthquakes, anc the slow movements of plate tectonics. Much of

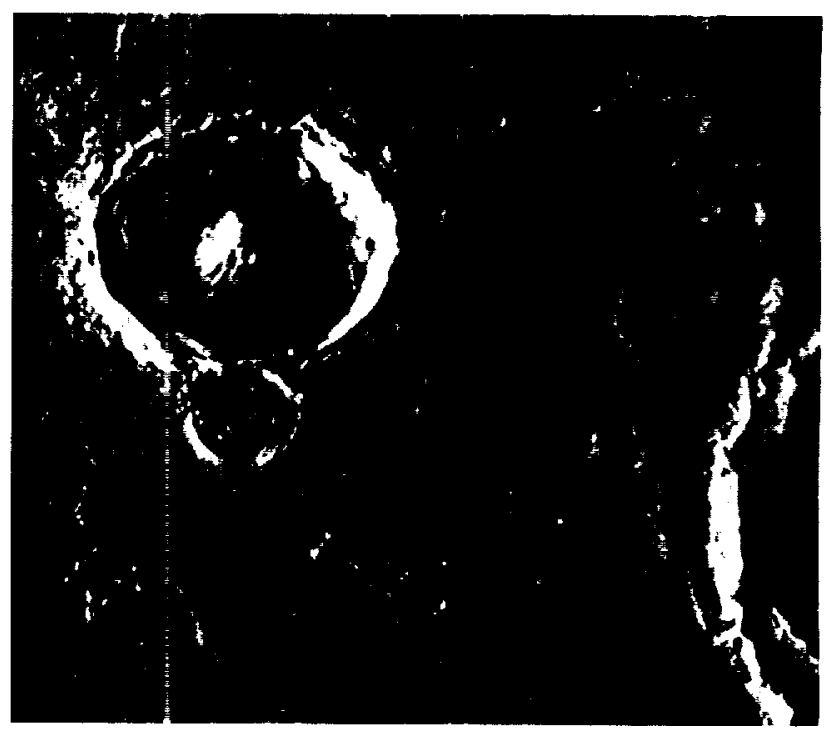

Fig. 1.8. A complex impact crater on Mars. This young complex crater (Yuty D $=19 \mathrm{~km}$ ) shows typical features: a circular outline, highly t rraced interior walls, an unusually pronounced central peak, and a surrounding blanket of highly lobate ejecta. The complex app sarance of the ejecta blanket suggests that it may have been partly $f$ uidized by water melted from ice deposits within the target by the impact, and the exaggerated central peak may also reflect the existence of a lower-strength, volatile-bearing target. The thinness of the ejecta deposits is indicated by the fact that the small pre-Yuty crater just tangent to Yuty can still be distinguished through them. The arcuate structure at lower right is part of the wall of an older, larger crater. (Viking Orbiter image 003A07.) 


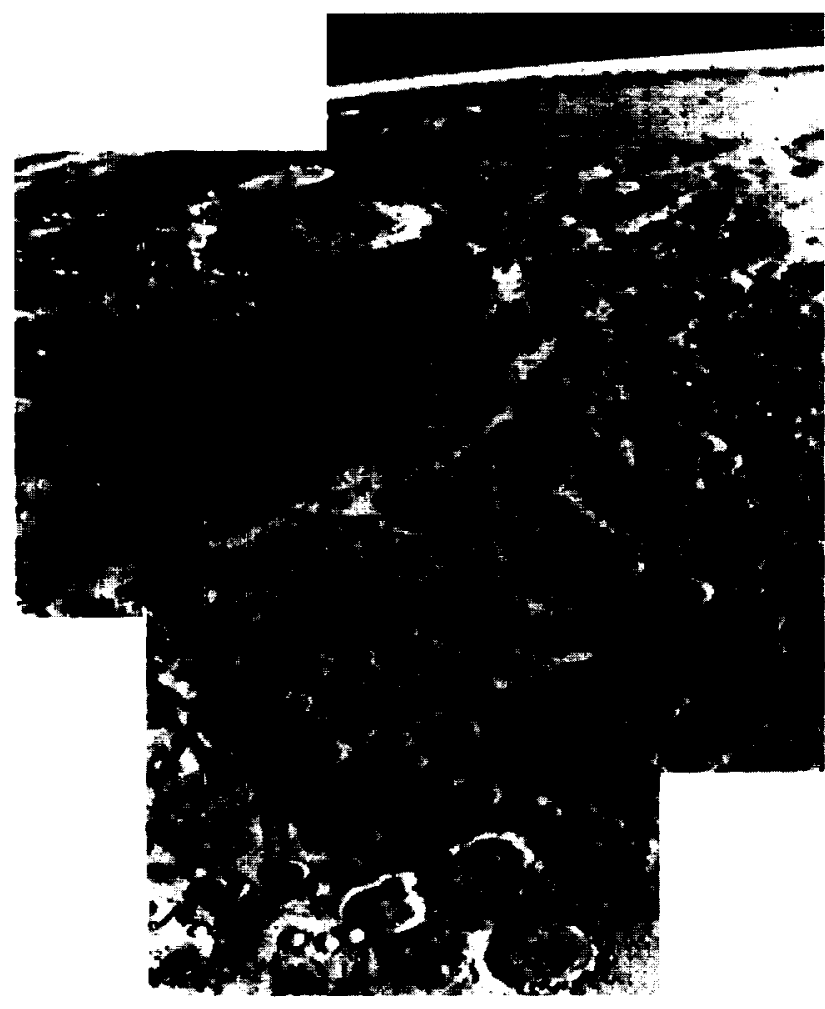

Fig. 1.9. An ancient multiring (?) impact basin on Mars. The flat-floored Argyre Basin (upper left) $(\mathrm{D}=900 \mathrm{~km})$ is apparently the youngest large impact basin recognized on Mars, but it is still an ancient and heavily eroded structure that has itself been struck by large projectiles since it formed (e.g., the large crater cutting the basin rim at top). This orbital panorama shows the smooth floor deposits within the basin and the mountainous nature of the enclosing rim. Because of the high degree of erosion, the actual diameter of Argyre is uncertain; a minimum diameter of about $900 \mathrm{~km}$ is indicated by the rugged rim shown in this picture, but the existence of additional rings (with diameters of 540,1140, and $1852 \mathrm{~km}$ ) has been suggested. The white streaks above the horizon (upper right) are hazes in the thin martian atmosphere. (Viking Orbiter image JPL P-17022.)

the past confusion and controversy about meteorite impact on Earth has arisen from the fact that the chief features of large impact events are unfamiliar to geologists and the public alike.

\subsubsection{Rarity}

Unlike other geological processes, large meteorite impacts are rare, even over geological timescales, and there have been (fortunately) no historical examples of such events. For most people, the impact process involves only the occasional falls of small meteorites, which produce excitement and public interest, but only occasional minor damage. This lack of direct human experience with large impact events sets them apart from more familiar recurrent geological "catastrophes" such as floods, earthquakes, and volcanic eruptions and makes them harder to appreciate.

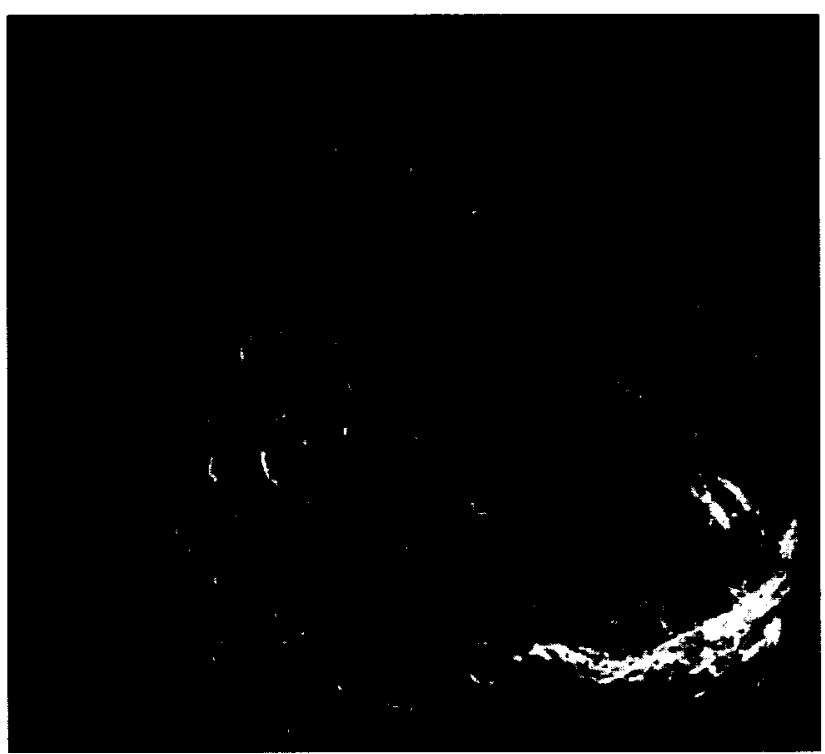

Fig. 1.10. Impact craters on one of Saturn's moons. Like many moons of the outer planets, Dione $(\mathrm{D}=1120 \mathrm{~km})$ is a low-density object composed largely or completely of ices. The surfaces of Dione and many other moons show abundant impact craters as well as a variety of other terrain types that probably reflect different degrees of internal activity. One hemisphere of Dione (left) shows abundant, well-preserved impact craters, while the other hemisphere (right) shows wispy streaks that may reflect fracturing or the eruption of volatiles. The larger craters show typical complex-crater morphologies with central peaks and terraced walls, e.g., Dido (left center; $\mathrm{D}=120 \mathrm{~km}$ ) and Aeneas (top, near horizon; $\mathrm{D}=155 \mathrm{~km}$ ). (Voyager 1 image JPL P-23101.)

\subsubsection{Immense Energy}

Large impact events release energies that are almost incomprehensibly large by the more familiar standards of earthquakes and volcanic explosions. The energy of an impact event is derived from the kinetic energy of the impacting projectile and is equal to $1 / 2 \mathrm{mv}^{2}$, where $\mathrm{m}$ is the projectile mass and $v$ its velocity. Because velocities of impacting objects are high, typically tens of kilometers per second, kinetic energies are also large, even for small objects (for details, see below and Table 2.1). An object only a few meters across carries the kinetic energy of an atomic bomb, and its impact could devastate a large ciry. Furthermore, unlike earthquakes and volcanic explosions, where the properties of Earth itself provide some upper bounds to the energy release, the impact energy is limited only by the mass and velocity of the projectile. The impact of an object only a few kilometers across (still smaller than many known asteroids and comets) can release more energy in seconds than the whole Earth releases (through volcanism, earthquakes, tectonic processes, and heat flow) in hundreds or thousands of years.

\subsubsection{Instant Effects}

Another critical difference between impacts and other geological processes is that the energy release in an impact event - and the formation of the resulting crater - is vir- 


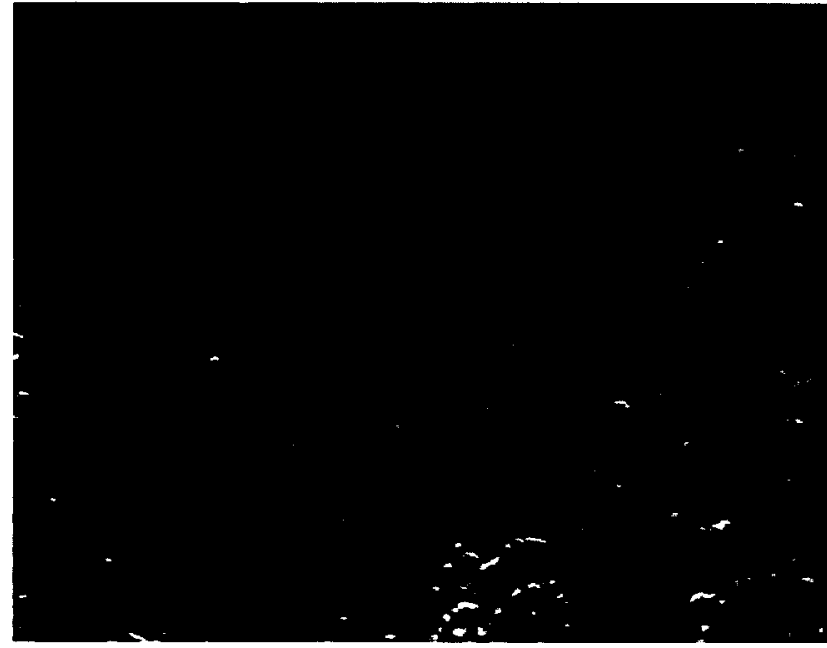

Fig. 1.11. Impact craters on a moon of Neptune. Triton, Neptune's largest moon $(\mathrm{D}=2700 \mathrm{~km})$, is now the most distant solid object in the solar system to be photographed at close range. When examined by the Voyager 2 spacecraft in 1989, Triton turned out to be an unexpectedly dense ice-rock world with a poorly understood geological history and a surface modified by ice deformation, possible melting and water flooding, erupting geysers of nitrogen, and strong winds. Despite this active and ongoing history, Triton's surface still preserves the results of meteorite bombardment. The large scalloped basin (left), about $200 \mathrm{~km}$ across, may represent a large impact structure subsequently modified by faulting, flooding, and filling with water ice. A sharp young impact crater about $15 \mathrm{~km}$ across has formed on the older surface, and other craters of similar size and sharpness are scattered across the region. The rarity of small, fresh, and young impact craters indicates that this part of Triton's surface is relatively young and has recently been modified by internal processes. (Voyager 2 image JPL P34692.)

tually instantaneous. At the instant of impact, the object's kinetic energy is converted into intense high-pressure shock waves, which radiate rapidly outward from the impact point through the target rocks at velocities of a few kilometers per second (see e.g., Melosh, 1989, Chapters 3-5). Large volumes of target rock are shattered, deformed, melted, and even vaporized in a few seconds, and even large impact structures form in only minutes. A 1-km-diameter crater [about the size of Barringer Meteor Crater (Arizona)] forms in a few seconds. A 200-km-diameter structure [like Sudbury (Canada) or Vredefort (South Africa)] forms in less than 10 minutes, although subsequent geological adjustments, largely driven by gravity, will continue for many years.

\subsubsection{Concentrated Energy Release}

Most forms of internal terrestrial energy (heat flow, seismic waves) are released over large areas that are subcontinental to global in extent. By contrast, the energy of an impact event is released instantly, at virtually a single point on Earth's surface. Most of the energy passes, directly and rapidly, into the near-surface target rocks, the atmosphere, and the biosphere, where it can produce immediate and catastrophic changes.
A small impact, releasing the energy of only a few million tons o TNT (approximately the amount released by a hydrogen tomb), is similar in total energy to a severe earthquake or v lcanic explosion, and its effects will be largely local (e.g., l'ring, 1997). But a large impact transmits so much energy intc the target that an impact structure tens or hundreds of ki ometers in diameter is formed, accompanied by catastrophiz environmental effects on a continental or global scale.

The near-surface release of impact energy, and the transfer of muct of the energy directly into the biosphere, makes large impar $t$ events especially effective in causing devastating and wislespread biological extinctions. Current impactrelated models for the major Cretaceous-Tertiary (K/T) extinction (e.g., Silver and Schultz, 1982; Sharpton and Ward, 1990; Krin., 1993; Ryder et al., 1996) indicate that, during the impact that formed the Chicxulub crater at $65 \mathrm{Ma}$, as much as $2:-50 \%$ of the projectile's original kinetic energy was conver :ed into heat. This heat not only vaporized the projectile it self, but also melted and vaporized large volumes of the near- surface sedimentary target rocks, releasing large amounts of $\mathrm{CO}_{2}$ (from carbonates) and $\mathrm{SO}_{2}$ (from evaporites). Introc uced into Earth's atmosphere, together with large quantities of impact-produced dust, these gases and their reaction pre ducts could produce major environmental effects: immediate Jarkening and cooling, subsequent global warming, and de uges of acid rain. Any of these consequences, or a combination of them, could have produced the resulting widespread extinction.

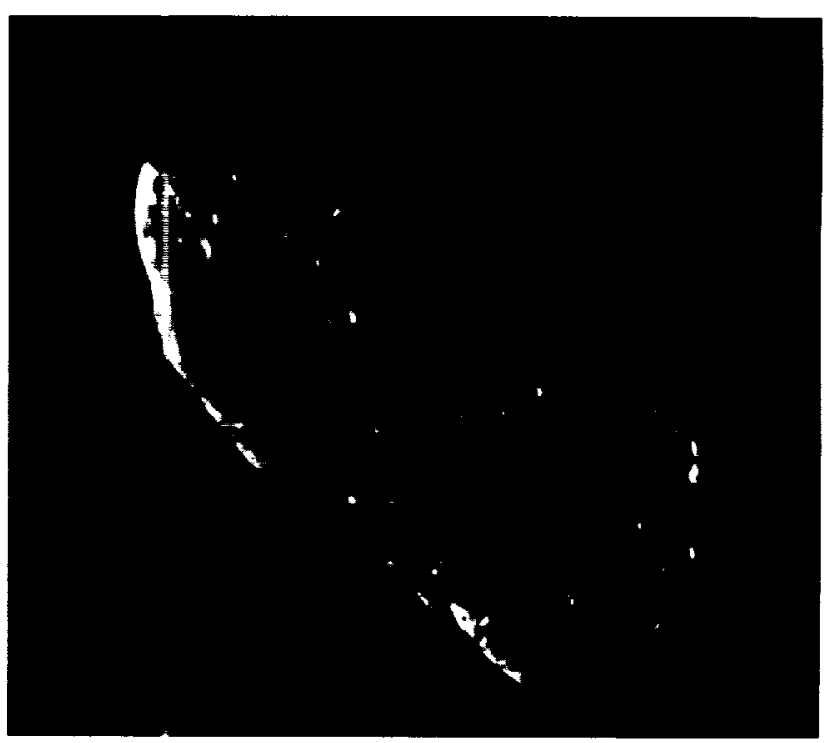

Fig. 1.12. Impact craters on an asteroid. The small asteroids that produce $\mathrm{im}_{\mathrm{j}}$ act craters on the larger planets and moons have themselves $t$ een bombarded by larger and smaller objects. Larger collisions cau break asteroids apart, leaving irregular objects such as Gaspra (w aich has dimensions of about $19 \times 12 \times 11 \mathrm{~km}$ ), shown in this flyby i nage taken by the Galileo spacecraft in 1991. Smaller collisions lerve surviving asteroids covered with large and small craters; the largest craters shown here on Gaspra are 1-2 km across. (Galileo ima ze JPL P-40450-C.) 


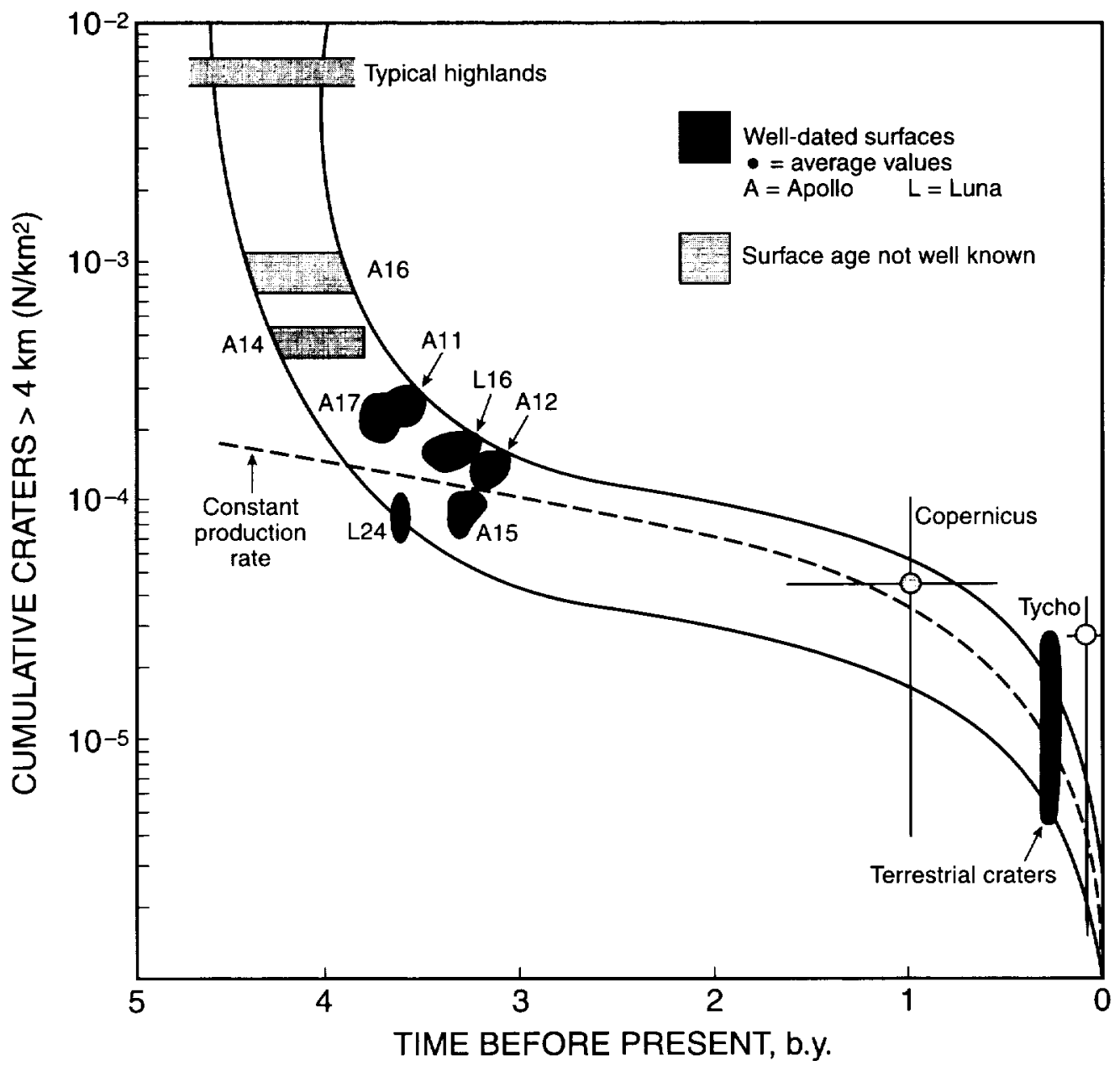

Fig. 1.13. Bombardment rates and crater formation during geologic time. This graph summarizes the results of studies in which the highly variable numbers of craters present on different lunar surfaces have been used to reconstruct the meteorite bombardment rate within the Earth-Moon system during the last 4 b.y. Lunar crater densities [expressed as the total number $(\mathrm{N})$ of craters with D $>4 \mathrm{~km}$ per square kilometer of surface] have been measured from spacecraft photographs of various highlands and maria surfaces whose ages have been determined from samples returned by the Apollo (A) and Russian robotic Luna (L) missions. The data (bounded by two solid lines that indicate estimated uncertainties) are most precise for the well-dated maria surfaces, which have ages of 3.7-3.2 Ga. Ages of the older highland surfaces are not as well determined, but it is clear that crater-production rates before $3.8 \mathrm{Ga}$ were much higher ( $\geq 100 \times$ ) than in more recent times. The much lower crater formation rate after $3.8 \mathrm{Ga}$ is not statistically different from a constant value (dashed line); this rate is also consistent with values estimated from the small population of preserved terrestrial impact structures. Age values for the large lunar craters Copernicus (about $1 \mathrm{Ga}$ ) and Tycho (about $100 \mathrm{Ma}$ ) have been indirectly determined from Apollo samples collected elsewhere on the Moon. (From Horz ef al., 1991, Fig. 4.15, p. 84.)

\subsubsection{Extreme Physical Conditions}

The mechanism by which impacts do their work - generation and transmission of intense shock waves through the target rocks - is also unfamiliar to many geologists. Under normal conditions, rocks in Earth's crust and upper mantle are subjected to static load pressures produced by the weight of overlying rocks. These pressures are less than a few gigapascals (GPa) (1 GPa, a standard unit of pressure, equals $10^{4}$ bar or about $\left.10^{4} \mathrm{~atm}\right)$. Normal geological stresses within Earth generate relatively low strain rates (typically $10^{-3} / \mathrm{s}$ to $10^{-6 / \mathrm{s}}$ ), and rocks either deform slowly at lower pressures or fracture at higher pressures when their yield strengths (a few $\mathrm{GPa}$ ) are exceeded. The general tendency of terrestrial rocks to fracture when the pressure gets too high, thus releasing the pressure, limits the pressure buildup in ordinary geological processes (e.g., earthquakes) to a few GPa.

These "normal" conditions do not exist in impact events. The rapid release of large amounts of energy in such events puts too much sudden stress on the target rocks for them to respond in the normal way. Typical impact velocities of tens of kilometers per second far exceed the velocities of sound in the target rocks (typically $5-8 \mathrm{~km} / \mathrm{s}$ ). The resulting impactproduced shock waves travel through the target rocks at supersonic velocities, and they impose intense stresses on the rocks without giving them time to give way by normal deformation. In the shock-wave environment, transient pres- 
sures may exceed $500 \mathrm{GPa}$ at the impact point and may be as high as 10-50 GPa throughout large volumes of the surrounding target rock. Transient strain rates may reach $10^{4 / s}-10^{6} / \mathrm{s}$, orders of magnitude higher than those in ordinary geological processes. At the higher shock pressures ( $260 \mathrm{GPa}$ ), shock-produced temperatures can exceed $2000^{\circ} \mathrm{C}$, and rapid, large-scale melting occurs immediately after the shock wave has passed.

\subsubsection{Unique Deformation Effects}

The extreme physical conditions of pressure, temperature, and strain imposed by transient shock waves produce unique effects (e.g., mineral deformation, melting) in the rocks and mineral grains through which they pass. These shock-metamorphic effects are distinct from features produced by normal geological deformation, and they are now generally accepted as unique products of impact events (for reviews and references, see French and Short, 1968; Stöfler, 1972, 1974; Stöfler and Langenhorst, 1994; Grieve et al., 1996).

Shock-metamorphic effects (or "shock effects") have been crucial in establishing the importance of extraterrestrial impact events. Preserved meteorites around an impact crater can provide definite evidence of an impact origin, but only a small fraction of terrestrial impact structures (about a dozen) have actual preserved meteorites associated with them. These structures $a$ re all relatively small and geologically young. The Barringer Meteor Crater (Arizona), $1.2 \mathrm{~km}$ in diameter and about 50,0.90 years old (Fig. 1.1), is the largest member of this group.

The abs snce of meteorite fragments around older impact craters resu ts from two causes: (1) the projectile itself is also subjected $t$, the intense shock waves generated by the impact, and $t$ is almost completely melted and vaporized; and (2) all neteorites are partly to completely composed of nickel-iron metal, and even surviving fragments of the projectile tenc to be rapidly destroyed by surface weathering, except in the driest desert regions or on polar icecaps.

The rap d destruction of meteorites means that other lines of evidence must be used to identify older or deeply eroded terrestrial in npact structures. Shock-metamorphic effects can be preserved in rocks for periods of $10^{6}-10^{9}$ years, and they provide a u ique means of identifying impact structures, especially ones that are old, deeply eroded, or both (French and Short, 1968). The great majority of currently known impact stru zures (currently over 150) have no preserved meteorites, but have been identified by the discovery of shockmetamorpl iic effects in their rocks (Grieve, 1991; Grieve et al., 1995; ('rieve and Pesonen, 1992, 1996). 


\section{n

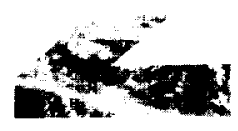

\section{Target Earth: Present, Past, and Future}

Current studies of Earth and the solar system have demonstrated clearly that impact events are a definite part of the present as well as the past. The multiple impacts of Comet Shoemaker-Levy 9 on Jupiter in July 1994 (Spencer and Mitton, 1995) provided the entire world with an awesome demonstration that, even 4.5 b.y. after formation of the solar system, the cosmic bombardment process in still going on, and the catastrophic effects produced by the impacts on Jupiter provided a graphic - and disturbing - example of what might happen if a similar object should strike Earth instead.

Several features of the present solar system demonstrate that impact events - both actual and potential - are part of the current state of Earth as well: (1) the Earth is accompanied in the solar system by thousands, possibly millions, of randomly moving kilometer-sized objects, some of which could collide with the Earth in the future; (2) small extraterrestrial objects are continually colliding with Earth, and larger ones have struck it in the recent past.

\subsection{COMETS AND ASTEROIDS: THE KILLER NEIGHBORS?}

The Earth is accompanied in the solar system by many other solid objects. In addition to the planets and moons, the solar system contains a large amount of lesser cosmic debris, objects ranging from microscopic dust particles to objects tens of kilometers in size, each of which moves in its own orbit around the Sun. In the size range of interest for impact events, from a few tens of meters up through tens of kilometers in size, two kinds of objects can be distinguished: asteroids and comets.

\subsubsection{Asteroids}

Asteroids are small, rocky bodies, regarded as the fragments of small objects (planetesimals) that existed in the in- ner solar system when the solar system formed, but were not swept up by growing planets (Binzel et al., 1989). Most asteroids are a few kilometers to a few tens of kilometers in size. A few are larger; Ceres, the largest known, has a diameter of about $1000 \mathrm{~km}$, or about the size of the state of Texas. Several thousand asteroids more than a kilometer across have been discovered, and millions of smaller ones almost certainly exist. Most asteroids, especially the largest ones, are located in the asteroid belt, a zone between the orbits of Mars and Jupiter, and most asteroids — but not all - tend to stay there, safely out of range of Earth.

\subsubsection{Comets}

Comets are also small objects, typically tens of kilometers in diameter. In contrast to the rocky asteroids, comets contain a significant amount of volatile ices in addition to rocky material (Wilkening, 1982; Newburn et al., 1991). The evaporation of these icy compounds when comets pass through the inner solar system and approach the Sun creates the long, shining tails that make comets such striking objects in history and superstition. Because they contain so much low-temperature material, scientists suspect that comets have probably formed as small bodies in the cold outer solar system.

Comets are divided into two types, based on the shape of their orbit and on how long they take to make one revolution around the sun. Short-period comets, such as Comet Encke and Comet Halley, orbit the Sun in $\leq 200$ years. However, most short-period comets have orbital periods of only a few years and travel on small, nearly circular orbits like those of planets and asteroids. Long-period comets, like the recently observed Comet Hale-Bopp, may take thousands of years to complete a single orbit, and they travel on highly elongate orbits that take them far beyond Pluto and perhaps $10 \%$ of the distance to the nearest star. It has been argued, both on theoretical grounds and from observations of the orbits of long-period comets, that the entire solar system is 
in fact surrounded, at a distance of about 50,000 AU, by a vast cloud containing billions of comets (the Oort Cloud), from which comets are occasionally perturbed (perhaps by passing stars) into orbits that carry them down into the inner solar system toward the Sun. A similar accumulation of small icy objects, the Kuiper Belt, may exist beyond the orbit of Neptune and may actually be the source of the short-period comets that enter the solar system (Rabe et al., 1994).

\subsubsection{Close Encounters}

There is nothing that isolates the Earth from these small but fast-moving objects. Any time the orbit of a comet or asteroid crosses the orbit of the Earth, a collision is possible. The majority of asteroids, whose orbits lie within the asteroid belt between Mars and Jupiter, remain at great distances from the Earth and pose no danger to it. But not all asteroids remain there. Even within the asteroid belt, the orbits of individual asteroids can be changed by close encounters with Mars or Jupiter, or by low-velocity collisions with other asteroids. These random perturbations can put asteroids into new orbits, some of which enter the inner solar system and cross the orbits of the inner planets. More than 150 near-Earth asteroids (NEAs) with diameters of $\geq 1 \mathrm{~km}$, whose orbits approach or cross the orbit of the Earth, have already been discovered, and several hundred more are believed to exist.

In the outer solar system, far beyond Pluto, similar perturbations, perhaps caused by passing stars, may nudge comets out of the distant Oort Cloud and put them onto highly elliptical orbits that also enter the inner solar system and may cross Earth's orbit. Eventually, over millions of years or more, some of the asteroids or comets that repeatedly cross Earth's orbit will collide with it. There is nothing to stop them.

\subsection{IN OUR TIME: SMALL CATASTROPHES}

Even at this moment, collisions of extraterrestrial objects with Earth are occurring by the billions. Steadily and quietly, Earth itself accumulates about 100 tons of extraterrestrial material every day (Taylor, 1992, pp. 176-177; Love and Brownlee, 1993). Almost all this material enters Earth's atmosphere as small particles (from microscopic dust to the size of golf balls); these objects burn up in the atmosphere to produce visible streaks of light (meteors or "shooting stars") in the night sky.

Among extraterrestrial objects in the solar system, small objects $(<1 \mathrm{~cm})$ are much more abundant than larger ones, but larger objects, even though rarer, also strike Earth. Some tens of objects, ranging in size from a few tens of centimeters to a few meters and weighing from a few kilograms to a few tons, also collide with Earth every year. Most of these objects are rocky or metallic fragments of asteroids, and they are large enough and solid enough to survive passage through Earth's atmosphere. As they pass through the atmosphere, their outer parts burn off, they slow down, they hit the ground at relatively low velocities, and they remain reasonably intact, becoming meteorites.
Earth s lows evidence of many small extraterrestrial collisions in the present, but its recent past shows that even larger obje zts have struck (or barely missed) Earth during just the las: few decades.

In 1947, an iron meteorite about $3 \mathrm{~m}$ across and weighing perhaf $s 100$ tons entered the atmosphere above the Sikhote-A in region of Siberia (Russia), broke up in midflight, and showered the region below with thousands of chunks of r uetal (Krinov, 1966, Chapter 4). Because the original object 1 roke up in the atmosphere, the resulting smaller fragments vere slowed down and produced no major damage on im lact. The kinetic energy of the original object, equivalent to about 4000 tons [ 4 kilotons (kT)] of TNT, was dissipa ed harmlessly in the atmosphere and by the lowvelocity im sacts on the ground.

In 1972, an object about $10 \mathrm{~m}$ across skimmed through the atmosphere above the western United States, leaving a bright trail hat was seen and photographed, before it bounced out into spice again. Had it struck Earth's surface instead, it would hav: released energy equivalent to that of several atomic bor bs, sufficient to destroy a large city (Weaver, 1986, pp. 416-417; Morrison, 1992, p. 7).

In 1908 an even larger object, perhaps 30-50 m across, exploded in the sky above the Tunguska River of Siberia (Russia), produc ng an air blast that was detected around the world and flatten :d about $2000 \mathrm{~km}^{2}$ of forest (an area more than half the size of Rhode Island) (Krinov, 1966, Chapter 3; Chyba et al, 1993). The energy released was equivalent to about $15 \mathrm{~m}$ llion tons [15 megatons (MT)] of TNT. Fortunately, even this large object was broken up by pressure waves generated c uring its passage through the atmosphere, and its kinetic a nergy was released as a huge explosion several kilometers ıbove the ground. If the object had survived to strike the gr sund intact, it would have produced a crater about $1 \mathrm{~km}$ in dianneter [about the size of Barringer Meteor Crater (Arizona)] and devastated much of the surrounding countryside $(K r n g, 1997)$. (The timing of the Tunguska event was also for unate. If the object had entered the atmosphere only a few sours later, the blast would have occurred over the city of $: t$. Petersburg, Russia, and would probably have destroyed thie city.)

Earth's situation in space, together with the observed record of th: present and recent past, demonstrates that there is nothing $~$ nusual or nonuniformitarian about extraterrestrial impact ; , even large ones. In fact, impacts are like other uniformitar an processes such as earthquakes and volcanic eruptions: there are lots of small ones and relatively few large ones. The s nall ones occur frequently, cause little damage, and tend to be ignored. The larger ones are much rarer, but they are the ones that do all the damage.

\subsection{T'HE PROBLEMS OF PREDICTION: HOW BIG, HOW OFTEN?}

\subsubsection{Ingredients of Catastrophe}

Collisions of large extraterrestrial bodies with Earth are rare, but they are far morc destructive than the impacts of 
smaller objects. Larger and heavier objects not only possess more kinetic energy than smaller ones, but they are also less affected by Earth's atmosphere. They are not slowed down, they survive intact to the ground, and their entire original kinetic energy is delivered to Earth's surface. Objects no more than a few tens of meters across may be massive enough (and coherent enough, especially if they are iron meteorites) to pass through the atmosphere without being slowed and to strike the ground at their original cosmic velocities.

Typical cosmic velocities are high. The minimum impact velocity for collisions with Earth is $11.2 \mathrm{~km} / \mathrm{s}$; this is, by definition, equal to the escape velocity for an object launched into space from Earth's surface. The maximum possible impact velocity onto Earth is the sum of two separate velocities: (1) The velocity of the impacting object in its orbit around the Sun (beliocentric velocity). This quantity, which can also be thought of as the escape velocity from the solar system, is about $42 \mathrm{~km} / \mathrm{s}$ at the orbit of Earth. (2) The orbital velocity of Earth itself around the Sun, which is about $30 \mathrm{~km} / \mathrm{s}$. The maximum possible impact velocity on Earth is the simple sum of these two velocities, or $72 \mathrm{~km} / \mathrm{s}$. However, the orbits of Earth and the colliding object will generally be inclined to one another; the two velocities will therefore add geometrically (as a vector sum), producing Earth-encounter velocities (geocentric velocities) between these two limits. Typical Earth-encounter velocities for asteroids are $15-25 \mathrm{~km} / \mathrm{s}$ (Chyba et al., 1994). Comets tend to have higher encounter velocities, e.g., as much as $60 \mathrm{~km} / \mathrm{s}$ for Comet Halley. At such speeds, these objects carry as much kinetic energy as $20-50 \times$ their weight in TNT, and all this energy is released when they strike the Earth.

Because impact velocities are high, the kinetic energy $\left(=1 / 2 \mathrm{mv}^{2}\right)$ of even small objects is also high. A stony meteorite only $6 \mathrm{~m}$ in diameter, colliding with the Earth at $20 \mathrm{~km} / \mathrm{s}$, releases as much energy $\left[8.3 \times 10^{13}\right.$ joules $(\mathrm{J})$ or 20,000 tons $(20 \mathrm{kT})$ of TNT] as an atomic bomb (see Table 2.1). The impact of a larger object, such as a moderate-sized comet or asteroid only a few kilometers across, releases in seconds amounts of energy measured in millions or even billions of MT ( $1 \mathrm{MT}=10^{6}$ tons of TNT or $4.2 \times$ $10^{15} \mathrm{~J}$ ). For comparison, the total energy released by the Earth, through volcanism, earthquakes, and heat flow, is about $1.3 \times 10^{21} \mathrm{~J} / \mathrm{yr}$, or about $310,000 \mathrm{MT} / \mathrm{yr}$ (Fowler, 1993, p. 226). A collision with a modest-sized asteroid thus releases in a few seconds more energy than the entire Earth releases in hundreds or thousands of years. Fortunately for terrestrial life and civilization, these larger catastrophes are rare, even over geological timescales of millions of years.

\subsubsection{Uncertain Estimates}

But just how rare is "rare"? How often is an impact crater of a given size produced on Earth? How often will bodies of a given size collide with Earth in the future? Scientists attempting to solve these problems for Earth (or any other planet) are faced with three complex and interrelated questions: (1) How often will an extraterrestrial object of a given size strike Earth? (2) How much energy (determined by the object's mass and impact velocity) will be released by the event? (3) How large a crater will be formed by this amount of energy?

Attempting to answer these questions causes major difficulties. Impact is a random process, not a regular one, and it is difficult to make a precise statistical estimate from only a small number of recorded events. The preserved terrestrial crater population is small; worse, it is biased toward younger and larger structures because of erosion and other postimpact processes. Better statistics are available from the more well-preserved lunar and planetary cratering records, but to apply this information to Earth requires corrections for different planetary gravity fields, target characteristics, and the variation of impact rates at different locations within the solar system. Finally, calculations of crater sizes depend on a large number of complicated factors: projectile characteristics (mass, density, physical properties, impact velocity, impact angle), target characteristics (structure, physical properties), the partitioning of the projectile's original kinetic energy into various forms (mechanical, kinetic, seismic, thermal) within the target, and the relationships between impact energy and crater size for various projectiles, targets, and impact velocities.

Efforts to determine impact frequencies date back to before the Apollo program and the planetary missions of the last few decades, and, despite the difficulties, much progress has been made. Many workers have used a large range of different astronomical and planetary data: the present measured impact rate of small bodies on the Earth; the number and sizes of known asteroids and comets; and the number and size of impact craters observed on the better-preserved surfaces of other planets, particularly the Moon, Mars, and (more recently) Venus (for reviews and different examples, see Taylor, 1982, Chapter 3; 1992, Chapter 4; Hörz et al., 1991; papers in Gebrels, 1994). Other scientists have calculated terrestrial bombardment rates from the small but growing population of preserved terrestrial craters (Grieve, 1991; Grieve and Shoemaker, 1994; Grieve and Pesonen, 1992, 1996; Shoemaker and Shoemaker, 1996). The various theoretical problems of energy partitioning and crater size have been extensively addressed in numerous theoretical and laboratory studies (e.g., O'Keefe and Abrens, 1975, 1977, 1993; Ahrens and O'Keefe, 1977; papers in Roddy et al., 1977; Holsapple and Schmidt, 1982, 1987; for reviews and literature, see also Melosh, 1989, Chapter 7).

Even with the large amount of observational, theoretical, and laboratory data now available, the uncertainties in such estimates remain large. Individual estimates of the frequency of impact on Earth for objects of the same size vary by factors of 5-10x, especially for larger objects. (Compare, e.g., the various estimates of Bottke et al., 1994; Neukum and Ivanov, 1994; Grieve and Shoemaker, 1994.) The material in Table 2.1 presents approximate estimates of terrestrial impact frequencies, energies, and resulting crater sizes. These data represent a combination of various current estimates, but they are only approximate and should be used only for general illustration. The uncertainties, in both the databases and the mathematical models used, are still too great to allow more precise estimates. 


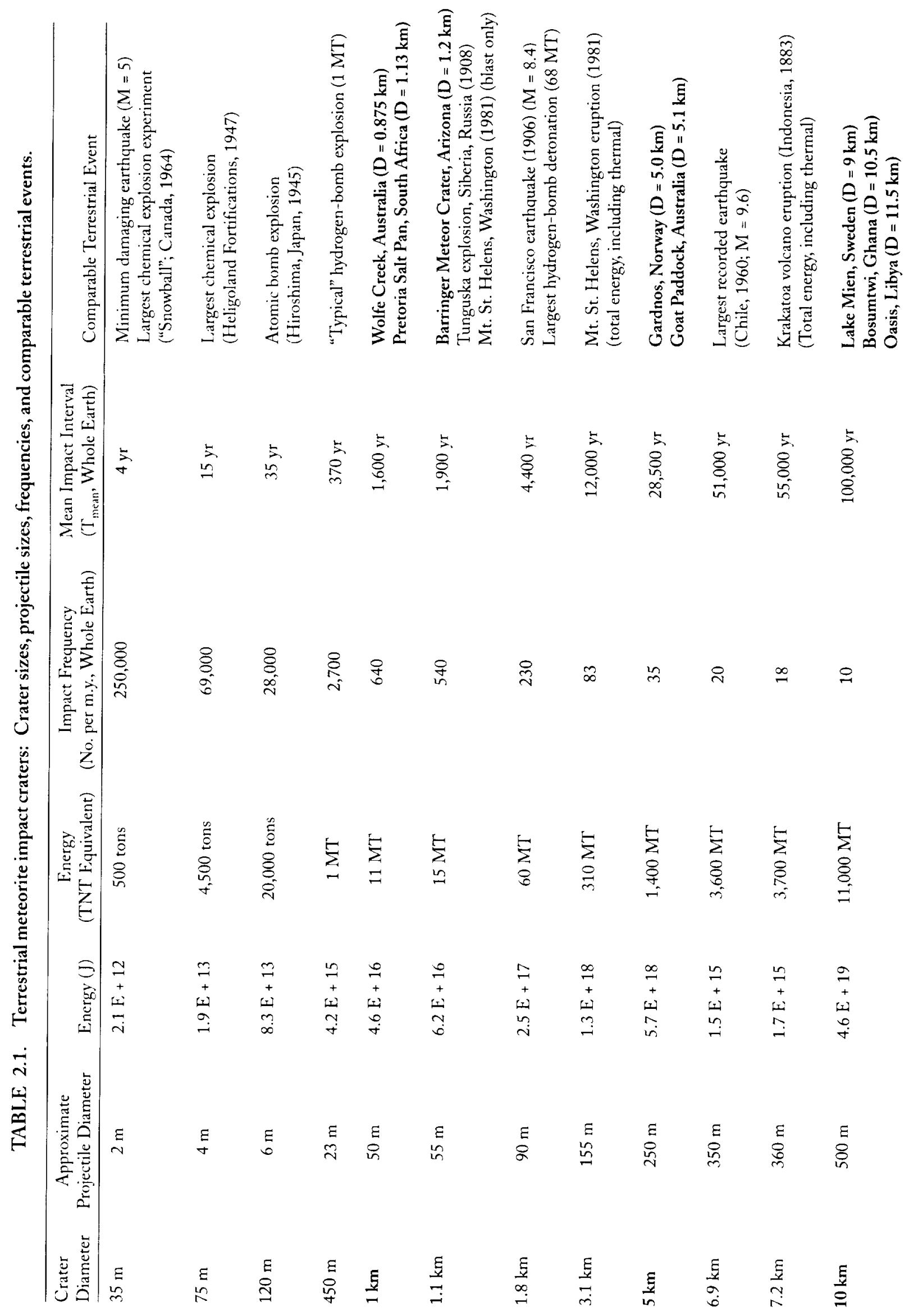




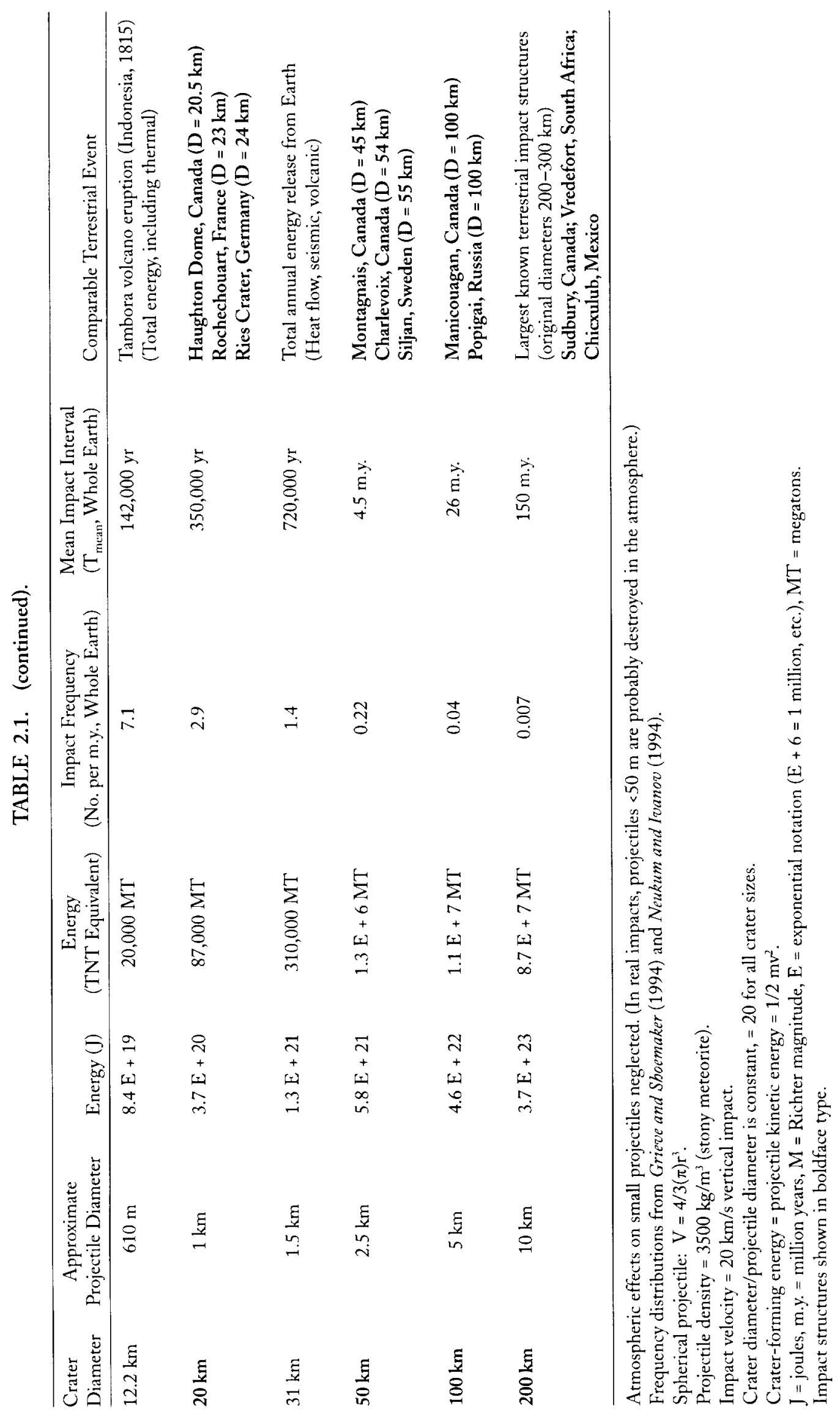


Geologically based estimates for the terrestrial impact rate have been obtained from the number of large ( $D \geq 20 \mathrm{~km}$ ) impact structures identified in stable, well-preserved regions of Earth (Grieve, 1991; Grieve and Shoemaker, 1994; Shoemaker and Shoemaker, 1996]. This value, $(5.6 \pm 2.8) \times 10^{-15}$ craters $/ \mathrm{km}^{2} / \mathrm{yr}$, is comparable with that deduced from astronomical data (chiefly from crater counts on the Moon's surface), although the stated $50 \%$ uncertainty is probably a minimum value. This rate implies that, over the whole Earth, a few (perhaps 1-5) craters of this size ( $D \geq 20 \mathrm{~km}$ ) should be produced every million years or so by the impact of projectiles $\geq 1-2 \mathrm{~km}$ in diameter. In these models, the average impact frequency varies approximately with the inverse square of the crater diameter, implying that about 10 craters of diameter $\geq 10 \mathrm{~km}$ should form in the same millionyear period, while a crater $\geq 100 \mathrm{~km}$ in diameter should be formed every $10 \mathrm{~m}$.y. or so. Other models for impact frequencies (e.g., Neukum and Ivanov, 1994) yield numbers of craters that are lower by factors of 5-10, cspecially for larger structures.

Nevertheless, these estimates are useful approximations, and they demonstrate that even very large impacts are not an unusual phenomenon when one thinks in terms of geological periods of time.

\subsubsection{An Uncertain Future?}

The frequency with which extraterrestrial objects collide with Earth, and the sizes of craters produced by the collisions, are not just interesting scientific problems. They are matters for serious concern about the future of our society, perhaps even of our species. We know that extraterrestrial bodies collide with Earth today, we have demonstrated that they have collided with it in the past, and we must face the fact that they will continue to collide with it in the future.
It is not a question of whether such collisions will occur; the only qu estions are when, how big, and what the effects will be.

The haz ards of such future collisions have been discussed in detail esewhere (Chapman and Morrison, 1989, 1994; Morrison, : 992; Gebrels, 1994; Verschuur, 1996). Large impact events are rare, but they cannot be ignored just for that reason. Such events are unpredictable and might happen at any momer $t$. The impact of an object only $50 \mathrm{~m}$ across, forming a crate' only a kilometers in diameter [e.g., Barringer Meteor $\mathrm{Cr}$.ter (Arizona)], would totally devastate an area of several tho ssand square kilometers around the impact site (Kring, 1957). The probability of a larger event, sufficient to cripple or jossibly destroy our current interconnected and technology-dependent civilization, although small, is very real (Chaprian and Morrison, 1994), and we do not yet know enough to valuate the danger.

Althoug huch of the concern for assessing and removing impact razards lies in other areas, particularly social and political, the scientific study of impact events can play a crucial role in inderstanding and possibly preventing the catastrophic dainage that would be caused by a large impact event in the futu $\mathrm{e}$. The geological structures left by past impact events can rive us information about the frequency of large impact ever ts, the sizes of the projectiles, the energy released, and the en ironmental damage produced over regional or global dista aces. At the same time, continued observation of the solar system can inventory the existing population of nearEarth aster ids and comets and can help estimate the chances of future cc llisions. With such data, the threat from extraterrestrial c bjects can be better evaluated, and people and governmen:s can determine what - if anything — can be done to avc id a catastrophic disaster in the future. 


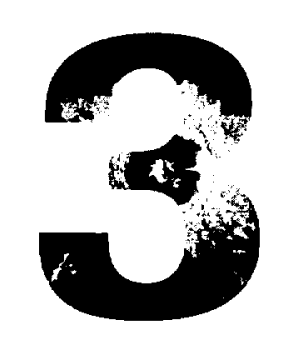

\section{Formation of Impact Craters}

The processes by which large impact craters form, and the sudden releases of huge quantities of energy involved, cannot be duplicated in the laboratory, and, fortunately, no such structure has formed during recorded human history. All our knowledge about large impact structures is therefore indirect, and it has come from combining several areas of once-separate research: theoretical and experimental studies of shock waves (for reviews and literature, see Melosh, 1989), experimental production of small craters (e.g., Gault et al., 1968; Gault, 1973; Holsapple and Schmidt, 1982, 1987; papers in Roddy et al., 1977), and geological studies of larger terrestrial impact structures (Shoemaker, 1963; Dence, 1968; Dence et al., 1977; Grieve and Cintala, 1981; Grieve et al., 1981; Scbultz and Merrill, 1981; Stöffler et al., 1988). The cratering process is complex, many details are still uncertain, and neither calculations nor predictions can be made with firm confidence. But these studies provide the essential basis for understanding how impact craters form and for deciphering the geological features they display.

\subsection{SHOCK WAVES AND CRATER FORMATION}

The general term "impact crater" is used here to designate a hypervelocity impact crater, the structure formed by a cosmic projectile that is large enough and coherent enough to penetrate Earth's atmosphere with little or no deceleration and to strike the ground at virtually its original cosmic velocity $(>11 \mathrm{~km} / \mathrm{s}$ ). Such projectiles tend to be relatively large, perhaps $>50 \mathrm{~m}$ in diameter for a stony object and $>20 \mathrm{~m}$ for a more coherent iron one.

Smaller projectiles, typically a few meters or less in size, behave differently in passing through the atmosphere. They lose most or all of their original velocity and kinetic energy in the atmosphere through disintegration and ablation, and they strike the ground at speeds of no more than a few hun- dred meters per second. In such a low-velocity impact, the projectile penetrates only a short distance into the target (depending on its velocity and the nature of the target material), and the projectile's momentum excavates a pit that is slightly larger than the projectile itself. The projectile survives, more or less intact, and much of it is found in the bottom of the pit. Such pits, sometimes called penetration craters or penetration funnels, are typically less than a few tens of meters in diameter.

Examples of these features include Brenham (Kansas), the many small pits made by the Sikhote-Alin (Russia) meteorite shower in 1947, and the pit dug by the largest piece of the Kirin (China) meteorite fall in 1976. The process of excavation is strictly a mechanical one, and high-pressure shock waves are not produced.

In sharp contrast, a hypervelocity impact crater starts to form at the instant that an extraterrestrial object strikes the ground surface at its original cosmic velocity. These impact velocities are much greater than the speed of sound in the target rocks, and the crater is produced by intense shock waves that are generated at the point of impact and radiate outward through the target rocks. Shock waves are intense, transient, high-pressure stress waves that are not produced by ordinary geological processes (for details, see Melosh, 1989, Chapter 3 and references therein). Peak shock pressures produced at typical cosmic encounter velocities may reach several hundred $\mathrm{GPa}$. These pressure are far above the stress levels $(\sim \mathrm{GPa})$ at which terrestrial rocks undergo normal elastic and plastic deformation, and the shock waves produce unique and permanent deformation effects in the rocks through which they pass.

The shock waves radiate from the impact point at high velocities that may exceed $10 \mathrm{~km} / \mathrm{s}$, much greater than the speed of sound in the target rocks. As they expand, they interact with the original ground surface to set a large volume of the target rock into motion, thus excavating the impact crater. The formation of an impact crater by shock waves, 
and the immediate modification of the newly formed crater by gravity and rock mechanics, is a complex and continuous process. However, it is convenient to divide this process, somewhat arbitrarily, into three distinct stages, each dominated by different forces and mechanisms: contact and compression, excavation, and modification (Gault et al., 1968; see also Melosh, 1989, Chapters 4, 5, and 8).

\subsubsection{Contact/Compression Stage}

This stage begins at the instant that the leading edge of the moving projectile makes contact with the ground surface. If the target is solid rock, the projectile is stopped in a fraction of a second and penetrates no more than $1-2 x$ its own diameter (Fig. 3.1) before its immense kinetic energy is transferred to the target rocks by shock waves generated at the interface between projectile and target (Kieffer and Simonds, 1980; O'Ketfe and Abrens, 1982, 1993; Melosh, 1989, Chapter 4).

The general features of this conversion of kinetic energy into shock waves have been determined from experiments and theoretical studies (e.g., O'Keefe and Abrens, 1975, 1977, 1993; Abrens and O'Keefe, 1977; papers in Roddy et al., 1977; Melosh, 1989, Chapter 4), although many details are still not
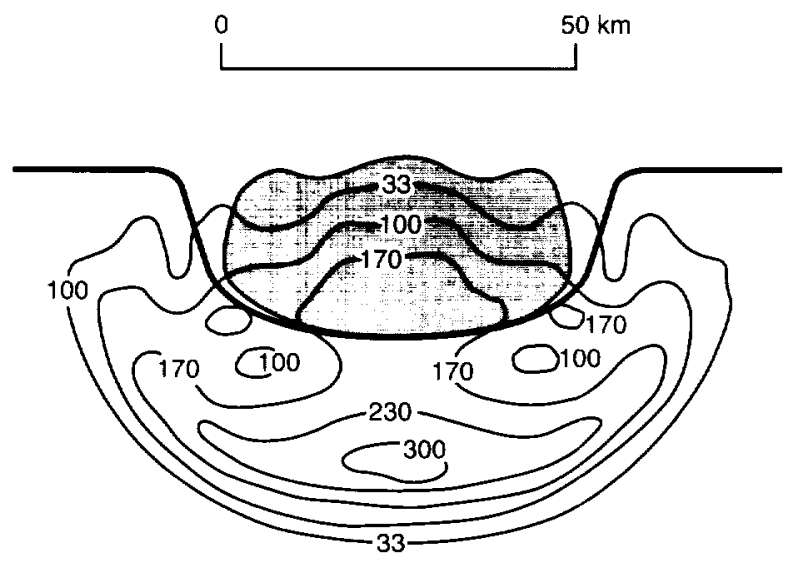

Fig. 3.1. Contact/compression stage: shock-wave generation and projectile deformation. Theoretical cross-section showing calculated conditions immediately after the impact of a large, originally spherical, projectile (stippled) onto a uniform target. The projectile has penetrated about half its diameter into the target, and intense shock waves (pressures in $\mathrm{GPa}$ ) are radiating outward into the target from the interface. The projectile itself has become intensely compressed, and similar shock waves from the interface are spreading toward the rear of the projectile. When this shock wave reaches the rear of the projectile, it will be reflected forward as a tensional wave or rarefaction, unloading the projectile and allowing it to transform, virtually instantaneously, into melt and vapor. The original model, developed for large lunar impact events (O'Kefe and Abrens, 1975), represents conditions about $1 \mathrm{~s}$ after the impact of a $46-\mathrm{km}$-diameter anorthosite projectile at $15 \mathrm{~km} / \mathrm{s}$ onto a gabbroic anorthosite target, but similar conditions will be produced by smaller impacts and other material compositions. (Modified from Melosh, 1989, Fig. 4.1a, p. 47.) well understood. One clear result is that, as one set of shock waves is tra ismitted outward from the interface into the target rocks, a complementary shock wave is reflected back into the project le (Fig. 3.1) (Melosh, 1989, Chapter 4; O'Keefe and Abrens, 1993).

The shock waves transmitted into the target rocks lose energy rap dly as they travel away from the impact point. Two factor: are involved in this energy loss: (1) the expanding shock $f$ :ont covers an increasingly larger hemispherical area with ir creasing radial distance, thus reducing the overall energy censity; (2) additional energy is lost to the target rocks throu gh heating, deformation, and acceleration. The peak pressu res of the shock waves therefore also drop rapidly with distance from the impact point. Theoretical models (Melost, 1989, pp. 60-66) and geological studies of shock-met: morphosed rocks in individual structures (Dence, 1968; Robe tson, 1975; Grieve and Robertson, 1976; Dence et al., 1977; Fobertson and Grieve, 1977; Dressler et al., 1998) indicate tha $t$ the peak shock-wave pressure $\left(\mathrm{P}_{\mathrm{s}}\right)$ drops exponentially $w$ th the distance $\mathbf{R}$ from the impact point accord-

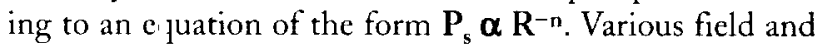
laboratory : tudies indicate a dependence of $\mathrm{R}^{-2}$ to $\mathrm{R}^{-4.5}$; the exact value of the exponent depends on projectile size and impact velc city (Abrens and O'Keefe, 1977).

On the basis of these studies, it is possible to regard the impact poir $t$ as surrounded by a series of concentric, roughly hemispherizal shock zones, each zone distinguished by a certain ranyre of peak shock pressure (Fig. 3.2) and characterized by a unique suite of shock-metamorphic effects produced in th e rocks. At the impact point, peak shock-wave pressures $\mathrm{n}$ ay exceed $100 \mathrm{GPa}(=1000 \mathrm{kbar}$ or $1 \mathrm{Mbar})$ for typical cosr ric encounter velocities, producing total melting, if not vapo ization, of the projectile and a large volume of surroundin $r$ target rock. Further outward, pressures of 10$50 \mathrm{GPa}$ ma y exist over distances of many kilometers from the impact ooint, producing distinctive shock-deformation effects in large volumes of unmelted target rock.

At even ,reater distances from the impact point, the peak shock-wavi pressures eventually drop to about 1-2 GPa (Kieffer anu Simonds, 1980). At this point, near the eventual crater rim, he shock waves become regular elastic waves or seismic war es, and their velocity drops to that of the velocity of sound in the target rocks (typically 5-8 km/s). These seismic waves r an be transmitted throughout the entire Earth, like similar waves generated by earthquakes and volcanic eruptions. 3ecause of their low pressures, they do not produce any pe manent deformation of the rocks through which they pass. However, seismic waves may produce fracturing, brecciation faulting, and (near the surface) landslides, and the results $\mathrm{r}$ ay be difficult to distinguish from those of normal geological processes.

The dur ation of the contact/compression stage is determined by the behavior of the shock wave that was reflected back into the projectile from the projectile/target interface (Fig. 3.1) (i Kelosh, 1989, pp. 57-59). When this shock wave reaches the back end of the projectile, it is reflected forward into the projectile as a rarefaction or tensional wave (also 


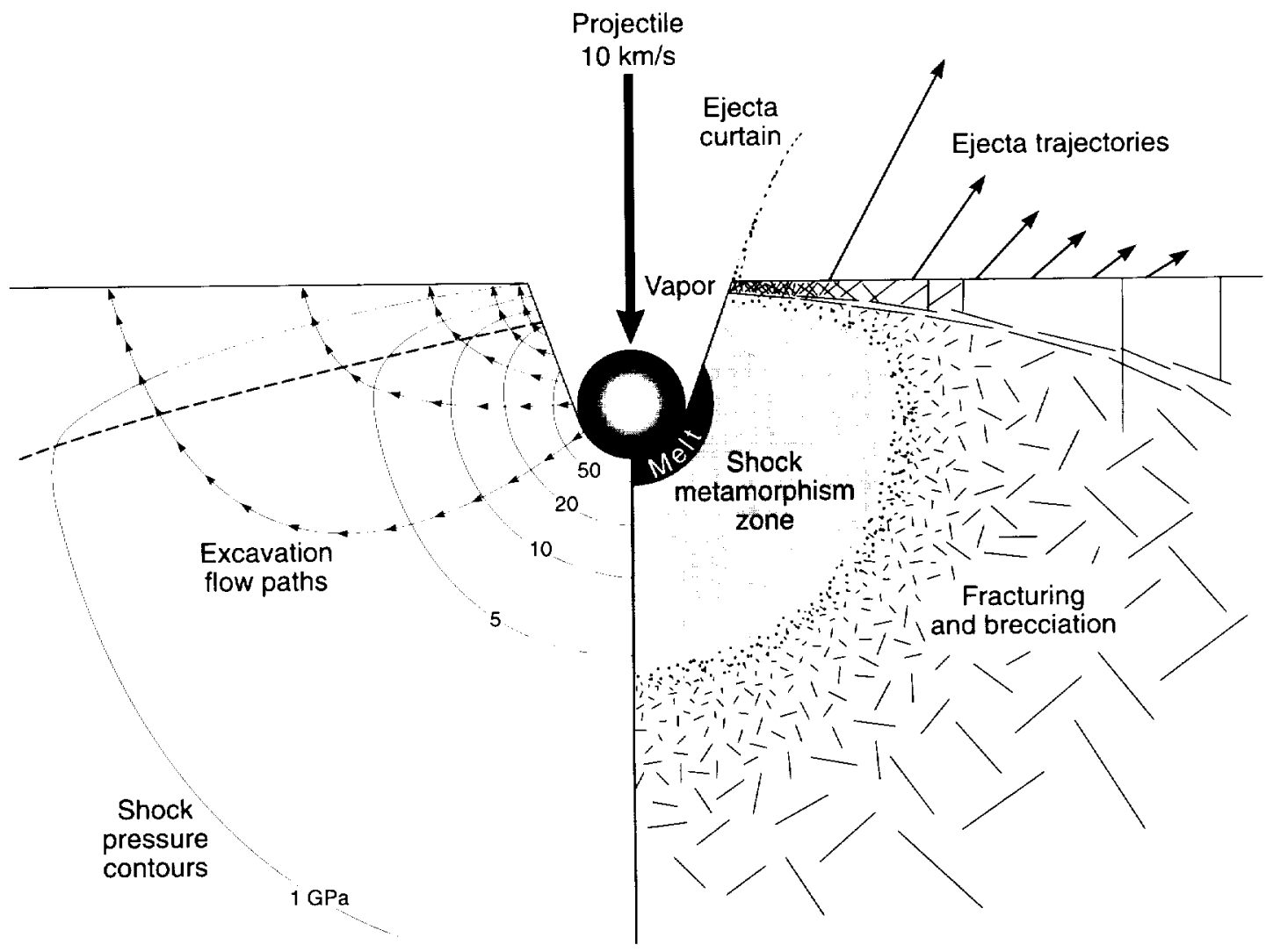

Fig. 3.2. Contact/compression stage: initial shock-wave pressures and excavation flow lines around impact point. Schematic crosssection showing peak shock pressure isobars (pressures in GPa) developed in the target around the impact point near the end of the contact/compression stage. The originally spherical projectile, after penetrating about two diameters into the target, has been almost completely destroyed and converted to melt and vapor. Shock waves radiating from the projectile-target interface decline rapidly outward in peak pressure (isobars in GPa on left side of cavity), creating concentric, approximately hemispherical zones of distinctive shock effects (right side of cavity). From the original interface outward, these zones involve: (1) melting ( $>50 \mathrm{GPa}$ ) and formation of a large melt unit; (2) shock-deformation effects (5-50 GPa); (3) fracturing and brecciation (1-5 GPa). The subsequent excavation stage involves two processes: (1) upward ejection (spalling) of large near-surface fragments and smaller ejecta (ejecta curtain) (upward-pointing arrows above ground surface); (2) subsurface flow of target material to form the transient crater (arrow paths crossing isobars at left side). (Modified from Melosh, 1989, Fig. 5.4, p. 64.)

called a release wave). As the release wave passes through the projectile from back to front, it unloads the projectile from the high shock pressures it had experienced. Because the shock pressures, and the associated temperatures, have been so high, this release results in the virtually complete melting and vaporization of the projectile. At the instant at which the release wave reaches the front end of the projectile, the whole projectile is unloaded, and the release wave continues forward into the target and begins to decompress it as well. This point, at which the release wave reaches the front of the projectile and begins to enter the adjacent compressed target, is taken as the end of the complete contact/ compression stage.

The contact/compression stage lasts no more than a few seconds, even for impacts of very large objects. The time required for the shock wave to travel from the projectile/ target interface to the rear edge of the projectile is approxi- mately equal to the time it takes the projectile to travel the distance of one diameter at its original velocity. Even for large projectiles, this time is short: $2 \mathrm{~s}$ for a $50-\mathrm{km}$-diameter projectile traveling at $25 \mathrm{~km} / \mathrm{s}$, and less than $0.01 \mathrm{~s}$ for a 100-m-diameter object traveling at the same speed. The additional time required for the release wave to travel from the rear to the front edge will be no more than a few times this value, depending on the properties of projectile and target rock (Melosh, 1989, pp. 48 and 58). For most impact events, the entire contact/compression stage is over in less than a second.

After the release wave has reached the front end of the projectile and unloaded it completely, the projectile itself plays no further role in the formation of the impact crater, and the actual excavation of the crater is carried out by the shock waves expanding through the target rocks. The vaporized portion of the projectile may expand out of the crater as part 
of a vapor plume (Melosh, 1989, pp. 68-71), and the remainder, virtually all melted, may be violently mixed into the melted and brecciated target rocks.

\subsubsection{Excavation Stage: The Transient Crater}

The brief contact/compression stage grades immediately into a longer excavation stage, during which the actual impact crater is opened up by complex interactions between the expanding shock waves and the original ground surface (Fig. 3.3) (Melosh, 1989, Chapter 5; Griez'e, 1991). As the contact/compression stage ends, the projectile is surrounded by a roughly hemispherical envelope of shock waves that expand rapidly through the target rock. Because the projectile has penetrated a finite distance into the target, the center of this hemisphere actually lies within the original target rock at a point below the original ground surface.

Within this hemispherical envelope, the shock waves that travel upward and intersect the original ground surface are reflected downward as rarefactions (release waves). In a nearsurface region where the stresses in the tensional release wave exceed the mechanical strength of the target rocks, the release wave is accompanied by fracturing and shattering of the target rock (Fig. 3.2). This reflection process also converts some of the initial shock-wave energy to kinetic energy, and the rock involved is accelerated outward, much of it as individual fragments traveling at high velocities (Fig. 3.4).

These complex processes drive the target rock outward from the impact point, producing a symmetric excavation flow around the center of the developing structure. Exact flow directions vary with location within the target rocks (Fig. 3.4). In the upper levels, target material moves dominantly upward and outward. At lower levels, target material moves dominantly downward and outward. These movements quickly produce a bowl-shaped depression (the transient cavity or transient crater) in the target rocks (Maxwell, 1977; Grieve at al., 1977; Grieve and Cintala, 1981; Melosh, 1989, pp. 74-78).

The transient crater is divided into approximately equal upper and lower zones (Figs. 3.4 and 3.5). Within the upper ejection zone, velocities imparted to the target rocks may be as high as several kilometers per second, high enough to excavate the fragmented material and to eject it beyond the rim of the final crater (Grieve et al., 1977; Dence et al., 1977;
Kieffer and Simonds, 1980; Melosh, 1989, pp. 74-76). Even at significa 1 t distances from the impact point, shock pressures and th e resulting ejection velocities remain high enough $(>100 \mathrm{~m} / \mathrm{s})$ to eject material. For this reason, the diameter of the final cr iter is many times larger (typically 20-30x) than the diamet $r$ of the projectile itself.

At deeper levels, tensional stresses in the release waves are lower. . s a result, fracturing is less pronounced, excavation flow $v$ :locities are lower, and the excavation flow lines themselves are not oriented to eject material beyond the crater rim ( $\mathrm{Fi}$, 3.4). This region forms a displaced zone in which mat rial is driven downward and outward more or less coheren itly.

Both zo.es in the transient crater continue to expand, accompanit $d$ by the uplift of near-surface rocks to form the transient clater rim, as long as the expanding shock waves and release waves are strong enough to eject or displace material from the developing cavity. However, these waves continually lose energy by deforming and ejecting the target rocks through which they pass. Eventually, a point is reached at which the shock and release waves can no longer excavate or displace taryet rock. At that point the growth of the transient crater zeases. There is an instant of theoretical balance in which th 2 energies of the shock wave no longer act, and the waiting forces of gravity and rock mechanics have not yet reasserte $d$ themselves. At this instant, the transient crater reaches ts maximum extent, the excavation stage ends, and the sub iequent modification stage begins immediately.

The excivation stage, although longer than the contact/ compressiou stage, is still brief by geological standards. If the near-sur face excavation flow has a minimum average velocity of $1 \mathrm{~lm} / \mathrm{s}$, then a $200-\mathrm{km}$-diameter transient crater can be excarated in less than 2 min. More detailed calculations (Melo.h, 1989, p. 123) indicate that excavation of a 1-km-diame ter crater (e.g., Barringer Meteor Crater [Arizona]) will xccur in about $6 \mathrm{~s}$, while a $200-\mathrm{km}$-diameter crater requises only about $90 \mathrm{~s}$.

The con ept of the transient crater has been developed from a combination of theoretical studies (Melosh, 1989, Chapter 5) a ad geological investigations (Dence, 1968; Grieve and Cintala, 1981; Grieve et al., 1981). The ideal transient crater is a b wwl-shaped depression with a structurally uplifted rim (igs. 3.4 and 3.5). Its shape is approximately hemispherical but is actually a paraboloid of revolution

Fig. 3.3. Development of a simple impact structure. Series of cross-section diagrams showing progressive development of a small, bowl-shaped simple impact structure in a horizontally layered target: (a) contact/ ompression stage: initial penetration of projectile, outward radiation of shock waves; (b) start of excavation stage: continued expansion of shock wave into target; development of tensional wave (rarefaction or release wave) behind shock wave as the near-surface part of oric inal shock wave is reflected downward from ground surface; interaction of rarefaction wave with ground surface to accelerate near-su face material upward and outward; (c) middle of excavation stage: continued expansion of shock wave and rarefaction wave; develojment of melt lining in expanding transient cavity; well-developed outward ejecta flow (ejecta curtain) from the opening crater; (d) end of excavation stage: transient cavity reaches maximum extent to form melt-lined transient crater; near-surface ejecta curtain reaches maxim im extent, and uplifted crater rim develops; (e) start of modification stage: oversteepened walls of transient crater collapse back into avity, accompanied by near-crater ejecta, to form deposit of mixed breccia (breccia lens) within crater; (f) final simple crater: a borl-shaped depression, partially filled with complex breccias and bodies of impact melt. Times involved are a few seconds to form the tr insient crater (a)-(d), and minutes to hours for the final crater (e)-(f). Subsequent changes reflect the normal geological processes of e: osion and infilling. 
(a)

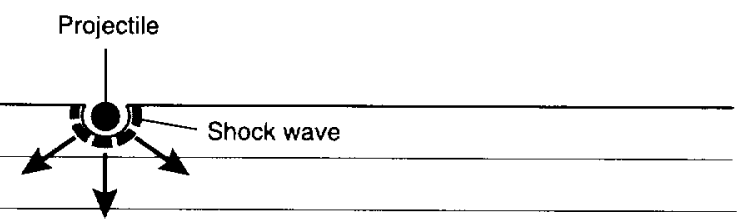

Contact/compression stage

(b)

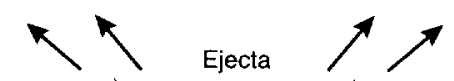

End contact/compression stage
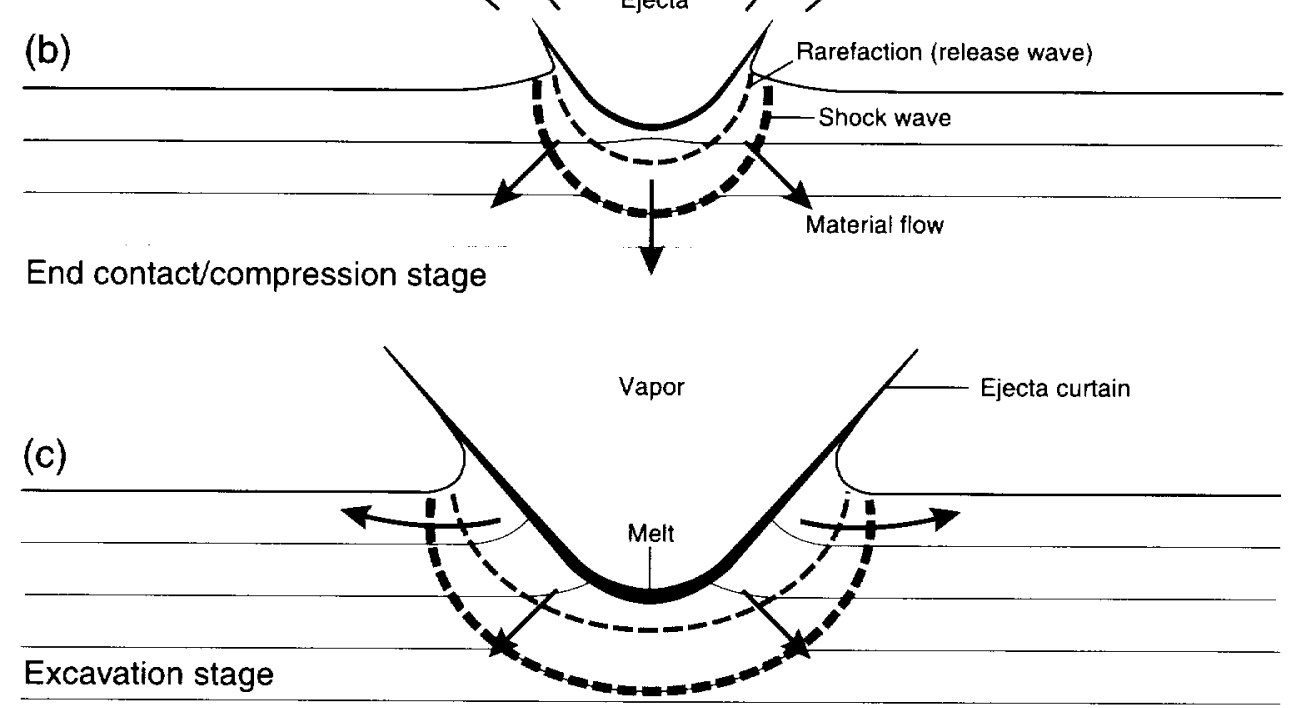

(d)
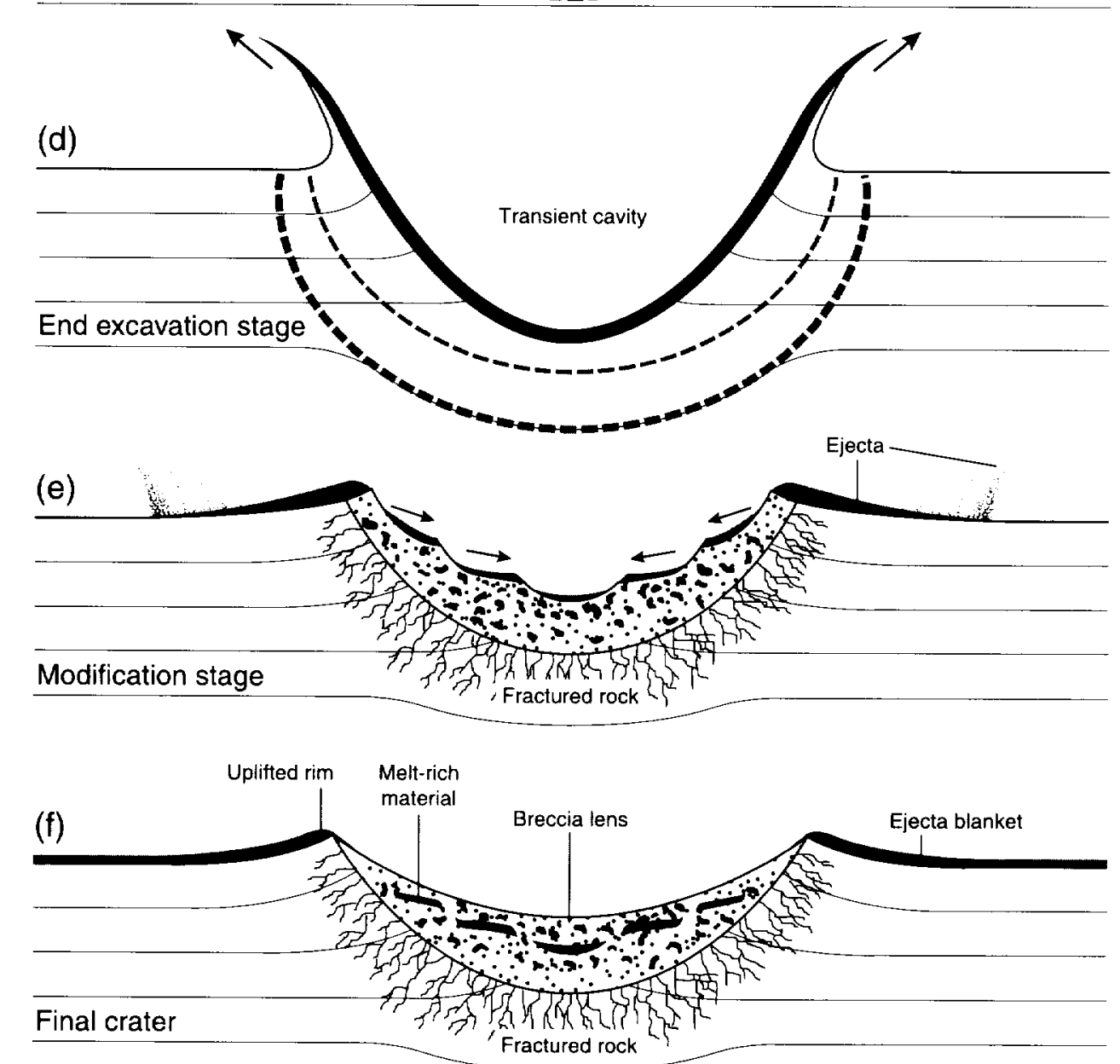


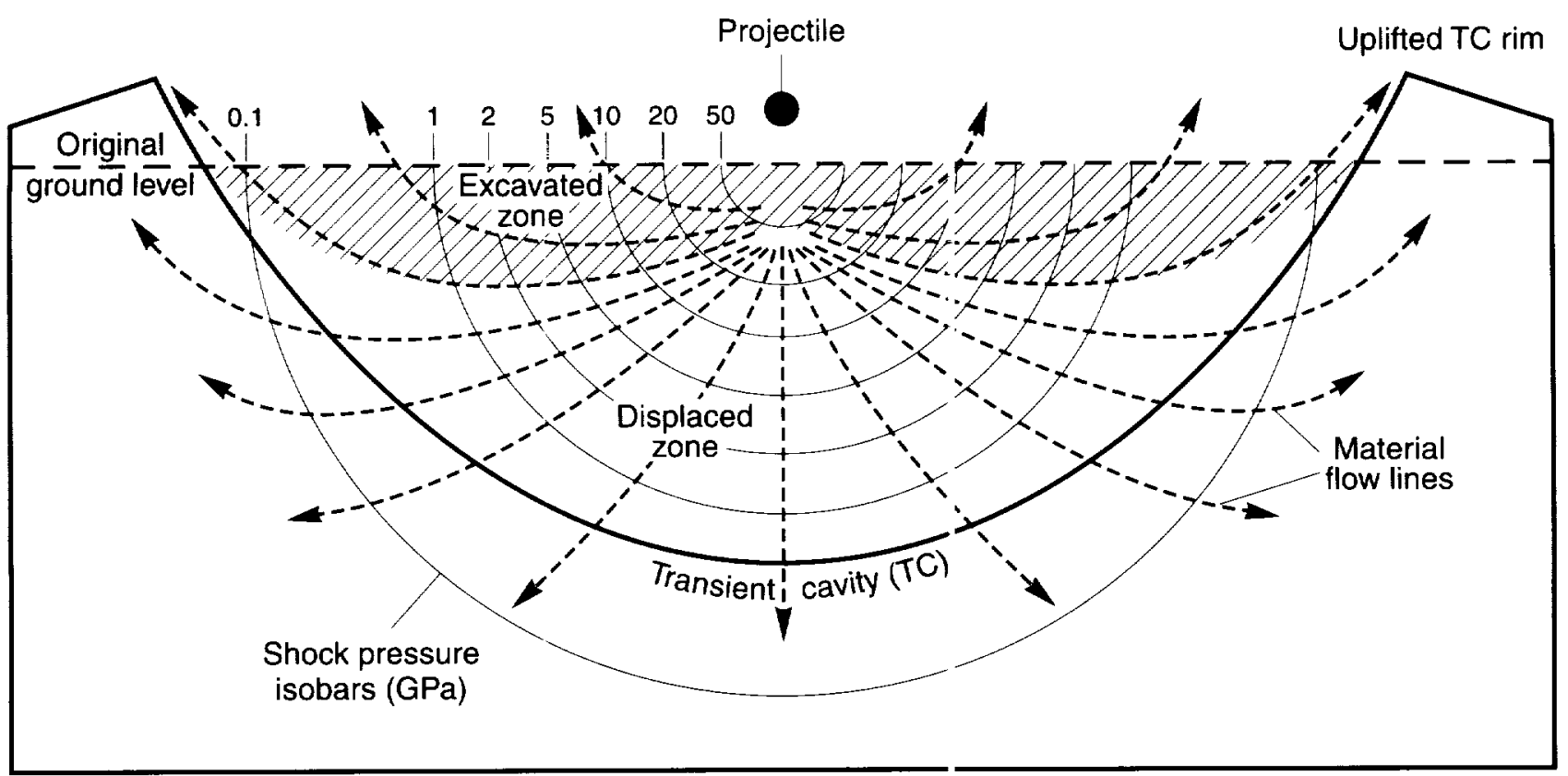

Fig. 3.4. Excavation stage: formation of transient crater. Theoretical cross s:ction showing development of the transient crater immediately after the contact/compression stage. Original peak shock pressures ( inits in GPa) around the impact point are shown for simplicity as hemispherical isobars (for details, see Fig. 3.2). Complex interacti ons of the shock wave, the ground surface, and the subsequent rarefaction wave produce an outward excavation flow (dashed arrows) hat opens up the transient crater. In the upper part of this region (excavated zone; ruled area), target material is fractured, excavated, ans ejected beyond the transient crater rim. In the lower region (displaced zone), target material is driven downward and outward, more o: less coherently, and does not reach the surface. This model yields two important geological results: (1) ejected material is derived only rom the upper part (approximately the top one-third to one-half) of the transient cavity; (2) because the excavation flow lines in the exca rated zone cut across the initially hemispherical shock isobars, ejected material will reflect a wide range of original shock pressures and deformation effects, ranging from simple fracturing to complete melting and vaporization. (Modified from Grieve, 1987, Fig. 5; Hörz et ul., 1991, Fig. 4.3a, p. 67.)

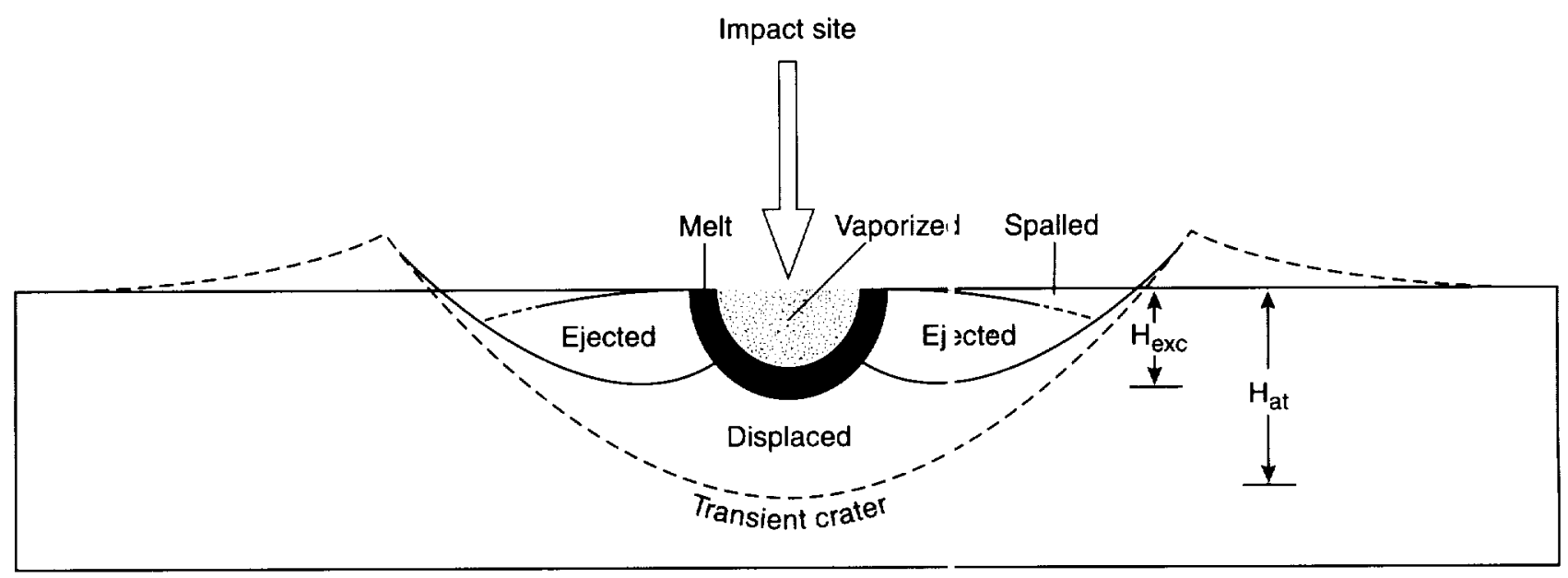

Fig. 3.5. Transient crater: locations of shock-metamorphosed materials. Cross section through a theoretical transient crater, showing discrete zones from which various shock-metamorphosed materials are derived. Tł e "vaporized" zone closest to the original impact point (stippled) contains a mixture of vaporized target rock and projectile, which expancs upward and outward into the atmosphere as a vapor plume. The adjacent "melt" zone (solid black) consists of melt that moves dowilward and then outward along the floor of the final transient cavity (for details, see Fig. 6.2). Material in the upper "ejected" zones on ither side of the melt zone, which contains a range of shock-metamorphic effects, is ejected outward to and beyond the transient crater im. The lower "displaced" zone moves downward and outward to form the zone of parautochthonous rocks below the floor of the final transient crater. $H_{a t}=$ the final transient crater depth; $\mathrm{H}_{\mathrm{exc}}=$ the depth of excavation, which is significantly less than the total depth. (From Melosh, 1989, Fig. 5.13, p. 78.) 
(Dence, 1973). Its maximum depth is approximately onethird its diameter, and this proportion seems to remain approximately constant for craters of widely different size (Maxwell, 1977; Croft, 1985).

The theoretical instant of ideal overall balance in a transient crater at the end of the excavation stage may not be actually attained during formation of a real crater. For example, in these models, the maximum diameter is normally attained after the maximum depth is reached. Subsequent modification of one part of an actual transient crater might therefore begin while other parts are still being excavated. Even so, the transient crater is a key concept in models of crater formation. All impact structures, regardless of their final size or the complexity of their subsequent development, are assumed to pass through the transient-crater stage, making this stage of critical importance in comparing impact structures of different sizes or on different planets. Defining the transient crater is also an essential step in determining critical characteristics of an impact structure: its original (pre-erosion) diameter and depth, the energy of impact, the size and velocity of the projectile, the distribution of shock pressures and shock effects within the crater, the amount of material melted and ejected during formation of the crater, the amount of structural uplift during formation of the central peak of complex impact structures, and the depth from which excavated materials were derived.

\subsubsection{Modification Stage}

The excavation stage ends when the transient crater has grown to its maximum size, and the subsequent modification stage begins immediately. The expanding shock waves have now decayed to low-pressure elastic stress waves beyond the crater rim, and they play no further part in the crater development. Instead, the transient crater is immediately modified by more conventional factors like gravity and rock mechanics.

The immediate part of the modification stage, during which the major impact-related changes occur, lasts only slightly longer than the excavation stage: less than a minute for a small structure, a few minutes for a large one (Melosh, 1989, Chapter 8, pp. 141-142). (One simple definition is that the modification stage ends "when things stop falling.") However, the modification stage has no clearly marked end, and the modification processes of uplift and collapse merge gradually into the normal processes of geological mass movement, isostatic uplift, erosion, and sedimentation.

\subsection{SIMPLE AND COMPLEX IMPACT STRUCTURES}

The extent to which the transient crater is altered during the modification stage depends on its size and (to a lesser extent) on the structure and properties of the target rock. Small transient craters are altered chiefly by the collapse of their upper walls, and the shape of the final crater is little changed from that of the original transient crater. In larger structures, modification may involve major structural changes: uplift of the central part of the floor and major peripheral collapse around the rim. Depending on the extent to which the transient crater is modified, three distinct types of impact structures can be formed: simple craters, complex craters, and multiring basins.

\subsubsection{Simple Craters}

The smallest impact structures occur as bowl-shaped depressions (simple craters) less than a few kilometers across, which help to preserve the shape and dimensions of the original transient cavity (Figs. 1.1 and 3.6). In evolving to a simple crater, the transient crater is modified only by minor collapse of the steep upper walls into the crater cavity and by redeposition of a minor amount of ejected material in the crater. As a result, the crater diameter may increase by as much as $20 \%$, but the original transient crater depth remains largely unaffected (Fig. 3.7) (Melosh, 1989, p. 129).

During modification, the simple crater is immediately filled, to perhaps half its original depth, by a mixture of redeposited (fallback) ejecta and debris slumped in from the walls and rim (Fig. 3.7). This crater-filling unit, variously called the breccia lens or crater-fill breccia, is a mixture of rock fragments, both shocked and unshocked, together with fragments or lenses of shock-melted rock (impact melt).

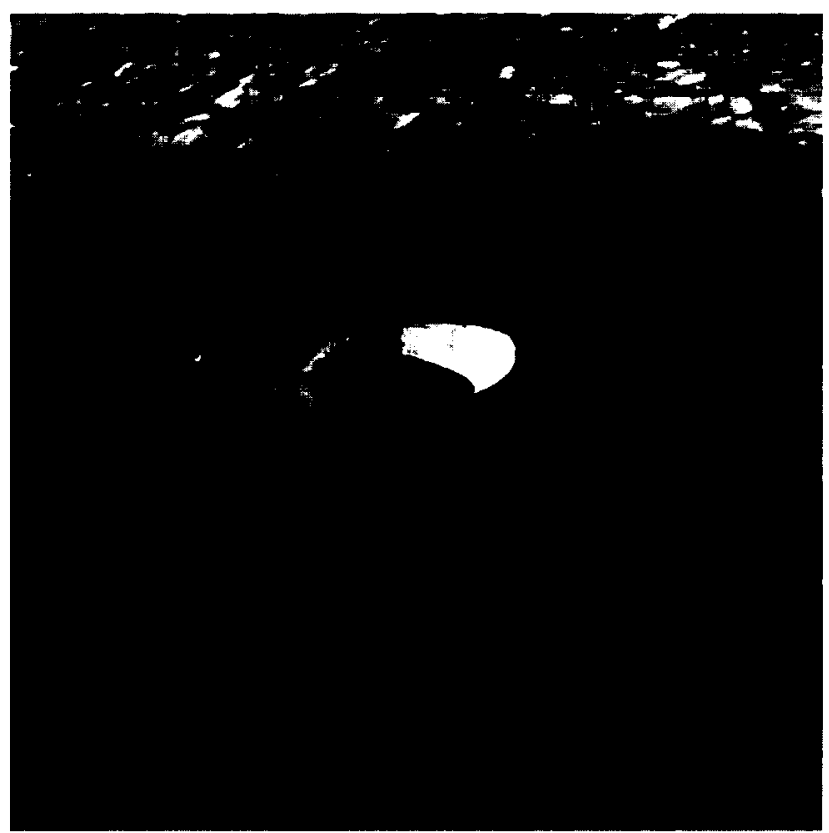

Fig.3.6. A simple lunar impact crater. This small, well-preserved crater (Moltke: $\mathrm{D}=7 \mathrm{~km}$ ) shows features typical of simple impact craters: a circular outline, a bowl-like shape, an uplifted rim, and hummocky deposits of ejecta around the rim. In the relatively low gravity of the Moon, this structure formed as a simple crater; a terrestrial structure of the same diameter, formed under Earth's higher gravity, would have formed as a complex crater with a central uplift. (Apollo 10 image AS10-29-4324.) 


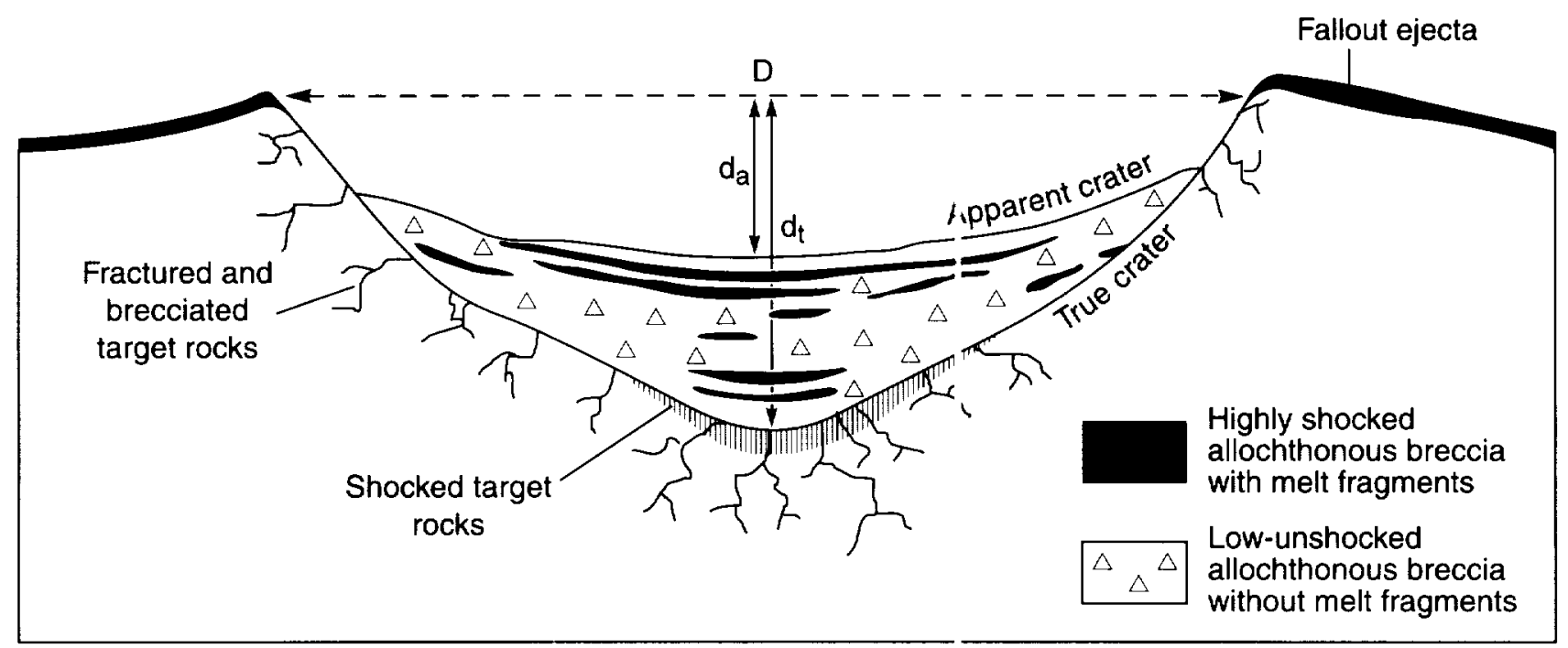

Fig. 3.7. Simple impact structure: locations of impactite types. Schematic cross section of a typical simple impact structure, showing the simple bowl shape and the locations of various types of impactites in and arou id the structure. The parautochthonous rocks below the true crater floor are fractured and brecciated but generally show no distinctive shock effects, except in a small zone (fine vertical ruling) in the center of the structure. The crater is filled, to approximately half its original height, with a variety of allogenic breccias and impact melts, which forms the crater-fill units or the breccia lens. A thinner layer of ejected material (fallout ejecta) overlies the uplifted crater rim and surrounds the crater. This unit is easily eroded and is present only in the youngest and best-preserved structures. $D=f i n a l$ crater diameter, which is 10-20\% greater than the diameter of the original, premorlification transient crater; $d_{t}=$ true depth of the final crater, which is approximately the depth of the original transient crater; $\mathrm{d}_{\mathrm{a}}=$ appare nt depth of the crater, or the depth from the final rim to the top of the crater-fill units. The diagram represents the state of the final crater sefore any subsequent geological effects, e.g., erosion, infilling. The model is based on drilling studies at Barringer Meteor Crater (Ariz ona) (Roddy et al, 1975; Roddy, 1978), Brent Crater (Canada) (Dence, 1968; Grieve and Cintala, 1981), and similar structures (e.g., Nasaitis et al., 1980; Gurov and Gurova, 1991). (From Grieve, 1987, Fig. 1.)

Depending on the subsequent geological history, the breccia lens may be eroded or may be covered and preserved by a cap of later sedimentary fill.

\subsubsection{Complex Craters}

The bowl-shaped form of simple craters appears only in relatively small structures less than a few kilometers across. Larger impact structures (complex craters) display a different and more complicated form, characterized by a centrally uplifted region, a generally flat floor, and extensive inward collapse around the rim (Figs. 1.3, 3.8, and 3.9) (Dence, 1968; Grieve et al., 1977, 1981; Grieve, 1991). For terrestrial structures, the transition between simple and complex craters occurs at a diameter of about $4 \mathrm{~km}$ in massive crystalline rocks, but at only about $2 \mathrm{~km}$ in sediments. (However, these values apply only to Earth. The transition diameter varies inversely with gravitational acceleration, and it is different on different planets.) The larger impact events that form complex craters apparently release enough energy to overcome the fundamental strength of the target rocks over a large volume beneath the large transient crater. As a result, late-stage modification involves complex interactions between shock-wave effects, gravity, and the strength and structure of the target rocks, and the modification is characterized by outward, inward, and upward movements of large volumes of the subcrater rocks.
The details of these interactions are uncertain, but the general result is that the original bowl-shaped transient crater is imm:diately modified as deep-seated rocks beneath the center of the transient crater rise to form a central uplift (Dence, 19t.8; Grieve et al., 1981). At the same time, rocks around the periphery of the transient crater collapse downward and ir ward along concentric faults to form one or more depressed rings (ring grabens) and a series of terraces along the outer $m$ argins of the final structure (Fig. 3.10). [A simple model of the formation of a complex crater and its central uplift is pr sented by the familiar slow-motion movies of a drop of liquid hitting a liquid surface (e.g., Melosh, 1989, p. 148; Tay'or, 1992, p. 168). There is the same initial cavity formation, the same outward and downward ejection of target matericl, the same upward rebound of the central cavity floor, and the same collapse of the periphery back into the cavity. Hov 'ever, in impact events, these processes take place in solid roc $<$ and may operate over distances of tens to hundreds of kilometers.]

The idea that such rapid deformation and subsequent uplift can "sccur in large volumes of crustal rocks has been difficult for many geologists to appreciate. Key evidence has come from studies of impact structures formed in sedimentary rocks, in which the actual uplift of key stratigraphic markers ha $i$ been established beyond question through drilling and gec physical studies (e.g., Milton et al., 1972, 1996a,b; 


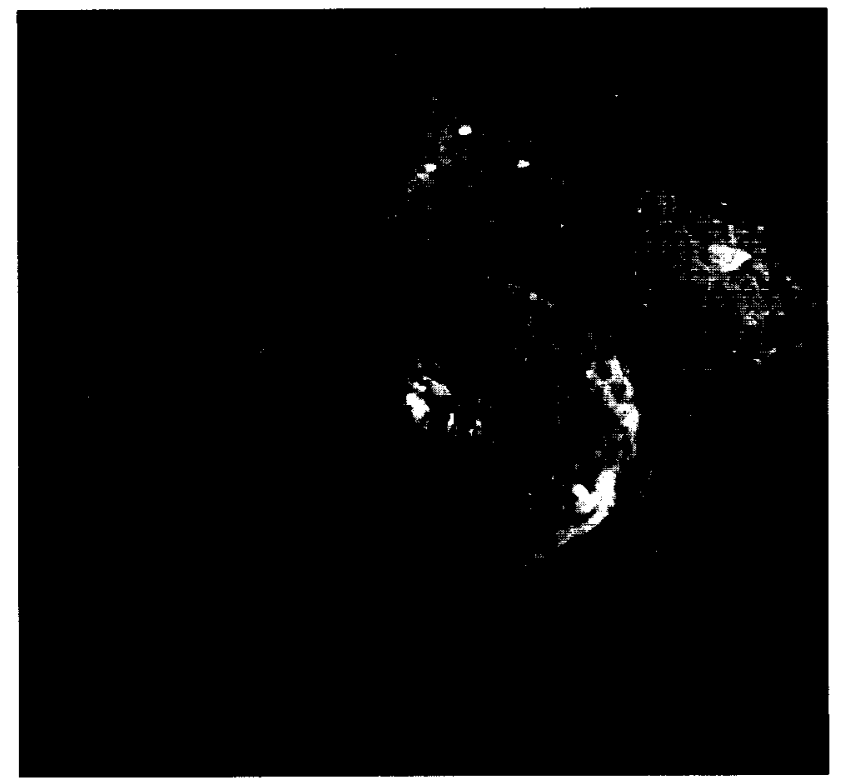

Fig. 3.8. A complex lunar crater. This relatively young crater (Theophilus: $\mathrm{D}=100 \mathrm{~km}$ ) displays well-preserved features that are typical of complex impact structures: a central uplift, a scalloped circular outline, ruggedly terraced walls with possible landslide deposits inside the rim, and hummocky ejecta deposits just outside the rim. This view also indicates the continuing nature of lunar cratering; an older impact crater (upper right) has been partly destroyed by Theophilus, while a younger small crater has formed within Theophilus itself (near rim, lower right). The flat dark area in the background (upper left) is made up of lava flows covering part of Mare Nectaris. The spiral-like rod at left center is an instrument boom on the Apollo 16 spacecraft, from which this orbital picture was taken. (Apollo 16 image AS16-M-0692.)

Grieve et al., 1981; Grieve and Pilkington, 1996). Geological studies have also established that the amount of actual stratigraphic uplift (SU) in impact structures is about one-tenth the final diameter (D) of the structure. A detailed statistical relation derived from studies of well-constrained complex impact structures (Grieve et al., 1981, p. 44) is $\mathrm{SU}=0.06 \mathrm{D}^{1.1}$ (both SU and D are in kilometers). A subsequent analysis, using more craters (Grieve and Pilkington, 1996, p. 404), gave $\mathrm{SU}=0.086 \mathrm{D}^{1.03}$. The two equations are virtually identical, and a value of $S U=0.1 \mathrm{D}$ is a reasonable approximation to either. For large $(D=100-200 \mathrm{~km})$ impact structures, these relations imply that the crustal rocks beneath the structure are uplifted vertically by $10-20 \mathrm{~km}$ during the impact event. An uplift of this magnitude has been estimated for the Vredefort (South Africa) structure on geological grounds (Reimold and Gibson, 1996; Therriault et al., 1997; Turtle and Pierazzo, 1998).

Both theoretical and field studies indicate that central uplifts form in only a few minutes, almost instantaneously by geological standards, even in the largest structures (Melosh, 1989, pp. 129 and 141-142). Theoretical studies also suggest that the central uplifts of structures $200-300 \mathrm{~km}$ in

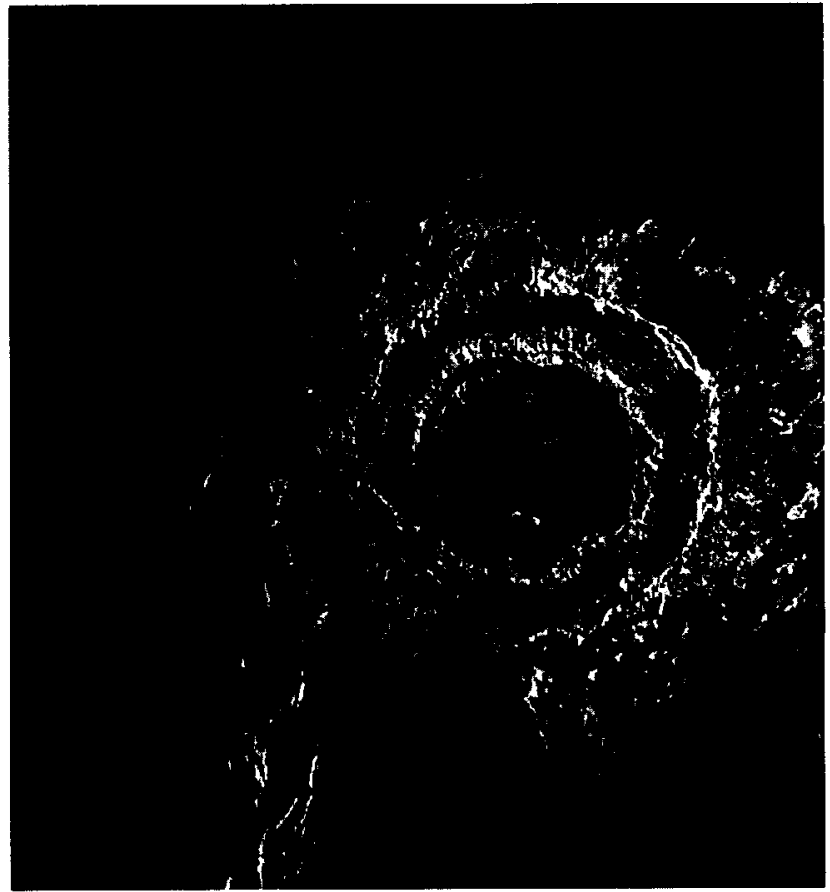

Fig. 3.9. A complex impact basin on Venus. A large, wellpreserved multiring impact basin on the surface of Venus (Meitner: $\mathrm{D}=150 \mathrm{~km}$ ) is revealed beneath the planet's opaque atmosphere by the imaging radar system of the Magellan spacecraft. Meitner, the third-largest impact structure identified on Venus, shows a flat smooth (dark-colored) interior, two circular rings, and a rough, irregular blanket of lobate ejecta (light-colored). The crater was formed on a surface of smooth plains, possibly underlain by lava flows and cut by abundant parallel fractures (white lines). (Magellan image F-MIDRP .55S319;201.)

diameter, such as Vredefort (South Africa), formed in less than 15 minutes (Melosh; 1989, pp. 141-142; Turtle and Pierazzo, 1998).

Despite the extensive evidence that central uplifts do form in large impact structures, the details of the process are still the subject of continuing uncertainty and active debate (Dence, 1968; Grieve et al., 1981; Melosh, 1989, Chapter 8; Hörzet al., 1991; Spudis, 1993). Even so fundamental a quantity as the ratio between the diameter of the initial transient crater and the diameter of the final complex impact structure has not been well established; values estimated by various workers, using both theoretical and geological studies, range from about 0.5 to 0.7 (see, e.g., Therriault et al., 1997, Table 2).

At larger crater diameters, the resulting structures, and especially the centrally uplifted area, become even more complicated. As the crater size increases the character of the central uplift changes, and the single central peak is progressively replaced by a more complex series of concentric rings and basins. At least three types of complex impact structures can be distinguished with increasing crater diameter: centralpeak structures, central-peak-basin structures, and peak- 

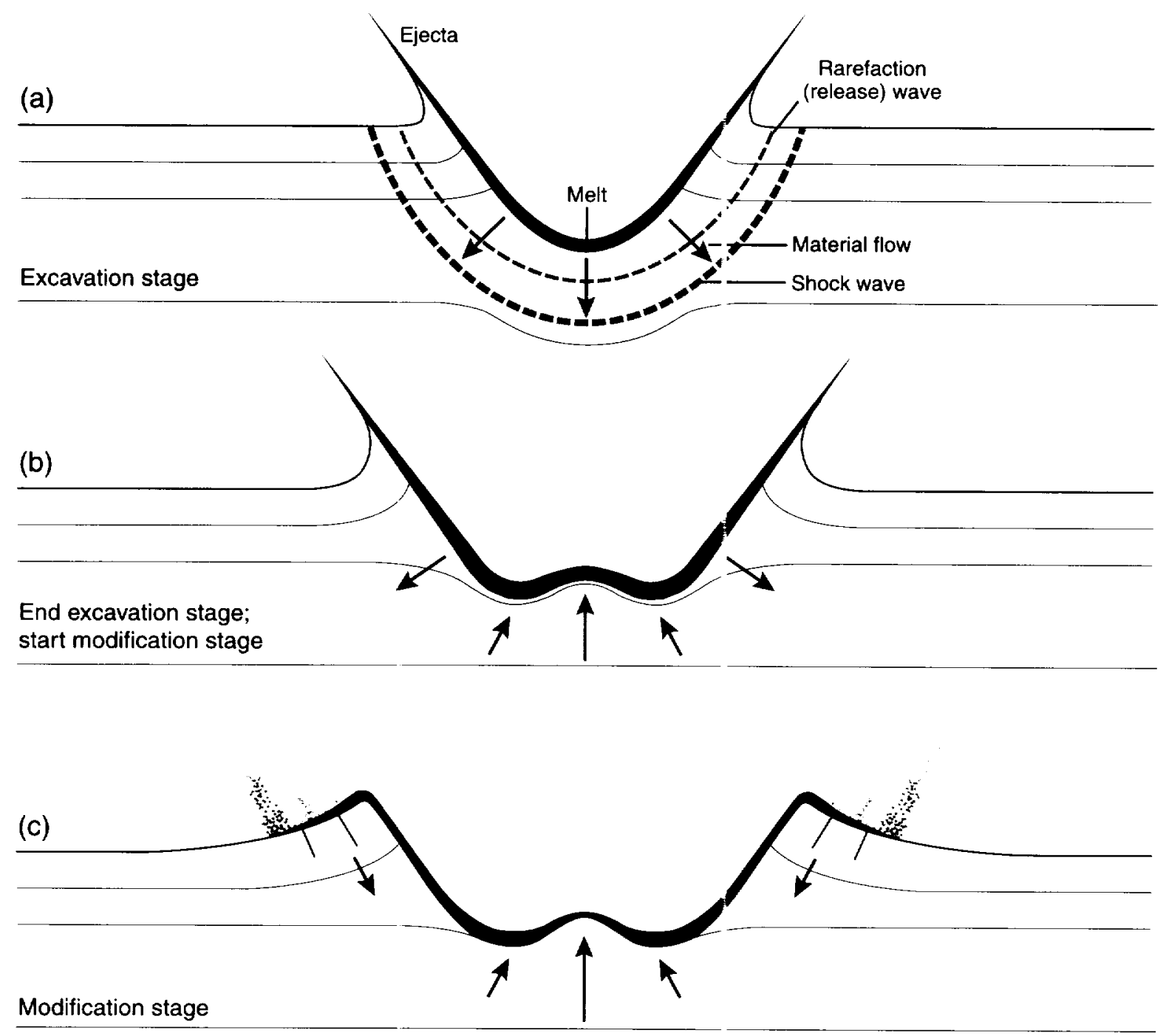

(d)

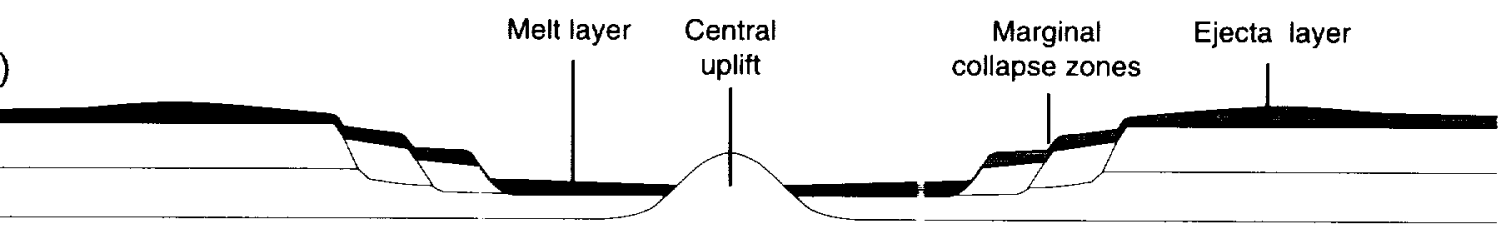

Fig. 3.10. Development of a complex impact structure. Series of cross sections s lowing progressive development of a large, complex impact structure in a horizontally layered target: (a) formation of a large transient $\mathrm{c}$ ater by the excavation process is virtually identical to transient crater formation in smaller structures (compare with Fig. 3.3a-d); (b) initia development of central uplift during the subsequent modification stage; (c) start of peripheral collapse, accompanied by continuing dev elopment of the central uplift and the thinning and draping of the original melt layer (black) over the uplifted rocks; (d) final structure, $v$ hich is of the central-uplift type, consists of a central uplift of deeper rocks, surrounded by a relatively flat plain and by a terraced rim p oduced by inward movement along stepped normal faults. The central uplift is surrounded by an annular deposit of allogenic breccias and impact melt (black), which may be absent from the central peak itself. An ejecta layer (stippled) covers the target rocks around the struc ure. The diameter of the final structure, measured at the outer rim beyond the outermost fault, may be $1.5-2 \times$ the diameter of the origit al transient crater. This central-peak morphology is observed in terrestrial structures ranging from about $2-25 \mathrm{~km}$ in diameter; larger str actures tend to develop one or more concentric rings within the crater (for details, see text). 
ring basin structures (Grieve at al., 1981; Melosh, 1989, Chapter 8; Spudis, 1993). As the terms suggest, these structures are characterized by the initial development of a basin in the central peak and eventually by the complete conversion of the central peak area to a ring structure (Figs. 1.3, 3.9 , and 3.11).

These distinctions, and the transition diameters at which they occur, have been most clearly established on airless bodies like the Moon, where even large ancient structures have been well preserved (Figs. 3.6, 3.8, and 3.11) (e.g., Taylor, 1982, 1992; Melosh, 1989, pp. 131-135; Spudis, 1993). Classification of large terrestrial structures (e.g., papers in Schultz and Merrill, 1981; Spudis, 1993, pp. 24-41) is more difficult and uncertain, because the impact structures, especially their critical upper parts, tend to be removed by erosion or buried by later sediments. Furthermore, the critical diameters at which one form changes to another depend inversely on the planetary gravity, making it difficult to apply data from structures on other planets to terrestrial features. For example, the transition between simple and complex craters occurs at about $20 \mathrm{~km}$ diameter on the Moon but at only $2-4 \mathrm{~km}$ on

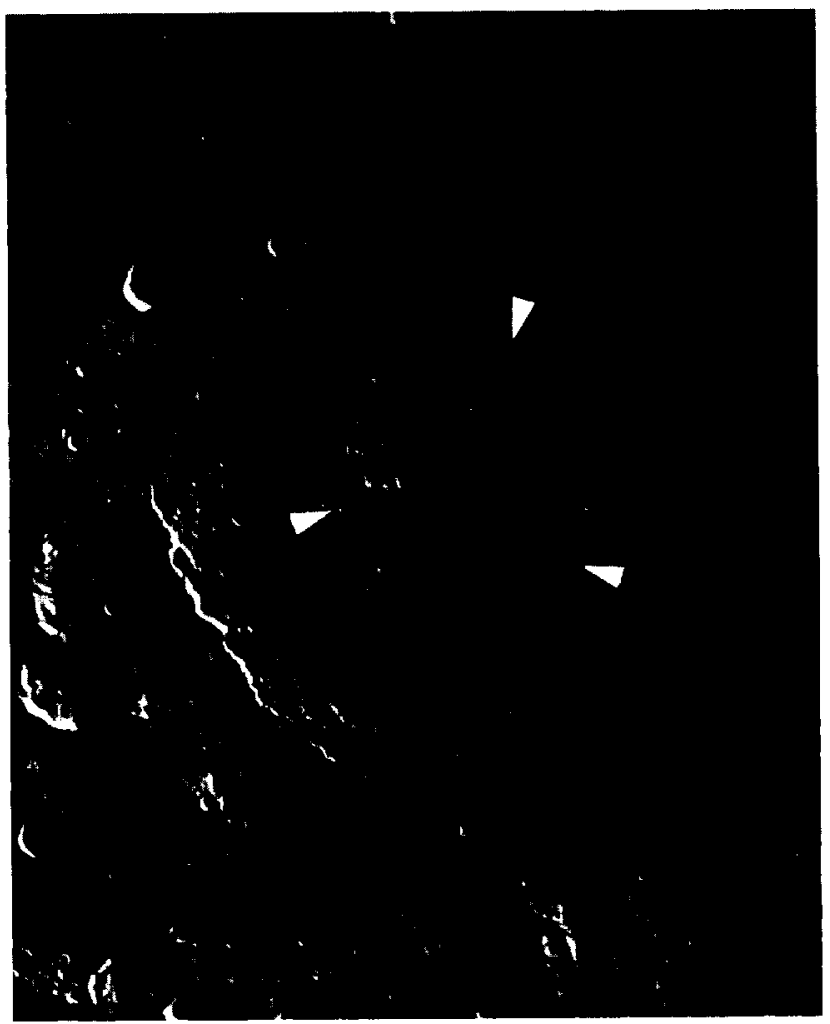

Fig. 3.11. A lunar impact basin. This large impact structure (Schrödinger: $\mathrm{D}=320 \mathrm{~km}$ ) is located on the lunar farside near the Moon's South Pole. Although ancient and highly degraded, it still preserves features distinctive of larger complex impact structures: a central uplift and terraced walls. However, in this large structure, the central uplift appears as an interior peak ring about $150 \mathrm{~km}$ in diameter (arrows), in sharp contrast to the simpler central peak formed in smaller complex structures. (Lunar Orbiter image LO-IV-8M.)
Earth. The subsequent transition between a central-peakbasin structure to a peak-ring structure occurs at about 150$200 \mathrm{~km}$ on the Moon, but at only about $20-25 \mathrm{~km}$ on Earth.

Despite the various difficulties, it has been possible to establish rough boundaries for different types of terrestrial complex structures (Grieve et al., 1981, p. 42, Fig. 2). These limits, and some typical examples, are: central-peak structures $(\mathrm{D}=4-22 \mathrm{~km})$ [Steinheim (Germany), Sierra Madera (Texas)]; central-peak-basin structures $(\mathrm{D}=22-30 \mathrm{~km})$ [Mistastin (Canada)]; peak-ring-basin structures $(\mathrm{D}=30$ $62 \mathrm{~km}$ ) [West Clearwater (Canada); Fig. 1.3]. These values are only approximations, and they will almost certainly change as more structures are studied in detail and as the formation of complex craters is better understood.

\subsubsection{Multiring Basins}

The largest planetary impact structures so far identified have diameters of a few hundred kilometers to more than $1000 \mathrm{~km}$ (e.g., papers in Schultz and Merrill, 1981; Melosh, 1989, Chapter 9; Spudis, 1993). In contrast to smaller impact structures, they appear as huge geological bulls-eyes, composed of multiple concentric uplifted rings and intervening down-faulted valleys (ring grabens) (Fig. 3.12). These features, designated multiring basins, are defined as structures that have two or more interior rings in addition to the outer rim of the structure.

Multiring impact basins have been produced by the impact of projectiles tens to hundreds of kilometers in diameter, and they date mainly from an early period in the solar system ( $\geq 3.9 \mathrm{Ga})$, when such large objects were more abundant and collisions were more frequent. The best multiring basins are best observed on planets with well-preserved ancient surfaces, such as the Moon, Mercury, parts of Mars, and some of the moons of Jupiter. Mare Orientale, on the Moon, with a diameter of at least $900 \mathrm{~km}$, is one of the most prominent and best-known multiring basins (Fig. 3.12), but even larger features exist, such as the Valhalla Basin (D $\sim 4000 \mathrm{~km}$ ) on Jupiter's icy moon Callisto. In addition, there are numerous large basins in the solar system that do not display a pronounced multiring structure, possibly because they have been deeply eroded since they formed. These include the Caloris Basin (Mercury; $\mathrm{D}=1300 \mathrm{~km}$ ), the Argyre Basin (Mars; D > $900 \mathrm{~km}$ ) (Fig. 1.9), and the recently identified South Pole-Aitken Basin on the Moon (D $\sim 2500 \mathrm{~km}$ ).

On the Moon, the transition to multiring basins occurs at diameters of about $400-600 \mathrm{~km}$. Because the transition diameters for different crater forms vary inversely with planetary gravity, this observation implies that multiring basins should begin to form on Earth at crater diameters greater than about $100 \mathrm{~km}$. Because the few terrestrial impact structures in this size range have been deeply eroded or buried (e.g., Fig. 1.4), it has not yet been possible to demonstrate clearly that any multiring basins exist on the Earth. The few possible candidates (and their current estimated diameters) are Manicouagan (Canada, $100 \mathrm{~km}$ ), Popigai (Russia, $100 \mathrm{~km}$ ), Vredefort (South Africa, >200 km), Sudbury 


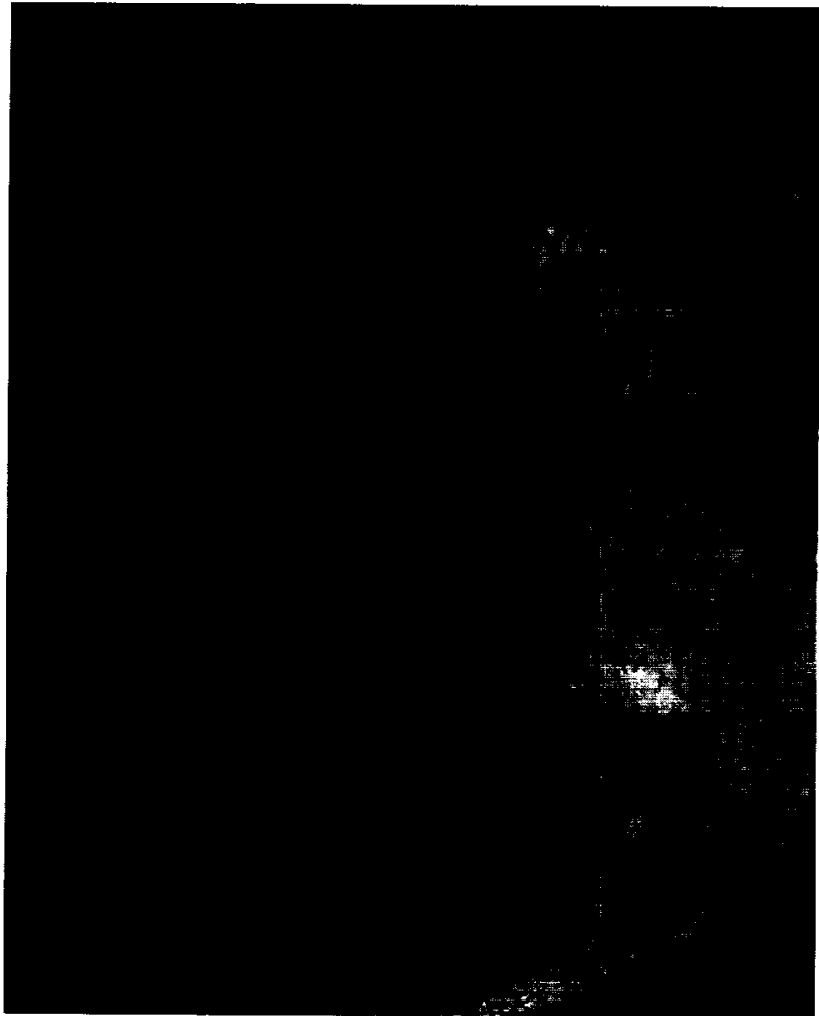

Fig. 3.12. A lunar multiring impact basin. One of the largest, freshest, youngest, and best-known multiring impact basins in the solar system, Mare Orientale $(\mathrm{D}=930 \mathrm{~km})$ lies on the boundary between the Earth-facing lunar nearside (right) and the lunar farside. The structure, formed at about $3.8 \mathrm{Ga}$, is bounded by an outer ring about $930 \mathrm{~km}$ in diameter (Cordillera Mountains), and inner rings with diameters of 620,480 , and $320 \mathrm{~km}$ can be distinguished. Mare Orientale is surrounded by radial features (especially at lower right) that may have been produced by the low-angle ejection of large blocks of excavated material. The postimpact history of the structure is also complex, and much of the area inside the rings has been modified by later volcanic activity. The flat dark areas at upper right are the younger lava flows that cover Oceanus Procellanum. (Lunar Orbiter image LO-IV-187M.)

(Canada, >200 km), and Chicxulub (Mexico, >180 km). It has not proved possible to establish beyond question the multiring character of these structures for various reasons, including deep erosion, postcrater deformation, or insufficient geological study. The strongest current candidate for a terrestrial multiring structure is Chicxulub, which, although buried, appears well preserved (Sharpton et al., 1993, 1996b; Morgan et al., 1997).

Multiring basins represent the most energetic and catastrophic impact events in the solar system, and the postimpact movements - upward, downward, and inward - of the target rock that modify the transient crater are far more complex and widespread than in smaller structures. It is therefore not surprising that the formation of multiring basins is even more uncertain and hotly debated than is the origin of smaller cor uplex impact structures (e.g., papers in Schultz and Merrill 1981; Melosh, 1989, Chapter 9; Spudis, 1993).

For exar uple, it is not clear whether the transition between smal ler impact structures and multiring basins is a natural deve lopment with increasing crater diameter (Herrick et al., 1997 , or whether multiring basins only form when special conc itions are present within the target, e.g., a crustmantle stru sture with a weak layer (asthenosphere) at depth within the flanet (see Melosh, 1989, pp. 176-180). Nor is it understood why some planetary features in the 1000-2000$\mathrm{km}$-diametar range have a pronounced multiring form (Fig. 3.12) Ind others do not (Fig. 1.9). Finally, it is not yet established whether multiring impact structures - ancient or modern - - do exist on Earth and which large structures they may be.

\section{3. ؟UBSEQUENT DEVELOPMENT OF IMPACT STRUCTURES}

When the crater formation process ends, the resulting circular structure, whether simple or complex, consists of deformed si bcrater rocks covered by an ejecta blanket outside the cra er and with crater-fill deposits (usually a mixture of brecc as and bodies of impact melt) within it (Figs. 3.7 and 3.13). This assemblage of distinctive near-surface rocks is immedia ely subject to more normal geological processes: eros on, burial, and tectonic deformation. If the crater forms o 1 land and remains exposed after formation, erosion will quickly remove the surface ejecta blanket and destroy any surviving meteorite fragments. At the same time, however, a l:ke may form in the crater depression, covering the crater-fil material with a preserving cap of sediments, e.g., as at B. ent (Canada) (Dence, 1968; Grieve, 1978) and the Ries Criter (Germany) (von Engelhardt, 1990).

If the ori; ;inal impact site is covered by water, the formation and sul sequent history of the resulting crater may be more compl :x. At the moment of impact, the overlying layer of water will be excavated with the underlying bedrock, and the developr zent of the crater and the deposition of the impact-produc d rock units will be modified by the immediate and violent $\mathbf{r}$ esurge of this displaced water back into the crater cavity (T berriault and Lindström, 1995; Lindström et al., 1996). If th : crater remains below the water level, it will immediately begin to fill with sediments, and its subsequent history will c epend on whether it remains below water level (continuous sediment filling) or is uplifted at some future time (begint ing of erosion). A number of such submarine impact struc ures have now been recognized; some have subsequently been raised above sea level [c.g., Lockne (Sweden) (Therric ult and Lindström, 1995; Lindström et al., 1996)] and others s:ill remain buried [e.g., Montagnais (Canada) (Jansa and Pe-Piper, 1987); the Chesapeake Bay Crater (USA) (Poag, 1996, 1997); and the recently discovered Mjolnir structure (Norway) in the Barents Sea (Dypuiket al., 1996)]. 

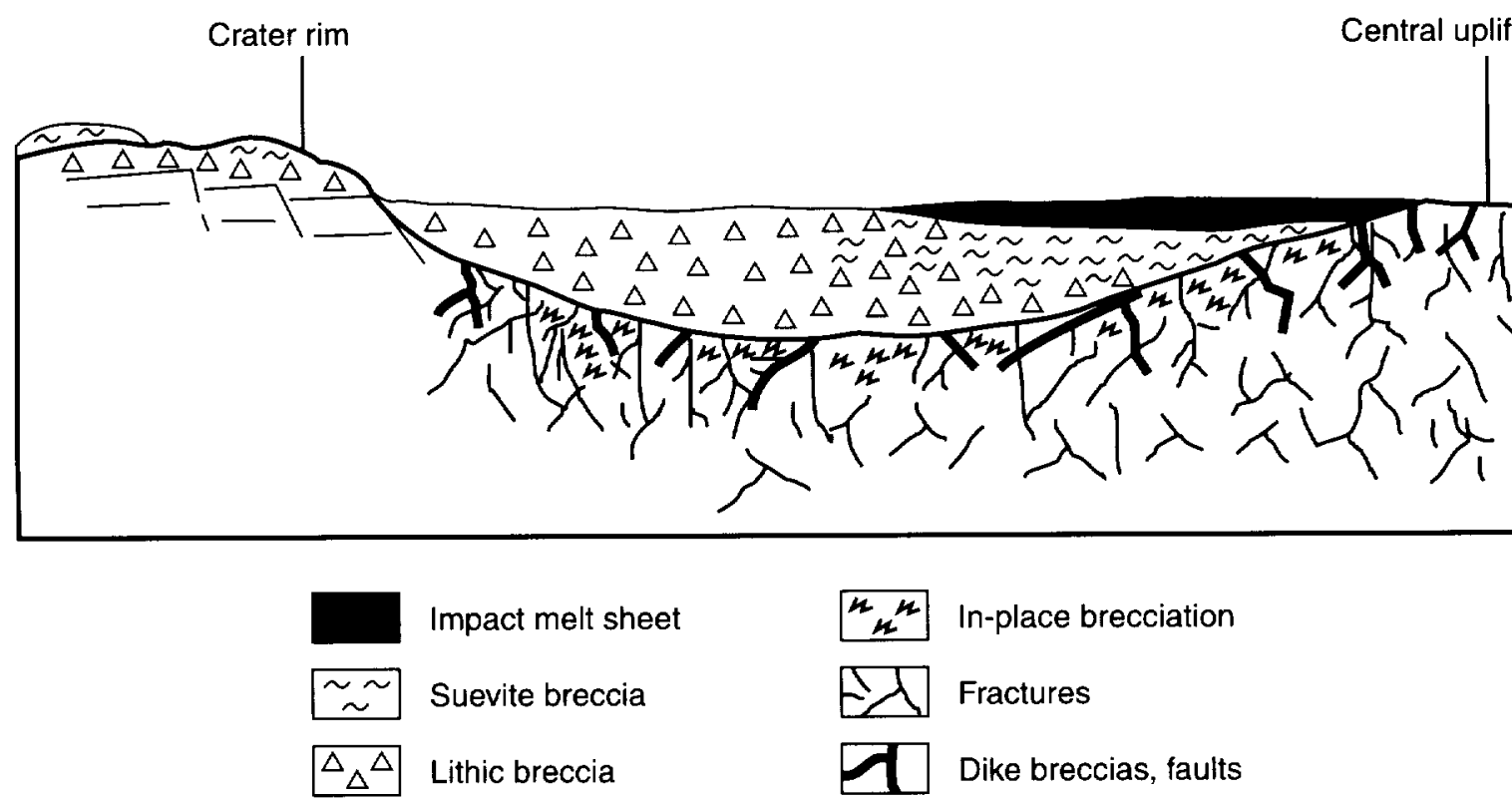

$\mu^{n}$ In-place brecciation

Fractures

Dike breccias, faults

Fig. 3.13. Complex impact structure: locations of impactite types. Schematic radial cross section across a complex impact structure of the central-uplift type, from the central uplift (right) to the outer, downfaulted rim (left). (Vertical scale is exaggerated.) The subcrater parautochthonous rocks, exposed in the central uplift, are highly fractured and brecciated and may contain distinctive shock features such as shatter cones. These rocks may also contain widespread pseudotachylite breccias and dike-like intrusive bodies of allogenic breccias and impact melts. Larger and thicker subhorizontal units of allogenic breccias and melts occur as an annular unit of crater-fill material that covers the parautochthonous rocks between the central uplift and the rim. The bulk of these crater-fill deposits consist of melt-free lithic breccias, with lesser amounts of melt-bearing suevite breccias. The melt component in the crater-fill deposits becomes more abundant toward the center and upward, and a discrete layer of impact melt (solid black) may occur at or toward the top of the crater fill. (Modified from Stöfler et al., 1988, Fig. 12, p. 290.)

Because impact is a near-surface process, the deformation associated with impact structures dies away rapidly with depth. Typical impact structures are relatively shallow, and impact-produced rocks form comparatively thin units. The distinctive rock types and shock effects in a structure tens of kilometers in diameter may extend only a few kilometers below the original ground surface. Impact structures are therefore especially vulnerable to erosion. Initial erosion will preferentially remove the near-surface ejecta deposits and the distinctively shocked and melted materials they contain, thus rapidly destroying the most convincing evidence for impact. Deeper erosion over longer periods of time will eventually produce major destructive changes in the crater. The breccias and melt units that fill the crater, and the distinctive shocked materials they contain, together with any protecting cap of sediments, will be reduced to small remnants or completely removed. The original circular outline will disappear. Eventually, all trace of the crater will be removed except for the weakly shocked subcrater rocks. If erosion continues long enough, the whole impact structure will be erased.

Impact structures that are not destroyed by erosion may be entirely filled and buried by younger sediments, so that their detection depends on geophysical methods and drilling rather than on surface field geology. About one-third of the presently known impact structures are subsurface (Grieve, 1991, 1997; Grieve and Masaitis, 1994; Grieve et al., 1995); they were first discovered during geophysical explorations, and their impact origin has been verified by the discovery of shocked rocks in drill core samples. This group includes several continental structures that are actual or potential petroleum producers [Ames (Oklahoma); Avak (Alaska); Marquez (Texas); Red Wing Creek (North Dakota)] (Donofrio, 1997), as well as a few submarine impact structures [e.g., Montagnais (Canada) (Jansa and Pe-Piper; 1987)]. Several large and relatively young buried impact structures have also been identified by geophysical techniques: the 90-km-diameter Chesapeake Bay Crater (USA) (Poag, 1996, 1997); the larger (>180-km diameter) Chicxulub structure (Mexico), which is associated with the $\mathrm{K} / \mathrm{T}$ event (Hildebrand et al, 1991; Sbarpton et al., 1992; papers in Ryder et al., 1996); and the large ( $\geq 70 \mathrm{~km}$ ?) Morokweng structure (South Africa) (Corner et al., 1997; Koeberl et al., 1997a). Many more impact structures remain to be found, and the evidence for their existence may already be sitting unrecognized in existing drill cores and geophysical records around the world.

Impact structures may also be caught up in subsequent tectonic deformation, with varying results. Horizontal compression may deform the original circular shape, making study and interpretation more difficult [as at Sudbury (Canada)]. 
Tectonism can also break up regions of original shocked rocks and disperse them as large discrete areas across the geological landscape [e.g., the Beaverhead (Idaho) structure (Hargraves et al., 1990; Fiske et al., 1994)]. Sufficient tectonism and metamorphism could destroy even large impact structures or make them totally unrecognizable.

Geologists must therefore be prepared to recognize impact structures in all states of preservation, from young, fresh, well-exposed circular structures filled with distinctive shocked breccias to slder features in which distinctive shock effects are scattere 1 , barely recognizable, or deeply buried. It is essential to be able to recognize the variety of distinctive shock effects asso:iated with impact structures and to understand where diffe ent types of shock effects may be located in the original cra er. 


\section{4}

\section{Shock-Metamorphic Effects in Rocks and Minerals}

\subsection{FORMATION CONDITIONS AND GENERAL CHARACTERISTICS}

The growing recognition since the 1960 s of the geological importance of meteorite impact events, and the large number of impact structures still preserved on Earth, is largely the result of two related discoveries: (1) The extreme physical conditions that are imposed by intense shock waves on the rocks through which they pass produce unique, recognizable, and durable shock-metamorphic effects; (2) such shock waves are produced naturally only by the hypervelocity impacts of extraterrestrial objects (French, 1968a, 1990b; French and Short, 1968). Shock-metamorphic effects (also called "shock effects" or "shock features") have been critical to the identification of terrestrial impact structures because of their uniqueness, wide distribution, ease of identification, and especially their ability to survive over long periods of geologic time.

With the acceptance of shock effects as a criterion for impact, the record of terrestrial impact events is no longer limited to small young structures that still preserve definite meteorite fragments. Equally convincing evidence for impact can now be provided by a wide variety of distinctive deformation effects in the rocks themselves, and it has become possible to identify numerous old impact structures from which weathering and erosion have removed all physical traces of the projectiles that formed them. The recognition of preserved shock effects has been the main factor behind the steady increase in the number of recognized impact structures since the 1960s (Grieve, 1991; Grieve et al., 1995; Grieve and Pesonen, 1992, 1996; for historical reviews, see Hoyt, 1987; Mark, 1987).

The approximate physical conditions that produce shockdeformation effects in natural rocks have been established by a combination of theoretical studies, artificial explosions (both chemical and nuclear), and experiments with laboratory shock-wave devices (for details, see papers in French and Short, 1968 and Roddy et al., 1977; also Stöffler, 1972; Kieffer and Simonds, 1980; Melosh, 1989; Stöfler and Langenhorst, 1994). Peak shock pressures produced in an impact event range from $\leq 2 \mathrm{GPa}(\leq 20 \mathrm{kbar})$ near the final crater rim to $>100 \mathrm{GPa}(\geq 1000 \mathrm{kbar})$ near the impact point. These pressures, and the resulting shock-deformation effects, reflect conditions that are far outside the range of normal geological processes (Fig. 4.1, Table 4.1). In ordinary geological environments, pressures equivalent to those of typical shock waves are attained only under static conditions at depths of $75-1000 \mathrm{~km}$ within Earth, well below the shallow-crustal regions in which impact structures are formed.

Shock-wave pressures differ in other important ways from pressures produced by more normal geological processes. The application of shock-wave pressures is both sudden and brief. A shock wave traveling at several kilometers per second will traverse the volume of a mineral grain or a rock sample in microseconds, and both the onset and release of pressure are highly transient. Shock-deformation effects therefore reflect transient stress conditions, high strain rates, and rapid quenching that are inconsistent with the rates of normal geological processes (Table 4.1). In addition, shock waves deposit energy in the materials through which they pass. A particular shock pressure will produce a specific postshock temperature, which depends chiefly on the nature of the target material. These postshock temperatures increase with increasing shock pressure (see the P-T curve labeled "Shock metamorphism" in Fig. 4.1). For large shock pressures, the resulting temperatures are high enough to produce melting and even vaporization within the target.

The unique conditions of shock-wave environments produce unique effects in the affected rocks. The nature and intensity of the changes depend on the shock pressures 


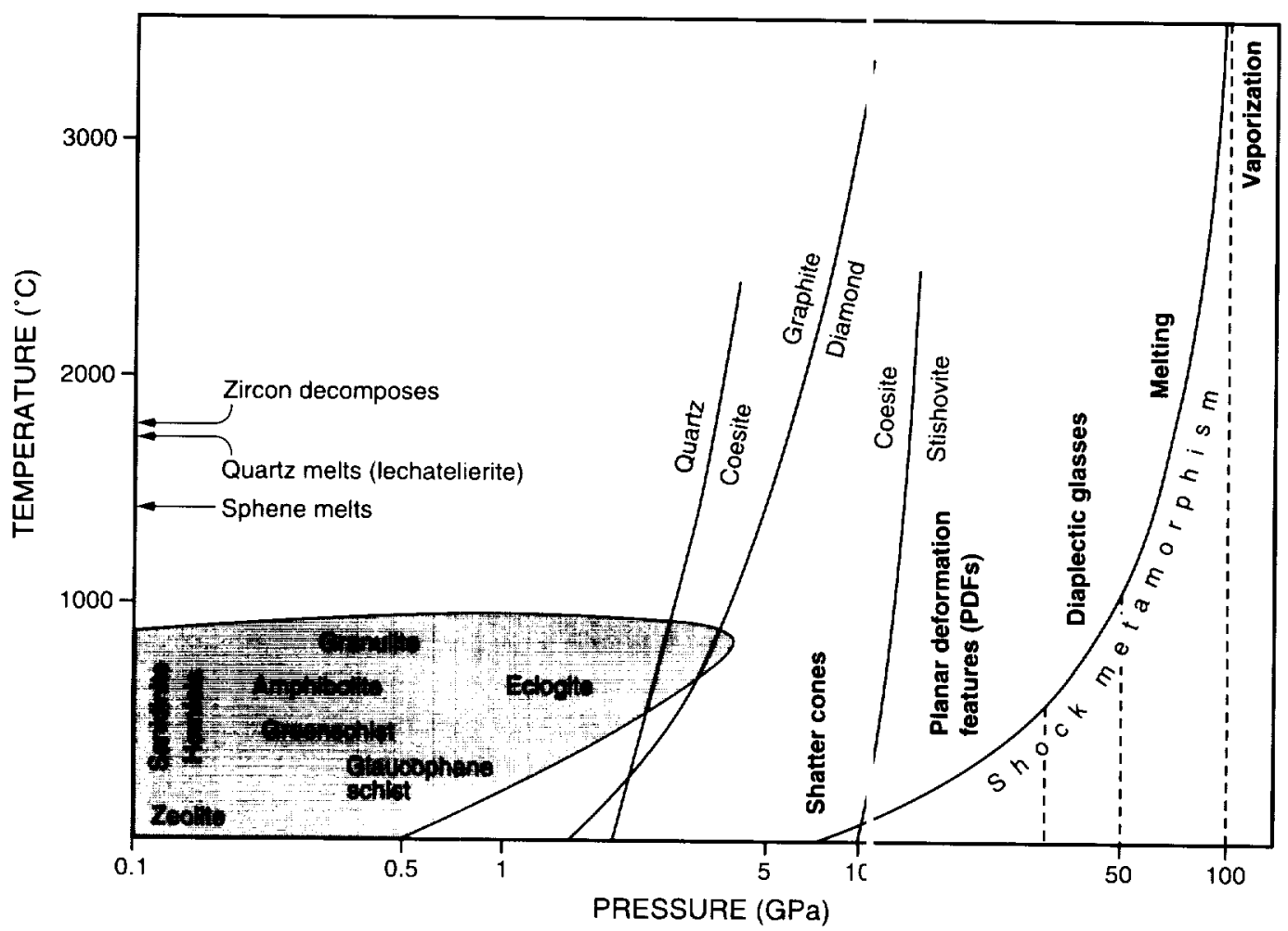

Fig. 4.1. Conditions of shock-metamorphism. Pressure-temperature plot showin g comparative conditions for shock metamorphism and normal crustal metamorphism. [Note that the pressure axis (X-axis, in $\mathrm{GPa})$ is 1 sgarithmic.] Shaded region at lower left $(\mathrm{P}<5 \mathrm{GPa}$, $\mathrm{T}<1000^{\circ} \mathrm{C}$ ) encloses the conventional facies (labeled) for crustal metamorphism. Shock-metamorphic conditions (at right) extend from $\sim 7$ to $>100$ GPa and are clearly distinct from normal metamorphic conditions. A sproximate formation conditions for specific shock effects (labeled) are indicated by vertical dashed lines, and the exponential curve ("Shock metamorphism") indicates the approximate postshock temperatures produced by specific shock pressures in granitic crystallin : rocks. Relatively high shock pressures ( $>50 \mathrm{GPa}$ ) produce extreme temperatures, accompanied by unique mineral decomposition reac ions (at left, near temperature axis). Stability curves for high-pressure minerals (coesite, diamond, stishovite) are shown for static equ librium conditions; formation ranges under shock conditions may vary widely. (Adapted from Stoffler, 1971, Fig. 1; Grieve, 1990, p. 7.; Grieve and Pesonen, 1992, Fig. 9.)

TABLE 4.1. Shock metamorphism: Distinction frorı other geological processes.

\begin{tabular}{|c|c|c|}
\hline Characteristic & $\begin{array}{c}\text { Regional and Contact Metamorphism; } \\
\text { Igneous Petrogenesis }\end{array}$ & Shock Metamorphism \\
\hline Geological setting & $\begin{array}{l}\text { Widespread horizontal and vertical regions } \\
\text { of Earth's crust, typically to depths of } 10-50 \mathrm{~km}\end{array}$ & Sur face or near-surface regions of Earth's crust \\
\hline Pressures & Typically $<1-3 \mathrm{GPa}$ & $\begin{array}{l}10 \mathrm{C}-400 \mathrm{GPa} \text { near impact point; } 10-60 \mathrm{GPa} \text { in large } \\
\text { volı mes of surrounding rock }\end{array}$ \\
\hline Temperatures & Generally $\leq 1000^{\circ} \mathrm{C}$ & $\begin{array}{l}\text { Up to } 10,000^{\circ} \mathrm{C} \text { near impact point (vaporization); } \\
\text { typ cally from } 500^{\circ} \text { to } 3000^{\circ} \mathrm{C} \text { in much of } \\
\text { surr sunding rock }\end{array}$ \\
\hline Strain rates & $10^{-3 / \mathrm{s}}$ to $10^{-6 / \mathrm{s}}$ & $10^{4}$ 's to $10^{6 / s}$ \\
\hline $\begin{array}{l}\text { Time for completion } \\
\text { of process }\end{array}$ & From $10^{5}-10^{7} \mathrm{yr}$ & $\begin{array}{l}\text { "Instantaneous": Shock-wave passage through } 10-\mathrm{cm} \\
\text { dist ince, }<10^{-5} \mathrm{~s} \text {; formation of large }(100-\mathrm{km}- \\
\text { diarneter }) \text { structure }<1 \mathrm{hr}\end{array}$ \\
\hline Reaction times & Slow; minerals closely approach equilibrium & $\begin{array}{l}\text { Rapid; abundant quenching and preservation of } \\
\text { metastable minerals and glasses }\end{array}$ \\
\hline
\end{tabular}


TABLE 4.2. Shock pressures and effects.

\begin{tabular}{|c|c|c|}
\hline $\begin{array}{l}\text { Approximate } \\
\text { Shock Pressure } \\
\qquad(\mathrm{GPa})\end{array}$ & $\begin{array}{c}\text { Estimated } \\
\text { Postshock } \\
\text { Temperature }\left({ }^{\circ} \mathrm{C}\right)^{*}\end{array}$ & Effects \\
\hline \multirow[t]{2}{*}{$2-6$} & \multirow[t]{2}{*}{$<100$} & Rock fracturing; breccia formation \\
\hline & & Shatter cones \\
\hline $5-7$ & 100 & $\begin{array}{l}\text { Mineral fracturing: }(0001) \text { and }\{10 \overline{1} 1\} \\
\text { in quartz }\end{array}$ \\
\hline $8-10$ & 100 & Basal Brazil twins (0001) \\
\hline \multirow[t]{2}{*}{10} & \multirow[t]{2}{*}{$100^{*}$} & \\
\hline & & Quartz with PDFs $\{10 \overline{1} 3\}$ \\
\hline $12-15$ & 150 & Quartz $\rightarrow$ stishovite \\
\hline 13 & 150 & Graphite $\rightarrow$ cubic diamond \\
\hline \multirow[t]{2}{*}{20} & \multirow[t]{2}{*}{$170^{*}$} & \\
\hline & & $\begin{array}{l}\text { Quartz with PDFs }\{10 \overline{1} 2\} \text {, etc. } \\
\text { Quartz, feldspar with reduced refractive } \\
\text { indexes, lowered birefringence }\end{array}$ \\
\hline$>30$ & 275 & Quartz $\rightarrow$ coesite \\
\hline \multirow[t]{2}{*}{35} & \multirow[t]{2}{*}{300} & \\
\hline & & Diaplectic quartz, feldspar glasses \\
\hline 45 & 900 & Normal (melted) feldspar glass (vesiculated) \\
\hline 60 & $>1500$ & $\begin{array}{l}\text { Rock glasses, crystallized melt rocks (quenched } \\
\text { from liquids) }\end{array}$ \\
\hline $80-100$ & $>2500$ & Rock glasses (condensed from vapor) \\
\hline
\end{tabular}

* For dense nonporous rocks. For porous rocks (e.g., sandstones), postshock temperatures $=700^{\circ} \mathrm{C}$ $(\mathrm{P}=10 \mathrm{GPa})$ and $1560^{\circ} \mathrm{C}(\mathrm{P}=20 \mathrm{GPa})$. Data from Stoffler (1984), Table 3; Melosh (1989), Table 3.2; Stöffler and Langenhorst (1994), Table 8, p. 175.

(Table 4.2). Lower shock pressures ( 2-10 GPa) produce distinctive megascopic shatter cones in the target rocks (Milton, 1977; Roddy and Davis, 1977). Higher pressures (>10-45 GPa) produce distinctive high-pressure mineral polymorphs as well as unusual microscopic deformation features in such minerals as quartz and feldspar (Stöfler, 1972). Even higher pressures ( $\geq 50 \mathrm{GPa}$ ) produce partial to complete melting and even vaporization ( $\geq 100 \mathrm{GPa}$ ) of large volumes of the target rocks.

An especially distinctive and convincing form of evidence for meteorite impact is the suite of unique microscopic deformation features produced within individual minerals by higher-pressure ( 10-45 GPa) shock waves. During the impact event, such pressures develop in target rocks near the center of the crater, and most of these rocks are immediately broken up and incorporated into the excavation flow that is being initiated by the expanding release wave (Figs. 3.4 and 3.5). As a result, these shock effects are found chiefly in individual target rock fragments in the breccias that fill the crater or in the ejecta deposited beyond the rim.

A wide variety of shock-produced microscopic deformation features has been identified in the minerals of shock- metamorphosed rocks (for reviews, see Chao, 1967; papers in French and Short, 1968; Stöffler, 1972, 1974; Stöffler and Langenhorst, 1994; Grieve et al., 1996). These include (1) kink bands in micas and (more rarely) in olivine and pyroxene; (2) several types of distinctive planar microstructures and related deformation effects in quartz, feldspar, and other minerals; (3) isotropic mineral glasses (diaplectic or thetomorphic glasses) produced selectively, most commonly from quartz and feldspar, without actual melting; (4) selective melting of individual minerals. Kink bands, although common in impact environments (Fig. 4.2), can also be produced by normal tectonic deformation; they are not a unique criterion for shock metamorphism, and they will not be discussed further. The other effects, particularly the distinctive planar microstructures in quartz and the diaplectic glasses, are now generally accepted as unique criteria for shock waves and meteorite impact events.

These shock-produced microscopic deformation features have several distinctive general characteristics. They are pervasive, and usually occur throughout a centimeter-sized rock sample, although they may be more erratically developed over larger distances (meters or tens of meters). They 


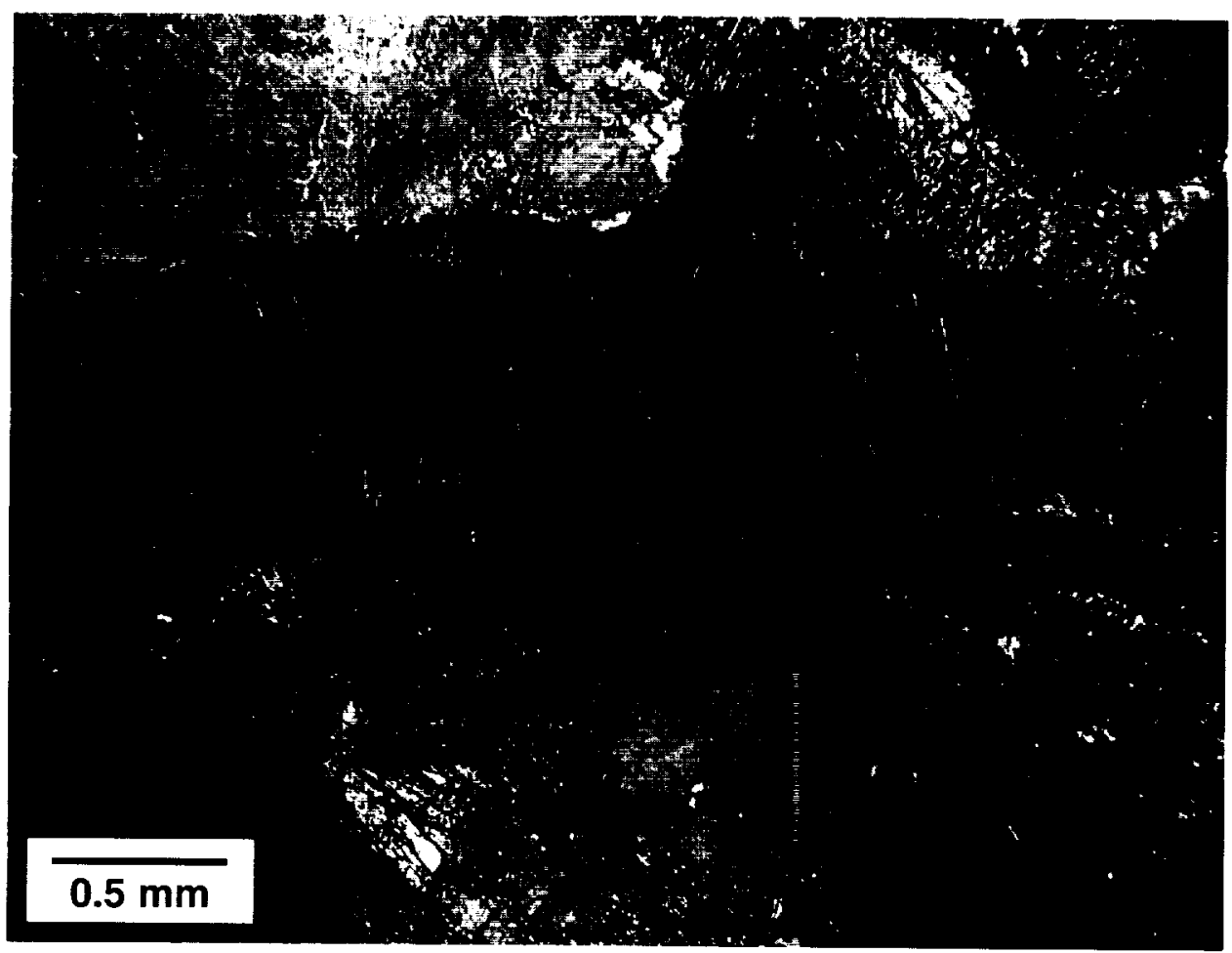

Fig. 4.2. Kink-banding; in biotite. Large biotite grain in basement granitic gne sses, northeast side of Sudbury structure (Canada), showing two sets of kink-banding at high angles to original cleavage (horizontal). Associated quartz (upper and lower left) and feldspar show no shock-deformation effects. Sample CSF-68-67 (cross-polarized light).

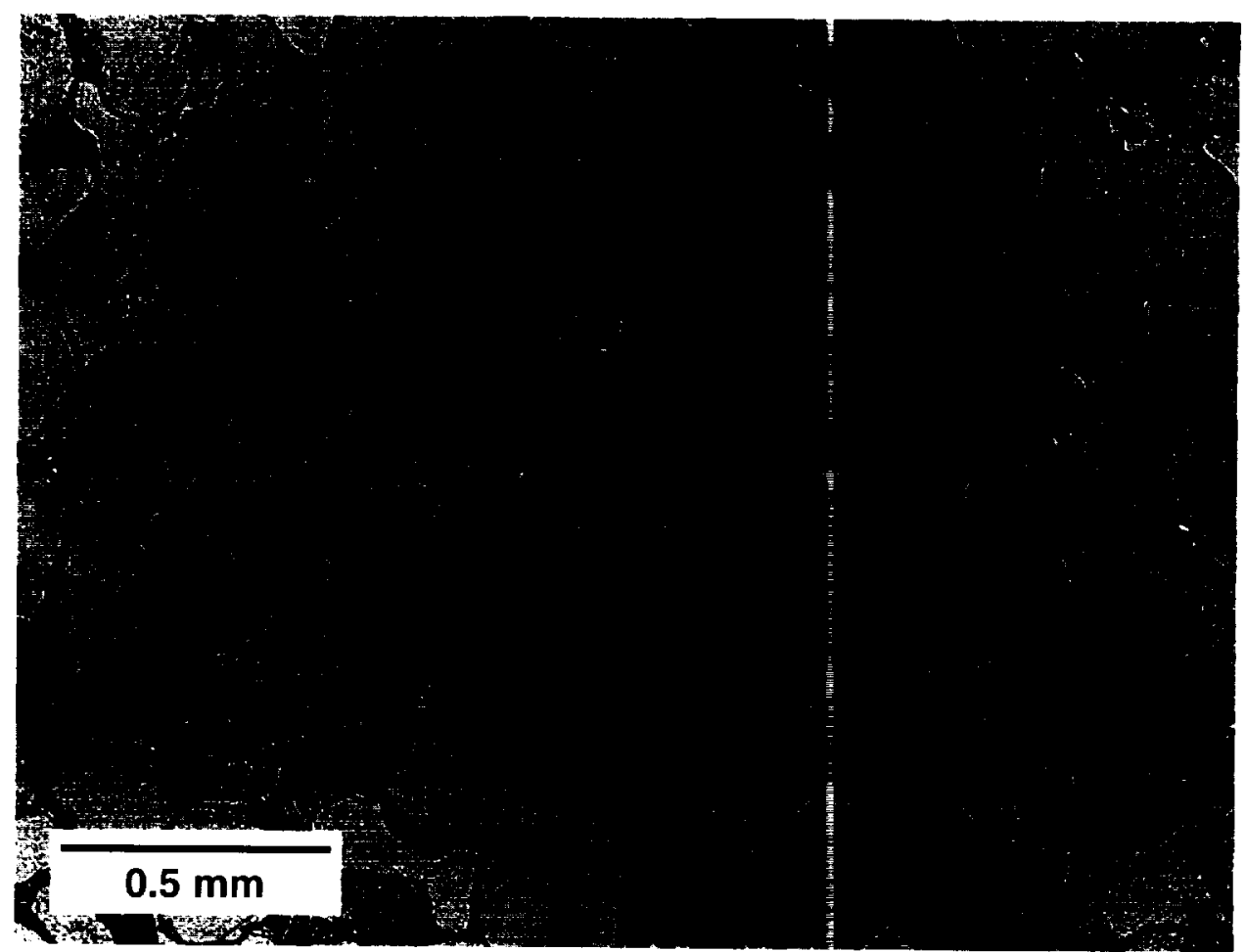

Fig. 4.3. Progressive shock metamorphism in sandstone (I). Unshocked Coco1 ino Sandstone from the Barringer Meteor Crater (Arizonil) is composed of well-sorted quartz grains with minor carbonate cement and pore space. The quartz grains are rounded to angular, clear, and undeformed; some grains display secondary overgrowths. (Black lots are bubbles in thin section mounting medium.) Fjecta sample trom rim of crater. Sample MCF-64-4 (plane-polarized light). 


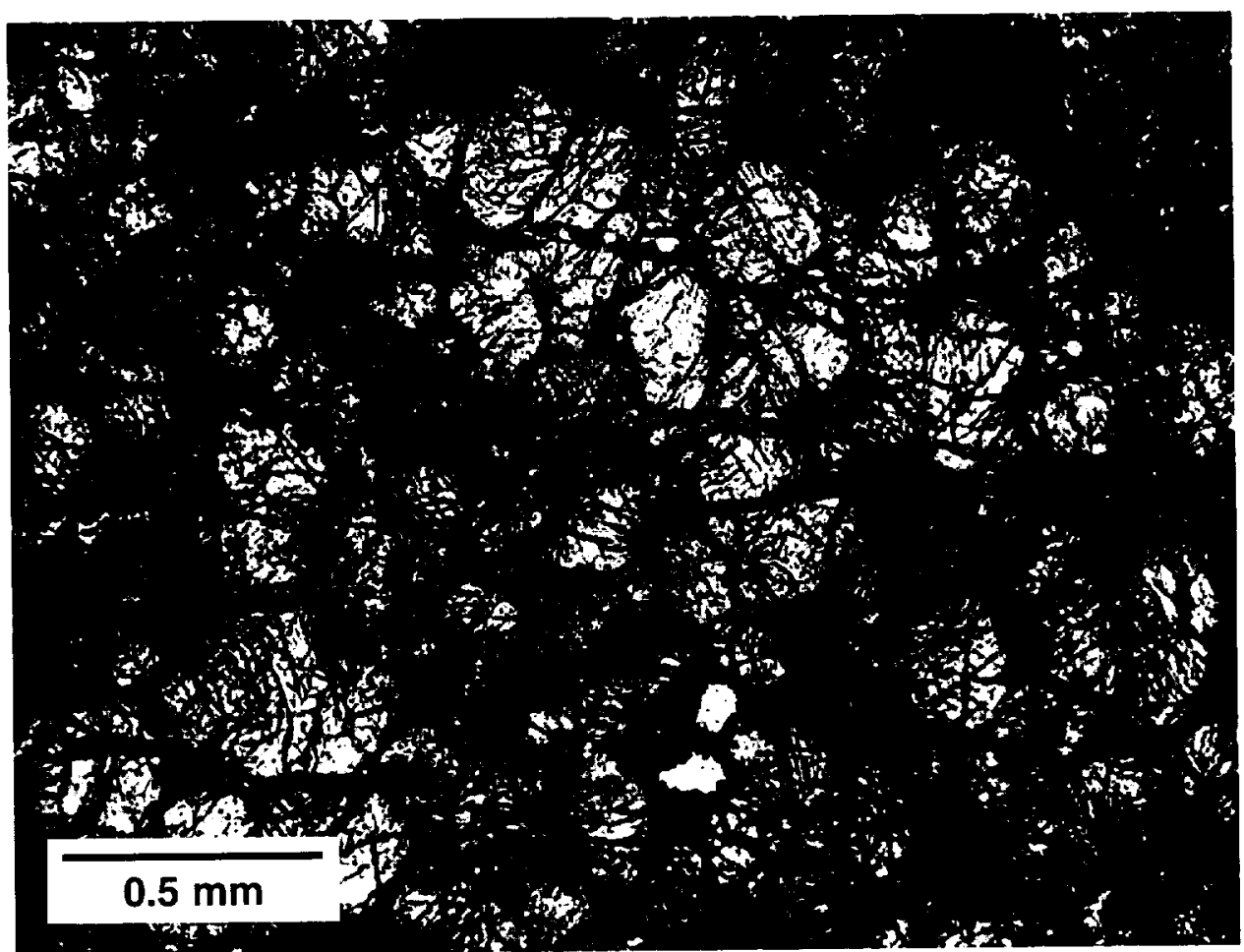

Fig. 4.4. Progressive shock metamorphism in sandstone (II). Moderately shocked Coconino Sandstone from the Barringer Meteor Crater (Arizona). The quartz grains are highly fractured and show numerous sets of subparallel fractures along cleavage planes. The original interstitial pore space has been collapsed and heated during passing of the shock wave, producing a filling of dark glass that frequently contains coesite. Ejecta sample from ground surface outside crater. Sample MCF-65-15-4 (planc-polarized light).

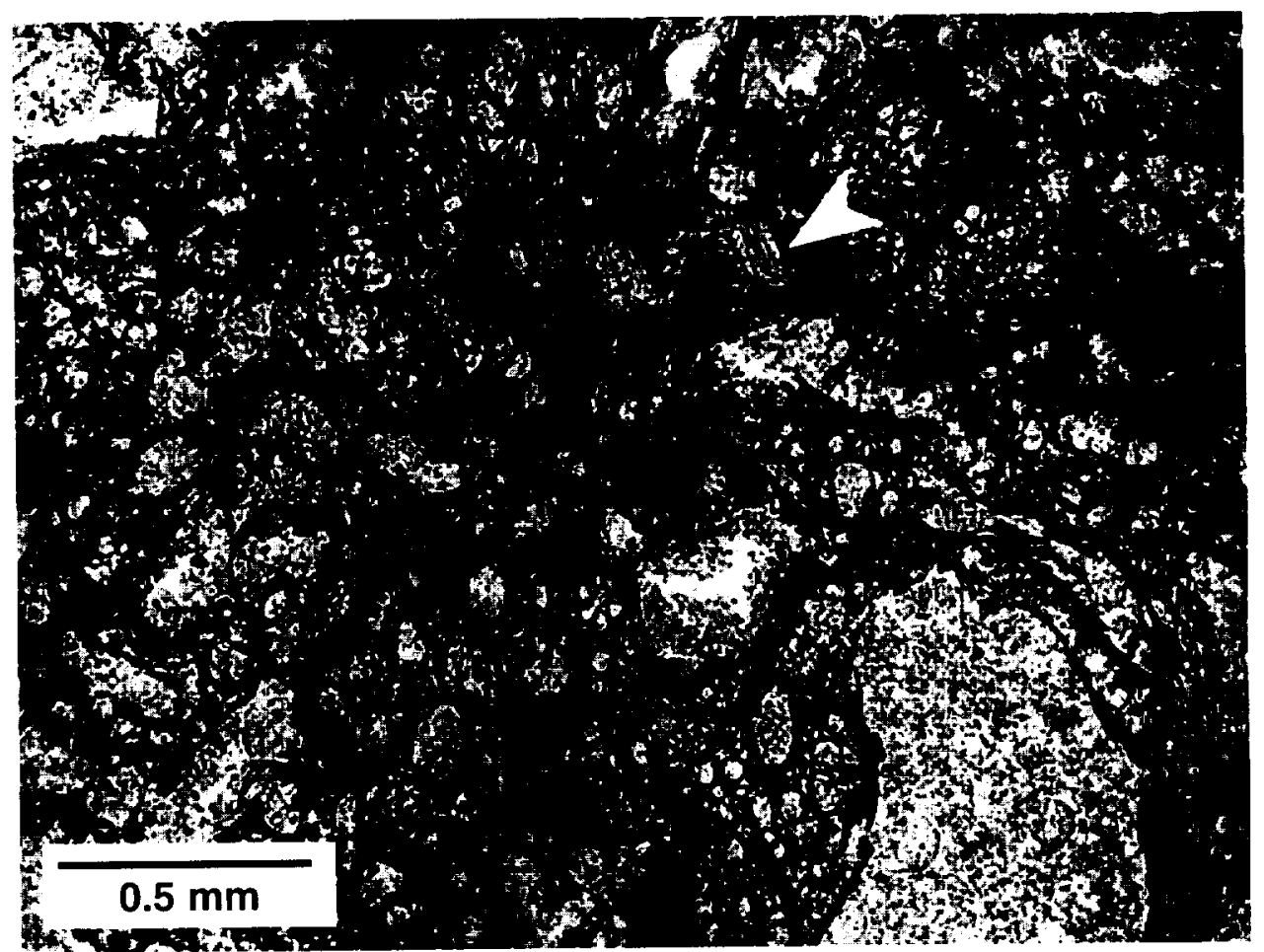

Fig. 4.5. Progressive shock metamorphism in sandstone (III). Highly shocked, melted, and vesiculated Coconino Sandstone from the Barringer Meteor Crater (Arizona). The original sandstone has been converted to a light, frothy, highly vesicular pumice-like material composed dominantly of nearly pure silica glass (lechatelierite). The vesicular glass contains a few remnant quartz grains (e.g., upper center, arrow) that are highly fractured and show development of distinctive PDFs in addition to the open cleavage cracks. Fjecta sample from ground surface outside crater. Sample MCF-65-11-2 (plane-polarized light). 
are mineralogically selective; a given effect (e.g., isotropization) will occur in grains of a single mineral (e.g., quartz or feldspar), but not in grains of other minerals, even adjacent ones. Shock metamorphism is also characterized by a progressive destruction of original textures with increasing shock pressure, a process that eventually leads to complete melting or vaporization of the target rock (Figs. 4.3, 4.4, and 4.5).

\subsection{STAGES OF SHOCK METAMORPHISM}

The fact that different shock pressures produce a variety of distinctive shock features (Table 4.2) has made it possible to recognize different levels or stages of shock metamorphism (Chao, 1967; Stöfler, 1966, 1971, 1984; von Engelhardt and Stöfler, 1968; Stöfler and Langenhorst, 1994). These stages are not equivalent to the different facies recognized in normal metamorphism, because shock metamorphism is a rapid and nonequilibrium process and many of the most distinctive features produced by shock waves (e.g., high-pressure minerals and diaplectic glasses) are metastable under normal geological conditions. Nevertheless, key shock features occur frequently and consistently in natural impact structures, and the production of the same features in experimental studies has made approximate pressure and temperature calibrations possible. As a result, the stages of shock metamorphism have become an important concept for field studies of impact structures and for using certain features as approximate shock-wave barometers.

Current classifications of shock-metamorphic stages are based almost entirely on features developed in nonporous, quartz-bearing, crystalline igneous and metamorphic rocks. These lithologies are abundant in many of the impact structures studied so far, and they develop a varied suite of shock features over a wide range of shock pressures. Individual classifications of shock-metamorphic stages in these rocks differ in details, but the following summary of distinctive shock features and their approximate shock pressures (based largely on Stöfler, 1966, 1971, 1984; Stöfler and Langenborst, 1994) provides a useful classification based on field and petrographic characteristics. [Other effects observed with increasing shock pressure include decreases in refractive index and increasing structural disorder (shock mosaicism) in mineral grains; for details, see Stöfler, 1972, 1974; Stöfler and Langenhorst, 1994).] It should be remembered that estimated pressures are only approximate, and that the formation of a given shock effect will also reflect such individual factors as rock type, grain size, and other structural features. The shock effects observed, and the inferred stages of shock metamorphism, will be different for other rock types, especially for carbonates, basaltic rocks, and porous rocks of any type.

For nonporous crystalline rocks, the following stages have been distinguished (see Table 4.2):

\section{$<2 \mathrm{GPa}$}

Fracturing and brecciation, without development of unique shock features (see Chapter 5).

\section{$>2 \mathrm{GPa}$ to <30? $\mathrm{GPa}$}

Shatter zones. At lower pressures ( 2 to $<10 \mathrm{GPa}$ ), occurring without distinctive microscopic deformation features. At higher $\mathrm{f}$ ressures $(10$ to $\leq 30 \mathrm{GPa}$ ), shatter cones may also contain dis inctive microdeformation features.

\section{$\sim 8 \mathrm{GPa}$ to $25 \mathrm{GPa}$}

Microsc spic planar deformation features in individual minerals, es pecially quartz and feldspar. It has been possible to subdivide this zone on the basis of different fabrics of deformatio a features in quartz (Robertson et al., 1968; Stöfler and Langen borst, 1994).

\section{$>25 \mathrm{GPa}$ t , $40 \mathrm{GPa}$}

Transformation of individual minerals to amorphous phases (dia slectic glasses) without melting. These glasses are often arcompanied by the formation of high-pressure mineral pol /morphs.

\section{$>35 \mathrm{GPa}$ tı $60 \mathrm{GPa}$}

Selective partial melting of individual minerals, typically feldspars. Ir creasing destruction of original textures.

\section{$>60 \mathrm{GPa}$ tı $100 \mathrm{GPa}$}

Comple1e melting of all minerals to form a superheated rock melt (s se Chapter 6 ).

\section{$>100 \mathrm{GPa}$}

Comple e rock vaporization. No preserved materials formed at t is stage (e.g., by vaporization and subsequent condensation to glassy materials) have been definitely identified so far.

\subsection{MEGASCOPIC SHOCK-DEFORMATION FEATURES: SHATTER CONES}

Shatter $\mathrm{c}$ snes are the only distinctive and unique shockdeformatior feature that develops on a megascopic (hand specimen to outcrop) scale. Most accepted shock-metamorphic features are microscopic deformations produced at relatively high st ock pressures ( $>10 \mathrm{GPa}$ ). Lower shock pressures (1-5 GPa) Froduce a variety of unusual fractured and brecciated rocks, but such rocks are so similar to rocks formed by normal tecto aic or volcanic processes that their presence cannot be used is definite evidence for an impact event. However, such low'shock pressures also generate distinctive conical fracturing patterns in the target rocks, and the resulting shatter cones hav e proven to be a reliable field criterion for identifying and studying impact structures (Dietz, 1947, 1959, 1963, 1968; Milton et al., 1972, 1996a; Roddy and Davis, 1977; Sharpion et al., 1996a; Dressler and Sharpton, 1997).

Shatter cones are distinctive curved, striated fractures that typically form partial to complete cones (Figs. 4.6 and 4.7). They are gesterally found in place in the rocks below the crater floor, usually in the central uplifts of complex impact structures, but they are also rarely observed in isolated rock 


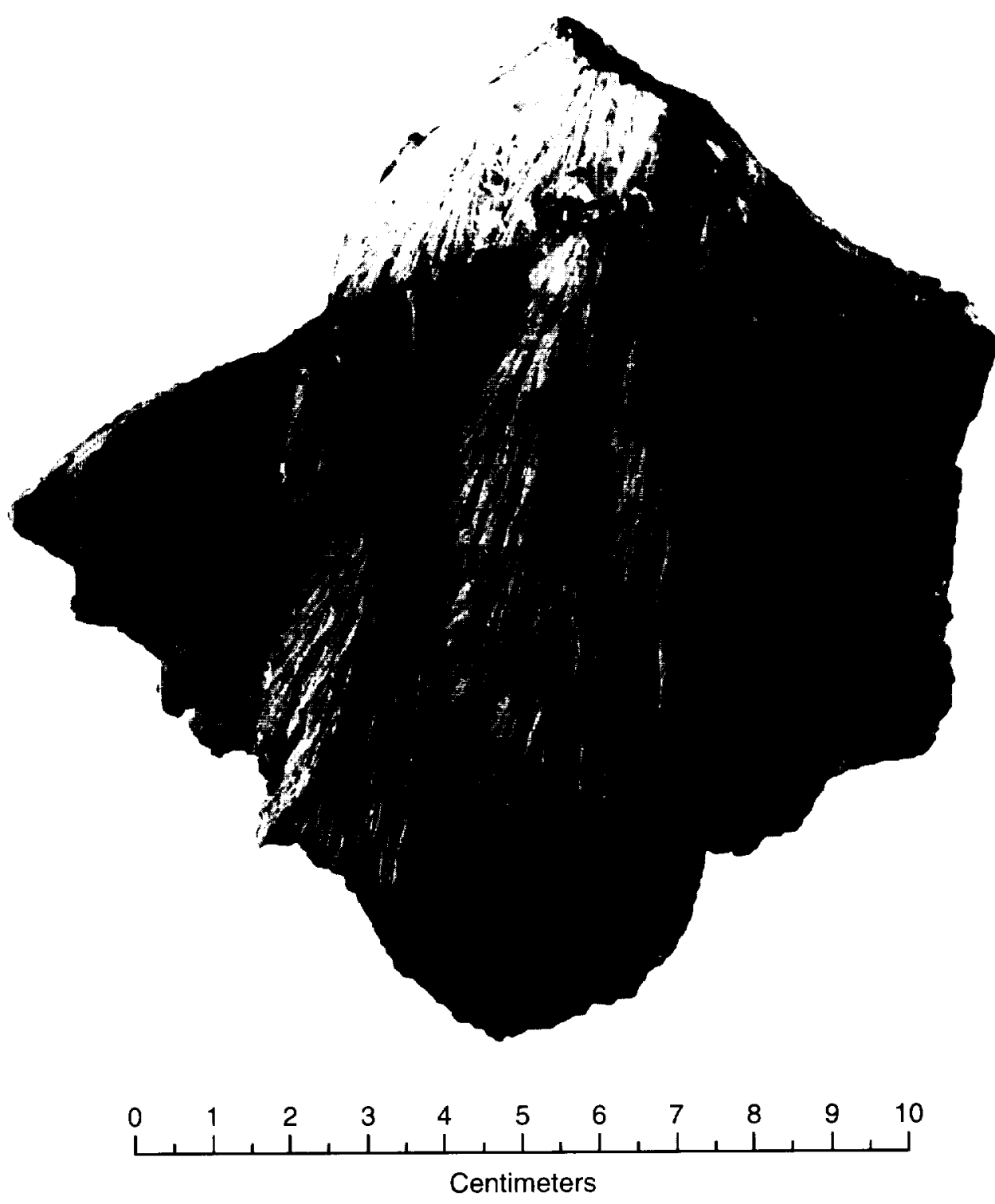

Fig. 4.6. Shatter cones; small, well-developed. Small, finely sculptured shatter cones, developed in fine-grained limestone from the Haughton structure (Canada). The cone surfaces show the typical divergence of striae away from the cone apex ("horsetailing"). Photograph courtesy of R. A. F. Grieve.

fragments in breccia units. Shatter cones occur as individuals or composite groups, and individual cones may range from millimeters to meters in length (Figs. 4.7,4.8, and 4.9) (Dietz, 1968; Sharpton et al., 1996a). Far more common, however, are partial cones or slightly curved surfaces with distinctive radiating striations ("horsetailing") on them (Fig. 4.10).

The details of shatter cone morphology are also distinctive. Smaller secondary ("parasitic") cones commonly occur on the surfaces of both complete and partial shatter cones, forming a unique composite or "nested" texture. The surfaces of shatter cones, and the striations on them, are definite positive/negative features. The striations are also directional; they appear to branch and radiate along the surface of the cone, forming a distinctive pattern in which the acute angle of the intersection points toward the apex of the cone (Figs. 4.6, 4.8, and 4.10).

Shatter cones form in all kinds of target rocks: sandstones, shales, carbonates, and crystalline igneous and metamorphic rocks. The most delicate and well-formed cones form in finegrained rocks, especially carbonates (Fig. 4.6). In coarser rocks, shatter cones are cruder, and their striations are larger, making the cones more difficult to recognize and distinguish from nonshock deformational features such as slickensides (Figs. 4.8 and 4.10).

Shatter cones, especially well-formed examples, are easy to distinguish from similar nonimpact features (see Table 4.3). Some shatter cone occurrences may superficially resemble the "cone-in-cone" structures produced during 
lithification of carbonate-bearing clastic sediments. However, the cones in cone-in-cone features have their axes normal to the bedding of the host rocks and their apexes pointing down. Shatter cones generally point upward, and their axes may lie at any angle to the original bedding, depending on the preimpact orientation of the target rock and its location relative to the impact point. Furthermore, the occurrence of shatter cones in a variety of rock types, especially nonsedimentary ones, is a good indication of an impact origin. The horsetailing striations on shatter cone surfaces sometimes resemble slickensides formed on faults, especially when the surfaces are approximately flat (Figs. 4.8 and 4.10). However, unlike slickensides, shatter cone striations are nonparallel and often show strong radiation and directionality, so that it is easy to determine the direction of the cone apex.

Shatter cones are now generally accepted as unique indicators of shock pressures and meteorite impact. They are especially valuable in this role because they form at relatively low shock pressures (typically 2-10 GPa, but perhaps as high as $30 \mathrm{GPa}$ ) and therefore develop throughout a large volume of target rock below the crater floor. They are typically widely and intensely developed in exposed central uplifts of large structures. Shatter cones form in a wide range of rock types, they are resistant to subsequent metamorphism, and (when well developed) they can be easily and immediately recognized in the field. Frequently, an initial discovery of shatter cones has spurred the search for, and discovery of, a range of equally definite shock effects produced at even higher pressures.

For well-developed shatter cones, it is possible to measure the orientation of the cone axes and to statistically determine the varying orientations of shatter cones throughout an impact structure. Such measurements (e.g., Manton, 1965; Guy-Bray et al., 1966; Milton et al., 1972, 1996a) have provided strong support for the use of shatter cones

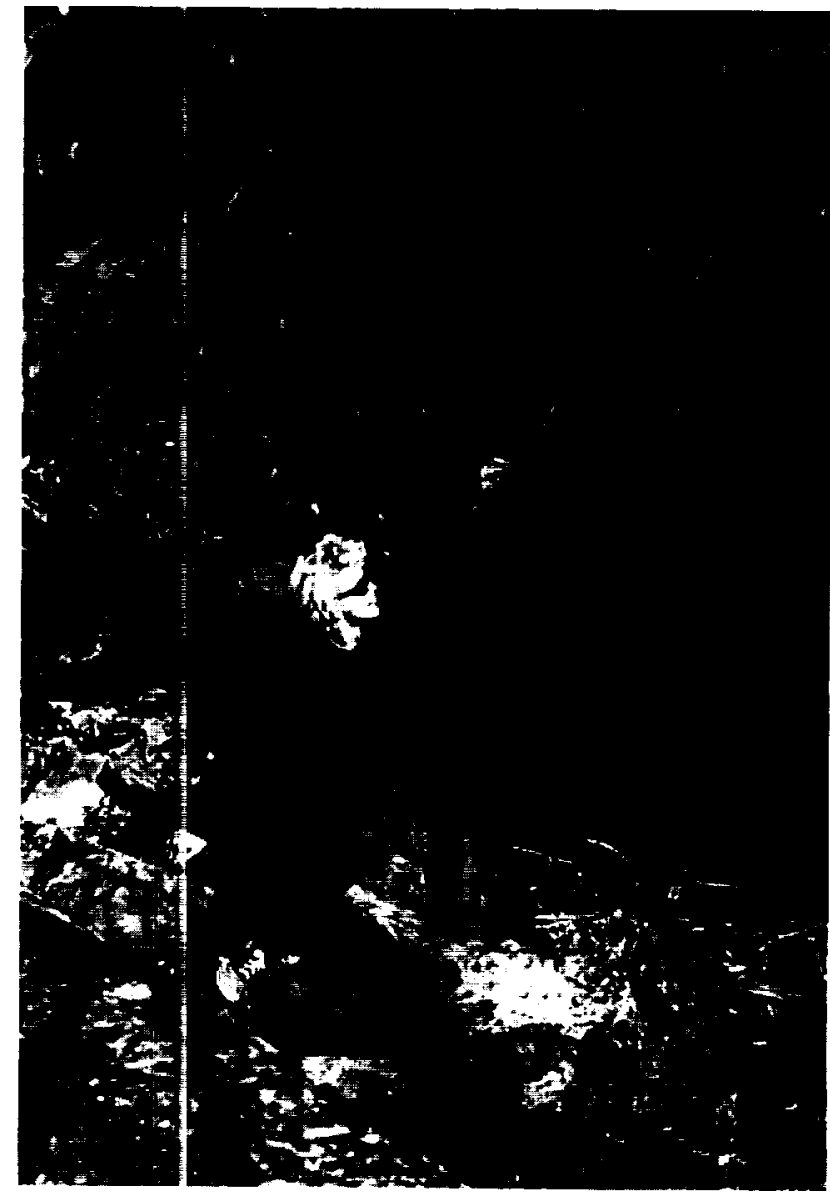

Fig 4.7. St atter cones; large. Large shatter cone and crudely conical striat $d$ surfaces in Mississagi Quartzite from the South Range (Kelley Lake) of the Sudbury structure (Canada). Cone axes point up ward and into the Sudbury Basin (toward viewer) at a high angle. Cone axes are nearly parallel to the original bedding in the quartz te, which dips steeply back and to the right.

Fig. 4.8. Shatter cone; huge, wellstriated. A large shatter cone, 2$3 \mathrm{~m}$ long, in quartzite in the central uplift of the Gosses Bluff structure (Australia). The cone axis plunges gently to the left, nearly normal to the original bedding in the quartzite, which appears as parallel joints dipping steeply to the right. Despite the crudeness of the large cone, the direction of the apex (right), parasitic cones, and distinctive horsetailing are all visible. Scale rule (at top) is $15 \mathrm{~cm}$ long.

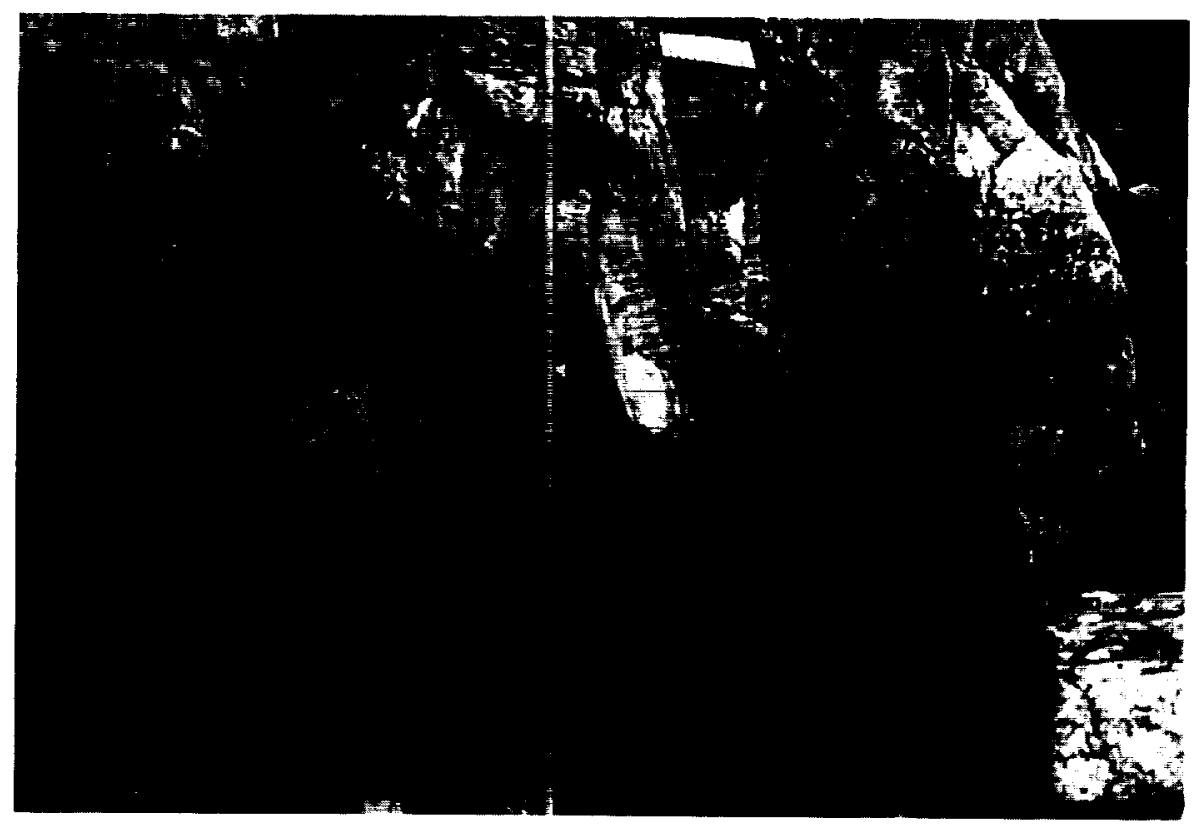




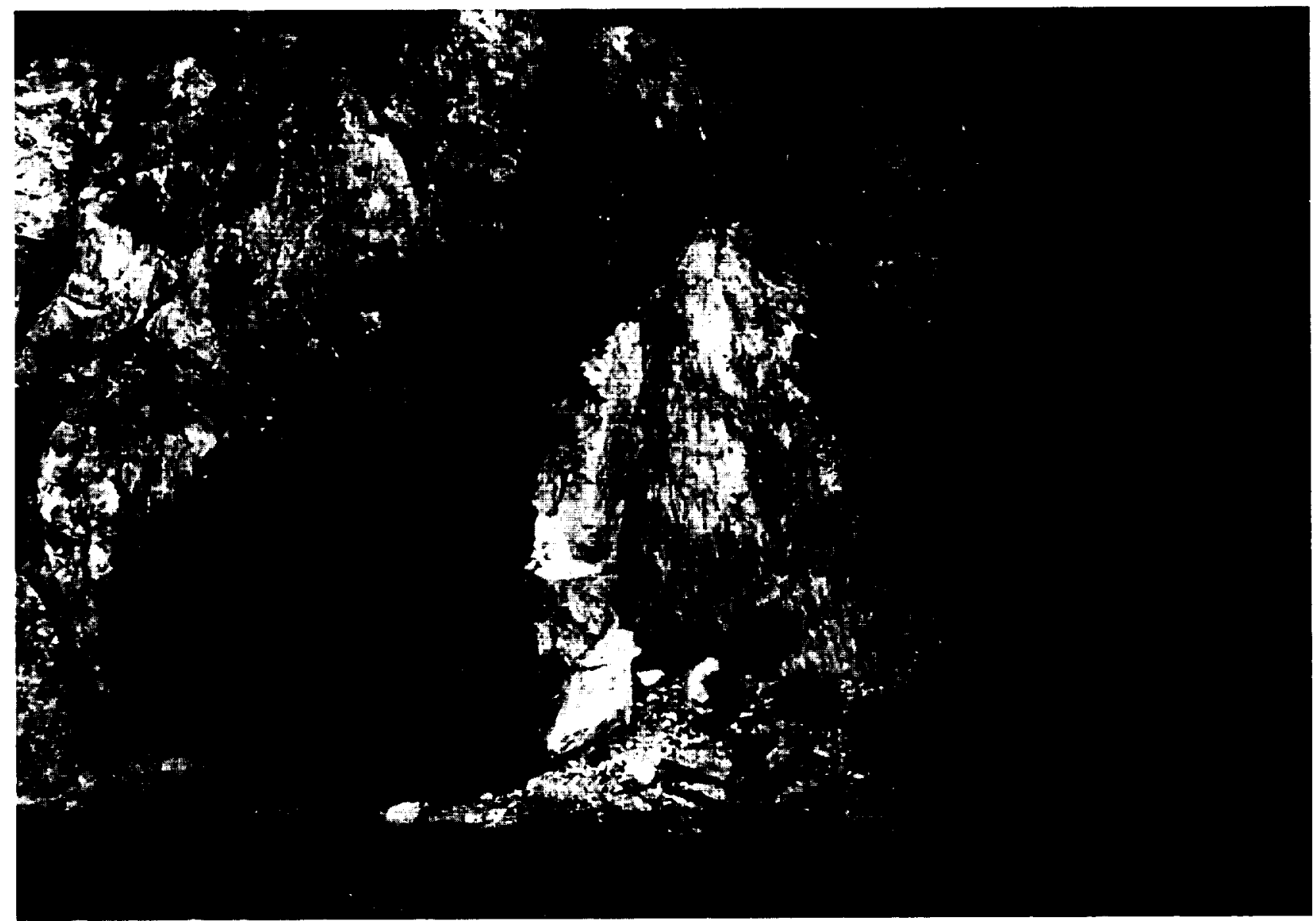

Fig. 4.9. Shatter cone; huge. Unusually large shatter cone (megacone) (light-colored area, center) exposed in a cliff along a wave-cut shoreline on Patterson Island, one of the islands in the Slate Islands impact structure, Lake Superior (Canada). The huge cone, developed in Archean felsic metavolcanic rocks, points nearly straight up and is at least $10 \mathrm{~m}$ in length. At the exposed base, the exposed surface of the cone is at least $7 \mathrm{~m}$ wide. Only $\sim 25^{\circ}$ of the cone's basal perimeter is exposed, indicating that the true width of the feature may exceed $20 \mathrm{~m}$ at its base. Horsetail striations and parasitic cones cover all exposed surfaces. Several other large, conical features are obvious on the near-vertical cliff, but because of the steep scree-covered slopes these features have not yet been examined in detail. Photograph courtesy of V. L. Sharpton.

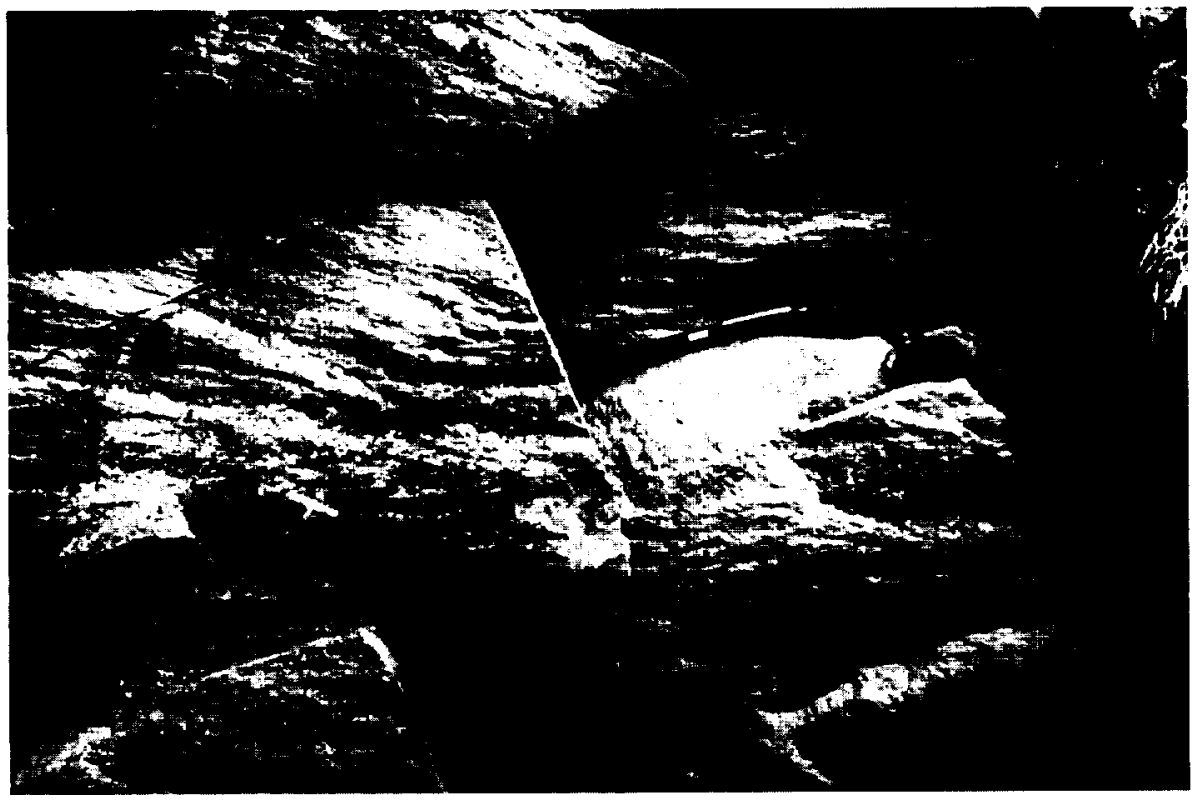

Fig. 4.10. Shatter cones; crude, striated surfaces. Poorly developed shatter cones in Serpent Quartzite, Sudbury (Canada). The cones are only partially developed, appearing as curved and striated surfaces. Divergence of the striae indicates that the cone apexes are to the right. Pen (at center) is $12 \mathrm{~cm}$ long. 
TABLE 4.3. Shatter cones: Distinction from o her geological features.

$\frac{\text { Cone-in-Cone }}{\text { Conical secondary growth features formed during }}$

diagenesis; found in undisturbed sedimentary rocks.

Restricted to carbonate-bearing rocks (limestones, limy shales); associated with secondary carbonate.

Cone axes normal to bedding planes.

Cones oriented point-down.

Striations along cone surface generally continuous, uniform.

Cone surfaces are growth surfaces against other cones or fine matrix in rock.

Rocks typically show no deformation, metamorphism.

\section{Shatter Cones}

Conical fracture features formed by transient shock waves $(P \sim 2$ to

$>10 \mathrm{GPa}$ ) and found i i meteorite impact structures, typically in uplifted central rocks.

Found in all rock type (sedimentary, igneous, metamorphic). Best developed in fine-grai led rocks, especially limestones.

Cone axes oriented at iny angle to bedding, depending on orientation of rock at time of impact and on postimpact movements.

Cones originally form pointing in direction of source of shock wave, i.e., inward and upward. Crientation varies over structure. Orientation further modified by developm ənt of central uplift or later postcrater deformation. When beds restored tc original horizontal position, cones point toward a focus above original surface, indicating external source of shock wave.

Striations along cone s.urface typically show development of divergent radiations ("horsetailir g") along surface. Development of secondary (parasitic) cones on $\mathrm{m}$ in cone is typical.

Cone surfaces are actu.l fracture surfaces; rock splits into new shatterconed surfaces along cone boundaries. Unlike slickensides, striated cone surfaces show no relatire motion, fit together without displacement.

Frequently contain kink-banded micas or quartz (coarser grains) with shock-produced plana: deformation features (PDFs). as a criterion for impact. In several impact structures that formed in originally flat-lying sediments, the apexes of shatter cones in the rocks point inward and upward when the rocks are graphically restored to their original horizontal preimpact position, indicating that the source of the shock wave that produced the shatter cones was located above the original ground surface (Guy-Bray et al., 1966; Dietz, 1968; Manton, 1965; Howard and Offield, 1968; Wilshire et al., 1972; Milton et al., 1972, 1996a). More recently, shatter cones in the Beaverhead (Idaho) structure (Hargraves et al., 1990) have been used to reconstruct the original shape and size of a large, ancient impact structure that was subsequently dissected and redistributed by major faulting during the Laramide Orogeny.

The use of shatter cones to identify impact structures requires caution, especially in cases where no other shock effects can be identified. Poorly developed shatter cones (Figs. 4.8 and 4.10 ) can be easily confused with normal fractures and slickensides, and the latter may be misidentified as shatter cones. Even in well-established impact structures, shatter cones may be entirely absent or poorly developed, or their orientations may be locally diverse and ambiguous (Fig. 4.11). Detailed studies of shatter cone orientations need to be done at more impact structures where they are well developed, but such studies need to be done with care (see, e.g., Manton, 1965; Milton et al., 1972, 1996a).

It is a paradox that, even though shatter cones are a proven and valuable indicator of shock metamorphism and impact structures, the exact mechanisms by which the radiating shock wave interacts with the target rock to generate shatter cones have not been studied in great detail and are still not understood (e.g., Dietz, 1968; Gash, 1971; Milton, 1977; Sbarpton et al, 1996a). A further complication in shatter cone format on is the evidence that, although the cones themselves form at relatively low shock pressures, localized melting and gla is formation can occur along the cone surfaces, probably as the result of a complex combination of shock and friction al mechanisms (Gay, 1976; Gay et al., 1978; Gibson and ipray, 1998). Combined theoretical, experimental, and fiel 1 studies to understand the exact conditions of shatter conc formation are a major challenge for the future.

\subsection{HIGH-PRESSURE MINERAL POLYMORPHS}

When st bjected to impact-produced shock waves, some minerals in target rocks (e.g., quartz, graphite) may transform to hig 1-pressure minerals, just as they do under high static presst res produced in laboratory experiments or deep in Earth's cr ust. Graphite (C) can be converted to diamond. Quartz can be converted to stishovite at shock pressures of >12-15 $\mathrm{GPa}$ and to coesite at $>30 \mathrm{GPa}$ (Stöfler and Langenhorst 1994). [These numbers illustrate one of the many differences between shock processes and normal geological deformation. Under conditions of static equilibrium, where reaction rates are slower and kinetic factors less im- 


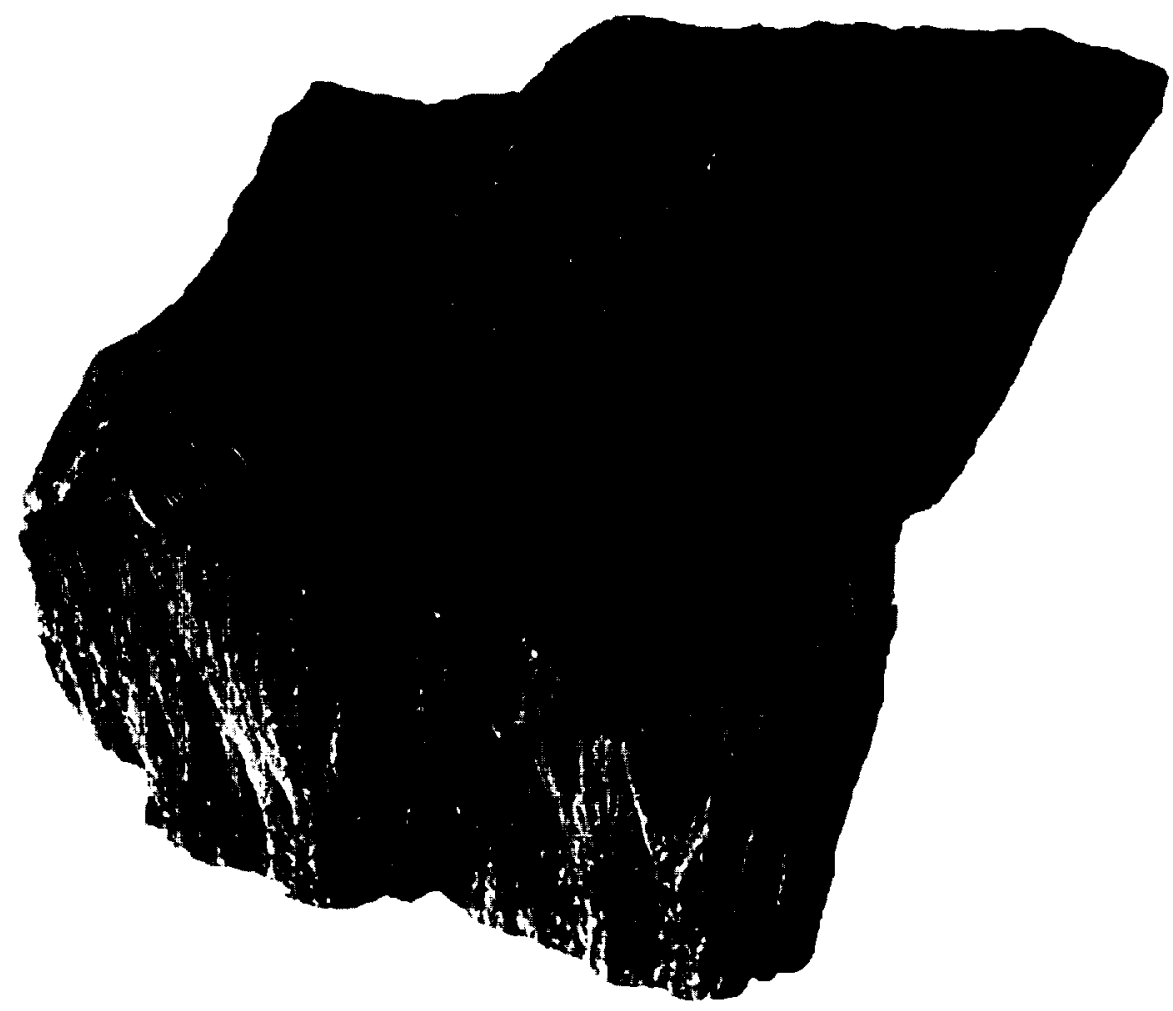

Fig. 4.11. Shatter cones; small, diversely oriented. This specimen shows a group of small, well-developed shatter cones, formed in a sample of Precambrian crystalline target rock at the Slate Islands structure (Canada). The cones show two distinct orientations, and cone axes appear to diverge above and below the coin. This type of diverse orientation may reflect small-scale nonuniformities in the shock waves, produced by local heterogeneities (bedding planes, joints, etc.) in the rock sample. Coin is about $2 \mathrm{~cm}$ in diameter. Photograph courtesy of V. L. Sharpton.

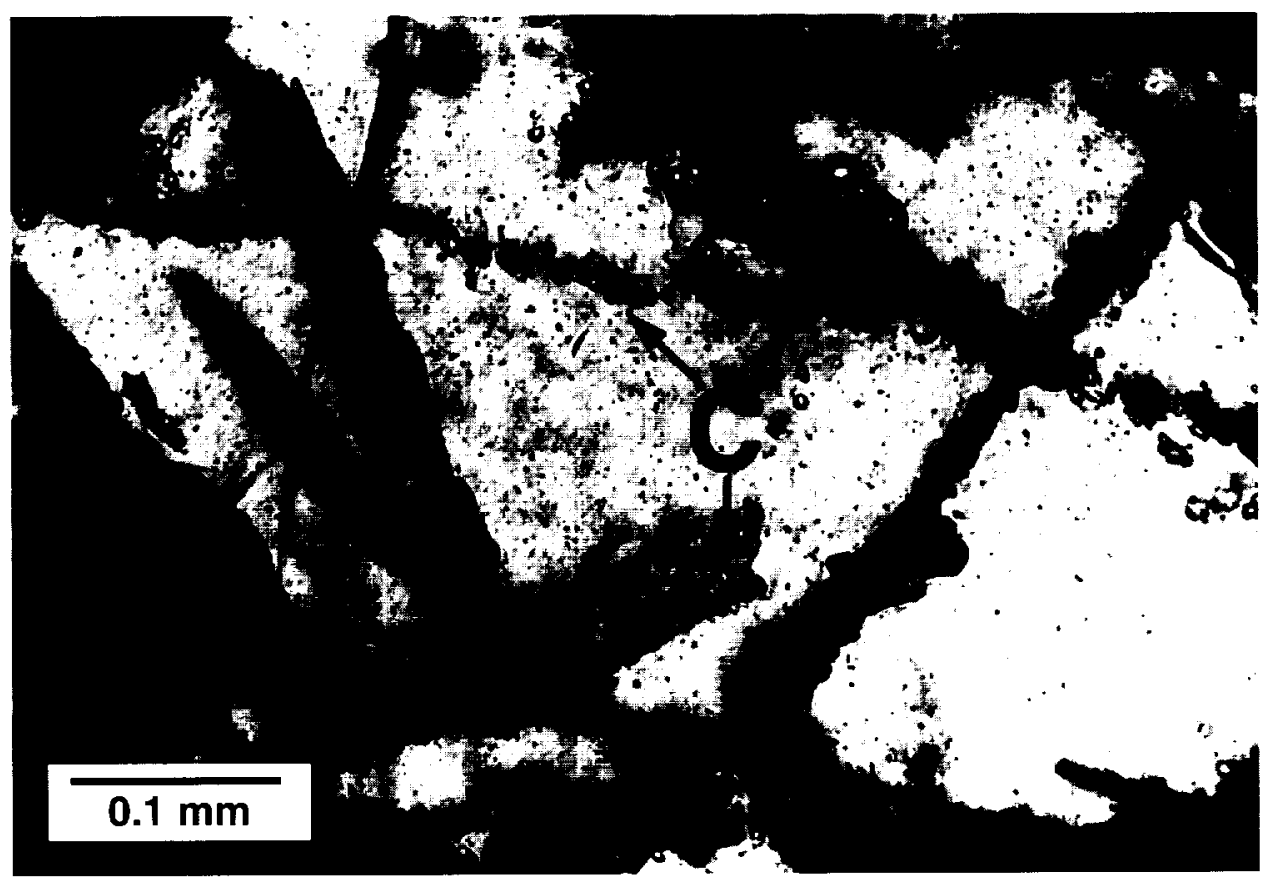

Fig. 4.12. Diaplectic quartz glass; with coesite. Diaplectic quartz glass (clear), with strings of small, high-relief crystals of coesite ("C"). From biotite granite inclusion in suevite breccia, Aufhausen, Ries Crater (Germany). Photograph courtesy of W. von Engelhardt (planepolarized light). 
portant, coesite forms from quartz at lower pressures (>2 GPa) than does stishovite (10-15 GPa).]

The identification of coesite and stishovite at several sites in the early 1960s provided one of the earliest criteria for establishing the impact origin of several structures, most notably the Ries Crater (Germany) (Chao et al., 1960; Shoemaker and Chao, 1961) (Fig. 4.12). Most subsequent identifications of impact structures have been based on shock-produced planar deformation features (PDFs) in quartz, which are more widely distributed and simpler to identify. However, the discovery of both coesite and stishovite in the ancient Vredefort structure (South Africa) (Martini, 1991) was an important step in the growing acceptance of this structure as an impact site. Diamond and other highpressure carbon compounds [e.g., lonsdaleite (hexagonal diamond)] produced from graphite in the shocked target rocks have also been identified at an increasing number of impact structures (Masaitis, 1998; Masaitis et al., 1972; Houghet al., 1995; Koeberl et al., 1997c).

Coesite, stishovite, and diamond, when they are found in near-surface rocks, are unique and reliable indicators of meteorite impact. None of these minerals has been identified, for example, as the result of explosive volcanic eruptions. The use of coesite and diamond as impact criteria does require some care, however, because both minerals also occur naturally in deep-seated (depth $>60 \mathrm{~km}$ ) terrestrial rocks, where they have formed in stable equilibrium at the high static pressures (>2 GPa) present at these depths. Both minerals may then be transported to Earth's surface: coesite by tectonic processes and diamond in fragments carried up by unusual mafic (kimberlite) volcanic eruptions. However, stishovite, formed only at pressures $>10 \mathrm{GPa}$, has never been identified in a nonimpact setting. Such static pressures could be produced only at depths of $300-400 \mathrm{~km}$ within Earth. Furthermore, the occurrence of such high-pressure minerals as coesite, stishovite, or diamond in near-surface crustal rocks [e.g., coesite and stishovite in sandstone at Barringer Meteor Crater (Arizona)], particularly when they occur as a disequilibrium assemblage with other chemically equivalent minerals (c.g., coesite + stishovite + silica glass + quartz), is definite evidence for meteorite impact.

\subsection{PLANAR MICROSTRUCTURES IN QUARTZ}

Shock waves produce a variety of unusual microscopic planar features in quartz, feldspar, and other minerals. These features typically occur as sets of parallel deformation planes within individual crystals. The recognition and interpretation of these features, particularly those in quartz, as unique products of meteorite impact has been a critical factor in identifying most new impact structures, in recognizing the impact origin of large, ancient, or deeply eroded structures, and in demonstrating the role of meteorite impact in the $\mathrm{K} / \mathrm{T}$ extinction event.

Distinctive planar features in quartz $\left(\mathrm{SiO}_{2}\right)$ have been one of the most widely applied criteria for recognizing impact structures ( or reviews, details, and literature references, see papers in French and Short, 1968; also von Engelhardt and Bertsch, 19t.9; Stöfler and Langenhorst, 1994; Grieve et al., 1996). Qua tz is an ideal mineral for this purpose. It is abundant in a wide range of sedimentary and crystalline rocks. It is stable ov 2 r long periods of geologic time, and it resists change by $;$.lteration and metamorphism. It is an optically simple (unicxial) mineral to study and to analyze on the Universal Stag، (U-stage). In particular, it displays a variety of different pl inar features whose development can be correlated with s lock pressure (Table 4.2) (Hörz, 1968; Robertson et al., 1968; Stöfler and Langenhorst, 1994), and can thus be used as a sh sck barometer to reconstruct the shock-pressure distributior that existed within an impact structure during the impact event (Robertson, 1975; Grieve and Robertson, 1976; Robertson and Grieve, 1977; Grieve et al., 1996; Dressler et al., 1998;.

The proluction and properties of planar microstructures in quartz hive been studied intensely since the early $1960 \mathrm{~s}$ by geological investigations, shock-wave experiments, and both optica and electron microscopy (papers in French and Short, 1968, also Stoffler and Langenborst, 1994). It is now recognized hat shock waves produce several kinds of planar microstruct ures in quartz, and their detailed characterization and interpretation has been - and still is - an active and much- tebated problem (e.g., Alexopoulos et al., 1988; Sharpton ard Grieve, 1990). At present, two basic types of planar featu res can be recognized, planar fractures and planar deform ttion features (PDFs) (Table 4.2).

\subsubsection{Planar Fractures}

Planar fiactures are parallel sets of multiple planar cracks or cleavage: in the quartz grain; they develop at the lowest pressures ، haracteristic of shock waves $(\sim 5-8 \mathrm{GPa})$ (Figs. 4.13 ind 4.14). The fractures are typically $5-10 \mu \mathrm{m}$ wide and sp iced $15-20 \mu \mathrm{m}$ or more apart in individual quartz grains. Simi ar cleavage also occurs rarely in quartz from nonimpact setti igs, and therefore planar fractures cannot be used independently as a unique criterion for meteorite impact. However, the development of intense, widespread, and closely spaced plan ir fractures (Fig. 4.15) is strongly suggestive of shock, and such fractures are frequently accompanied in impact stru tures by other features clearly formed at higher shock pressures (Robertson et al., 1968; Stöffler and Langenhorst 1994; Grieve et al., 1996; French et al., 1997).

\subsubsection{Pla aar Deformation Features (PDFs)}

Planar $\mathrm{d}$ :formation features (PDFs) is the designation currently used for the distinctive and long-studied shockproduced $m$.crostructures that were formerly given a variety of names (e g., "planar features," "shock lamellae"). In contrast to plar ar fractures, with which they may occur, PDFs are not open cracks. Instead, they occur as multiple sets of closed, extremely narrow, parallel planar regions (Fig. 4.16). Individual I'DFs are both narrow (typically $<2-3 \mu \mathrm{m}$ ) and more closely spaced (typically $2-10 \mu \mathrm{m}$ ) than planar fractures (Figs. 4.17 and 4.18). Detailed optical and TEM studies have shown that, within individual PDFs, the atomic 


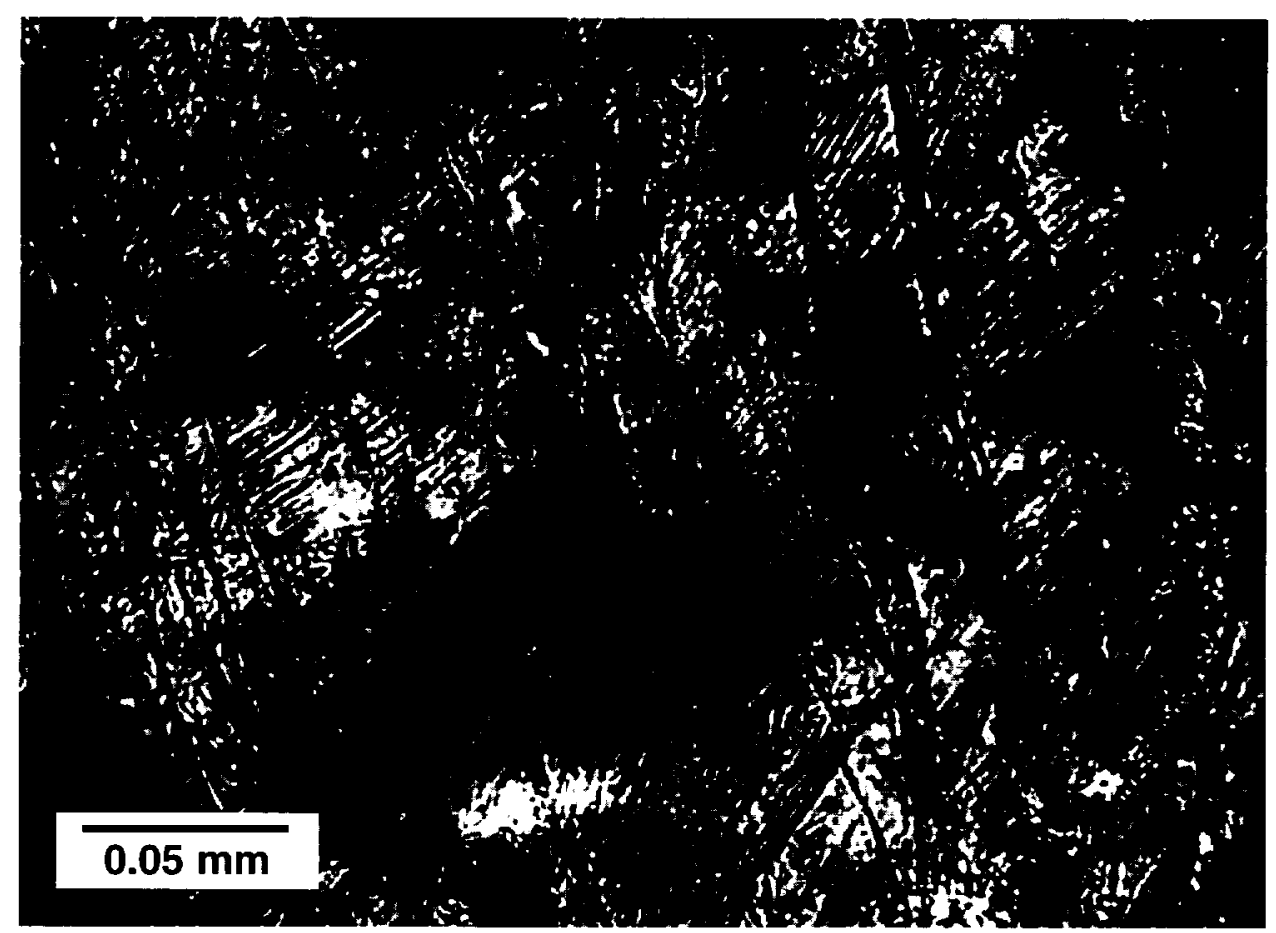

Fig. 4.13. Quartz; cleavage and PDFs. High-magnification view of relict deformed quartz grain in highly shocked and vesiculated Coconino Sandstone [Barringer Meteor Crater (Arizona)]. The quartz grain shows irregular, subparallel fractures (dark, near-vertical), combined with shorter cross-cutting light-and-dark planar features, possibly PDFs (upper right/lower left). Note the irregular extinction in the grain. Sample MCF-65-15-3 (cross-polarized light).

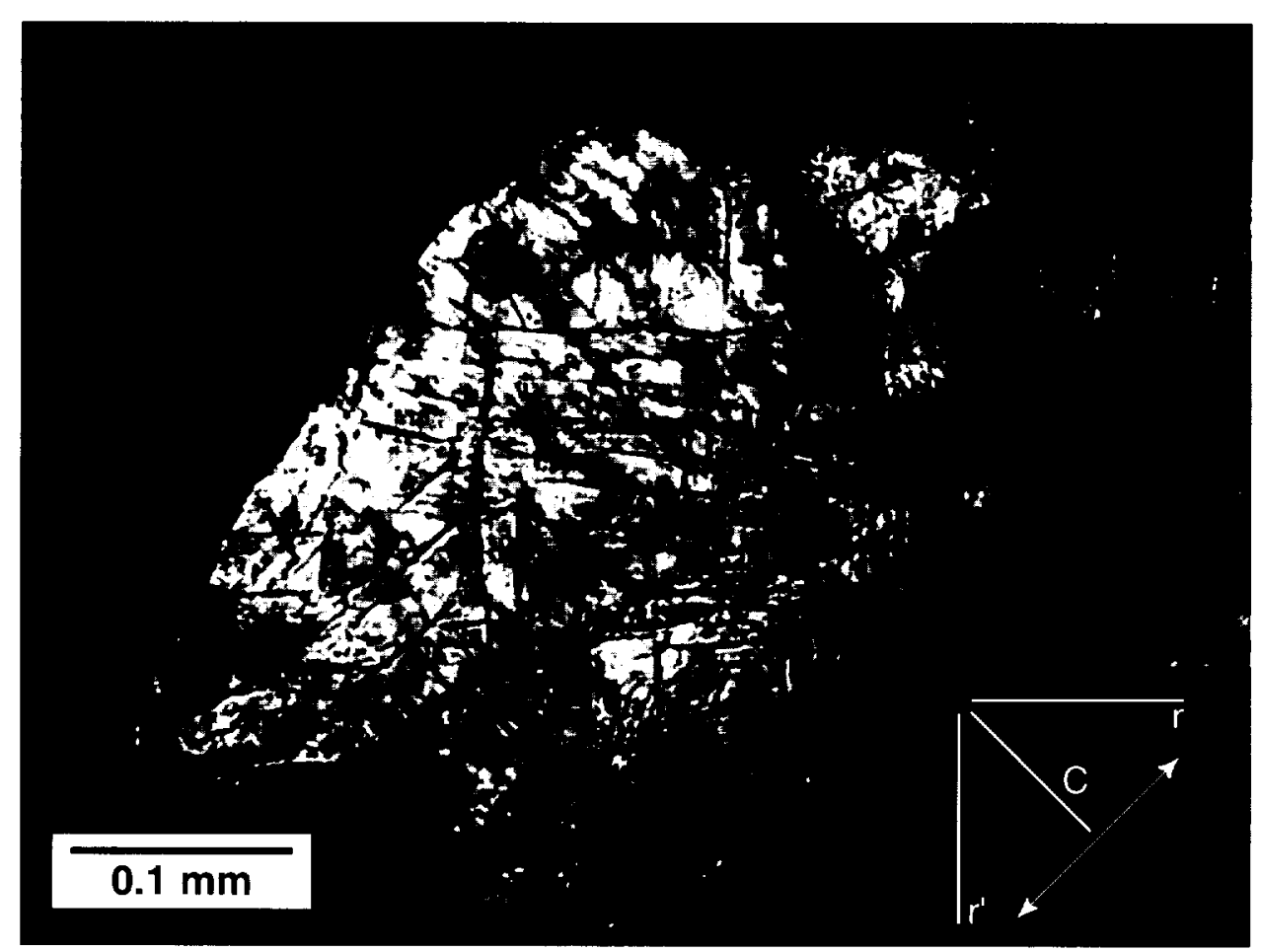

Fig. 4.14. Quartz; cleavage. Quartz grain in moderately shocked Coconino Sandstone from Barringer Meteor Crater (Arizona), showing irregular extinction and multiple sets of cleavage fractures parallel to $c(0001), m\{10 \overline{1} 0\}, r\{10 \overline{1} 1\}$, and $r^{\prime}$. c-axis direction (arrow) and directions of cleavage traces indicated in inset. Photograph courtesy of T. E. Bunch (cross-polarized light). 


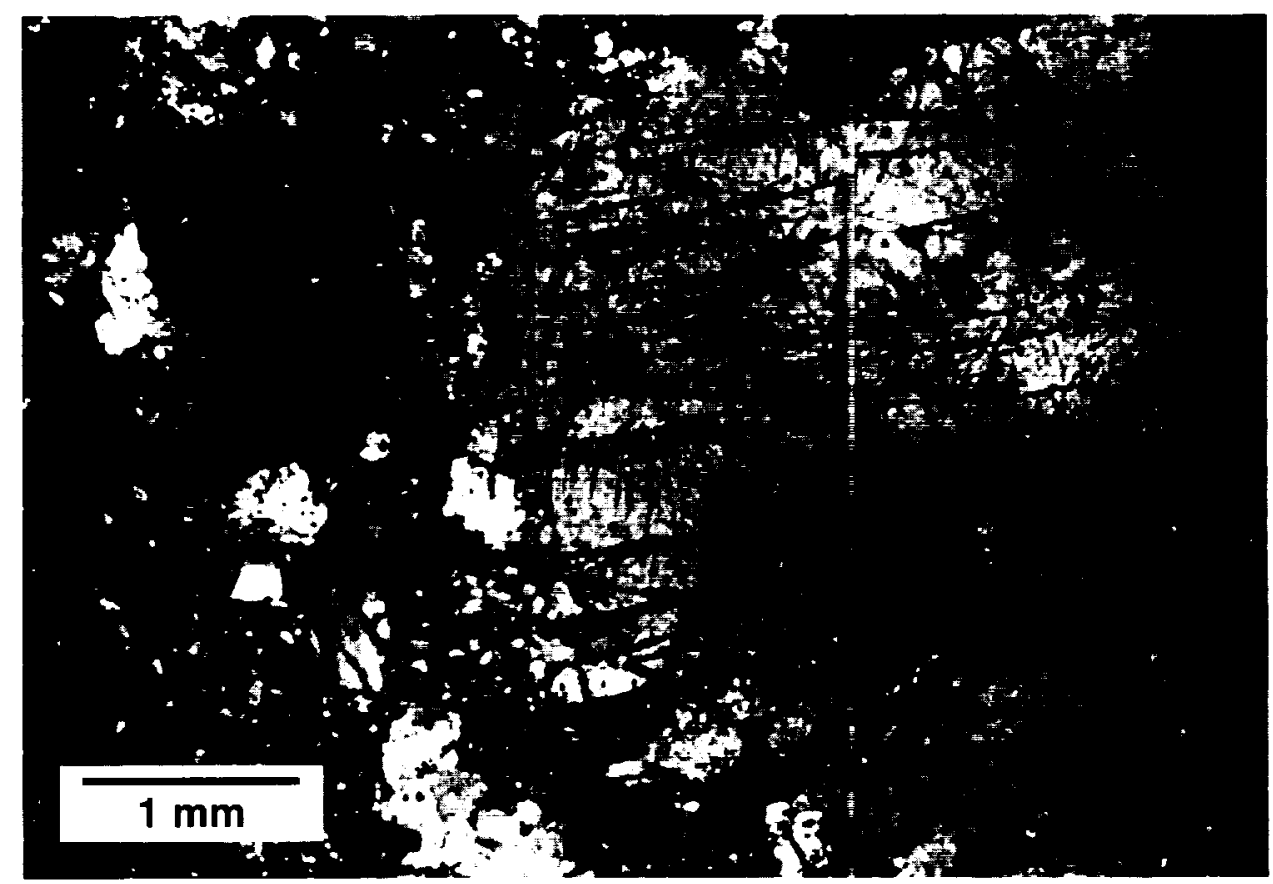

Fig. 4.15. Quartz; fractured, in quartzite. Intense fracturing of quartz in a coarsı-grained metamorphosed orthoquartzite target rock from the Gardnos structure (Norway). The large quartz grain (right) grades into a finer-grained recrystallized shear zone (left). The quartz grain is cut by numerous subparallel planar fractures (longer, dark, subhorizo ttal lines) and by much shorter planar features (short, dark, near-vertical lines) that originate along the fracture planes. These latter featıres may be relicts of actual PDFs or of Brazil twins parallel to the base (0001). Within the Gardnos structure, the originally white quart ite is dark gray to black and highly fractured, and the fractures within the quartz grains contain carbonaceous material. Sample NG-94- .7B (cross-polarized light).

structure of the original crystalline quartz is severely deformed, so that the quartz has been transformed into a distinct amorphous phase (Müller, 1969; Kieffer et al., 1976a; Goltrant et al., 1991, 1992).

The importance of PDFs arises from the fact that they are clearly distinct from deformation features produced in quartz by nonimpact processes, e.g., cleavage or tectonic (metamorphic) deformation lamellae (Böhm lamellae) (Carter, 1965, 1968; Alexopoulos et al., 1988; Stoffler and Langenhorst, 1994). Cleavages are open fractures; they tend to be relatively thick $(\sim 10 \mu \mathrm{m})$ and widely spaced $(\geq 20 \mu \mathrm{m})$. Deformation lamellae consist of bands of quartz typically $10-20 \mu \mathrm{m}$ thick and $>10 \mu \mathrm{m}$ apart that are optically distinct and slightly misoriented relative to the host grain. In contrast to these features, shock-produced PDFs are narrow $(<2-3 \mu \mathrm{m})$ straight planes consisting of highly deformed or amorphous quartz, and they are generally oriented parallel to specific rational crystallographic planes in the host quartz crystal, especially to the base $c(0001)$ or to low-index rhombohedral planes such as $\omega\{10 \overline{1} 3\}, \pi\{10 \overline{1} 2\}$, and $r\{10 \overline{1} 1\}$ (Table 4.4).

The presence of well-developed PDFs produces a striking and distinctive appearance in thin section. Unaltered PDFs form multiple sets of continuous planes that extend across most or all of the host grain (Figs. 4.16, 4.17, and 4.18). These fresh, continuous PDFs tend to be observed only in unaltered material from shock-wave experiments and from younger, well-preserved impact structures, e.g., Barringer Meteor Crater (Arizona) (age $50 \mathrm{ka}$ ) (Fig. 4.13) and the Ri ss Crater (Germany) (age $15 \mathrm{Ma}$ ) (Fig. 4.16). However, f reservation of fresh, continuous PDFs depends on geologi al circumstances, including cooling rate and postimpact temperatures. Fresh, well-preserved PDFs are also presen in older structures, e.g., Sierra Madera (Texas) (age <100 Ma) (Fig. 4.19) and Gardnos (Norway) (age $>400 \mathrm{Ma}$ ) (7ig. 4.20). The occurrence of striking fresh PDFs in quartz es actly at the K/T boundary, a worldwide layer of ejecta from the Chicxulub structure (Mexico) (age $65 \mathrm{Ma}$ ) (Figs. 4.17 and 4.18), provided some of the most important initial evid snce that a large meteorite impact event had occurred at that time.

In altered, geologically old, or metamorphosed samples, PDFs have an equally distinctive but discontinuous character. The original amorphous material in the PDF planes is recrystalliz :d back to quartz, and in the process, arrays of small (typi ally $1-2 \mu \mathrm{m}$ ) fluid inclusions ("decorations") develop alo ag the original planes (Figs. 4.21 and 4.22). The resulting fe atures, called decorated PDFs (Robertson et al., 1968; Stöf,er and Langenhorst, 1994) preserve the orientation of the original PDFs, and the distinctive shock-produced fabric can still be recognized in old rocks that have even under zone metamorphism [e.g., greenschist facies at Sudbury (Canada); Fig. 4.23]. More intense recrystallization produces arrays of small mosaic quartz crystals (subgrains;, especially along PDFs originally parallel to the base c(0001) of the quartz grain (Leroux et al., 1994).

A secord type of PDF, oriented parallel to the base $c(0001), h$ s s recently been identified, chiefly by studies of 


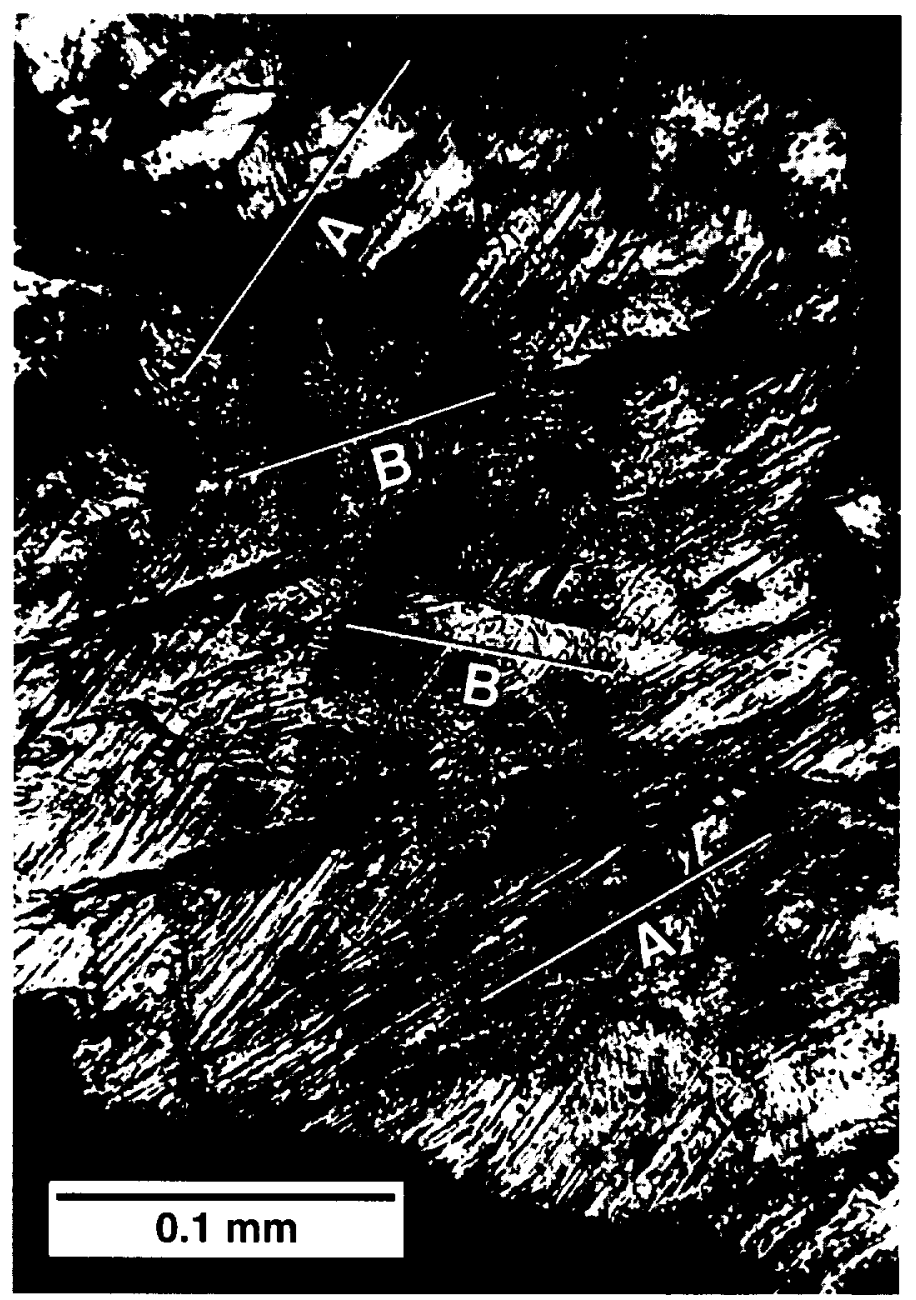

Fig. 4.16. Quartz; multiple PDFs, fresh. Striking multiple sets of PDFs developed in a quartz grain from a shocked granite inclusion in suevite from the Ries Crater (Germany). "A" indicates PDFs parallel to $\{10 \overline{1} 3\}$ or $\{01 \overline{1} 3\}$; " $B$ " indicates PDFs parallel to $\{10 \overline{1} 1\}$ or $\{01 \overline{1} 1\}$. Note the irregular mottled extinction within the quartz grain. From von Engelhardt and Stoffler (1965), Fig. 1. Photograph courtesy of W. von Engelhardt (cross-polarized light).

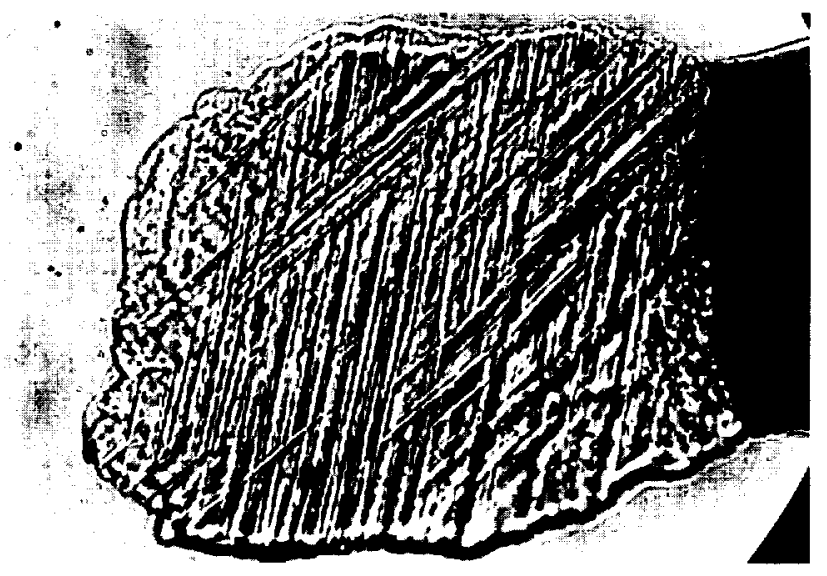

Fig. 4.17. Quartz; multiple PDFs, fresh. Small quartz grain $(0.20 \mathrm{~mm}$ long) from $\mathrm{K} / \mathrm{T}$ boundary ejecta layer, showing two prominent sets of fresh (undecorated) PDFs. (Small dots with halos are artifacts.) Specimen from Starkville South, a few kilometers south of Trinidad, Colorado. Photograph courtesy of G. A. Izett. Spindle stage mount (plane-polarized light).

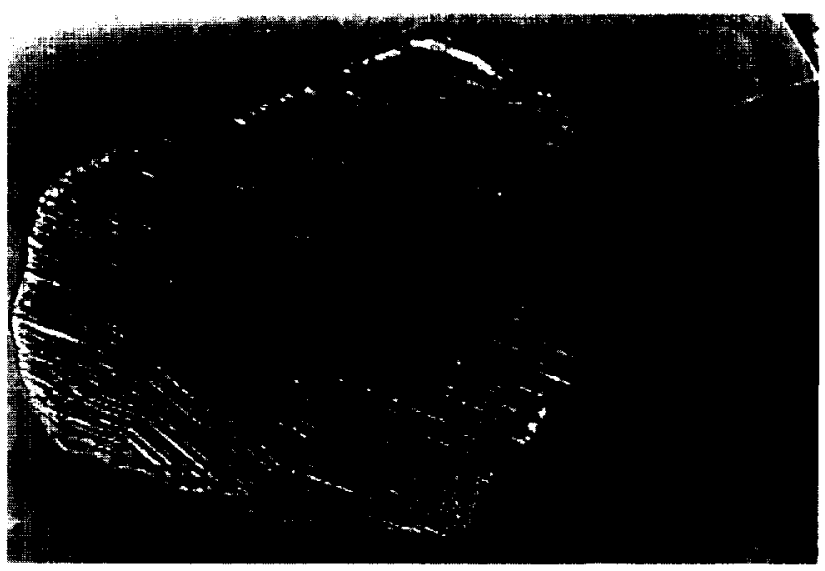

Fig. 4.18. Quartz; multiple PDFs, fresh. Small quartz grain ( $0.36 \mathrm{~mm}$ long) from $\mathrm{K} / \mathrm{T}$ boundary ejecta layer, containing one opaque inclusion and multiple (3-5?) prominent sets of fresh (undecorated) PDFs. Specimen from Clear Creek North, a few kilometers south of Trinidad, Colorado. Photograph courtesy of G. A. Izett. Spindle stage mount (plane-polarized light). 
TABLE 4.4. Typical crystallographic orientations of planar microstructures in shocked quartz (mıdified from Stöffler and Langenborst, 1994, Table 3, p. 164).

\begin{tabular}{|c|c|c|}
\hline Symbol & Miller Indexes & $\begin{array}{c}\text { Polar Angle } \\
\text { (Ang e Between Pole to Plane } \\
\text { and Quartz c-axis) }\end{array}$ \\
\hline c & ${ }^{*}(0001)$ & $0^{\circ}$ \\
\hline$\omega, \omega^{\prime}$ & ${ }^{*}\{10 \overline{1} 3\},\{01 \overline{1} 3\}$ & $23^{\circ}$ \\
\hline$\pi, \pi$ & ${ }^{*}\{10 \overline{1} 2\},\{01 \overline{1} 2\}$ & $32^{\circ}$ \\
\hline $\mathrm{r}, \mathrm{z}$ & ${ }^{*}\{10 \overline{1} 1\},\{01 \overline{1} 1\}$ & $52^{\circ}$ \\
\hline $\mathrm{m}$ & $\{10 \overline{1} 0\}$ & $90^{\circ}$ \\
\hline$\xi$ & $\{11 \overline{2} 2\},\{2 \overline{1} \overline{1} 2\}$ & $48^{\circ}$ \\
\hline s & $\{11 \overline{2} 1\},\{2 \overline{1} 11\}$ & $66^{\circ}$ \\
\hline \multirow[t]{2}{*}{ a } & $\{11 \overline{2} 0\},\{2 \overline{1} \overline{1} 0\}$ & $90^{\circ}$ \\
\hline & $*\{22 \overline{4} 1\},\{4 \overline{2} \overline{2} 1\}$ & $77^{\circ}$ \\
\hline $\mathrm{t}$ & $\{40 \overline{4} 1\},\{04 \overline{4} 1\}$ & $79^{\circ}$ \\
\hline $\mathrm{k}$ & $\{51 \overline{6} 0\},\{6 \overline{1} \overline{5} 0\}$ & $90^{\circ}$ \\
\hline $\mathrm{x}$ & $\begin{array}{l}\{51 \overline{6} 1\},\{6 \overline{5} \overline{1} 1\} \\
\{6 \overline{1} \overline{5} 1\},\{15 \overline{6} 1\}\end{array}$ & $82^{\circ}$ \\
\hline - & $\begin{array}{l}\{31 \overline{4} 1\},\{4 \overline{3} \overline{1} 1\} \\
\{4 \overline{1} \overline{3} 1\},\{13 \overline{4} 1\}\end{array}$ & $78^{\circ}$ \\
\hline - & $\begin{array}{l}\{21 \overline{3} 1\},\{3 \overline{2} \overline{1} 1\} \\
\{3 \overline{1} \overline{2} 1\},\{12 \overline{3} 1\}\end{array}$ & $74^{\circ}$ \\
\hline
\end{tabular}

*Prominent planes in typical shock fabrics.

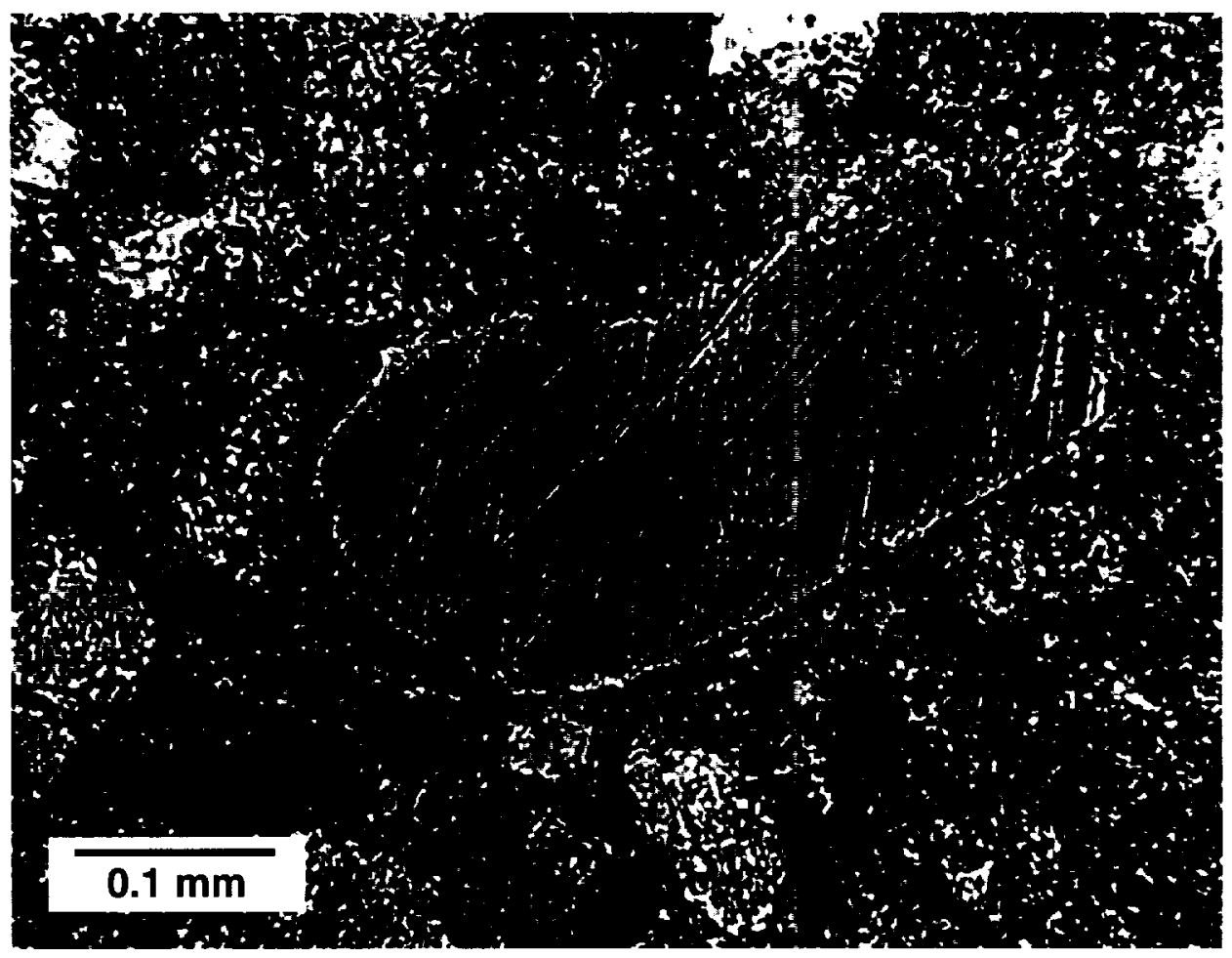

Fig. 4.19. Quartz; multiple PDFs, fresh. Shocked quartz grain containing multijle sets of fresh PDFs. The grain is included with rare sandstone fragments in a carbonate breccia dike that cuts the deformed basement rocks at Sierra Madera (Texas), an impact structure developed in a target composed dominantly of carbonate rocks. The closely spaced PDFs give a distinctive darkened, yellowish appearance to the quartz grain. Sample SMF-65-2-2 (planc-polarized light). 


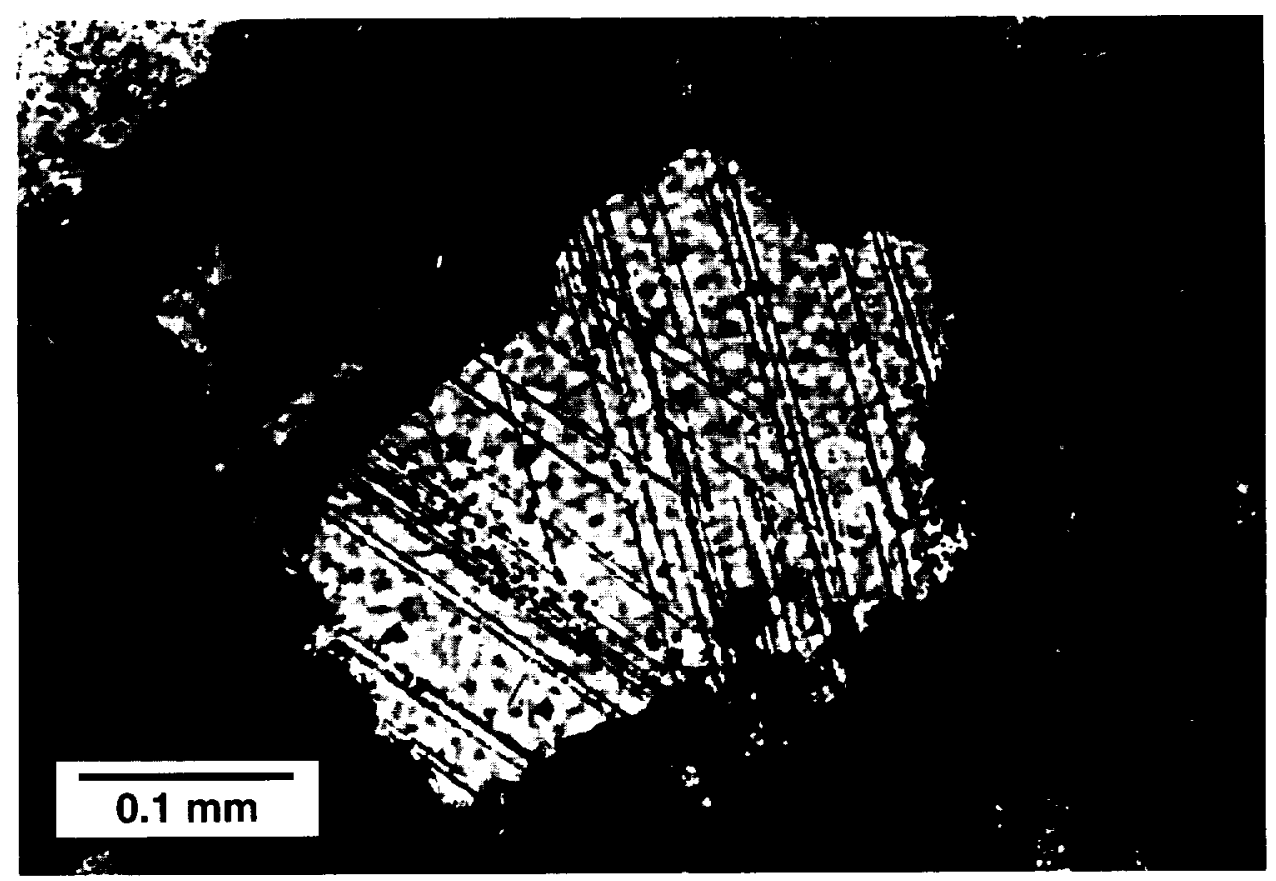

Fig. 4.20. Quartz; multiple PDFs, slightly decorated. Quartz grain in a carbon-bearing crater-fill breccia from Gardnos (Norway), showing two well-developed sets of $\{10 \overline{1} 3\}$ PDFs. In places, the normally continuous PDFs break down into a string of small fluid inclusions (small black dots) that follow the original trace of the PDFs. This process, by which the originally glassy material in the PDFs is recrystallized and replaced by fluid inclusions, has produced decorated PDFs, in which the original PDFs are visible only by the arrays of fluid inclusions that reproduce their original orientations. Sample NG-94-31 (plane-polarized light).

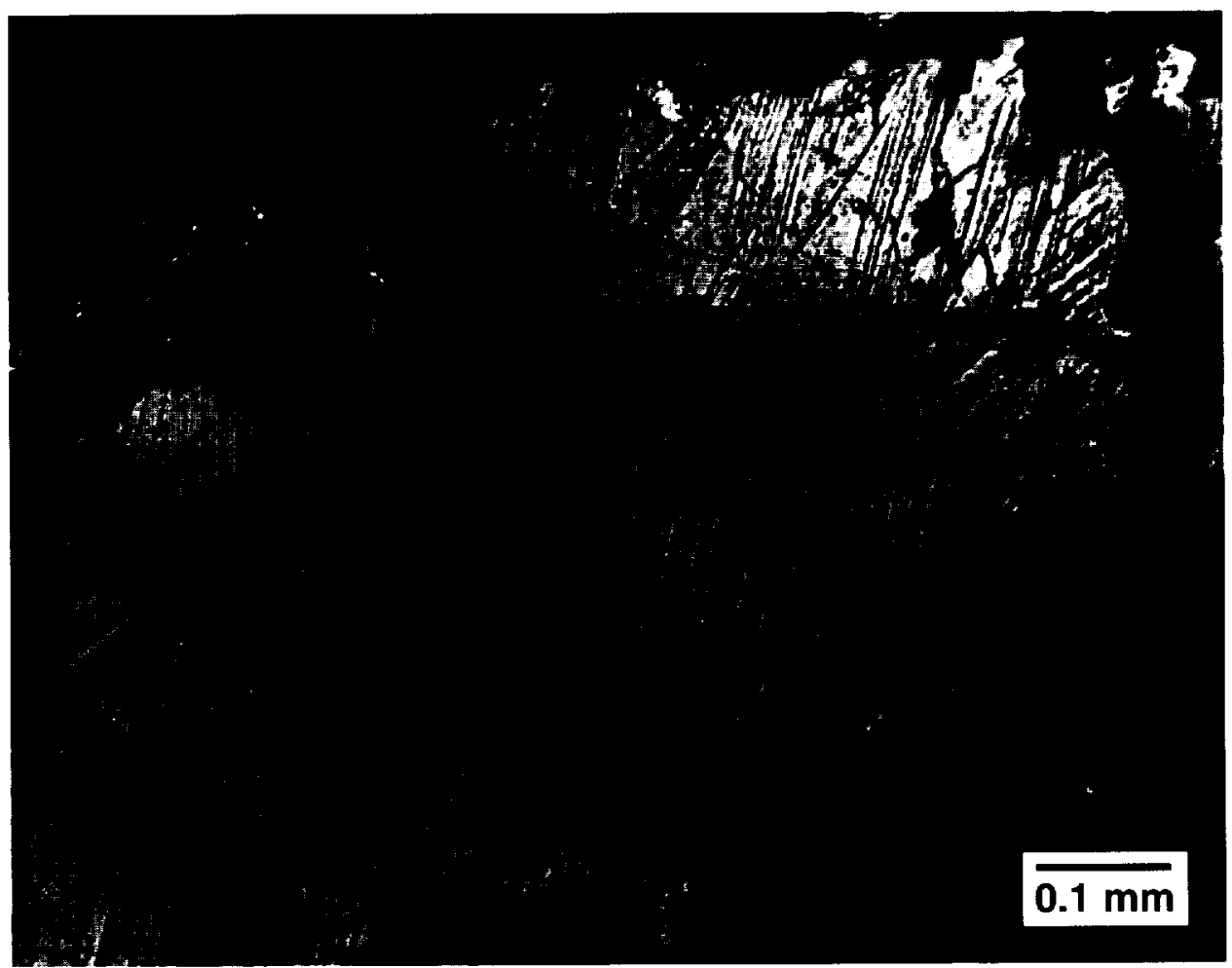

Fig. 4.21. Quartz; multiple PDFs, decorated. Large compound quartz grain from shocked basement rock inclusion in suevite breccia from Rochechouart (France), showing two prominent sets of partially decorated PDFs (north-northeast/south-southwest; northeast/ southwest). Original, partly continuous PDF traces are still recognizable from the location of small fluid inclusions (black dots) along the original PDF planes. Sample FRF-69-16 (cross-polarized light). 


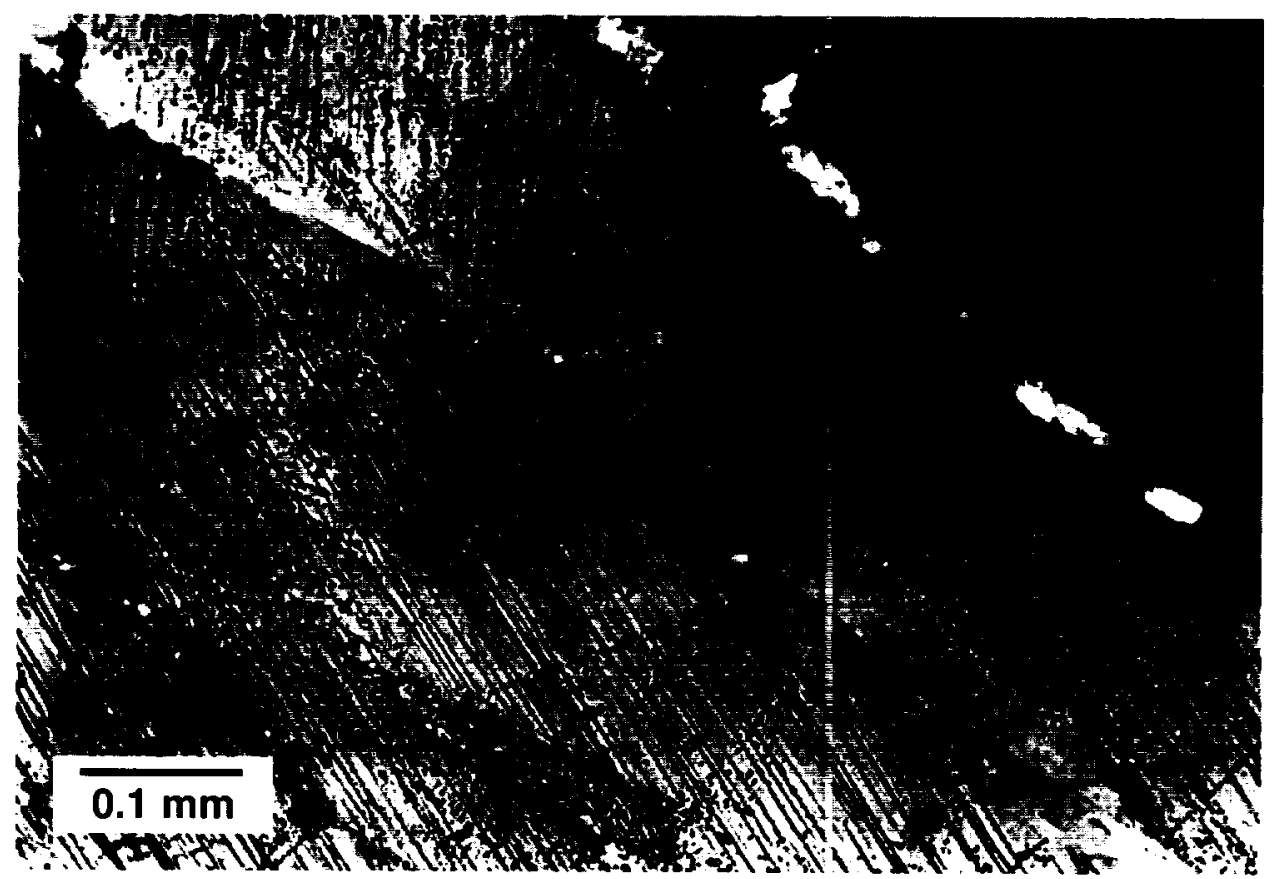

Fig. 4.22. Quartz; multiple PDFs, decorated. Compound quartz grain showing 1 wo prominent sets of decorated PDFs (north/south; northwest/southeast). The original PDF planes are now largely replaced by arrays of small fluid inclusions that preserve the original PDF orientations. Sample from Precambrian basement gneiss in the central uplift of the Carswell Lake structure (Canada). Photograph courtesy of M. R. Dence. Sample DCR-11-63l3 (cross-polarized light).

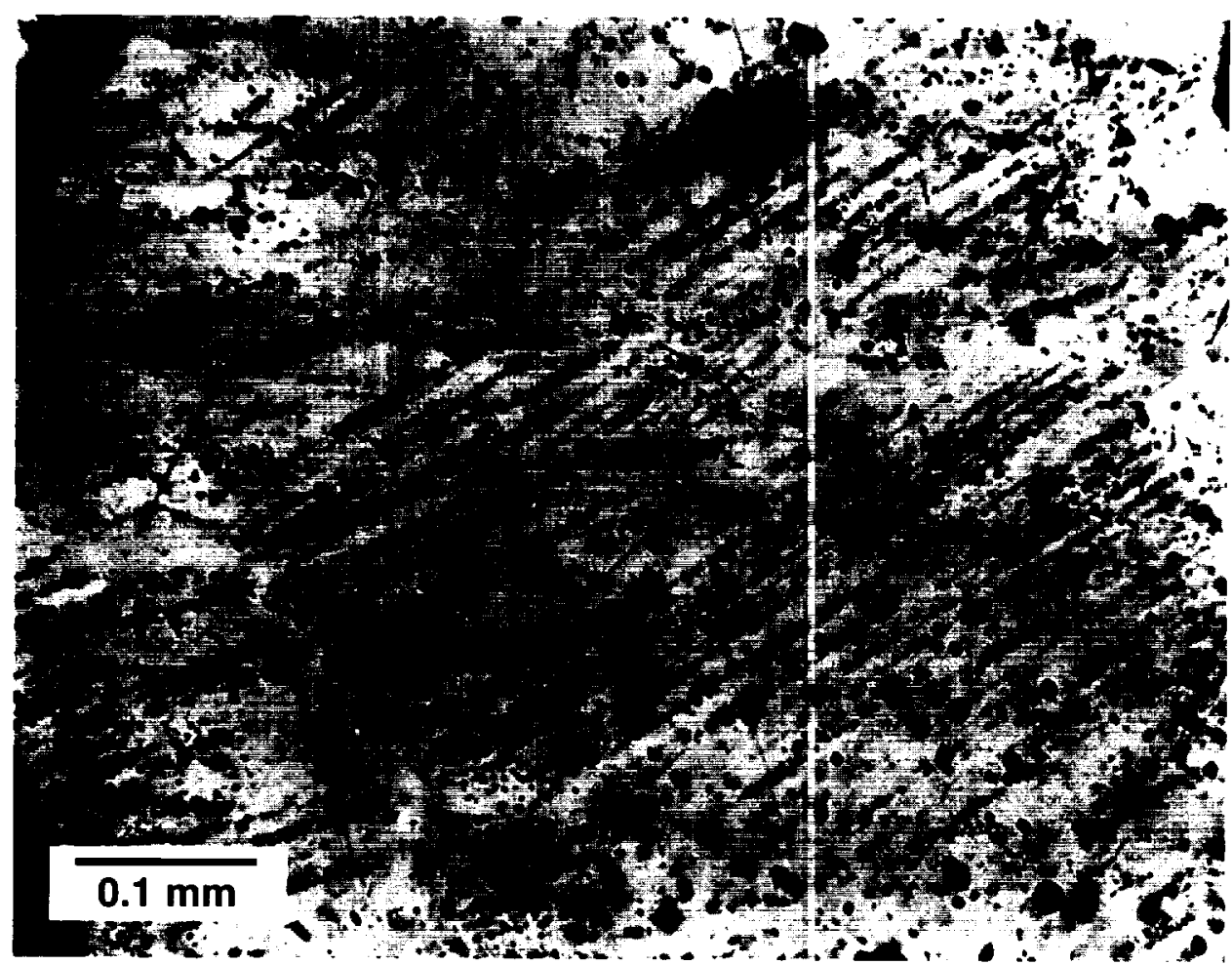

Fig. 4.23. Quartz; multiple PDFs, decorated. High-magnification view of shocked quartz from ejecta block in metamorphosed suevite, showing multiple sets of recrystallized PDFs (northwest/southeast; east/west) now expressed by arrays of small fluid inclusions (black dots). Quartz grain also contains numerous random larger fluid inclusions scattered through the grain. Sample from a small granitic gneiss inclusion in the Onaping Formation "Black Member," from the ty je locality, Onaping Falls (Highway 144, Dowling Township), northwestern corner of the Sudbury structure (Canada). Photograph c) surtesy of N. M. Short. Sample CSF-66-39 (crosspolarized light). 


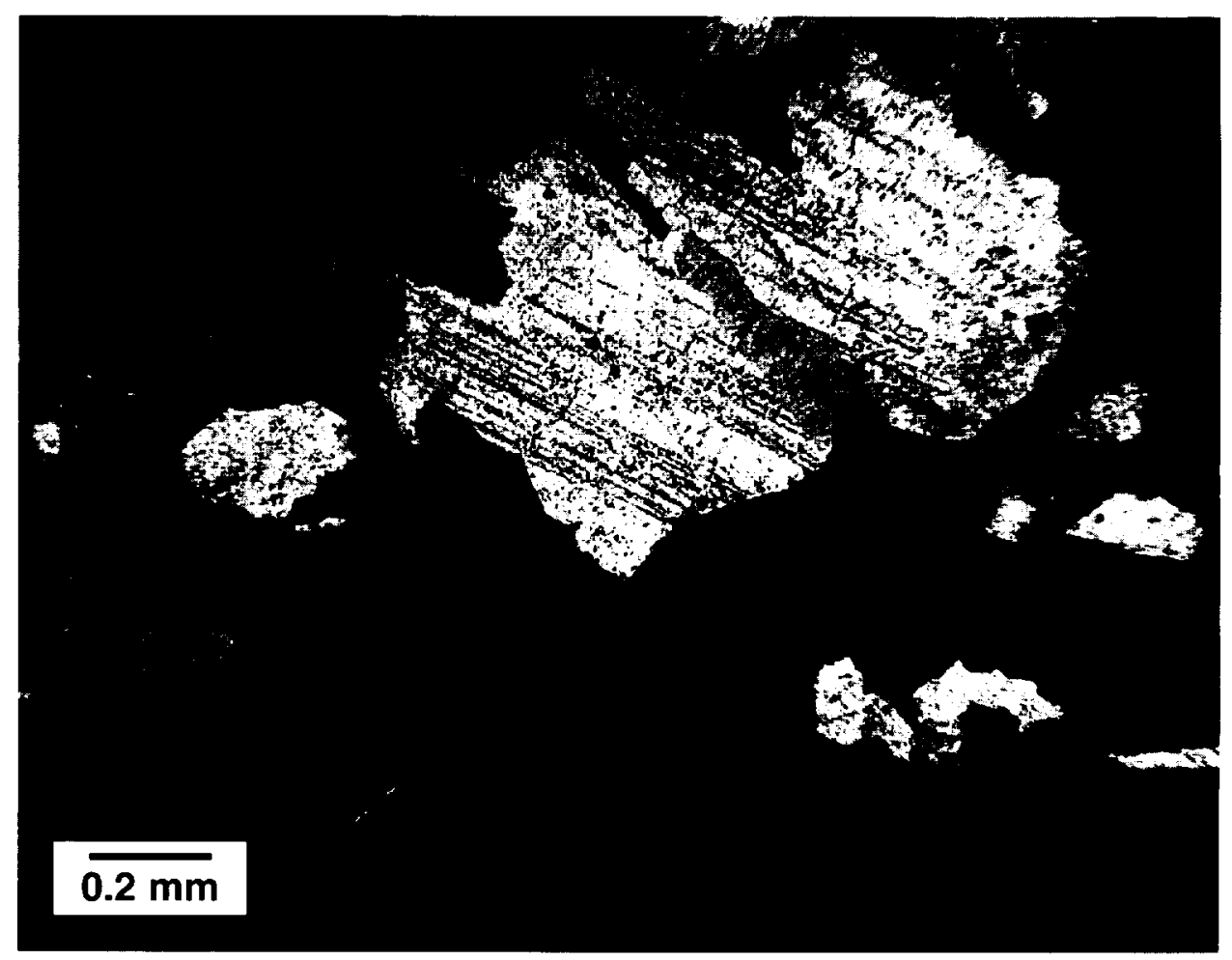

Fig. 4.24. Quartz; basal PDFs. Large irregular quartz grain associated with sericitized feldspar (dark) in footwall granitic rocks on North Range of Sudbury structure (Canada), together with shatter cones and pseudotachylite. Grain shows one well-developed set of PDFs (upper left/lower right), which appear as linear arrays of small fluid inclusions parallel to the base (0001) of the quartz grain. Sample CSF-67-55-2 (cross-polarized light).

shocked quartz with transmission election microscopy (TEM), as Brazil twins (Fig. 4.24) (Leroux et al., 1994; Joreau et al., 1996). This form of twinning also occurs in natural unshocked quartz, but it has never been observed parallel to the base in such samples. Experimental formation of basaloriented Brazil twins in quartz requires high stresses (about $8 \mathrm{GPa}$ ) and high strain rates, and it seems probable that such features in natural quartz can also be regarded as unique impact indicators (Stöffler and Langenborst, 1994).

\subsubsection{PDF Orientations}

Despite the distinctive appearance of PDFs in thin section, appearance alone is not adequate to distinguish them from nonshock features or to argue that they are impact produced. An additional and definitive characteristic of PDFs is their tendency to form along specific planes in the quartz crystal lattice. Measurements of PDF orientations within the host quartz grain therefore provide a simple and reliable method to distinguish them from planar structures produced by nonshock processes. PDF orientations can be measured using standard petrofabric procedures on a U-stage (for details, measurement techniques, and specific studies, see Carter, 1965, 1968; Robertson et al., 1968; von Engelhardt and Bertsch, 1969; Alexopoulos et al., 1988; Stöffler and Langenborst, 1994) or on the related spindle stage (Bloss, 1981; Medenbach, 1985; Bobor et al., 1984, 1987; Izett, 1990).

The procedures involve measuring, in a single quartz grain, both the orientation of the pole (normal) to each set of PDFs and the orientation of the c-axis (= optic axis) of the grain. The measurement data are then plotted on a standard stereonet, and the results are expressed as the location of the pole to the PDFs relative to the $\mathrm{c}$-axis. If a large number of PDF measurements can be made on a sample, a convenient, although not entirely rigorous, method to present comparative results is to plot a frequency diagram (Bistogram) of the angles between the $\mathrm{c}$-axis and the pole to each set of PDFs.

Because shock-produced PDFs in a given quartz grain are parallel to only a few specific crystallographic planes, the angles measured between the quartz $c$-axis and the poles to the PDFs tend to concentrate at a few specific values. In a histogram plot, the poles appear as sharp concentrations at specific angles, each of which corresponds to a particular plane (Figs. 4.25 and 4.26).

This sharply peaked pattern of PDF orientations, typically characterized by peaks at $\mathrm{c}(0001)\left(0^{\circ}\right), \omega\{10 \overline{1} 3\}\left(23^{\circ}\right)$, and $\pi\{10 \overline{1} 2\}\left(32^{\circ}\right)$, is one of the most useful and most-used indicators of meteorite impact. Such plots clearly demonstrate the great difference between PDF distributions (Figs. 4.25a-c) and the more widely distributed, bell-shaped distribution characteristic of metamorphic deformation lamellae (Fig. 4.25e). Such plots are also used to distinguish different shock-produced fabrics that reflect different shock pressures (Fig. 4.26).

Experimental and geological studies have demonstrated that PDFs form in quartz at pressures of $\sim 7-35 \mathrm{GPa}$, or at the lower end of the range of shock-metamorphic pressures 

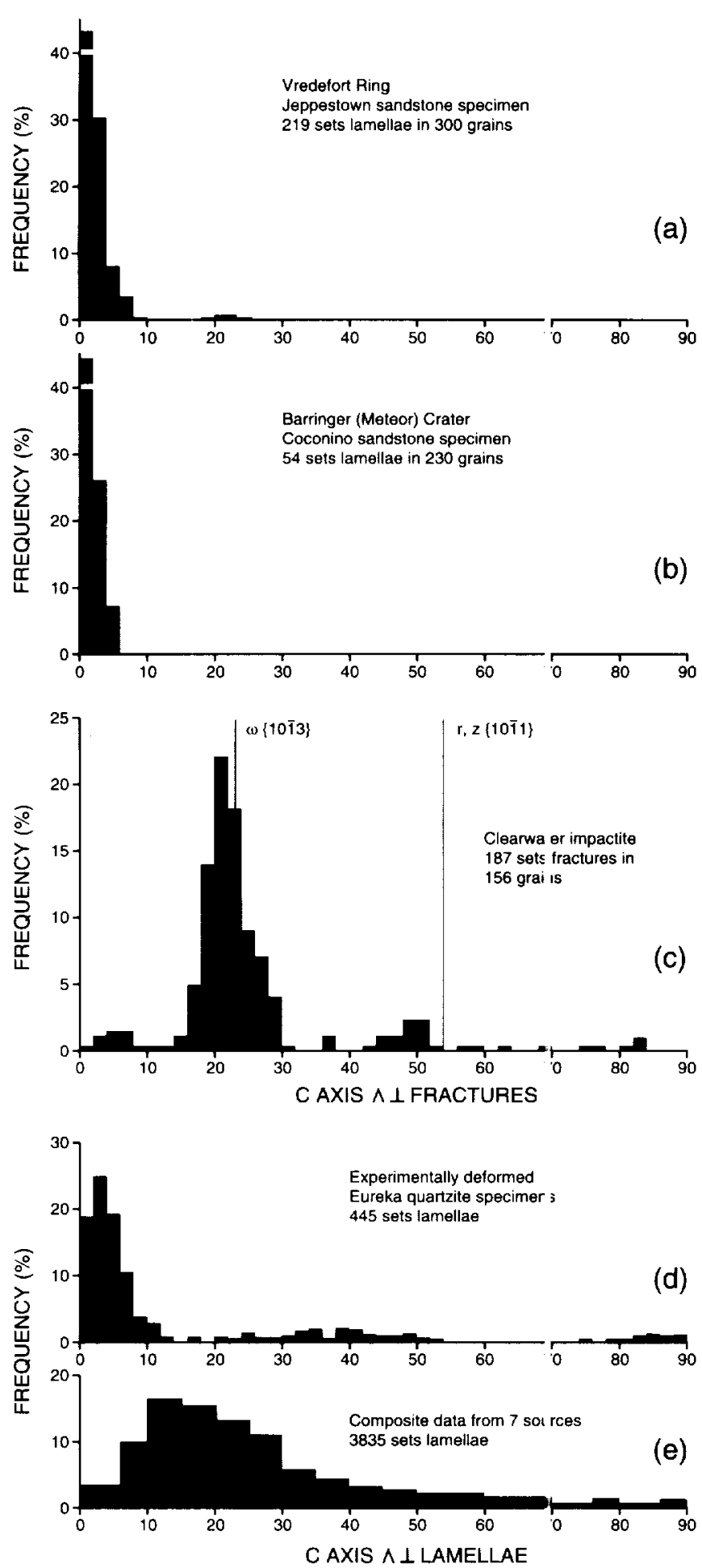

Fig. 4.25. Quartz; PDF orientations. Comparative histograms showing orien ations of shock-produced PDFs and other planar deformation features in quartz (from Carter, 1965). In each diagram, the angle b stween the quartz c-axis and the pole to the planar feature is plotted on the $x$-axis; $y$-axis indicates frequency for each given angle. Shock-produced fabrics are characterized by strong orientations parallel to a few specific crystallographic planes. (a) and (b) Basal-orient dd sets of deformation lamellae in shocked sandstones from the Vredefort (South Africa) and Barringer Meteor Crater (Arizona) structures; (c) distinctive PDFs showing the distinctive concentration parallel to $\omega\{10 \overline{1} 3\}$ [shocked crystalline rocks; Clearwater Lakes (Carada)]; (d) low-angle, near-basal fabric of deformation lamellae generated under high-strain experimental conditions; (e) broad distribution of metamorphic deformation lamellae (Böhm lamellae) produced by normal metamorphic conditions. The distinctive differences between shock-produced fabrics (a), (b), and (c) and those of normal metamorphism (e) have been one of the strongest arguments for the meteorite impact origin of suspected impact structures. 

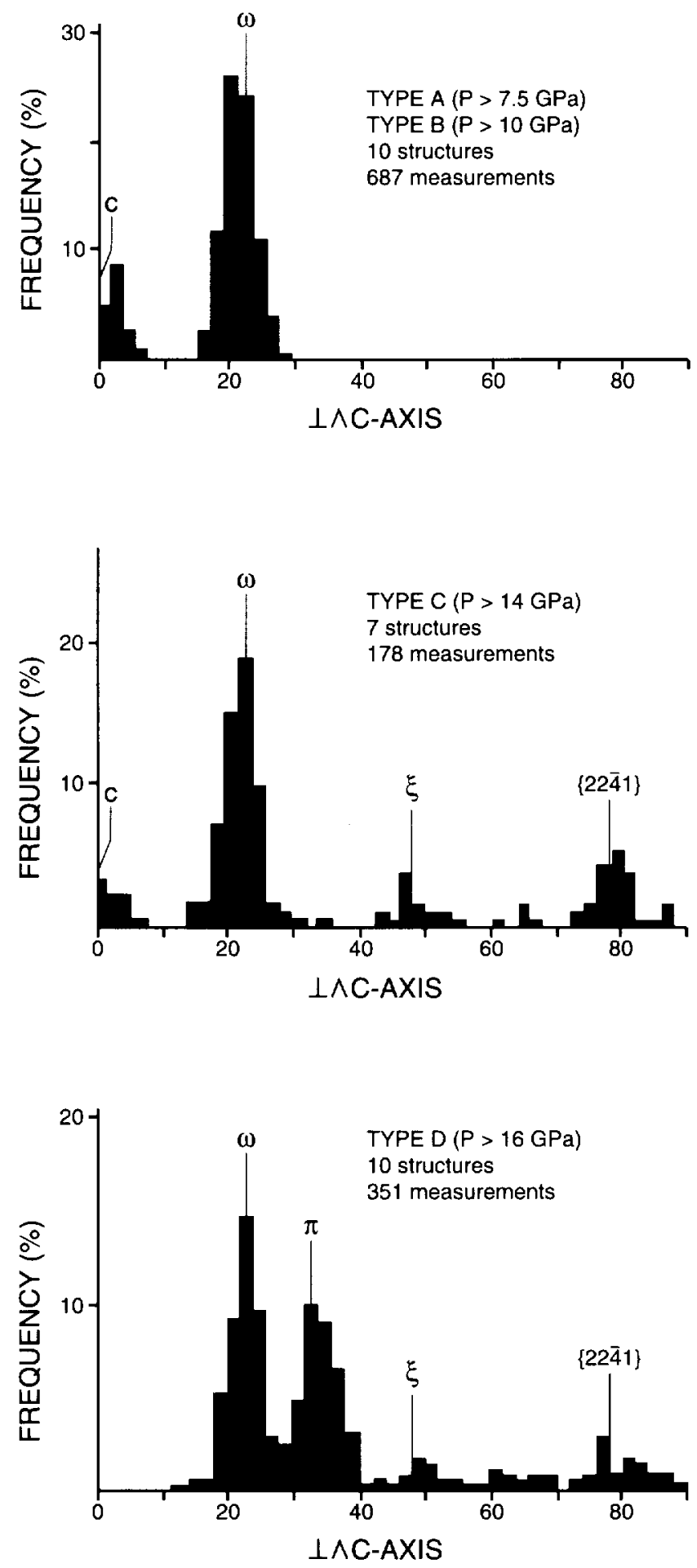

Fig. 4.26. Quartz; PDF orientations. Comparative histograms showing different fabrics displayed by PDFs in quartz produced at different shock pressures, based on measurements of shocked crystalline rocks from several Canadian impact structures (from Roberison et al., 1968). With increasing shock pressures, both the total number of PDFs and the number of different orientations increase. The following fabrics, and the minimum shock pressures estimated to form them (Grieve and Robertson, 1976, pp. 39-40), can be recognized: type $A(\mathrm{P}>7.5 \mathrm{GPa})$ : basal PDFs only; type $B(\mathrm{P}>10 \mathrm{GPa})$, appearance of $\omega\{10 \overline{1} 3\}$ planes, typically with basal planes; type $C$ $(\mathrm{P}>14 \mathrm{GPa})$, appearance of $\{22 \overline{4} 1\}$ planes with others; type $\mathrm{D}(\mathrm{P}>16 \mathrm{GPa})$, appearance of $\pi\{10 \overline{1} 2\}$ planes with others. These fabrics have been used as shock barometers to measure the intensity and distribution of shock pressures in several structures (Grieve and Robertson, 1976; Robertson and Grieve, 1977; Dressler and Sharpton, 1997). From Carter (1965). 
(e.g., Hörz, 1968; Stöfler and Langenhorst, 1994). However, the relative abundance of different PDF orientations varies significantly with shock pressure. Basal Brazil twins, although little studied so far, appear restricted to shock pressures below $10 \mathrm{GPa}$. PDFs parallel to $\omega[10 \overline{1} 3\}$ develop at about $\geq 7-$ $10 \mathrm{GPa}$, and PDFs parallel to $\pi\{10 \overline{1} 2\}$ at about $\geq 20 \mathrm{GPa}$. At higher pressures, e.g., 20-35 GPa, the total number of PDF sets increases, and additional orientations appear (Fig. 4.26). The PDFs formed at these higher levels tend to be intensely developed and very closely spaced within the quartz grains (Figs. 4.16, 4.18, and 4.27).

\subsubsection{PDFs in Sedimentary Rocks}

Although PDFs and their orientations can be reliably used as indicators of shock and impact events, it is becoming clear that our current knowledge about such features is incomplete and unrepresentative. Nearly all our information to date has come from impact structures formed in dense, coherent, quartz-bearing crystalline rocks. There is relatively little information about the effects of shock deformation in other kinds of quartz-bearing rocks, e.g., porous sandstones or finegrained shales.

Several studies have demonstrated that shocked sandstones and shales also develop PDFs in quartz, and even diaplectic quartz and feldspar glasses, similar to those observed in shocked crystalline rocks, and these features have been obser red in sedimentary rocks from several impact structures (Kieffer, 1971, Kieffer et al., 1976a; Grieve et al., 1996).

Despite these similarities, a growing amount of data now indicates th at sedimentary rocks, especially porous ones, respond diffe rently to shock waves than do nonporous crystalline rock. One indication of significant differences is that PDF fabric; measured in sediments show a large proportion of PDFs w lose poles are oriented at high angles $\left(>45^{\circ}\right)$ to the quartz :-axis (Grieve et al., 1996; Gostin and Therriault, 1997). Other possible differences are that PDFs may first appear, or a particular PDF fabric may develop, at different shock press ires in sedimentary rocks than in crystalline rocks.

A more important difference between porous and nonporous rocls is that a shock wave passing through porous sediments vill generate more heat than in passing through crystalline ocks, chiefly because more of the shock-wave energy is ab sorbed by the numerous grain interfaces and pore spaces in the sediment (Kieffer, 1971; Kieffer et al., 1976a; Kieffer and Simonds, 1980; Stöfler, 1984). As a result, extensive meltinģ; will occur at lower shock pressures in sediments than in cry talline rocks, i.e., at about $15-20 \mathrm{GPa}$ in sandstone vs. $50-60 \mathrm{GPa}$ in crystalline rocks (Stöfler, 1972, 1984). Therefore, 1 he higher-pressure fabrics of quartz PDFs, which form at 20-30 GPa in crystalline rocks, may not be found in sediments, sither because they did not form or because they

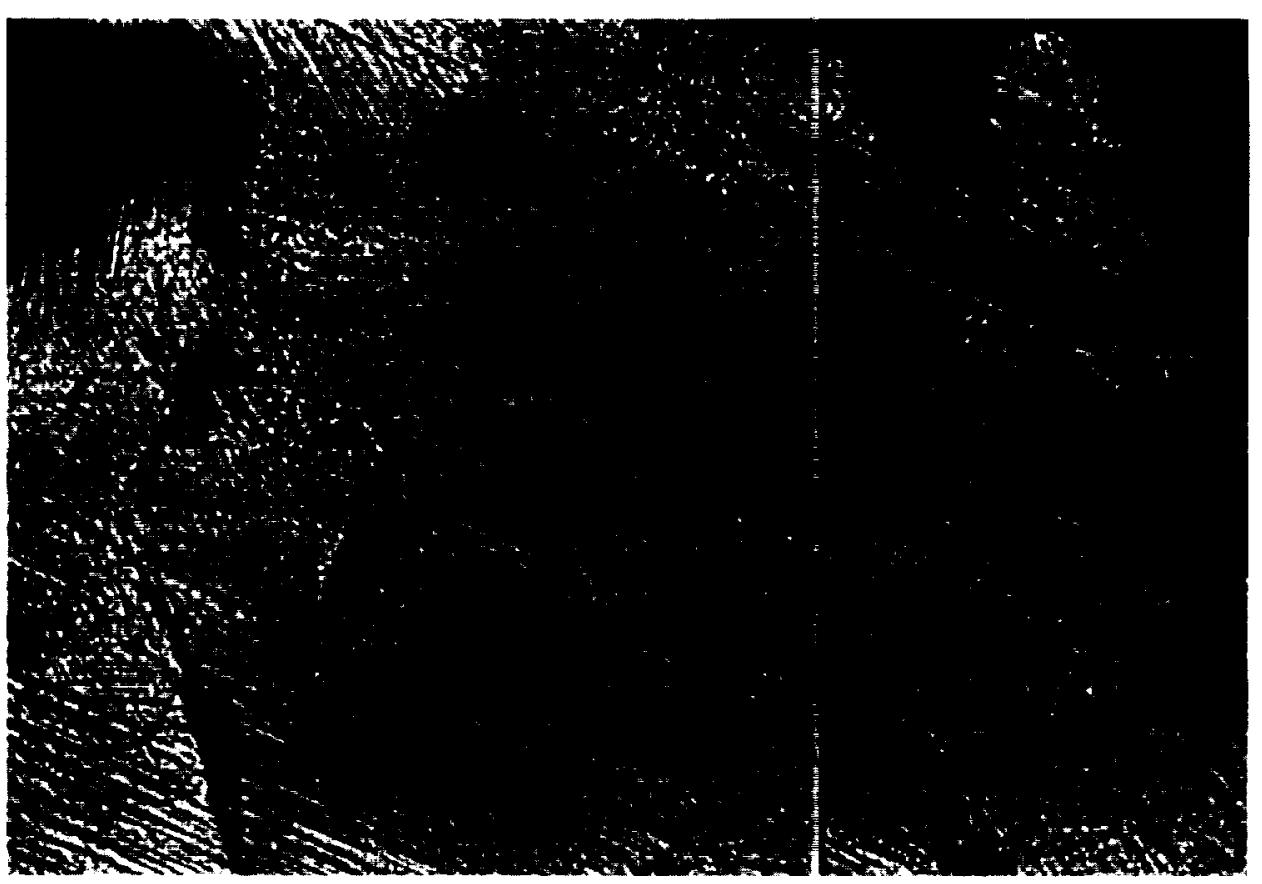

Fig. 4.27. Quartz; multiple PDFs, fresh. Photomicrograph showing at least four sets of fresh PDFs in a shocked quartz grain from crystalline target rocks at the Lake St. Martin impact structure, Manitoba (Canada). Two prominent PDF sets (northwest/southeast and west-northwest/east-southeast) are accompanied by less obvious sets oriented approximately north/south and east/west. Petrofabric measurements with a $U$-stage show that the PDFs are oriented parallel to both $\omega\{10 \overline{1} 3\}$ and $\pi\{10 \overline{1} 2\}$, indicating moderately high shock pressures (>15 GPa). Patches of diaplectic glass, associated with the shocked quartz, appear as dark zones (e.g., upper right). Width of field is $\sim 100 \mu \mathrm{m}$. Photograph courtesy of V. L. Sharpton (cross-polarized light). 
were immediately destroyed by postshock melting. The unique shock effects observed in sedimentary rocks can still provide conclusive evidence for an impact origin [e.g., at Barringer Meteor Crater (Arizona) (Kieffer, 1971)], but the details of such occurrences cannot be accurately interpreted on the basis of results from shocked nonporous crystalline rocks (Grieve et al., 1996).

\subsection{PLANAR MICROSTRUCTURES IN FELDSPAR AND OTHER MINERALS}

Similar planar microstructures are produced by shock in many other minerals (e.g., Stöffler, 1972, 1974), but such features have been less used as indicators of meteorite impact. Feldspars of all kinds (both alkali varieties and plagioclase) display various shock-produced planar microstructures: fractures, deformation bands, kink bands, and actual PDFs. Frequently, short and closely spaced PDFs may be combined with longer and more widely spaced features (deformation bands or albite twinning) to produce a distinctive ladder texture (Figs. 4.28, 4.29, and 4.30).

Although several studies have been made of shock-produced planar features in feldspars (e.g., Stöffer, 1967, 1972; papers in French and Short, 1968), these features have been less studied and less well characterized than those in quartz. There are several reasons for this: the greater diversity and complexity of such features, the greater optical complexity (biaxial) of feldspars, and the common secondary alteration of the feldspar and its planar features to clays, iron oxides, etc. (Figs. 4.29 and 4.30). Another factor in studies focused on identifying new impact structures is the fact that shocked feldspar in crystalline rocks is generally associated with shocked quartz, whose features (especially PDFs) provide a quicker and simpler method for establishing an impact origin.

Planar microstructures, both planar fractures and true PDFs, have also been observed in other minerals, including pyroxene, amphiboles, and several accessory phases (apatite, sillimanite, cordierite, garnet, scapolite, and zircon) (Stöffler, 1972). Less is known about PDF formation and orientations in these minerals, because appropriate rocks are less abundant in most impact structures, and because the specific minerals have not been studied in detail. However, recognition of shock-produced PDFs in zircon has been especially important in applying U-Th-Pb dating methods to individual zircons in shocked target rocks to determine the ages of impact structures (e.g., Krogh et al., 1984, 1993; Kamo and Krogh, 1995).

The development of distinctive shock-metamorphic features such as PDFs in denser mafic minerals like amphibole, pyroxene, and olivine apparently occurs at higher pressures and over a more limited pressure range than in quartz and feldspar. At pressures $<30 \mathrm{GPa}$, sufficient to form PDFs in both quartz and feldspar, the most common shock effects observed in mafic minerals are planar fractures, mechanical twins, and general comminution (Stöfler, 1972); features

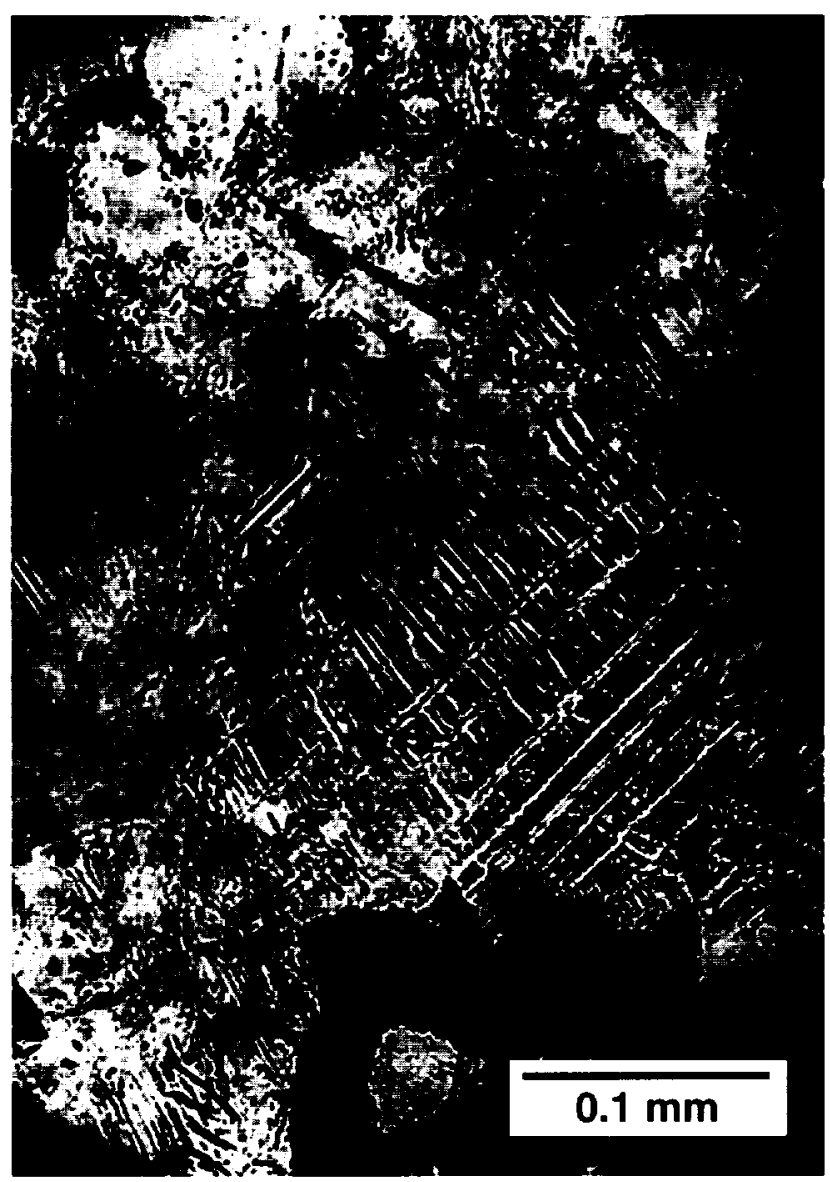

Fig. 4.28. Feldspar; multiple PDFs and diaplectic glass (maskelynite). Shocked plagioclase feldspar grain from the Ries Crater (Germany), showing development of multiple sets of PDFs (lower right) and gradational conversion of the same crystal to diaplectic glass (maskelynite) (upper left). Original polysynthetic albite twin lamellae (northwest/southeast) are still preserved in part of the crystal (lower right), but alternate twin lamellae have either been converted to maskelynite (clear) or are crosscut by short, closely spaced PDFs to form a distinctive "ladder" structure. Elsewhere in the crystal (upper left), both the original twins and the subsequent shock-produced PDFs disappear, and the whole crystal consists of maskelynite. Sample from a moderately shocked amphibolite fragment in suevite breccia. From Stoffler (1966), Fig. 4 (plane-polarized light).

resembling true PDFs are only rarely observed. At higher pressures, mafic minerals in naturally and experimentally shocked basalts generally show only extreme comminution, accompanied by the melting and flow of associated feldspar (Kieffer et al., 1976b; Schaal and Hörz, 1977). PDFs are therefore unlikely to be observed in mafic minerals in impact structures. The higher pressures apparently required for their formation imply that they will form in a correspondingly smaller volume of shocked rock in the structure. Furthermore, the higher shock pressures required are closer to pressures that produce partial to complete melting of the rock, so that PDFs, even if formed, would not survive any subsequent melting episode. 


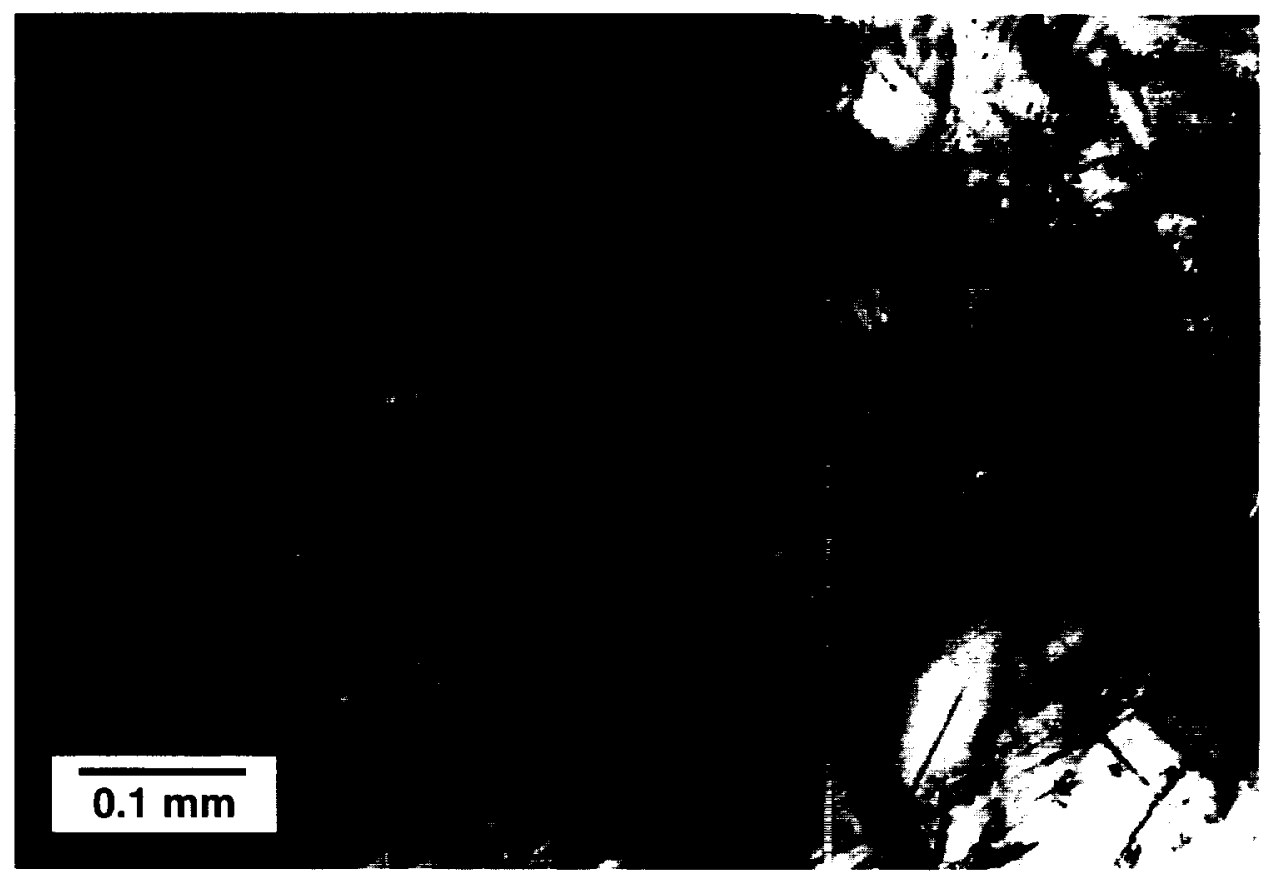

Fig. 4.29. Feldspar; multiple PDFs, "ladder” texture. Shocked K-feldspar, showi in multiple sets of altered PDFs. Two types of planar deformation features are present: (1) long, thicker, widely spaced planes (clear area;, approximately east/west) that may be deformation bands or kink bands; (2) short, narrower, closely spaced features (northeast/southwest and north-northwest/south-southeast) that combine with the first type to form a distinctive "ladder" texture. The planar features have a bı ownish-red color, possibly caused by altcration of the feldspar to clay minerals and iron oxides. Sample from a small granitic gneiss inclusion in the Onaping Formation "Black Member" from the type locality, Onaping Falls (Highway 144, Dowling Township), northwestern corner of the Sudbury structure (Canada). Photograph courtesy of N. M. Short. Sample CSF-66-39 (cross-polarized light).

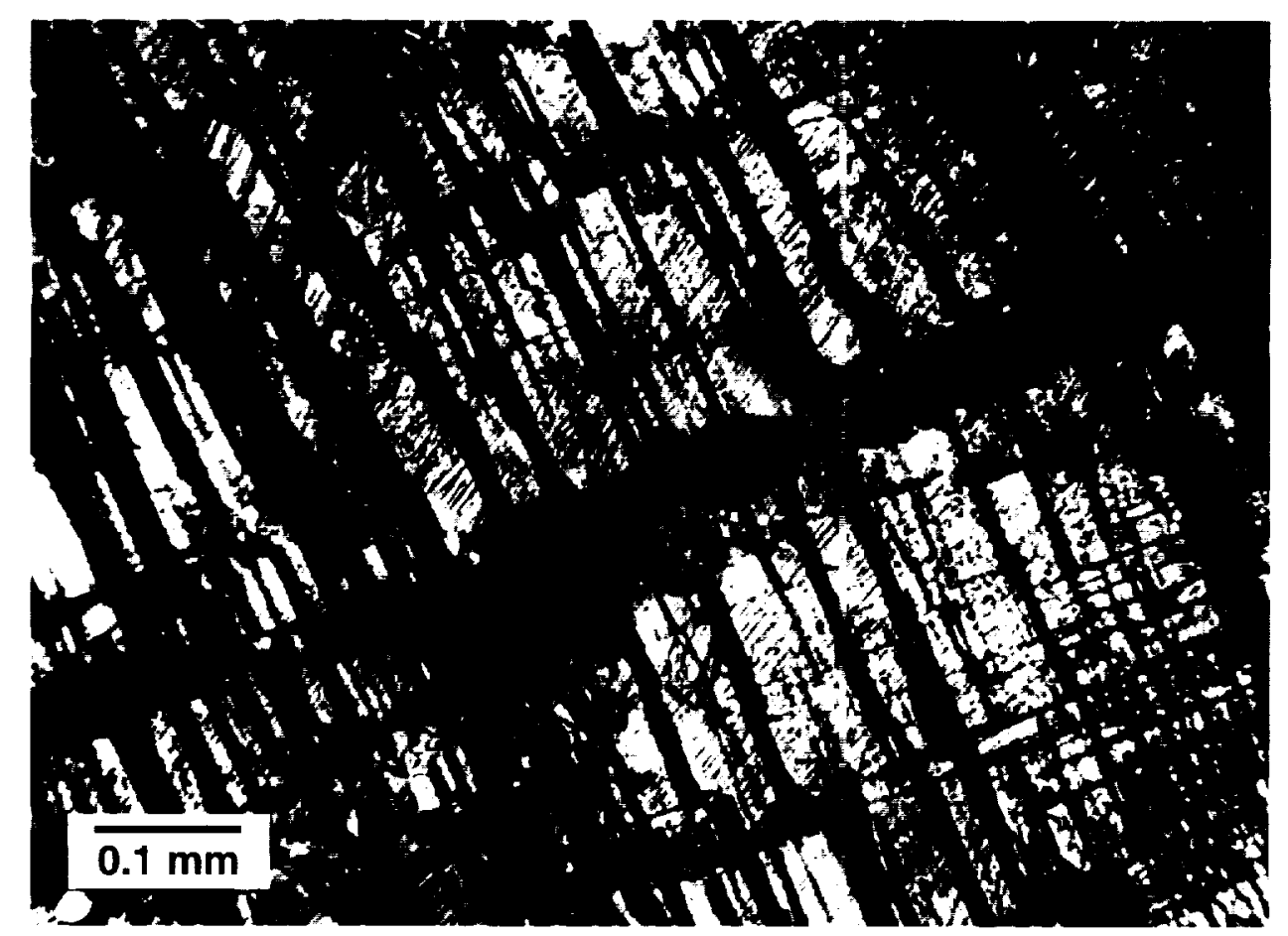

Fig. 4.30. Feldspar; twinning and PDFs. Large deformed feldspar crystal (microcline?) in granitic fragment in suevite breccia. Original twinning in the feldspar (light/dark pattern, northwest/southeast) is deformed and faulted along multiple parallel fractures (east-northeast/ west-southwest). Elsewhere, the feldspar is cut by a single set of short, narrow, closely spaced planar features (northeast/southwest) that may be actual PDFs. Sample from a small block of granitic gneiss from the Onaping Formation "Black Member," Sudbury (Canada). Sample CSF-67-73 (cross-polarized light). 


\subsection{SHOCK ISOTROPIZATION AND DIAPLECTIC GLASSES}

Planar microstructures form at relatively low shock pressures (>7-35 GPa) (Table 4.2) (Stöffler and Langenborst, 1994) and involve only partial and localized deformation of the host crystal. PDFs, which develop in the upper part of this range (10-35 GPa), involve actual conversion of the quartz crystal structure to an amorphous phase within the individual planes. Higher shock pressures (35-45 GPa), which transmit more energy into the crystal, do not form PDFs. Instead, the shock waves convert the entire crystal to an amorphous (glassy) phase.

This shock-produced diaplectic glass (also called thetomorphic glass) (Stöfler, 1966, 1967, 1972, 1984; Cbao, 1967; papers in French and Short, 1968) is completely different from conventional glasses produced by melting a mineral to a liquid at temperatures above its melting point. Diaplectic glasses do not melt or flow; they preserve the original textures of the crystal and the original fabric of the mineral in the rock. In addition, although diaplectic glasses are optically isotropic (i.e., they show no birefringence when examined petrographically under crossed polarizers), studies of quartz and feldspar diaplectic glasses by $\mathrm{X}$-ray diffraction and infrared spectrometry have shown that they retain much of the ordered atomic structure of the original crystal (e.g., Bunch et al., 1967, 1968; Stöfler, 1974, 1984; Arndt et al., 1982).
Samples of diaplectic feldspar glasses have also been experimentally annealed by heating at ambient pressure to produce original single crystals (Bunch et al., 1967, 1968; Arndt et al., 1982) or microcrystalline aggregates that preserve the shapes of the original feldspar crystals (Arndt et al., 1982; Ostertag and Stöffler, 1982).

Quartz and feldspar are the most common examples of minerals converted to diaplectic glasses by shock waves. Diaplectic plagioclase feldspar glass, called maskelynite, was in fact observed in meteorites more than a century before it was discovered in shocked terrestrial rocks. The same material, often well preserved, is also observed at several impact structures where highly shocked rocks are preserved, e.g., the Ries Crater (Germany) (Figs. 4.28, 4.32, and 4.33) and Manicouagan (Canada) (Fig. 4.31).

In these occurrences, the unique textures of the diaplectic glasses clearly indicate formation without melting to the liquid state. The overall grain fabric of the rock is unchanged, and the diaplectic glasses preserve the shapes of the original quartz and feldspar grains. In some grains, the transformation to diaplectic glass is incomplete, and areas of relict birefringence remain in the otherwise isotropic material (Figs. 4.28 and 4.31). In some shocked plagioclase grains, one set of alternating albite twins is converted to maskelynite, while the twins of the other set remain birefringent. Other minerals (e.g., amphibole, garnet, micas), associated with (or even in contact with) grains of diaplectic glass, show little

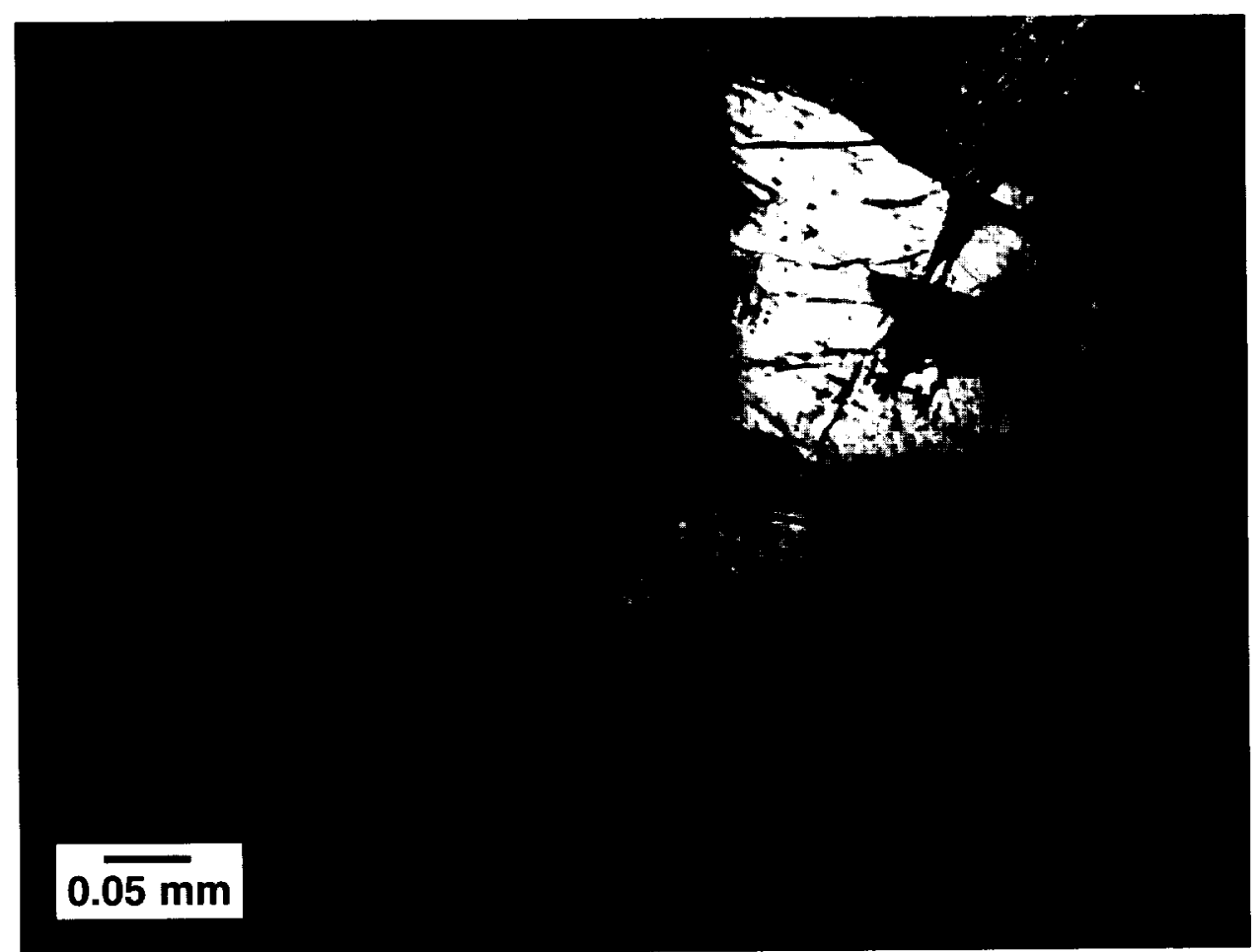

Fig. 4.31. Feldspar; diaplectic glass (maskelynite). Shocked plagioclase feldspar, partially converted to isotropic diaplectic feldspar glass (maskelynite). Parts of the original coarse feldspar grains remain crystalline and birefringent (light areas); these regions grade into adjoining areas of maskelynite (dark). Drill-core sample from coarse-grained basement anorthosite, exposed in the central uplift of the Manicouagan structure (Canada). Photograph courtesy of M. R. Dence. Sample DMM-73-63B (cross-polarized light). 


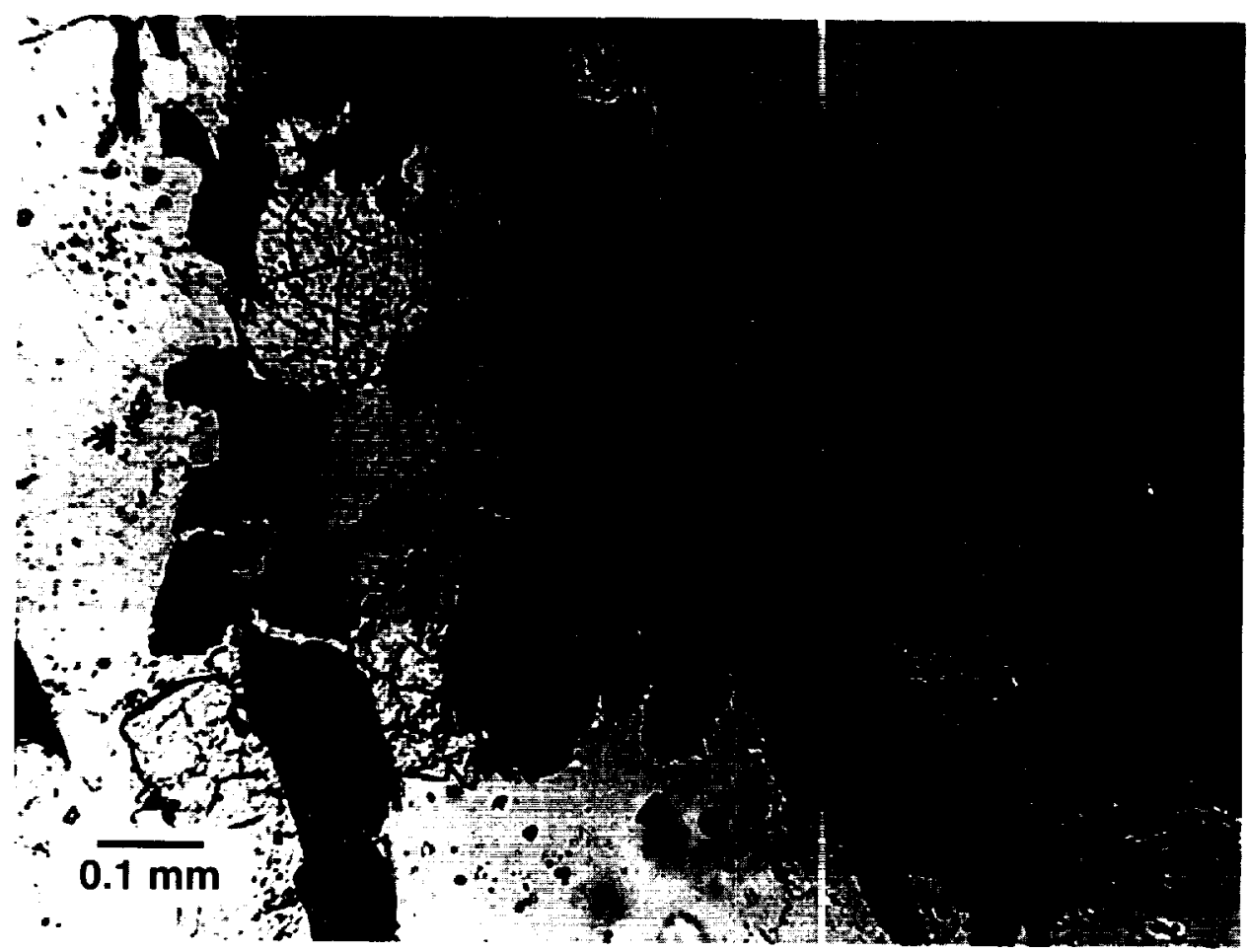

Fig. 4.32. Feldspar and quartz; diaplectic glasses. Biotite gneiss containing diaplectic feldspar glass (maskelynite) (clear, low relief; e.g., upper right) and diaplectic quartz glass (clear, higher relief, e.g., lower right). The associated biotite crystals (dark) have retained their original shape and have remained crystalline and birefringent, despite the corr plete transformation of adjacent quartz and plagioclase into glassy phases (compare with Fig. 4.33). Biotite gneiss inclusion in suevite b eccia, Otting, Ries Crater (Germany). From Stöfler (1967), Fig. 12a. Photograph courtesy of D. Stöffler (plane-polarized light).

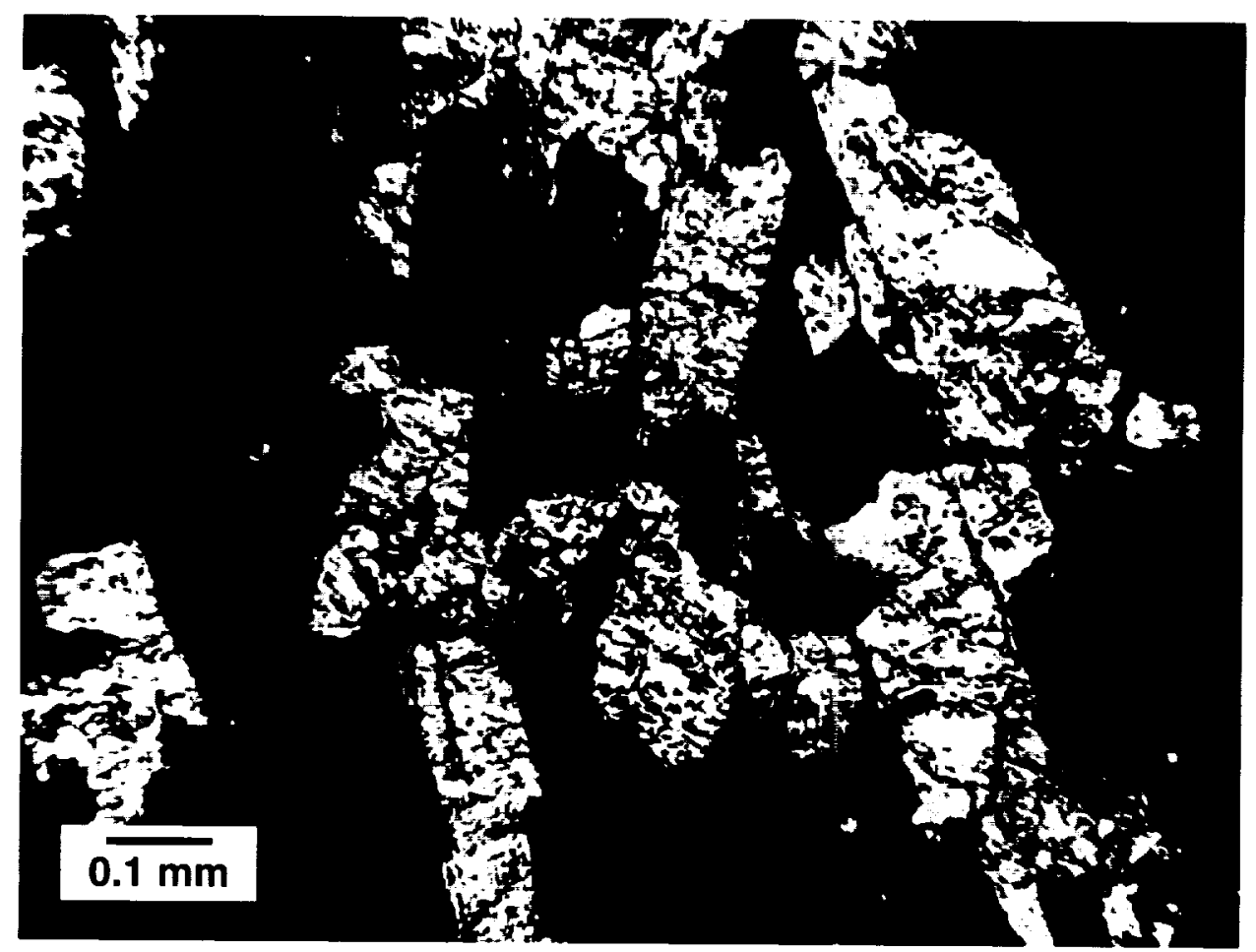

Fig. 4.33. Feldspar and quartz; diaplectic glasses. Biotite gneiss containing diaplec ic feldspar glass (maskelynite) and diaplectic quartz glass (compare with Fig. 4.32). Both phases are isotropic (dark) under crossed pola izers. The associated biotite crystals have retained their original shape and have remained crystalline and birefringent, despite the compls te transformation of adjacent quartz and plagioclase into glassy phases. Biotite gneiss inclusion in suevite breccia, Otting, Ries Crater (Germany). From Stöfler (1967), Fig. 12b. Photograph courtesy of D. Stöffler (cross-polarized light). 


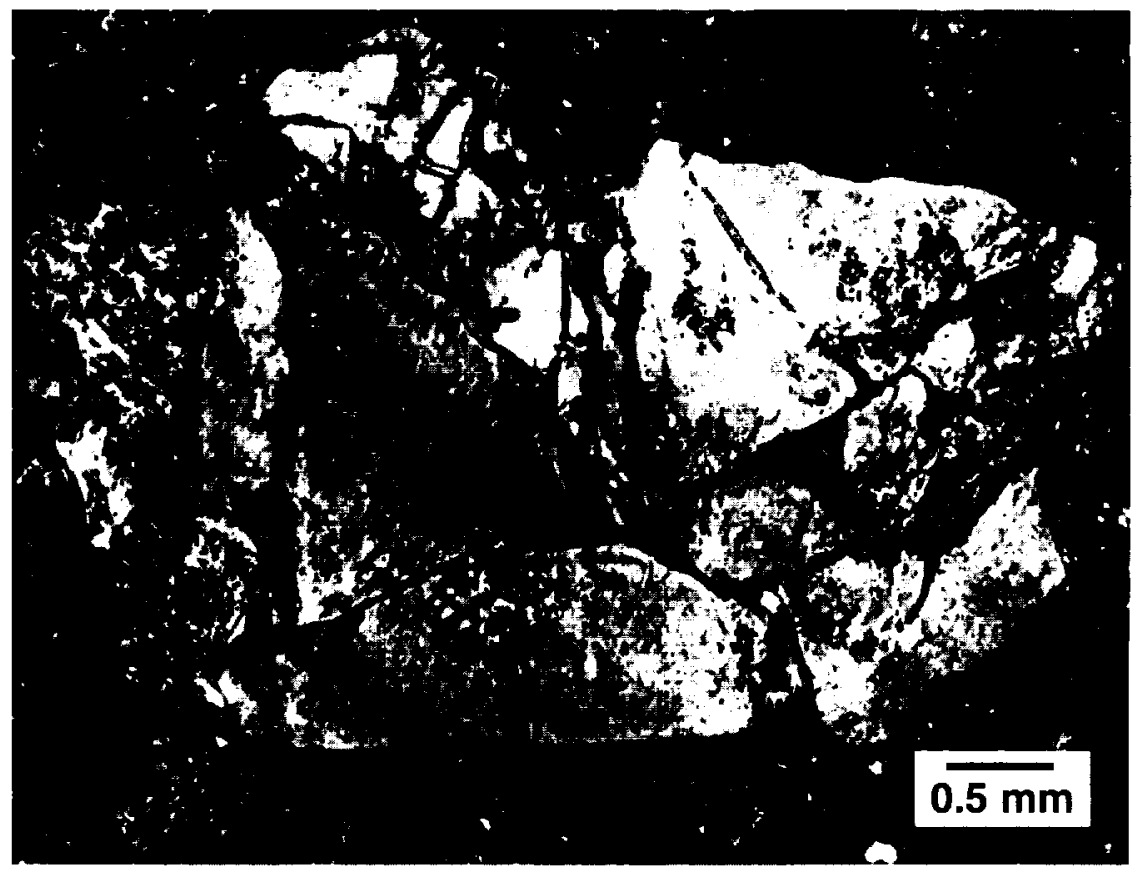

Fig. 4.34. Feldspar; possible diaplectic glass, recrystallized. Large, highly deformed and recrystallized feldspar clast in suevite breccia, surrounded by finer fragments in an opaque carbon-bearing matrix. The feldspar shows deformation and recrystallization throughout, as indicated by the intensely mosaic extinction. The crystal is subdivided by thin irregular zones of nearly isotropic material, possibly original melt. Plastic behavior of the fragment is also suggested by indentations of the matrix into the clast (e.g., at top). This clast can be interpreted as a fragment of diaplectic feldspar glass that has subsequently been recrystallized to form a fine-grained microcrystalline texture that is still similar to the original crystal. Similar reactions have been produced in experimentally annealed maskelynite. Another possibility is that the fragment was shock-heated above its melting point, but was rapidly quenched (perhaps during deposition) before extensive flow could occur. In any case, the unusual texture has been preserved despite subsequent metamorphism of the unit in which it occurs. Fragment in Onaping Formation "Black Member" from type locality, Onaping Falls (Highway 144, Dowling Township), northwestern corner of Sudbury structure (Canada). Sample CSF-66-37-2 (cross-polarized light).

deformation and retain their original form (Figs. 4.32 and 4.33), although they may show reduced birefringence and reddening produced by the formation of hematite (e.g., Feldman, 1994) and cordierite (Stäble, 1973).

Diaplectic glasses formed from other minerals (e.g., scapolite) have rarely been observed. Mafic minerals (e.g., pyroxene, amphibole, and biotite) do not seem to form diaplectic glasses, probably because the pressures required are higher than those for quartz and feldspar, high enough so that shockproduced melting occurs instead.

Diaplectic quartz and feldspar glasses are metastable. They apparently do not survive if they are exposed to even relatively mild postimpact thermal effects. Diaplectic glasses are not observed in impact structures that have been even slightly metamorphosed, even though decorated PDFs may still be preserved in associated quartz. In such settings, instead of diaplectic glasses, one observes quartz and feldspar grains that are recrystallized to microcrystalline aggregates that replace the original crystal (Figs. 4.34, 4.35, and 4.36). Textures in the altered feldspars sometimes suggest intense plastic deformation and flow within the original grain. These features are often accompanied by the development of plumose or spherulitic microcrystalline textures that may reflect significant thermal effects as well. Such grains of quartz and feldspar have been tentatively interpreted as original diaplectic glasses that have been annealed and recrystallized, either by immediate postshock thermal effects or by subsequent metamorphism (McIntyre, 1968; French, 1968b, pp. 401-404).

\subsection{SELECTIVE MINERAL MELTING}

The high-pressure (35-45 GPa) shock waves that produce diaplectic glasses also generate significant and sudden postshock temperature rises of several hundred degrees Celsius in the rocks and minerals through which they pass (Fig. 4.1). In the region of diaplectic glass formation, postshock temperatures are still low enough $\left(300^{\circ}-900^{\circ} \mathrm{C}\right)$ that virtually no actual melting occurs, and rapidly quenched samples of diaplectic glasses suffer no further immediate alteration. However, at slightly higher shock pressures $(\sim 45-50 \mathrm{GPa})$, the higher postshock temperatures $\left(\geq 1000^{\circ} \mathrm{C}\right)$ begin to exceed the melting points of typical rock-forming minerals, and distinctive localized melting effects appear in the affected rocks.

This shock-produced selective mineral melting differs significantly from normal equilibrium melting. Under nor- 


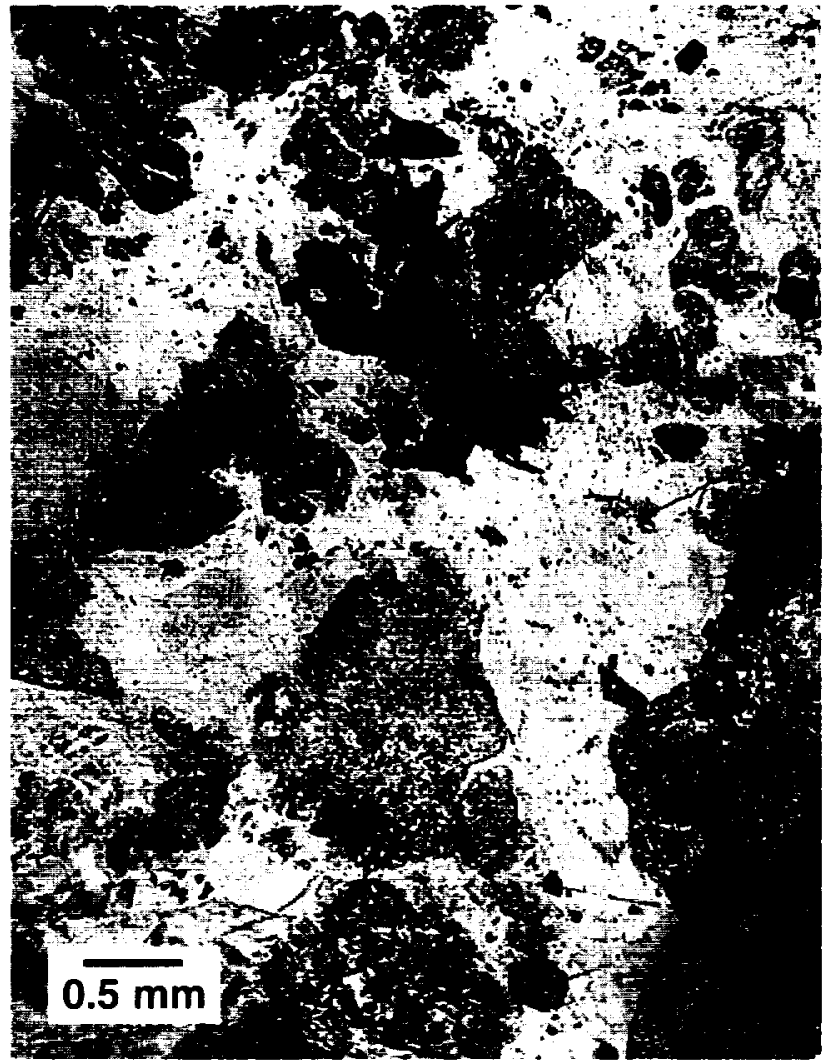

Fig. 4.35. Feldspar; possible diaplectic glass, recrystallized. Shock-deformed and recrystallized feldspar and quartz from a coarse-grained granitic fragment in suevite breccia. Large original quartz grains (lower center; gray, higher relief) are recrystallized to finely crystalline mosaic quartz. Original feldspar grains (clear, lower relief) are generally finely recrystallized and virtually isotropic in some areas (compare with Fig. 4.36), although some areas of original feldspar crystals are preserved. From granitic inclusion in Onaping Formation "Black Member" at type locality, Onaping Falls (Highway 144, Dowling Township), northwestern corner of Sudbury structure (Canada). Sample CSF-66-50-13 (planepolarized light).

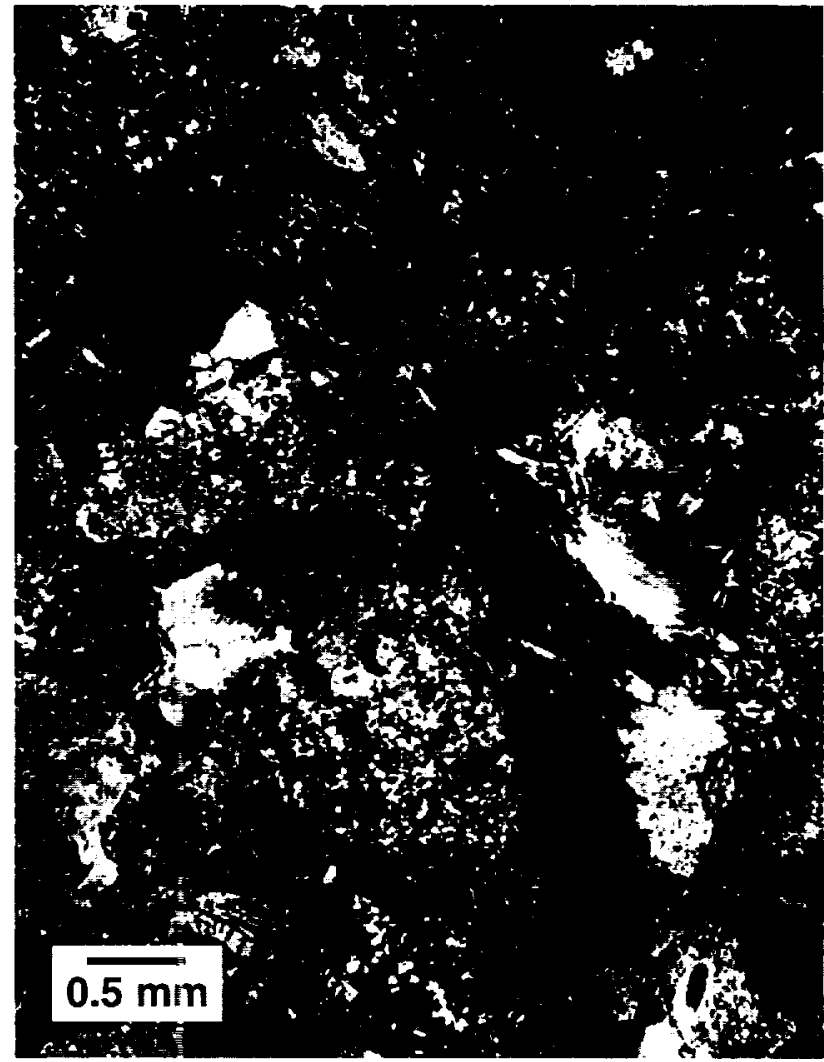

Fig. 4.36. Teldspar; possible diaplectic glass, recrystallized. Shock-defor:ned and recrystallized feldspar and quartz from a granitic fragr nent in suevite breccia. Large original quartz grains are recrystal ized to finely crystalline mosaic quartz. Original feldspar grai is are generally finely recrystallized and virtually jsotropic in s me areas, although some areas of original feldspar crystals are p eserved (compare with Fig. 4.35). In one such area (right center), a plagioclase crystal has been plastically deformed, bending the original polysynthetic albite twinning (light/dark bands) throu th a large angle. Despite the intense deformation of quartz and $f_{\mathrm{e}}$ ldspar, a single apatite grain (lower right) shows no deformation. Sample from granitic inclusion in Onaping Formation "Black Mem ser" at type locality, Onaping Falls (Highway 144, Dowling Township), northwestern corner of Sudbury structure (Canada). Sa nple CSF-66-50-13 (cross-polarized light).

nal mineral before any flow or mixing takes place, and the melt region: will initially be distributed through the rock in the same patern as the original mineral grains.

Selective melting therefore produces unusual textures in which one $\mathrm{r}$ more minerals in a rock show typical melting features wh:le others - even immediately adjacent ones do not. Sho cked granitic inclusions from the Ries Crater (Germany) iequently show a texture in which feldspar has melted, flov ed, and vesiculated, but the adjacent quartz remains in the form of unmelted diaplectic glass (Cbao, 1967; Stöfler, 1972, 1984). Similar textures can be preserved even in subsequently metamorphosed rocks, in which flowed and recrystallized feldspar is accompanied by recrystallized but undeformed grains of quartz (Fig. 4.37). 
At higher shock pressures, where temperatures are higher and cooling times may be longer, these selective melting textures may be complicated by the effects of normal eutectic melting at grain boundaries (Fig. 4.37). In some shocked rocks, postshock temperatures may exceed the melting points of all the minerals present, and the rock will melt to a mixture of heterogeneous glasses that may preserve (depending on the amount of subsequent flow and mixing) the original shapes and mineral compositions. If such rocks are quenched before flow and mixing can occur, the chemically diverse glasses can survive and be recognized, even after significant metamorphism (Fig. 4.38) (Peredery, 1972).
Such distinctive selective melting textures are relatively uncommon in rocks from impact structures. The region of shock pressures that produces them is relatively narrow $(\sim 45-$ $55 \mathrm{GPa}$ ), and their preservation, once formed, requires rapid quenching, most commonly as small inclusions in crater-fill breccias. At progressively higher shock pressures ( $255 \mathrm{GPa}$ ), postshock temperatures increase rapidly, melting becomes complete, flow and mixing processes become dominant in the melted rock, and more chemically homogeneous bodies of impact melt are produced (see Chapter 6).

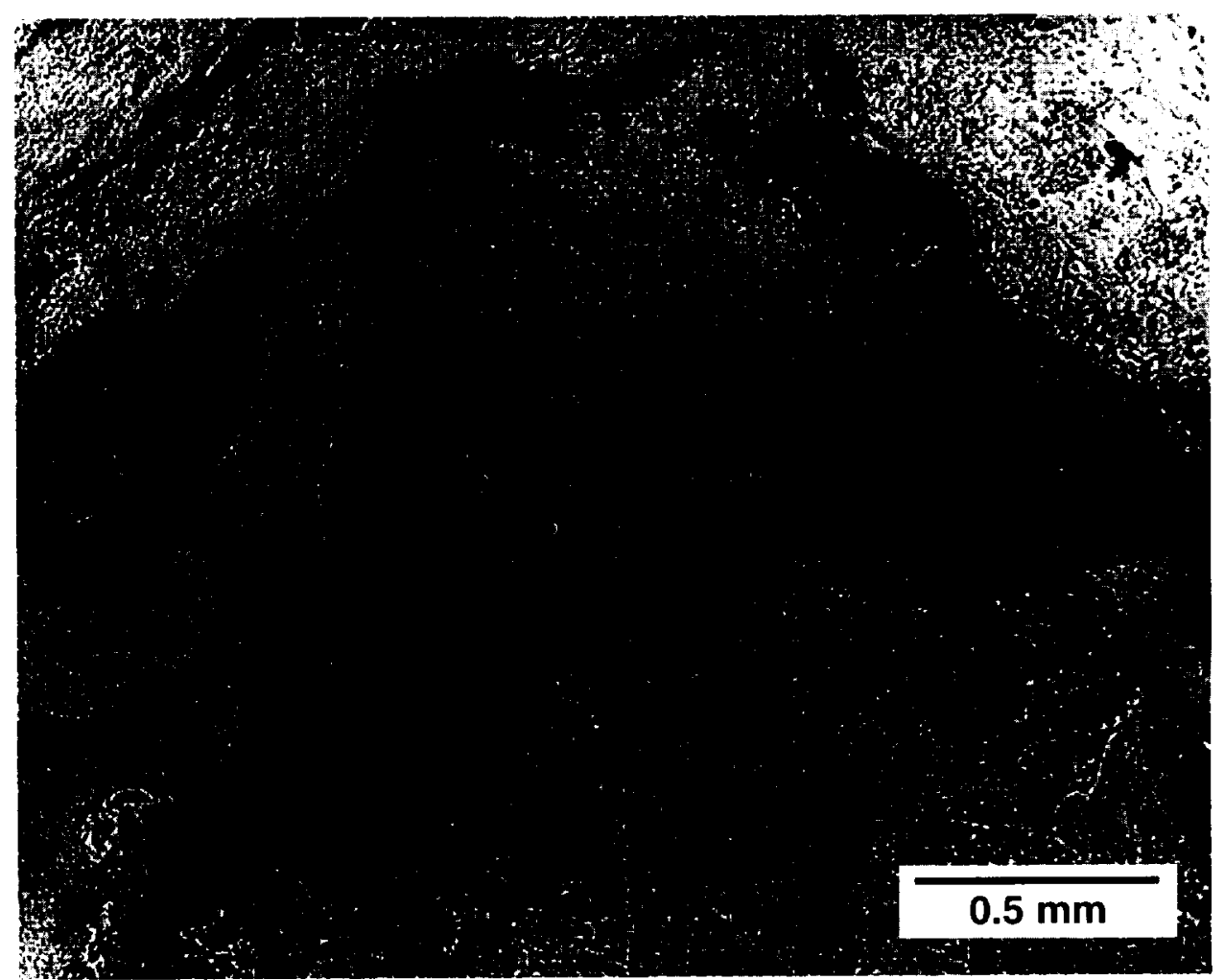

Fig. 4.37. High-temperature effects; plastic deformation, grain-boundary melting. Highly shocked and recrystallized quartzofeldspathic inclusion in metamor phosed suevite breccia, showing extreme deformation of quartz and feldspar. Quartz (gray, higher relief, lower right) is recrystallized to a fine mosaic of small quartz grains. Feldspar (clear, lower relief, top) shows intense, contorted flow structure, indicating either incipient melting or extreme plastic flow. Definite incipient melting has occurred at the grain boundaries, forming a brown melt (dark) with lath-like microlites (white; feldspar?). (Circular feature at center is a bubble in the thin section.) Coarse-grained granitic inclusion in Onaping Formation "Black Member," Sudbury structure (Canada). Sample CSF-67-67 (plane-polarized light). 


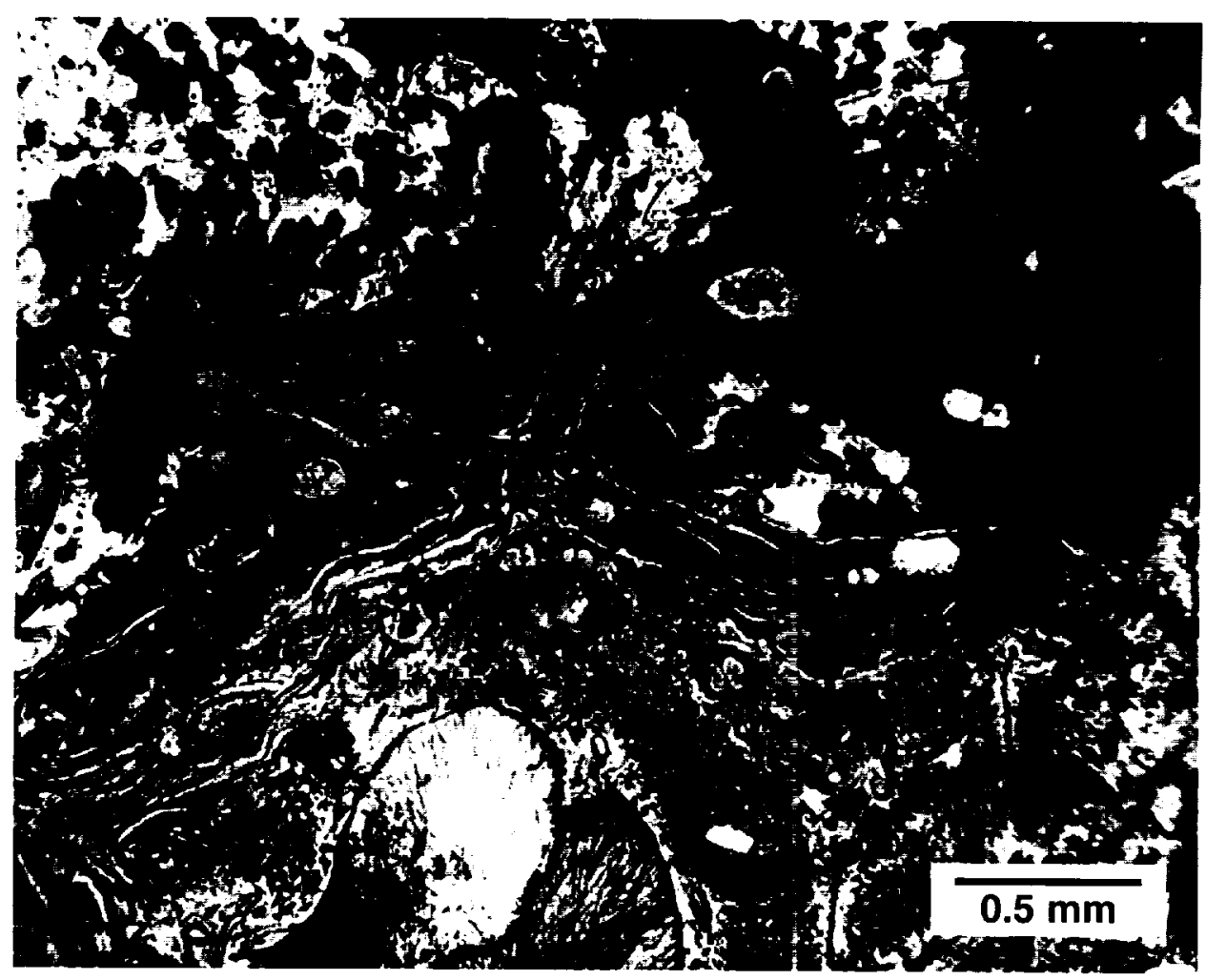

Fig. 4.38. High-temperature effects; complete melting. Highly shocked, melted, ind recrystallized rock inclusion in metamorphosed suevite breccia. Postshock temperatures apparently exceeded the melting points of all component minerals, converting the originally crystalline rock into an initially heterogeneous glass that developed limited flow textures before it was quenched. The inclusion was subsequently recrystallized to secondary minerals such as quartz, feldspar, amphibo: a, and chlorite, but the original mineralogy and the character of the shock-formed heterogeneous glass are still detectable in the distribut on and chemical variations in the secondary mineral assemblage. Inclusion in Onaping Formation "Black Member" at the type locality, Onaping Falls (Highway 144, Dowling Township), northwestern corner of Sudbury structure (Canada). Sample CSF-66-50-3 (plane-jrolarized light). 


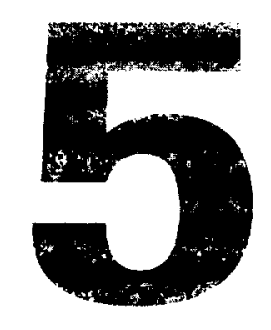

\section{Shock-Metamorphosed Rocks (Impactites) in Impact Structures}

\subsection{ROCK TYPES IN THE FINAL IMPACT STRUCTURE}

A wide variety of distinctive rock types - breccias, melts, and shock-metamorphosed target rocks - are produced during formation of impact structures. The classification of these complex and diverse rocks is an active and muchdebated activity (see below). However, the general term impactite is used here as a convenient overall designation for all rocks affected by, or produced by, the shock waves and other processes generated by hypervelocity meteorite impact events.

Different varieties of impactites are produced at different times during the impact process, and they occur in different locations beneath, within, and around the final impact structure. The diverse features of impactites reflect, in varying ways, different aspects of the impact event itself: (1) the initial shock-wave distribution around the impact point; (2) the subsequent excavation flow, formation of the transient crater, and ejection of material from it; (3) the crater modification processes. The general model described below will be modified, in actual impact structures, by such individual factors as the target lithology, stratigraphy, and the nature and impact angle of the projectile, but the model provides a general basis for the identification and classification of impactites (see also Dence, 1968; Grieve, 1991; Stöffler et al., 1988).

The basic distribution of shock-wave pressures around the impact point is largely established by the end of the contact/compression stage. The expanding shock waves deposit energy continuously in the target rocks through which they pass, and both their peak pressures and the resulting postshock temperatures drop rapidly with distance from the impact point. As the contact/compression stage ends, and the transient crater begins to form, the zones of shock pressure form a series of approximately hemispherical shells around the impact point, with the peak shock pressure decreasing rapidly outward (Fig. 3.2).

During the subsequent excavation stage and formation of the transient crater, virtually all the target rock exposed to shock pressures of $\geq 25-30 \mathrm{GPa}$, which now consists of a mixture of vapor, superheated rock melt, and coherent but highly shocked target rock, is broken up and accelerated outward (Dence, 1968; Dence et al., 1977; Grieve and Cintala, 1981). Because the excavation flow lines cut across the originally hemispherical shock-pressure zones (Fig. 3.4), the excavated material will consist of a mixture of target rocks subjected to widely differing shock pressures and showing a wide range of shock effects. A melt-rich portion flows downward and outward from the center to form a coating along the floor and walls of the growing crater (Grieve et al., 1977). The remainder, a mixture of rock fragments and smaller bodies of melt, is impelled outward from the center of the cavity. Much of this material may be entirely ejected from the transient crater; some may remain within the crater as a unit of mixed rubble and melt above the fractured crater floor.

The subcrater rocks beneath the zone of excavation are subjected to lower shock pressures ( $\leq 30 \mathrm{GPa})$, and the dominant effects produced are shatter cones, brecciation, and inplace fracturing. As the upper part of the target rocks are excavated from the transient crater, these rocks are displaced downward, more or less coherently, to form the floor of the transient crater and the zone of parautochthonous rocks beneath it.

The final modification of the transient crater into a simple or complex impact structure involves several distinct gravity-related processes that influence the distribution of impactite units: (1) rapid relative movements of large blocks of subcrater target rocks downward, inward, and upward along relatively narrow faults; (2) collapse of oversteepened 
crater walls into the crater cavity; (3) deposition of a minor amount of ejected material within the crater. The first process may create additional breccias and related rock types beneath the crater. The other two processes produce a large portion of the crater-fill deposits, which are characterized by a generally fragmental character and the presence of shockmetamorphic effects that range from simple fracturing to complete melting.

\subsection{CLASSIFICATION OF IMPACTITES}

The definition and classification of impact-produced materials, both individual rock fragments and large formations, is a complex, longstanding, and difficult subject (for details, see Stöffler, 1971; Stöfler et al., 1979; Taylor et al., 1991; Stöfler and Grieve, 1994, 1996; Reimold, 1995). No attempt will be made here to develop a complete and unanimously acceptable system. The simplified system presented here emphasizes field and petrologic characteristics and is based, as far as possible, on objective features that are observable in outcrop, hand specimen, and thin section. This classification also uses, as much as possible, traditional terms already applied to equivalent rocks (e.g., breccias, melt rocks) formed by common geological processes. Although this system is generally consistent with more detailed classifications (e.g., Stöfler and Grieve, 1994), it is restricted to terrestrial rock types produced in single impact events and does not consider the special complexities of cratering on other planets, including the effects of multiple impacts or the absence of an atmosphere (see Taylor et al., 1991; Stöffler and Grieve, 1994, 1996).

The term impactite is used here to designate all rocks produced during an impact event, including shock-metamorphosed (but still recognizable) target rocks (both in place and as fragments in breccias), breccias, and impact melts. Under this umbrella, the classification and terminology of impactite formations are based on a few key features: location with respect to the crater, source(s) of component materials, and lithologic characteristics (Table 5.1).

More detailed discriminators, used in other classifications, include (1) particle sizes and size ranges; (2) relative percentages of components in breccias, e.g., ratios of fragments/ matrix, and lithic/glassy fragments; (3) shock-metamorphic effects in individual breccia fragments (both the shock level in individual fragments and the range of shock effects in multiple fragments); and (4) textures and crystallinity of melt rocks.

In earlier discussions of impactites and the cratering process (Dence, 1965, 1968; Grieve, 1991), a fundamental and useful distinction has been made between the parautochthonous rocks beneath the crater floor and the allogenic (or allochthonous) units (breccias and melt rocks) that fill the crater (crater-fill units) and form the units of ejecta outside it (Figs. 3.7 and 3.13). The observed characteristics of these different rock types are frequently distinctive enough that they can be listinguished, even in isolated hand specimens or outcrops.

The parc utochthonous rocks beneath the crater have remained re atively coherent during crater formation, although they have been deformed and displaced. These rocks, which corre: pond to the lower displaced zone of the transient crater, are subjected to relatively lower shock pressures, and ot served shock-deformation effects are generally limited to fri cturing, brecciation, and the formation of shatter cones, a though higher-pressure mineral-deformation features may be developed in a relatively small volume beneath the criter floor. The allogenic rocks, chiefly breccias and melts, th at fill the crater and make up the ejecta beyond the crater ri n, are characterized by a more diverse lithology, a fragniental or melted character, and a wide range of observed hock effects. In particular, the crater-fill breccias are a cor nplex mixture of materials with different histories of shock pressures and transport: unshocked rocks derived fronı the distant parts of the crater rim and walls, more highly shocked and melted fragments excavated from the transien: crater and redeposited, and large and small bodies of im sact-generated melt.

The follo wing sections discuss impactites on the basis of location wi h respect to the impact structure: (1) $s u b-$ crater: para itochthonous rocks, cross-cutting allogenic units, and jseudotachylite; (2) crater interior: allogenic crater-fill de posits (lithic breccias, suevite breccias, and impact melt b eccias); (3) crater rim region: proximal ejecta deposits; $(4$ distant from crater: distal ejecta. A detailed discussion o: impact melt rocks in these different environments is pro rided in Chapter 7.

\subsection{SUBCRATER ROCKS}

\subsubsection{For nation Conditions}

During $f$ rrmation of the transient crater, the rocks located in the lisplaced zone below the zone of excavation are driven dow: wward and outward, more or less coherently (Fig. 3.4), b it they are not completely broken up or excavated. Instea 1 , they are deformed, thinned, and moved downward and ou ward as the transient crater forms, and then (in the central $\mathrm{f}$ arts of larger structures) rapidly elevated as the central uplif: forms (Dence, 1968; Dence et al., 1977; Kieffer and Simonds 1980; Grieve and Cintala, 1981; Grieve et al., 1981; Stöffleret al, 1988).

During ti rese movements, the subcrater rocks are generally displacerl as large individual blocks typically tens to hundreds of me ers (or even larger) in size. However, adjacent regions with $\mathbf{n}$ this zone may display little displacement relative to each other, and original stratigraphy and structural features may be well preserved within individual blocks. The term parauteschthonous has therefore been applied to these rocks to indicate their general relative coherence.

The shock pressures imposed on the parautochthonous rocks vary uidely because of the complex relationship be- 
TABLE 5.1. Criteria for impactite classification.

1. Location with respect to crater $\left(R_{c}=\right.$ crater radius $)$

\begin{tabular}{l} 
Crater Floor and Subcrater \\
\hline $\begin{array}{l}\text { Parauthochtonous rocks: } \\
\text { target rocks (coherent) } \\
\text { lithic breccias }\end{array}$ \\
Allogenic rocks (cross-cutting) \\
breccia dikes \\
impact melt dikes \\
Pseudotachylite
\end{tabular}

\begin{tabular}{l} 
Within Crater \\
\hline Allogenic rocks: \\
Crater-fill deposits \\
(= crater-fill breccias) \\
(= "breccia lens") \\
lithic breccias \\
melt-bearing breccias \\
suevites \\
impact melt breccias \\
(= melt-matrix breccias) \\
impact melt rocks
\end{tabular}

Crater Rim and Near-Surface

Allogenic rocks:

Ejecta:

proximal $\left(<5 \mathrm{R}_{\mathrm{c}}\right)$

distal $\left(>5 \mathrm{R}_{c}\right)$

\section{Sources of component materials}

Parautochthonous rocks

Approximately in place (local). Original stratigraphy and structure (largely) preserved.
Allogenic rocks

Derived from single or multiple sources elsewhere.

\section{Breccia characteristics}
a. Fragment character
Lithic breccia
Rock/mineral fragments only
Suevite (breccia)
Melt/glass fragments present
Rock/mineral fragments
b. Fragment lithology
Monomict (breccia)
Single rock type
c. Matrix character
Clastic-matrix (breccia)
Discrete fragments
Polymict (breccia)
Multiple rock types
Impact melt breccia (= melt-matrix breccia)
Coherent melt (glassy or crystalline)

\section{Melt rock character (standard geological terms)}

Holohyaline (glassy)

Hypocrystalline (mixed glassy/crystalline)

Holocrystalline (completely crystalline)
For grain size, texture, etc., use other standard igneous rock discriminators, e.g.:

Microcrystalline

Porphyritic

Trachytic, etc. tween the original shock-wave distribution and the subsequent crater modification. Shock pressures in the parautochthonous rocks are therefore highest near the center of the structure and decrease rapidly outward toward the margin. Along the floor of the transient cavity (approximately the floor of the final crater), shock pressures may exceed 25$30 \mathrm{GPa}$ in the center, decreasing to $\leq 2 \mathrm{GPa}$ at the rim, the minimum pressure needed to excavate material from the transient crater (Grieve and Robertson, 1976; Robertson and Grieve, 1977; Kieffer and Simonds, 1980; Dressler et al., 1998). Shock pressures also drop off rapidly with increasing depth below the crater floor. In the center, pressures typically drop from about $25-30 \mathrm{GPa}$ to a few $\mathrm{GPa}$ over distances of less than a few hundred meters in small structures (Dence et al., 1977; Grieve et al., 1981) and over no more than a few kilometers in larger ones (Stöfler et al., 1988).

\subsubsection{In-Place Shock-Metamorphosed Rocks}

The shock effects preserved in the parautochthonous subcrater rocks therefore reflect a wide range of shock pressures. In a small region immediately below the central part of the crater floor (i.e., at the base of the excavation zone), 
pressures of 10-30 GPa produce distinctive microscopic deformation effects in quartz and feldspar, while creating postshock temperatures of $\leq 300^{\circ} \mathrm{C}$. In smaller impact structures, this zone of identifiably high shock pressures is less than a few hundred meters thick, partly because of the rapid decay of the original shock wave with distance from the impact point, and partly because of the subsequent compression, thinning, and displacement of the subcrater rocks during transient crater formation (Dence et al., 1977; Grieve and Cintala, 1981). Beneath this zone, lower shock pressures (possibly 2-6 GPa) produce distinctive megascopic deformation features (shatter cones) in a deeper region near the center of the crater.

Shock pressures over most of the zone of parautochthonous rocks are too low ( $\leq 2 \mathrm{GPa}$ ) to produce distinctive shock-deformation effects, but they are high enough to exceed the yield strengths of near-surface crustal rocks (typically <1-2 GPa; Kieffer and Simonds, 1980). As a result, large volumes of rock beneath the crater floor are broken and crushed during the early stages of crater formation, producing units of in-place lithic breccia that generally lack distinctive high-pressure shock-metamorphic effects. At the same time, and subsequently, larger fractures that develop in this zone may be intruded by allogenic materials (rock fragments and/or melt) to form cross-cutting dikc-like bodies (c.g., Lambert, 1981; Bischoff and Oskierski, 1987; Dressler and Sharpton, 1997).

The parautochthonous rocks below the crater may also be strongly affected by subsequent large-scale movements during the crater modification stage. Such movements may produce equally striking but different breccias. In large structures, where modification involves the development of a central uplift, deep-seated parautochthonous rocks may be suddenly uplifted for distances of hundreds of meters to sevcral kilometers. This uplift may bring distinctively shocked rocks (e.g., containing shatter cones) to the surface, where they may provide definite evidence for the impact origin of a large structure. However, these rapid movements may also generate additional varieties of breccias and destroy the original spatial relations of the parautochthonous rocks to each other, making the geology and history of the structure more difficult to decipher.

Understanding the variety of breccias in subcrater rocks is complicated by several factors (e.g., Lambert, 1981; Bischoff and Oskierski. 1987; Dressler and Sharpton, 1997). Breccias may form at valrious stages in the cratering process: (1) during the initial shock-wave expansion and transient crater formation; (2) during the subsequent modification of the transient crater, including (in large structures) movements associated with the rise of the central uplift and peripheral collapse around the rim. Even within the brief formation time of an impact crater, it is possible for multiple generations of breccia to develop and to produce distinctive crosscutting relations, even though the time between one breccia generation and the next may be measured in seconds or minutes (Lambert. 1981; Bischoff and Oskierski, 1987; Dressler and Sharpton, 1997). Another problem is melt formation; rocks can $b_{r}$ : shock-melted by the initial impact and then distributed $\mathrm{s}$ melts or melt-bearing breccias throughout the crater basen ent, but rocks can also be melted subsequently by friction $\xi$ enerated during the rapid movements of large volumes of sock involved in crater modification and central uplift forma :ion.

\subsubsection{Litlic Breccias (Parautochthonous)}

Impactit: breccias that form by the shattering and pulverizing of target rock essentially in place (autoclastic) typically form ir egular bodies tens to hundreds of meters in size, which show gradational contacts against areas of similar but more crherent target rocks. These lithic breccias are composed e tirely of rock and mineral fragments in a clastic matrix of sinaller, but similar, fragments. Fragments tend to be anguli $r$ to sharp, although fragments of softer rocks like carbonctes and shales may be well rounded. The breccias themselves tend to be poorly sorted. The fragments are derived fron local target rocks, and the breccias may be monomict $\mathrm{r}$ polymict, depending on the lithologic variety present in the nearby target rocks. Distinctive shock-metamorphic eff scts (e.g., PDFs in quartz) are generally absent in the fragr uents. The breccias show no evidence of significant trat sport, and they contain no exotic fragments or glassy material.

These ro $\mathrm{ks}$ often resemble breccias formed by more normal geologizal mechanisms such as volcanic explosions or tectonic mo rements, and their identification as impact products is often difficult and uncertain. In general, the subcrater regions of in ipact structures display highly localized and variable deformation over short distances, a close association of different kiıds of breccias developed from basement rocks, and the pres ence of allochthonous dike-like bodies of breccia and mel. This variability in deformation and rock types contrasts with the more uniform or gradational effects produced by en dogenic mechanisms. Even so, identification of these rocks as impact breccias can generally not be done directly, but depends on demonstrating their association with more highly shocked rocks whose impact origin is clear (e.g., French et al. 1997).

\subsubsection{Cruss-Cutting (Allogenic) Breccias}

Other b sdies of breccia in the subcrater rocks contain significant $\mathrm{c}$ mounts of material that have clearly been introduced into them from elsewhere, and they are therefore considered here as allogenic breccias. These bodies tend to have more regul: $r$ shapes and to show sharp contacts and clear cross-cuttin $r$ relations against the subcrater rocks. Such breccias often 0 :cur as distinctive breccia dikes, which typically range from ess than a meter to tens of meters in width and may be as $m$ uch as a kilometer long (Lambert, 1981; Bischoff and Oskierski, 1987; Dressler and Sharpton, 1997). These bodies contain fragments of target rock that are angular to rounded and range in size from $<1 \mathrm{~mm}$ to several meters. These breciias tend to be polymict, with lithologically diverse fragments, indicating mixing over distances of at least several hundred meters. In addition, they frequently contain 
significant amounts of allogenic material, such as fragments from even more distant rock units. This allogenic material is frequently derived from more central regions of the crater, often from above the present location of the dike, and it often consists of distinctive highly shocked rock fragments or melt.

A wide variety of such cross-cutting breccias has been reported from several impact structures (Lambert, 1981; Bischoff and Oskierski, 1987; Dressler and Sharpton, 1997): (1) melt-free, typically polymict, lithic breccias with a clastic matrix; (2) melt-fragment breccias containing fragments of heterogeneous glass, rocks, and minerals in a clastic matrix; (3) melt-matrix breccias (impact melt breccias), composed of rock and mineral fragments in a matrix of glassy or crystalline melt; (4) impact melt rocks, composed of glassy or crystalline melt with few or no inclusions (e.g., Dence, 1971). Many of these dikes are similar to units of breccia or melt in the crater-fill units above the crater floor, and they may in fact be continuous with them (e.g., Lambert, 1981).

Subcrater breccia dikes often contain materials (e.g., rock fragments or melt) that were originally located at higher stratigraphic levels closer to the impact point, indicating that the materials in the dikes have been emplaced downward and/or outward into fractures that opened in the crater floor during formation and modification of the crater. In many structures, more than one generation of dikes occurs, with later ones cutting earlier ones (Lambert, 1981; Dressler and Sharpton, 1997). These relations indicate that, even during the brief duration (seconds to minutes) of crater formation and modification, a variety of distinct breccia types can be generated and emplaced. However, in the crater environment, cross-cutting relations between breccia bodies do not imply the passage of significant amounts of time between emplacements, a conclusion supported by the fact that the cross-cutting relations between different types of breccia may not be consistent from place to place within the whole structure (Dressler and Sharpton, 1997).

\subsubsection{Pseudotachylite}

Pseudotachylite is an unusual, much-studied, and longdebated type of impactite breccia that occurs in the parautochthonous rocks of large impact structures (for recent reviews, see Reimold, 1991, 1995; Spray, 1995). Pseudotachylite is most strikingly developed at two large, ancient impact structures: Vredefort (South Africa) (Shand, 1916; Reimold, 1991; Reimold and Colliston, 1994) and Sudbury (Canada) (Fairbairn and Robson, 1941; Speers, 1957; Dressler, 1984; Thompson and Spray, 1994; Spray and Thompson, 1995), where it forms striking and extensive exposures (Figs. 5.1 and 5.2). The Vredefort pseudotachylite, first described more than 80 years ago (Shand, 1916), typically occurs as abundant irregular, anastomosing, and dike-like bodies that contain numerous large and small rounded inclusions of target rock set in a dense, aphanitic or crystalline matrix that is generally black to blackish-green in color. Similar breccias, although developed on a much smaller scale, have been observed in other impact structures, e.g., Rochechouart

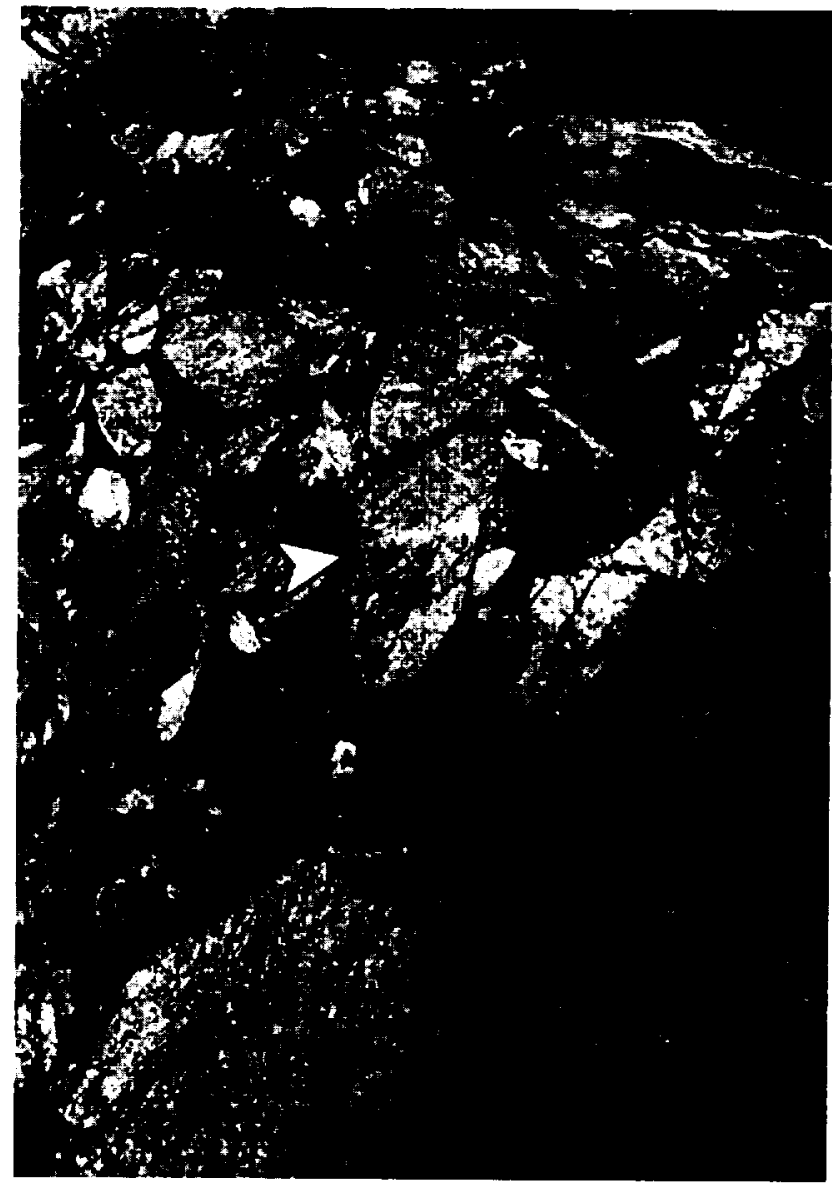

Fig. 5.1. Pseudotachylite in granitic gneisses. Pseudotachylite exposure, showing rounded gneiss inclusions from a few centimeters up to a few meters in size in a dense black matrix. The inclusions show a significant amount of rotation relative to each other. Southwest sector of the Vredefort structure (South Africa) (farm Samaria 484). Black pen on large inclusion in center (arrow) is $15 \mathrm{~cm}$ long; inclusion itself is about $50 \mathrm{~cm}$ long. From Reimold and Colliston (1994); photograph courtesy of W. U. Reimold.

(France) (Reimold et al., 1987), Manicouagan (Canada) (Dressler, 1990), and Slate Islands (Canada) (Dressler and Sharpton, 1997).

At Sudbury and Vredefort, pseudotachylite is extensive. Pseudotachylite exposures at Sudbury cover as much as $100-$ $200 \mathrm{~km}^{2}$, or a few percent of the total area of the structure. Individual pseudotachylite bodies can also be large; the largest body so far recognized at Sudbury is more than $11 \mathrm{~km}$ long, more than $400 \mathrm{~m}$ wide, and contains discrete fragments that are hundreds of meters in size (Dressler, 1984). In smaller impact structures, pseudotachylite bodies are smaller and less abundant; the material typically occurs as irregular dike-like bodies less than a meter across.

The individual pseudotachylite bodies in impact structures are not uniform over long distances and may change size and shape radically within meters or tens of meters. The more elongate dike-like bodies show little or no preferred orientation in direction. The fragment/matrix ratio in 


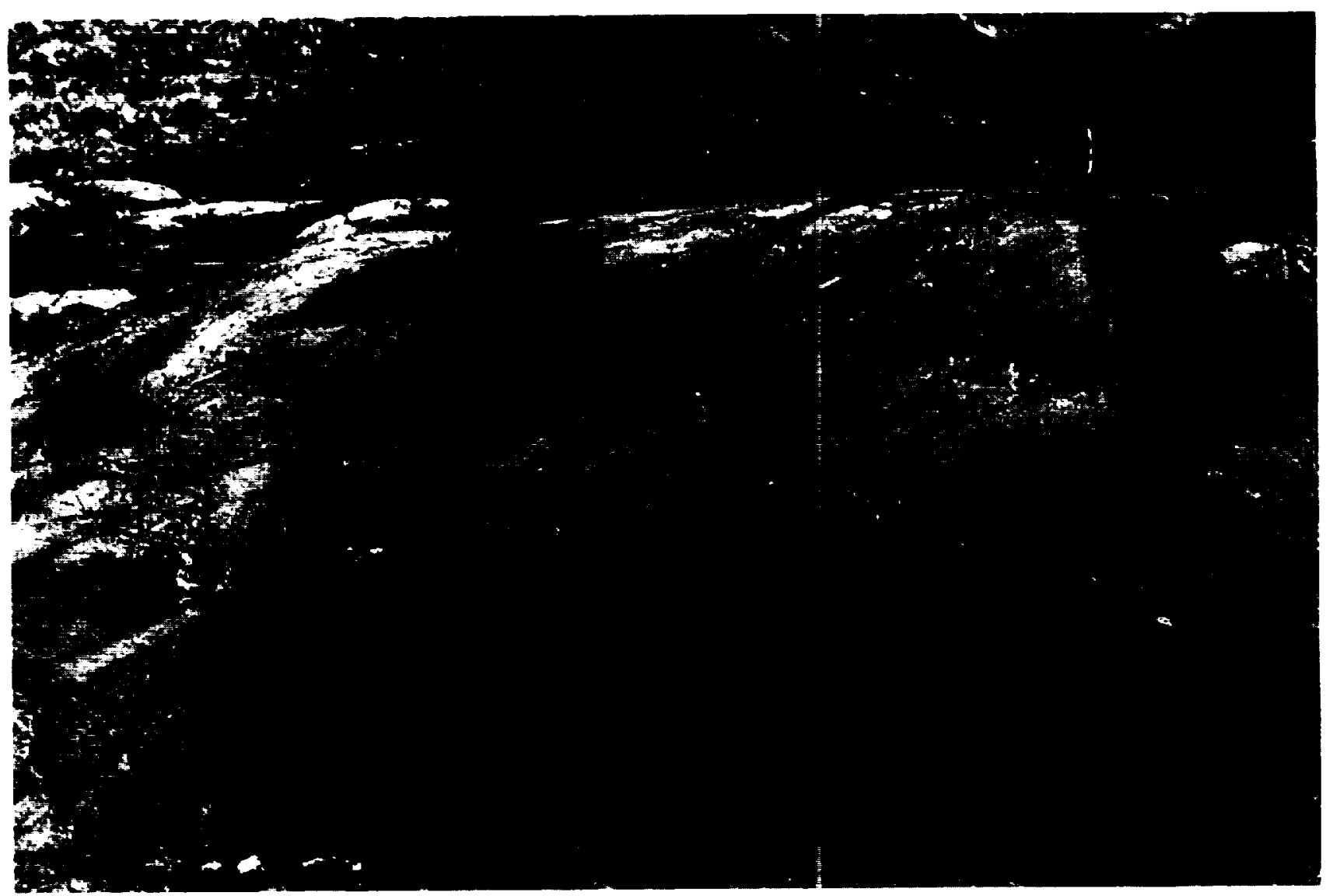

Fig. 5.2. Pseudotachylite; metamorphosed, in quartzite. Dark pseudotachylite (“Sudbury Breccia”) in Mississagi Quartzite on South Range of Sudbury structure (Canada). Exposure shows large rounded blocks of qua: tzite in a pervasive black matrix (note penetration of matrix into large quartzite block at lower right). Hammer (upper right) gives scale. Photograph courtesy of W. Peredery.

pseudotachylite bodies also varies significantly over short distances, and some pseudotachylite breccias consist only of fractured target rocks cut by thin veins of black matrix less than a few millimeters wide. (The descriptive term "cobweb breccias" has been used as a convenient field label for such occurrences.)

Contacts between pseudotachylite bodies and the enclosing target rock are irregular and generally not parallel on opposite sides. Offsets of wallrock along pseudotachylite bodies are uncommon, and observed displacements are minor (e.g., $<100 \mathrm{~m})$. In very large pseudotachylite bodies with large inclusions, the boundary between the breccia body and the unbrecciated wallrock may not be clear. In such occurrences, e.g., at Sudbury, the exact boundaries between breccia and undisturbed wallrock may be difficult to establish (Dressler, 1984).

Inclusions in pseudotachylite range from submicroscopic to hundreds of meters in size. They invariably consist of local bedrock, and there is generally no evidence for significant long-distance $(>100 \mathrm{~m})$ transport of fragments during formation. The inclusions are irregularly oriented, and outcrops of the breccia give the strong impression of an overall tensional or explosive environment (Figs. 5.1 and 5.2), rather than the narrower compressional/shear environment that is characteristic of zones of major thrust faulting (Philpotts,
1964; Sibsoi!, 1975; Spray, 1995). Larger inclusions ( $>1 \mathrm{~cm}$ ) are generall $r$ rounded, while smaller ones tend to be angular or sharp. Cintacts between both large and small inclusions and the sur ounding matrix are generally sharp. However, some inclu: ions may be deformed at the rims, forming a flow structure that can be observed, both megascopically and micros sopically, to grade into the surrounding matrix (Fig. 5.3).

The ma rix between larger rock fragments is dense and coherent. I 11 hand specimen, the matrix often shows a conchoidal or rackly texture on broken surfaces. The color is commonly lilack to blackish green on fresh surfaces, although the color $m$ xy vary slightly with the host rock involved. The matrix occu rs in a wide variety of forms. It may cover large (meter-size l) areas of inclusion-poor material, or it may form tiny submil imeter filaments that penetrate bedrock and inclusions an 1 often terminate within them. In hand specimen and thin section, the matrix is commonly structureless (Fig. 5.4), $\mathrm{t}$ ut flow-banding is often observed, especially in thin sectior. (Fig. 5.3). This flow-banding may involve inclusions thit have been plastically deformed and possibly melted (Fig. 5.5).

The ma rix, generally aphanitic in hand specimen, is extremely fin z-grained and difficult to characterize, even in thin sectior. In some samples, the matrix shows definite mi- 


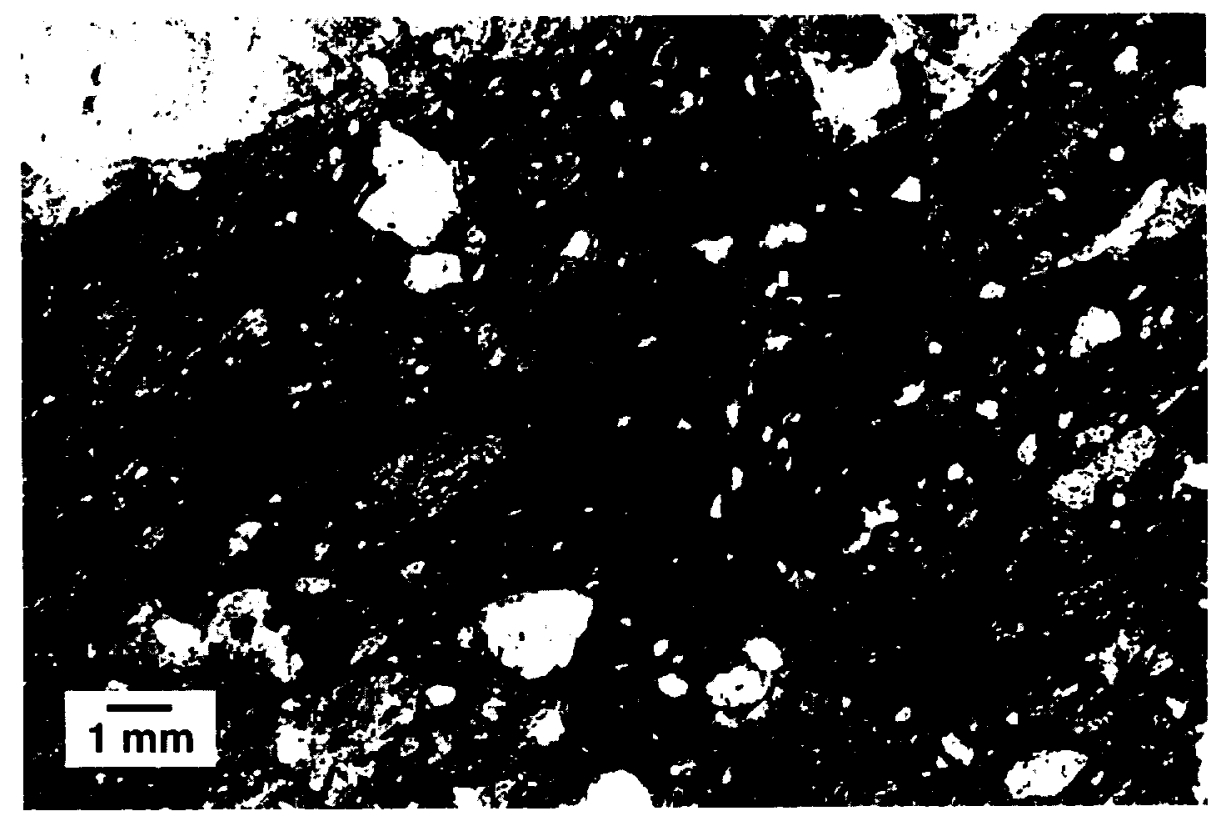

Fig. 5.3. Pseudotachylite; flow-banded texture. Pseudotachylite ("Levack breccia") in granitic gneisses from the North Range of the Sudbury structure (Canada). In thin section, the black pseudotachylite matrix material consists of small irregular rock and mineral inclusions in a dark microcrystalline to aphanitic groundmass. Numerous inclusions (white) show plastic deformation and alignment to form a flow structure; note concentric deformation of the flow structure around larger inclusions (e.g., top right). Thin vertical white lines are filled hairline fractures in the specimen. Sample CSF-67-53 (plane-polarized light).

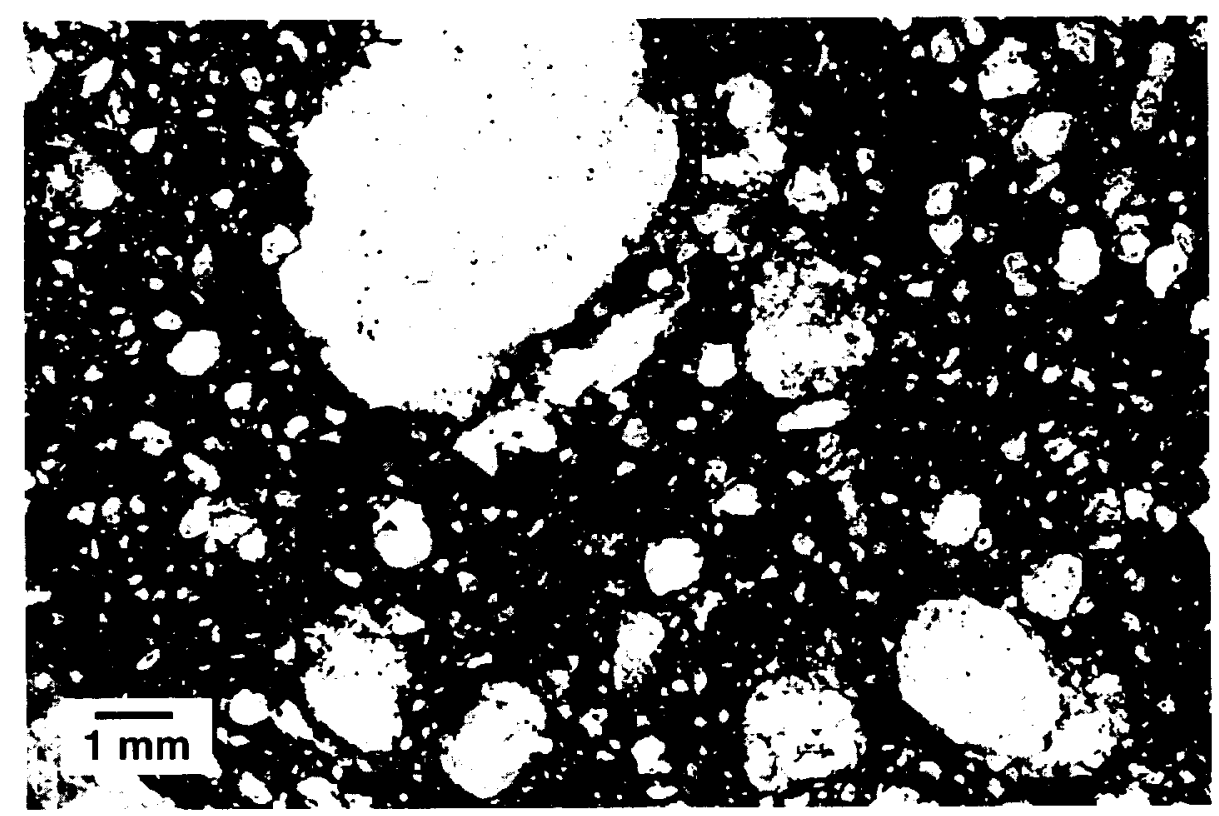

Fig. 5.4. Pseudotachylite; structureless matrix. Pseudotachylite from Vredefort (South Africa), showing typical irregular to rounded inclusions, ranging in size from $<100 \mu \mathrm{m}$ to several millimeters, in a dark aphanitic groundmass. Inclusions, which are rock and mineral fragments from granitic gneisses, show sharp contacts with the matrix. In this pseudotachylite sample, the matrix is structureless, and the inclusions show no deformation, preferred orientation, or other flow structures. Sample AV-81-53 (plane-polarized light). 


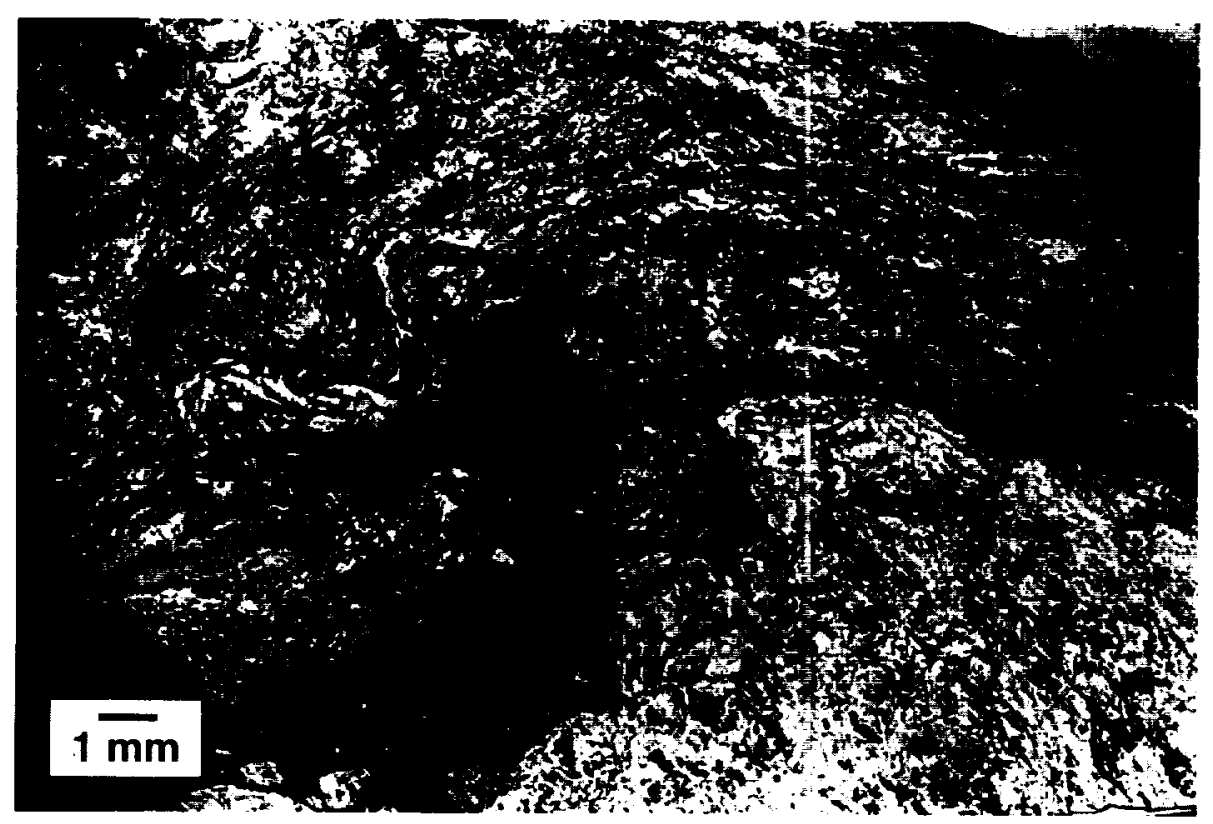

Fig. 5.5. Pseudotachylite; extensive melting and flow. Pseudotachylite ("Levack lireccia") from granitic gneisses in the North Range of the Sudbury structure (Canada). The pseudotachylite consists of a heterogeneous mixture of plastically deformed and possibly melted wallrock fragments (light-colored), mixed with discontinuous areas of more typical pseudotachylite material (dark) consisting of small rock and mineral fragments in a fine black matrix. Sample CSF-88-2A (plane-pola ized light).

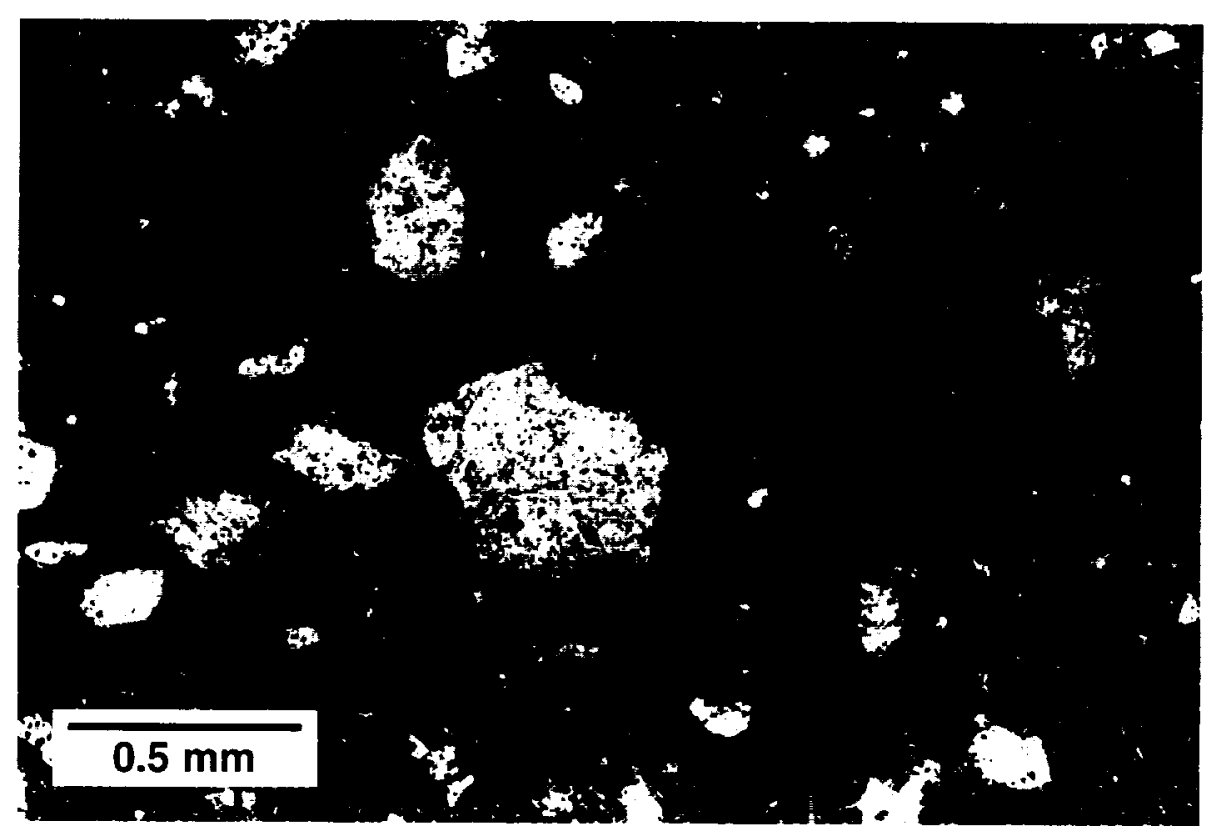

Fig. 5.6. Pseudotachylite; igneous matrix with microlites. Black pseudotachylite developed in central granitic gneisses at Vredefort structure (South Africa), consisting of small, irregular, generally rounded rock and $m$ neral fragments in a black, finely crystalline matrix. Matrix shows igneous flow-banding, expressed by alignment of small feldspar micrulites typically $50-100 \mu \mathrm{m}$ long. The microlites are often concentrically aligned around larger inclusions. Sample AV81-52A (plane-po'arized light).

crocrystalline melt textures at SEM or microscopic scales (Fig. 5.6). This characteristic, i.e., a matrix of igneous melt, has been proposed (but not unanimously accepted) as a distinguishing feature of pseudotachylite breccias (Spray, 1995). In other samples, the matrix appears to consist of small frag- ments in a cataclastic texture, and distinguishing between the two type:s is a difficult process with important implications for both classification and origin (Reimold, 1995).

Chemical studies of pseudotachylites (e.g., Dressler, 1984; Reimold, 1991) have shown that they correspond closely to 
the adjacent host rocks, indicating that they have formed essentially in place by locally generated cataclastic milling and/or frictional melting processes.

Controversy and debate over the characteristics, terminology, and origin of pseudotachylite has existed ever since the term was first used (Shand, 1916) and continues actively today (e.g., Spray, 1995; Reimold, 1995). Shand (1916, pp. 188-189) deliberately coined the word "pseudotachylite" to distinguish the Vredefort material from tachylite (basaltic glass) and also from highly crushed and melted materials formed tectonically along major faults ("flinty crusb-rock," ultramylonite, byalomylonite, etc.). Unfortunately, Shand's term has since been widely applied to the latter type of material, so that it now designates similar glassy breccias that are clearly tectonic in origin (Philpotts, 1964; Sibson, 1975; Reimold, 1995). Such breccias form in entirely different environments and are the results of intense deformation (including frictional melting) of rocks along the linear trends of faults. They form in a compressional/shear regime, but they can resemble impact-produced pseudotachylite, including the presence of melted material in the matrix (Philpotts, 1964).

Recently, some workers have suggested that impactproduced pseudotachylites are formed in the same way as tectonic ones, i.e., by frictional heating during the rapid movements of late-stage crater development and modification (e.g., Thompson and Spray, 1994; Spray, 1995, 1997; Spray and Thompson, 1995). In this view, impact-produced pseudotachylites have essentially the same frictional-melt origin as tectonic ones. One possible way to distinguish between them may be size. Bodies of tectonic pseudotachylite tend to be linear and less than a few meters wide (Sibson, 1975; Spray, 1995). Impact-produced pseudotachylites, at least at Sudbury and Vredefort, form more irregular bodies, some of which may reach tens to hundreds of meters in size (Thompson and Spray, 1994; Spray and Thompson, 1995).

Another problem, even within the study of impact-produced breccias, is that the term "pseudotachylite" has been used to designate different types of impact-produced breccias formed at different stages (and possibly by different mechanisms) during crater formation (Martini, 1991; Reimold, 1995; Dressler and Sharpton, 1997). One suggestion (Martini, 1991) is to use the term "type A pseudotachylite" to designate relatively rare, small, glassy veins, typically less than a centimeter wide, that contain fragments in a matrix of melted material, often accompanied by shockproduced high-pressure mineral polymorphs such as coesite and stishovite (Martini, 1991). Such veins are believed to form during the early, higher-pressure, compressive stages of shock-wave expansion. In contrast, the more abundant, widespread, and more intensely studied material (called "type B pseudotachylite") is thought (Martini, 1991) to form later, during crater modification and central uplift formation, probably by friction generated by the rapid movement of large volumes of target rock below the crater.

Pseudotachylite breccias (especially the more familiar "type B" variety) are distinctive and recognizable at Vredefort and
Sudbury, but their wider use as unique indicators of impact is complicated by several factors. First, since they form below the original crater floor, they are found only in impact structures that have been deeply enough eroded to expose target rocks originally located beneath the crater, and pseudotachylites are usually restricted to the central-uplift regions of larger structures. Second, pseudotachylites resemble rocks formed by nonimpact processes, and the distinction is difficult unless definite preserved shockmetamorphic effects can be found. The current confusion in terminology and formation mechanisms, combined with the scarcity of distinctive shock effects in many impact-produced pseudotachylites, makes it difficult to use pseudotachylites by themselves as unique indicators of impact structures.

Despite these problems, well-developed pseudotachylites may still be a useful field tool for identifying possible impact structures for more detailed study. Pseudotachylites can be widespread in impact structures, and their distinctive appearance can survive even high-grade metamorphism (Fig. 5.2). The striking irregular and anastomosing character of pseudotachylite bodies, their rounded inclusions (often altered at the rims), their development over large areas, and the frequent absence of a regular shape or of compressional effects typical of similar fault-related breccias make them a valuable field indicator of a possible impact structure, and their discovery should be followed up with an intensive search for more definite shock effects. In addition, melt-rich pscudotachylite breccias in established impact structures have proven valuable for determining the formation ages of the structures themselves (Spray et al., 1995; Kelley and Spray, 1997).

\subsection{CRATER INTERIOR: CRATER-FILL DEPOSITS (BRECCIAS AND MELT ROCKS)}

\subsubsection{Formation Conditions}

During the modification stage, material excavated from various locations in the growing transient crater is deposited within the final crater to form crater-fill deposits of breccia and melt rock. These allogenic units consist of four main components: (1) material cjected ballistically on steep or near-vertical trajectories that impacts within the final crater; (2) large and small bodies of impact melt that do not travel beyond the rim of the final crater; (3) large and small fragments of unshocked target rock that collapse from the oversteepened walls and rim of the original transient crater; (4) ejecta originally deposited near the transient crater rim and caught up in the subsequent collapse.

As a result of these processes, the final crater is partially filled with a complex mixture of rock fragments (shocked and unshocked) together with bodies of impact melt. These deposits consist mostly of crater-fill breccias, often accompanied by discrete units of impact melt rocks. In small, bowlshaped, simple craters, the various components tend to be mixed together, and the final deposit may fill the crater to 
about half its depth. [This crater-fill unit is also called the breccia lens because of its shape (Fig. 3.7).] In larger complex structures, particularly those formed in crystalline target rocks, the crater-fill rocks typically contain discrete units of breccias and impact melts that form a large annular deposit around the central uplift (Fig. 3.13).

Subsequent to formation of the crater and the deposition of impact-produced crater-fill breccias, the structure may be filled, and the breccias buried, by younger crater-fill sediments deposited more slowly by the conventional processes of erosion, transport, and deposition. These sediments not only preserve the underlying impact-produced breccias, but, because of their circular outcrop pattern and often anomalous character, they may call attention to previously unsuspected impact structures. In this section, the discussion and the term "crater-fill deposits" are limited only to the impactproduced breccias that fill the crater during and immediately after formation and do not include any ordinary sediments that may also be present.

Many of the individual fragments in the crater-fill deposits have been derived from within the zone of crater excavation (Fig. 3.4) and may be highly shocked. Much of the target rock within the excavation zone is subjected to relatively high shock pressures of about $5 \mathrm{GPa}$ to $>100 \mathrm{GPa}$. The lowest pressures in this range are sufficient to shatter and brecciate the target rocks extensively; at higher pressures, the rocks are deformed and melted as well. Shocked

Fig. 5.7. Crater-fill breccias. Recent drill coring along the southern flank of the Chicxulub structure (Mexico), has recovered impact breciias and melt rocks only shallowly buried beneath the younger carbonate sediments. This mosaic shows the sequence of diverse crater-fill breccias retrieved from the UNAM-5 drill core located near the village of Santa Elena in southern Yucatan, $112 \mathrm{~km}$ from the center of the basin. The core pieces are arranged so that each represents $10 \mathrm{~m}$ of core. The top of the impact sequence (top of picture) occurs at a depth of $\sim 330 \mathrm{~m}$ below the surface and is characterized by a $30-\mathrm{m}$ interval of highly vesicular and pulverized impact melt rock (M). The melt rock horizon is almost completely altered to clay but contains abundant clasts of the target rock assemblage. Below this horizon is a varicolored continuous unit of suevite breccia (SB). As is typical of suevites, this unit has a clastic matrix containing a substantial proportion of highly shocked and melted clasts derived from lithologies that were originally deep within the target assemblage. The upper $50 \mathrm{~m}$ of the UNAM-5 suevite (SB1) is characterized by abundant, centimeter-scale clasts of vesicular melt rock, similar to that of the overlying melt horizon but less altered. The middle $50 \mathrm{~m}$ of the suevite (SB2) is dominated by larger clasts of shocked to partially melted silicate basement rock showing abundant evidence of shock deformation. The matrix of the lower section of suevite (SB3) is more melt-rich and contains a greater proportion of centimeter-scale silicate clasts. Total depth was reached at the UNAM-5 well while still in the suevite. Coin is $\sim 3 \mathrm{~cm}$ in diameter. Photograph courtesy of V. L. Sharpton.

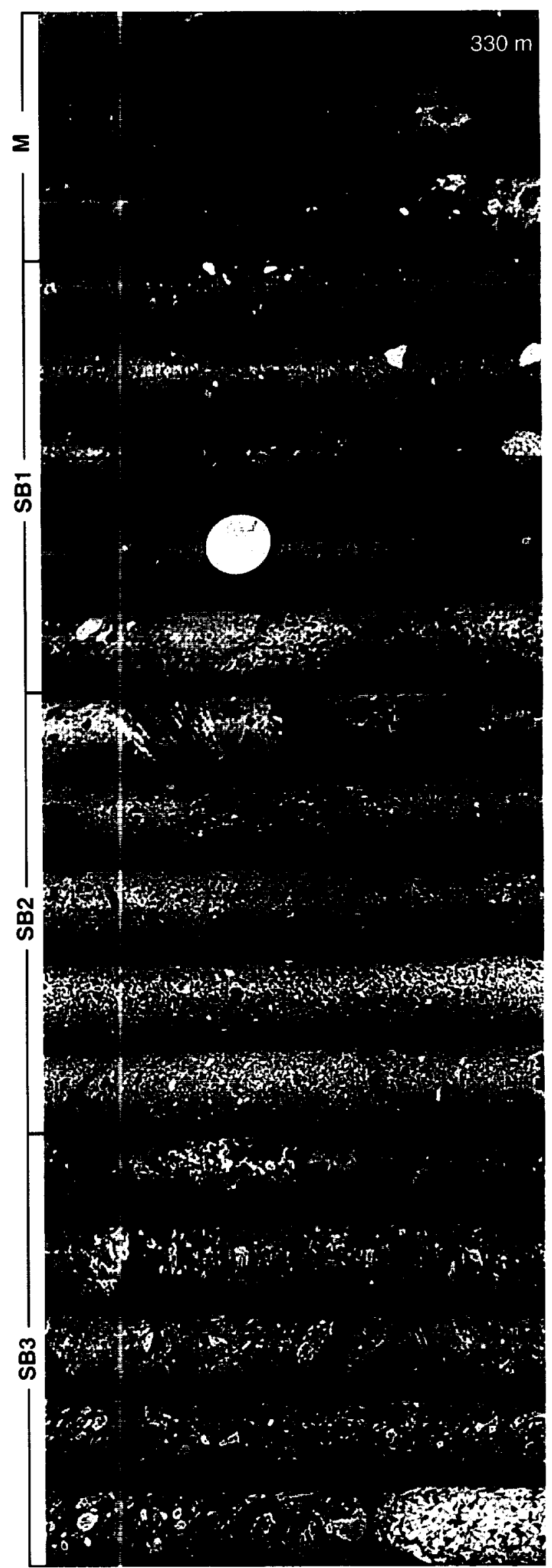


rock fragments, derived from this zone and deposited in the crater-fill breccias, have provided the best evidence for the impact origin of numerous structures.

The crater-filling process is both rapid and chaotic, and mixing of the different components is not complete. The crater-fill deposits therefore contain a variety of distinctive allogenic breccias and melt rocks (Fig. 5.7). The simple classification used below is based on (1) fragment lithologies (lithic vs. melt-fragment breccias; (2) nature of the matrix (clastic vs. melt-matrix). (For more detailed discussions and classifications, see, e.g., Stöffler et al., 1979; Taylor et al., 1991; Stöfler and Grieve, 1994, 1996.)

\subsubsection{Lithic Breccias (Allogenic)}

Melt-free breccias (lithic breccias) form a common and distinct lithology in both large and small impact structures (Figs. 3.7 and 3.13). In small impact structures, e.g., Brent (Canada) (Dence, 1968; Grieve and Cintala, 1981), lithic breccias may form units hundreds of meters thick that extend over much of the final crater. At the larger Ries Crater (Germany), a distinctive allogenic polymict lithic breccia [the Bunte ("colored") Breccia] occurs beneath the overlying melt-bearing suevite breccias both inside and outside the crater (Hörz, 1982; Hörz et al., 1983), with a sharp contact between the two units. In some impact structures, especially those formed in carbonate target rocks, lithic breccias may be the only type of crater-fill material present (Roddy, 1968; Reiff, 1977).

Lithic breccias consist of rock and mineral fragments in a clastic matrix of finer-grained similar material (Fig. 5.8). The breccias are poorly sorted; fragment sizes generally range from $<1 \mathrm{~mm}$ to tens of meters. Fragments are typically sharp to angular in appearance. Unlike the lithic breccias found in parautochthonous rocks, crater-fill lithic breccias are more apt to be polymict because their fragments have been derived from a wider region of the original target rocks. Because most of the material in lithic breccias is derived from less-shocked regions around the walls and rim of the transient crater, distinctive shock effects are only rarely observed in the fragments.

Within the crater-fill deposits, lithic breccias are often associated, both horizontally and vertically, with units that contain a melt component as discrete fragments or as a matrix for lithic fragments. Breccias with a few percent or more of a melt component are regarded as melt-bearing breccias, but the transition between these breccia types appears continuous, and no formal boundary has been established. Such melt-bearing breccias typically form a smaller proportion of the crater fill, perhaps $10-25 \mathrm{vol} \%$, and the amount of melt component they contain varies from a few percent to >90 vol\% (e.g., Hörz, 1982; Masaitis, 1983; von Engelhardt, 1990, 1997).

Two basically different types of melt-bearing breccias can be distinguished. In melt-fragment breccias (suevites), the melt component occurs as large (centimeter-sized) discrete bodies; in melt-matrix breccias (impact melt breccias), the melt forms a matrix for rock and mineral fragments (Stöfler and Grieve, 1994, 1996).

\subsubsection{Melt-Fragment Breccias (Allogenic) (Suevites)}

Melt-fragment breccias (suevites, pronounced “SWAYvites") are composed of discrete fragments of rocks and minerals, together with bodies of melt, in a clastic matrix of similar but finer-grained materials. Many of the rock and mineral

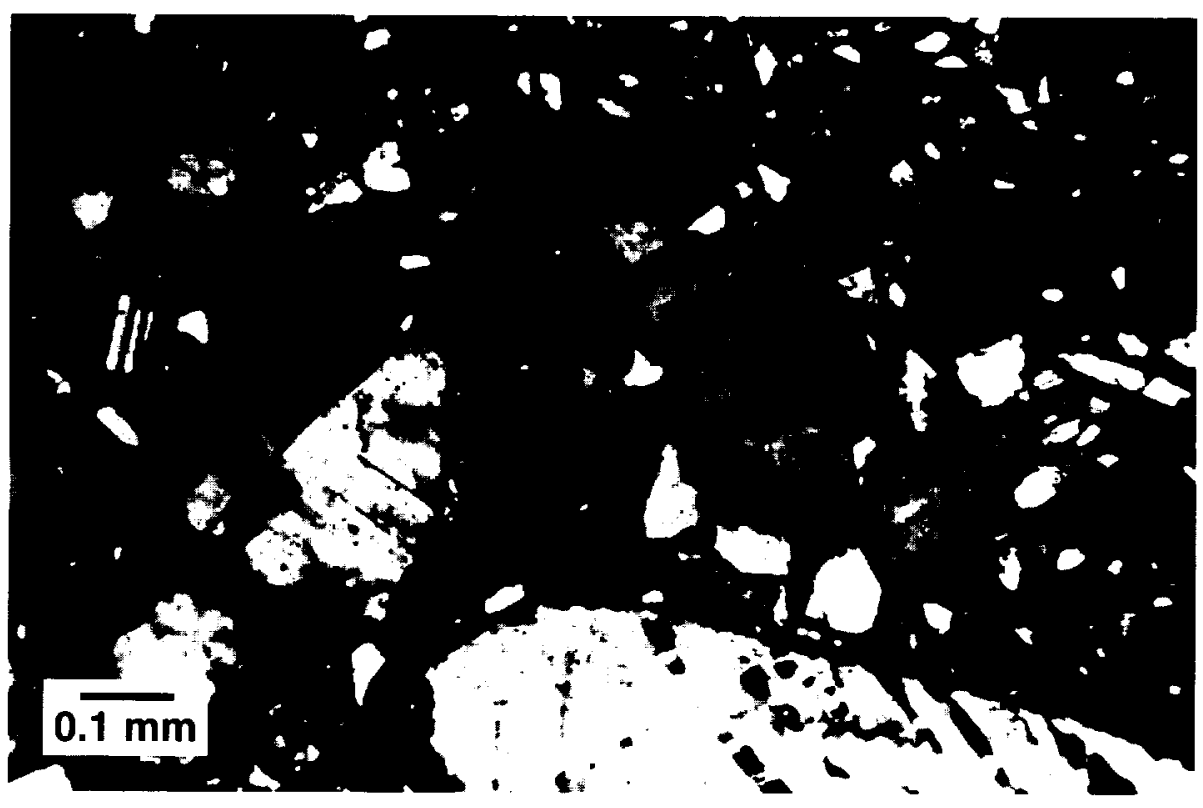

Fig. 5.8. Crater-fill breccia; lithic breccia. Poorly sorted crater-fill lithic breccia composed of angular to sharp fragments of granitic rocks and constituent minerals (quartz, feldspar, etc.) in a finer clastic matrix. Drill core sample from the Brent Crater (Canada). Photograph courtesy of R. A. F. Grieve (cross-polarized light). 


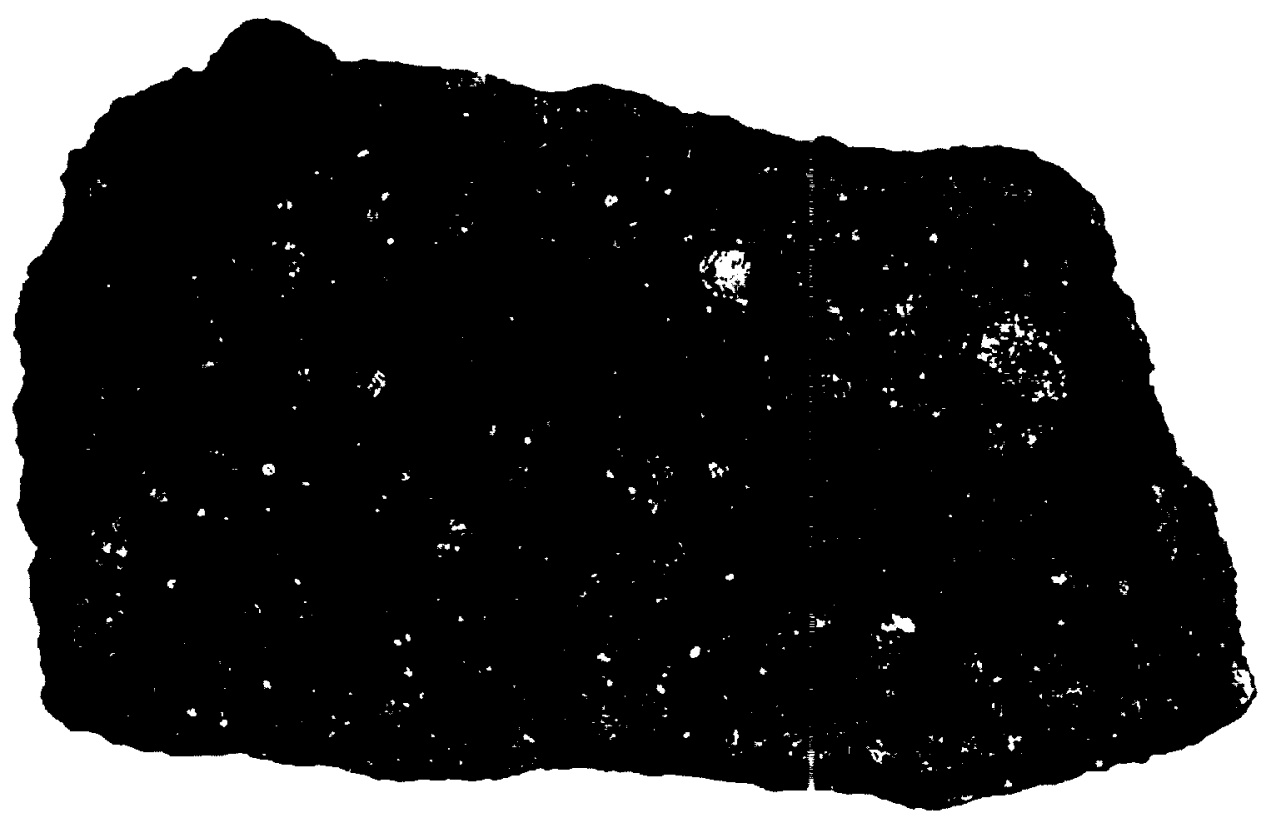

Fig. 5.9. Crater-fill breccia; suevite. Large hand specimen, about $45 \mathrm{~cm}$ long, of :ypical fresh suevite from the Ries Crater (Germany) (Otting quarry). The specimen consists of irregular and contorted individual frag nents of glass (dark), which show a roughly parallel elongation, and crystalline rock fragments (light) in a fine clastic matrix. The g ass fragments, which range up to $5 \mathrm{~cm}$ in size, are composed of a mixture of rock and mineral fragments in heterogeneous, flow-bant ed glass. Photograph courtesy of D. Stöfler.

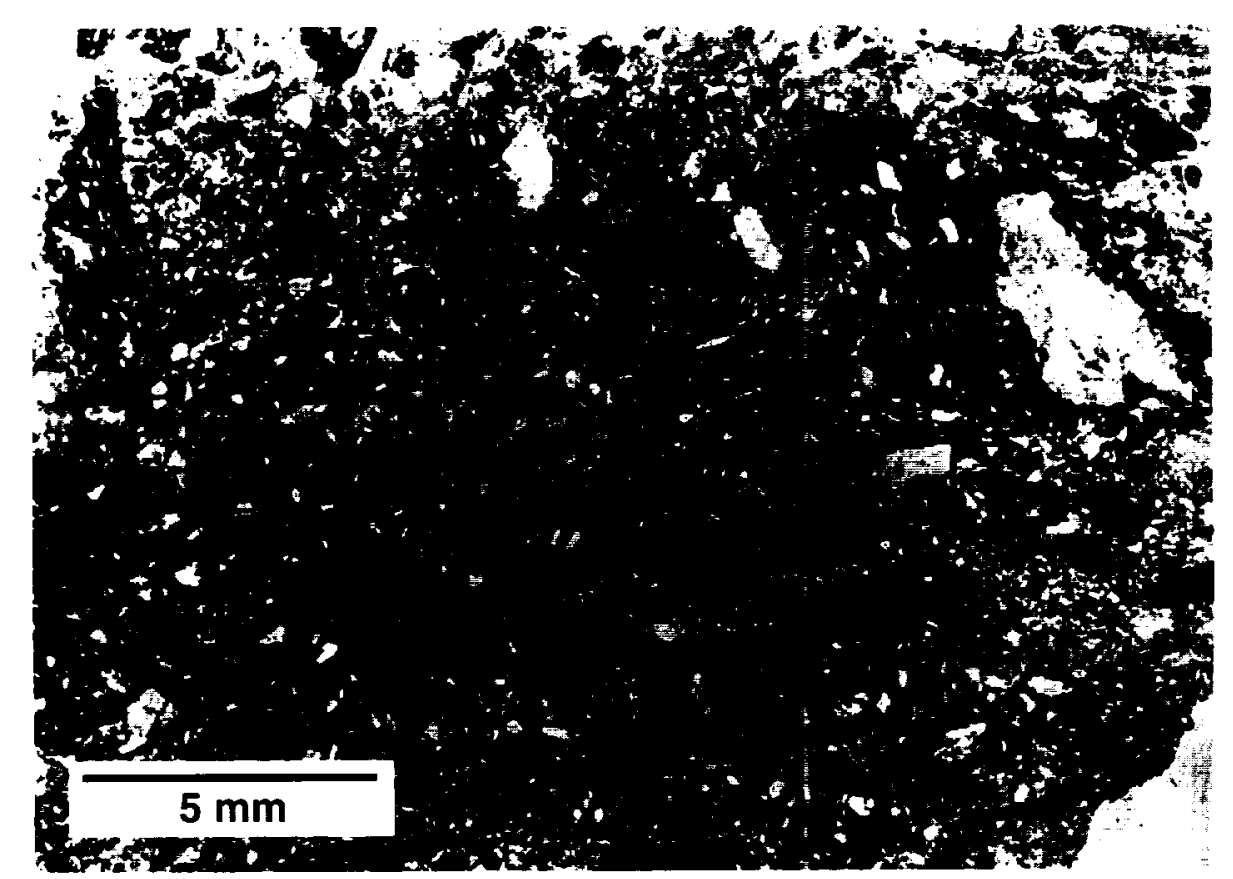

Fig. 5.10. Crater-fill breccia; suevite. Suevite breccia from Nicholson Lake (Car ada), containing glass fragments (dark) with rock and mineral clasts in a finer fragmental matrix. The glass fragments are heterogeneous : nixtures of mineral clasts (light) in dark, flow-banded glass. Photograph courtesy of M. R. Dence (plane-polarized light). 
fragments are highly shocked, and these breccias often provide the most distinctive evidence for a meteorite impact origin of the structures in which they are found.

The term suevite was originally applied to melt-fragment breccias from the type occurrence at the Ries Crater (Germany), a relatively young ( $15 \mathrm{Ma}$ ) and well-preserved structure $24 \mathrm{~km}$ across, in which well-exposed suevites and other impactites have been extensively studied and drilled (for reviews, see von Engelhardt et al., 1969; von Engelhardt and Graup, 1984; von Engelhardt, 1990, 1997). Suevite breccias are found both inside the structure (crater suevite or fallback suevite) and as preserved ejecta deposits (ejecta or fallout suevite) as far as $40 \mathrm{~km}$ from the center of the Ries structure.

Suevite breccias from the Ries Crater and other impact structures typically consist of large (centimeter-sized) and smaller glassy bodies (typically 5-15 vol\%), together with rock and mineral clasts in a matrix of finer fragments (Figs. 5.9 and 5.10). Glass-rich suevites are also known, in which the glass fragments may make up $>50 \mathrm{vol} \%$ of the rock (Masaitis, 1994). Individual rock and glass fragments typically range from a maximum size of $10-20 \mathrm{~cm}$ down to submillimeter dimensions.

The glassy bodies in the fallout suevite beyond the Ries Crater rim typically show irregular to contorted shapes and textures (Hörz, 1965). These bodies are typically heterogeneous, consisting of a polymict mixture of rock and mineral clasts (frequently highly shocked or partially melted) in a matrix of glass that may be compositionally heterogeneous and often shows well-developed flow structure (Fig. 5.11). At the Ries Crater, the larger $(5-20 \mathrm{~cm})$ glassy fragments in the ejecta deposits outside the structure, called Fladen, show a grooved and lobate flow structure that is evidence of aerodynamic sculpturing during their flight through the atmosphere (Hörz, 1965). These bodies also show brittle fractures developed on landing, implying that they were solid when they struck the ground. In contrast, glass bodies in the crater suevite are smaller (normally $<5 \mathrm{~cm}$ ) and lack distinctive sculpturing, implying that they did not travel through the atmosphere for any significant length of time (Fig. 5.12) (von Engelhardt and Graup, 1984; von Engelhardt, 1990).

Although the Ries suevites are the best-known and most intensely studied examples of this rock type, impressive suevite breccias have been recognized in many other impact structures. However, in many of these structures, erosion has largely removed the ejecta deposits outside the crater, and the sucvites occur only as crater-fill units, where they are associated with, and often interbedded with, lithic breccias and impact-melt rocks. Examples include Brent (Canada) (Dence, 1965, 1968; Grieve, 1978); Rochechouart (France) (Kraut and French, 1971); Popigai (Russia) (Masaitis et al., 1980; Masaitis, 1994); Manson (Iowa) (Koeberl and Anderson, 1996a; Koeberl et al., 1996b); Gardnos (Norway) (French et al., 1997); Slate Islands (Canada) (Dressler and Sharpton, 1997); and Roter Kamm (Namibia) (Reimold et al., 1997a). The Onaping Formation, a complex and metamorphosed

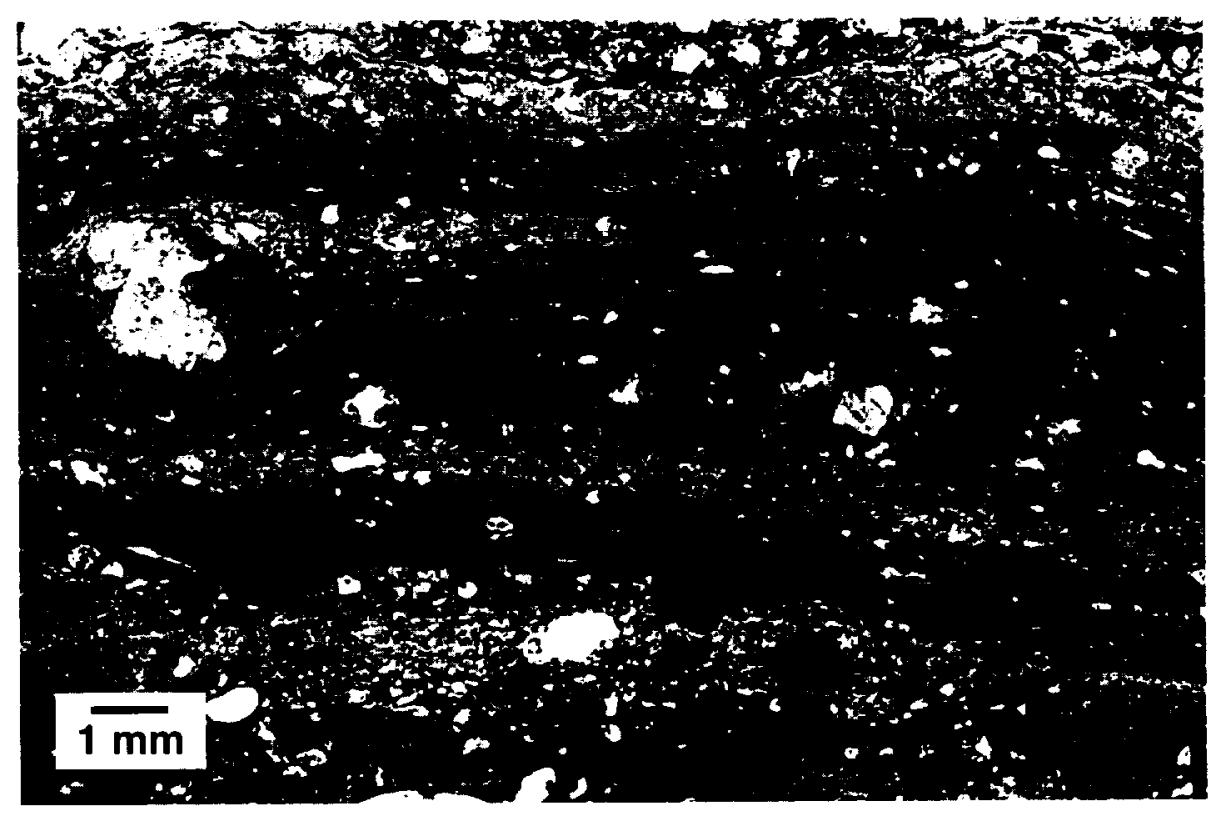

Fig. 5.11. Crater-fill breccia; suevite; glassy inclusion. Heterogeneous, fragment-rich glassy fragment (Fladen) in suevite breccia from Lake Mien (Sweden), showing complex, multiple layering with varying amounts of rock and mineral inclusions. The mineral inclusions are typically sharp to angular and do not show the phenocryst shapes that are typically observed in glassy volcanic rocks. The generally laminar flow-banding is emphasized by a sharp difference in clast content and by dark streaks that may represent decomposed and melted opaque minerals. Note that flow-banding in the clast-rich layers (e.g., top) is more highly contorted. Sample NBS-61-0487 (planepolarized light). 


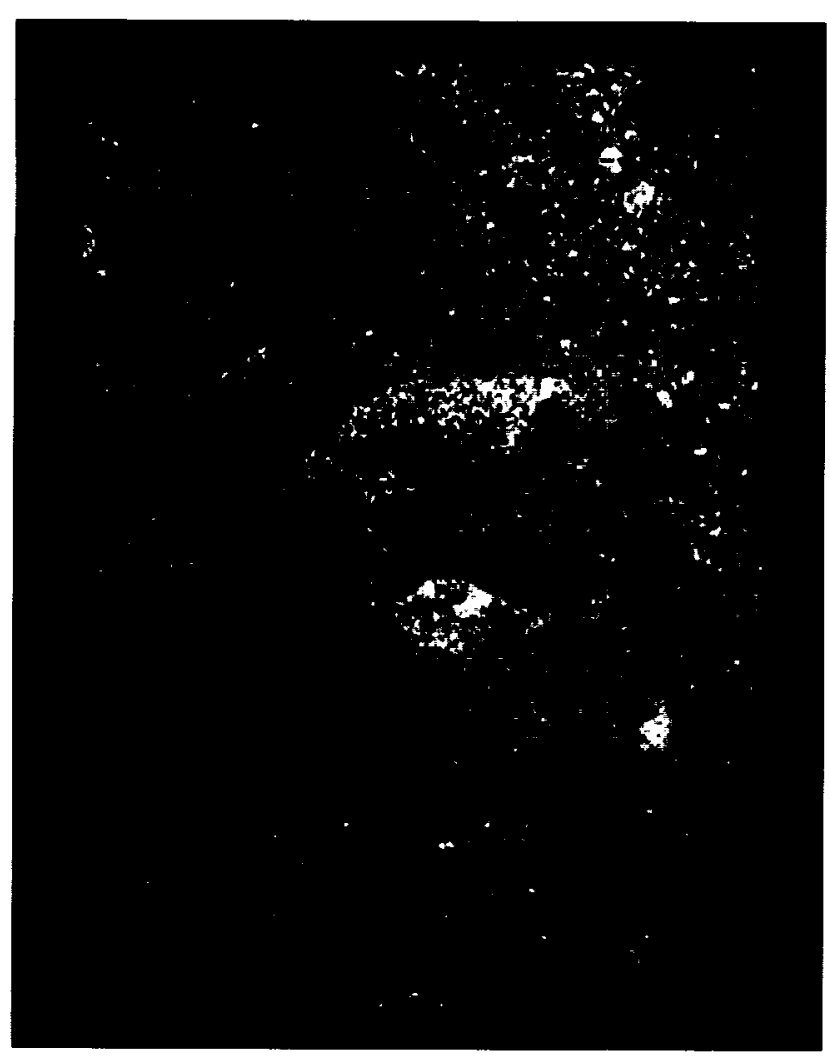

Fig. 5.12. Crater-fill breccia; suevite. Typical poorly sorted suevite breccia in a core sample from the Nördlingen deep drill hole (369.9 m depth), Ries Crater (Germany). The unit contains crystalline rock fragments (light-colored) and glassy fragments (Fladen) (dark) in a fine clastic matrix. Inclusion at upper left contains a rock fragment (core) surrounded by a rim of flow-banded glass. Specimen is $10 \mathrm{~cm}$ wide. Photograph courtesy of $\mathrm{H}$. Newsom.

crater-fill unit at the $1.85-\mathrm{Ga}$ Sudbury (Canada) impact structure, contains the oldest suevite unit identified so far (Fig. 5.13) (French, 1968b; Muir and Peredery, 1984; Avermann, 1994).

Because of their high melt content and the occurrence of individual glassy bodies, suevite breccias resemble conventional volcanic breccias, and the suevite from the Ries Crater was considered to be a volcanic tuff for nearly two centuries. However, suevites differ from volcanic breccias in several ways, both in hand specimen and microscopically. Fragments in suevites show no volcanic textures; such typical volcanic features as feldspar phenocrysts or corroded quartz phenocrysts are absent (Figs. 5.10, 5.11, 5.14, and 5.15). Rock fragments in suevites are not deep-seated volcanic xenoliths but are derived entirely from the underlying shallow target rocks. Suevites often contain cored inclusions, composite fragments in which a rim of glass is wrapped around a fragment of basement rock, indicating that both rock and melt were ejected into the air at the same time (Figs. 5.16, 5.17, and 5.18). Most convincing is the presence of unique high-pressure shock-metamorphic effects (such as PDFs in quartz or the high-pressure minerals coesite and stishovite), in rock and mineral inclusions in the suevite. High-temp sature melting effects, e.g., the formation of silica glass (lecha elierite) from quartz, may also be present in the glass fragm :nts in suevite.

Despite heir widespread distribution, suevite breccias are not found $i$ i all meteorite impact structures. In some cases, their absence is probably due to erosion, which has removed these near-surface deposits from the structure. However, the nature of th : target rocks also seems important in determining whethel suevites are formed (Kieffer and Simonds, 1980; Grieve and (intala, 1992). Suevites have so far been observed only in imp ict structures formed largely or entirely in crystalline silici te rocks, possibly because these rocks melt to produce coliererent and durable bodies of glass. No suevite deposits have yet been found in impact structures formed in carbonate riscks, in which decarbonation and volatile loss, rather than melting, would be important.

\subsubsection{Melt-Matrix Breccias (Impact-Melt Breccias)}

Suevites nside the crater are closely associated with a different type of melt-bearing breccia: melt-matrix breccias or impact-nielt breccias. In these units, the melt occurs, not as individual fragments, but as a matrix that typically makes up 25-75 vc 1\% of the rock and may range from glassy material to comp letely crystalline igneous rock. The fragments, which cons st of target rocks and minerals, are frequently shocked or inelted.

Impact- $\mathrm{t}$ elt breccias form distinct bodies of widely varying size, from small glassy inclusions in suevite breccias to distinct dike-like and sill-like units tens to hundreds of meters thick. As th = melt component increases, impact-melt breccias grade ir to impact melt rocks (see Chapter 6), in which the melt cor pponent is dominant and the included fragments are minor or entirely absent. These rocks often have the appearance of zonventional igneous rocks.

\subsection{CF ATER RIM ZONE AND PROXIMAL EJECTA DEPOSITS}

The regi in near the rim of the transient crater is subjected to rel tively low shock pressures (typically $<1-2 \mathrm{GPa}$ in smaller structures; Fig. 3.4) (Kieffer and Simonds, 1980). These press ares are high enough to fracture and brecciate target rocks jut are too low to produce unique shock-deformation feat Ires in them. The dominant effects in this region are related to the excavation of the crater and the ejection of material f :om it. In simple craters, which are only slightly larger than $t$ e original transient crater, the rim is characterized by struc tural uplift (and even overturning) of the target rocks that o:curs during development of the original transient crater 'Fig. 3.3). Even though much of this original transient crater rim may collapse into the final crater during modification, significant uplift may be preserved, especially in smaller ar d younger craters (e.g., Shoemaker, 1963; Roddy et al., 1975; Roddy, 1978). Such rim uplift and overturn- 


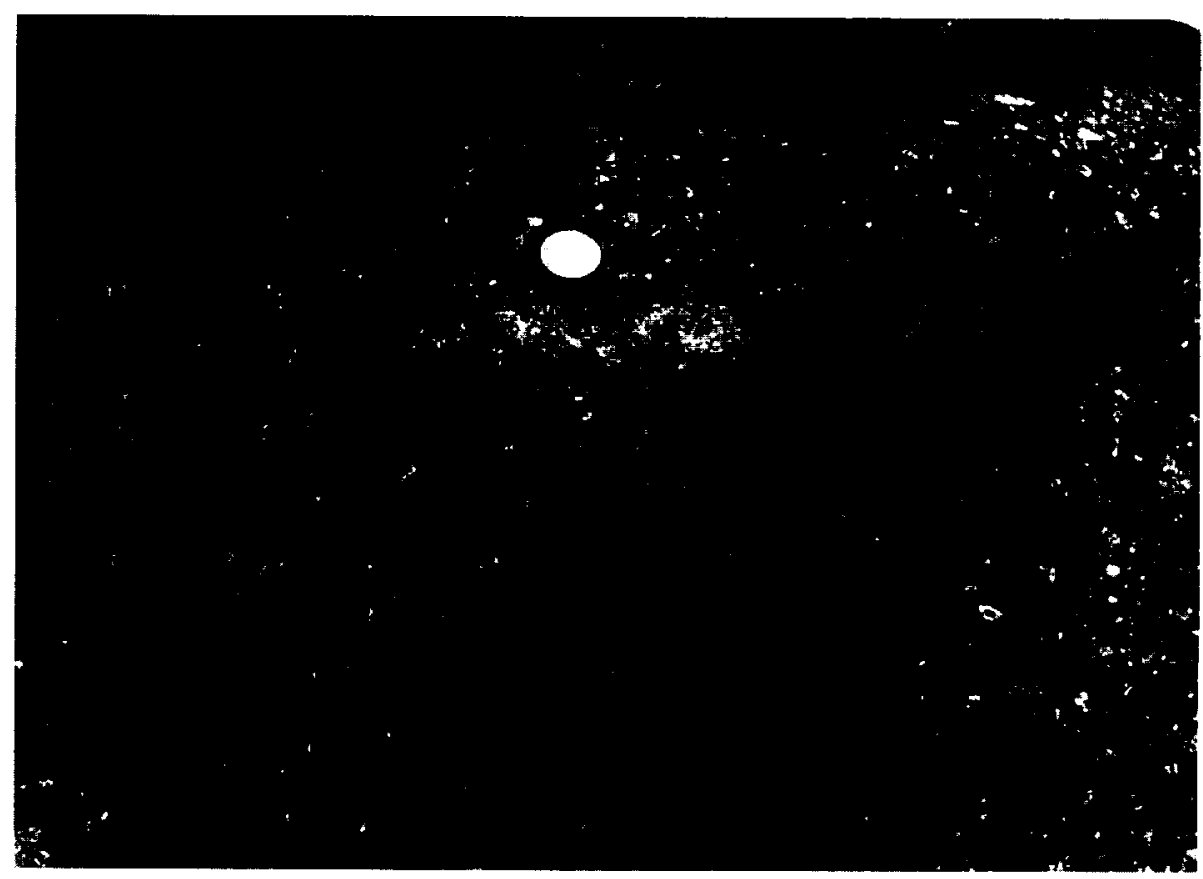

Fig. 5.13. Crater-fill breccia; suevite, metamorphosed. Typical exposure of Onaping Formation "Black Member," showing centimetersized fragments of rock fragments and contorted recrystallized glassy inclusions in a black fragmental matrix. Despite color differences, the unit has a strong resemblance to fresh suevite from the Ries Crater (Germany) (see Fig. 5.9). Exposure located at "Black Member" type locality at Onaping Falls (Highway 144, Dowling Township) in the northwestern part of the Sudbury structure (Canada). Diameter of coin near large glassy inclusion is about $2 \mathrm{~cm}$. Photograph courtesy of J. Guy-Bray.

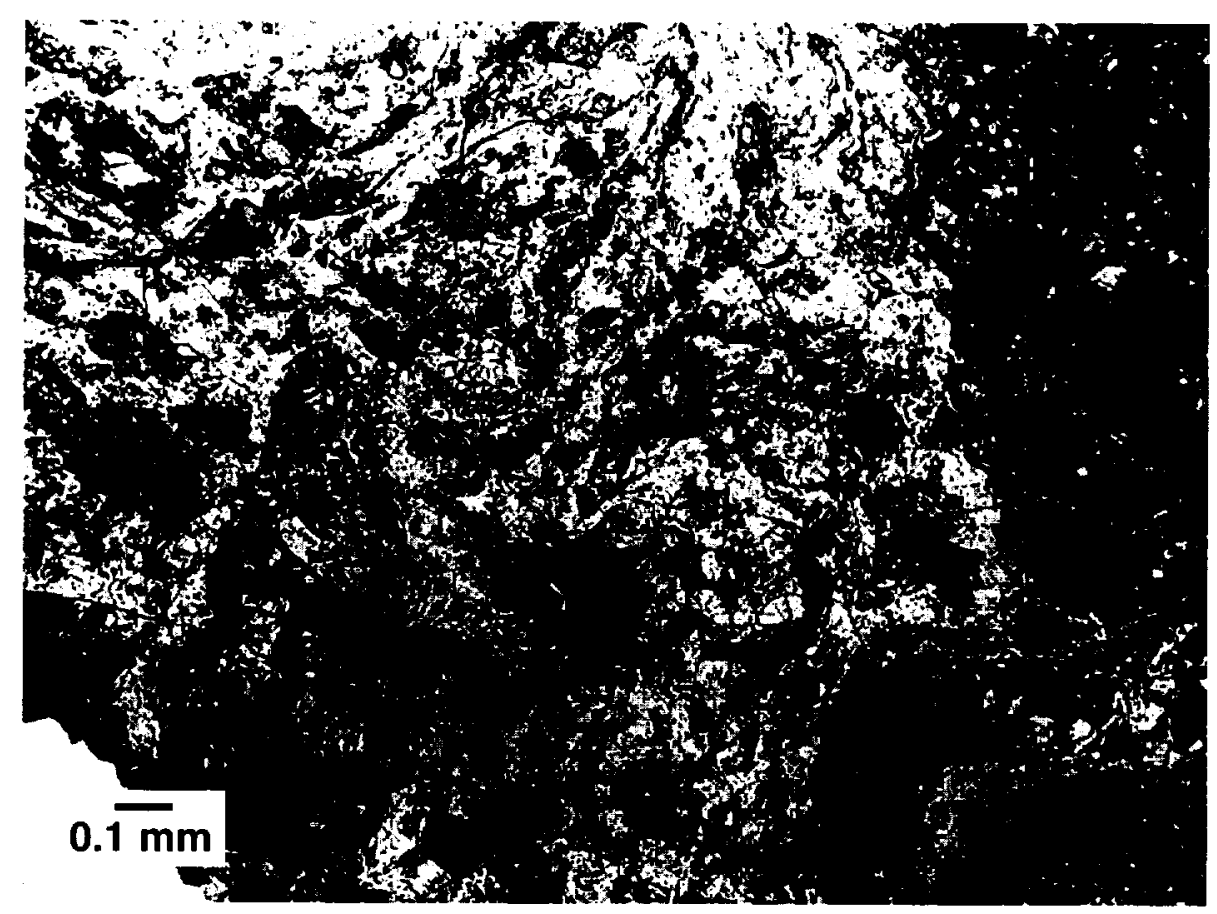

Fig. 5.14. Crater-fill breccia; suevite, heterogeneous glasses. Complex heterogeneous glassy breccia from West Clearwater Lake (Canada), composed of distinct areas of light- and dark-colored mixed glasses, which show short-range turbulent flow and mixing. The glassy areas contain abundant small rock and mineral fragments. Photograph courtesy of M. R. Dence (plane-polarized light). 


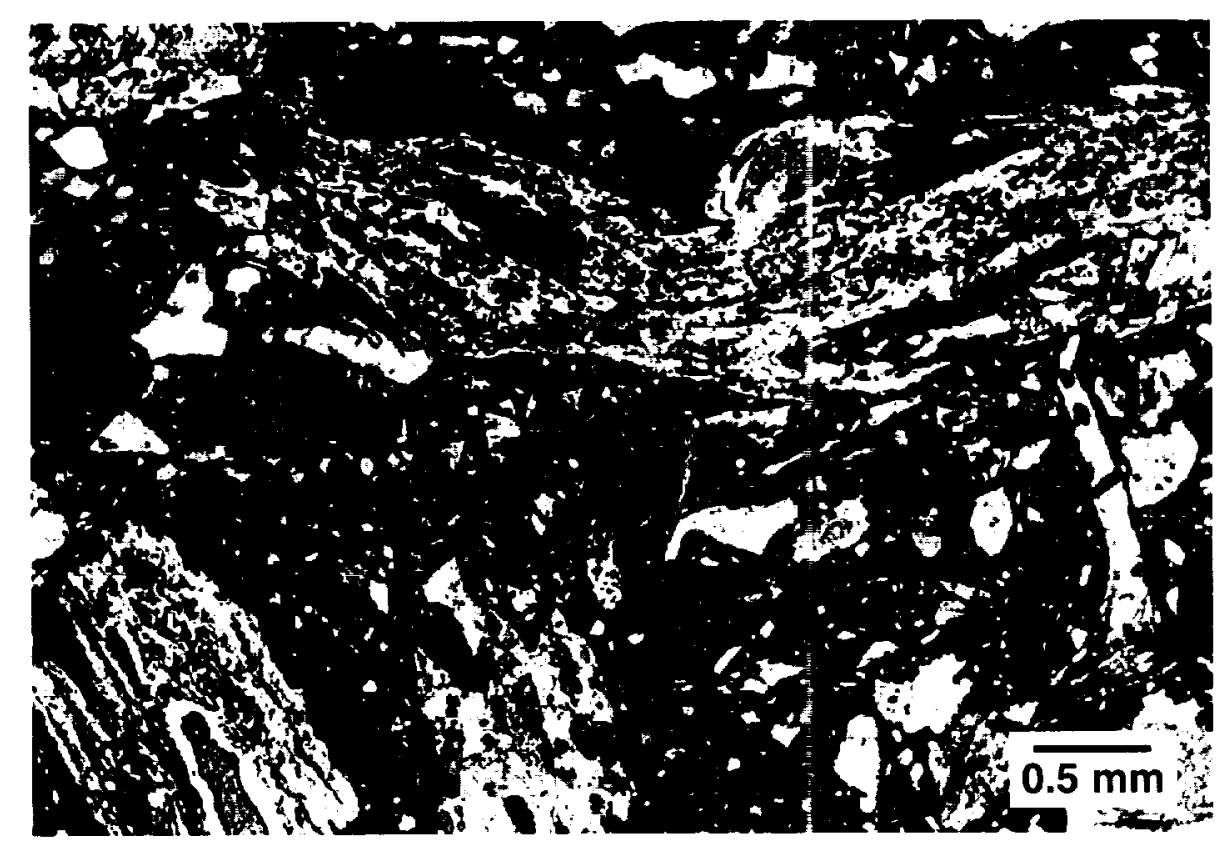

Fig. 5.15. Crater-fill breccia; suevite, metamorphosed. Heterogeneous glassy b eccia consisting of fragments of recrystallized glass, together with rock and mineral fragments, in a fine opaque carbon-bearing matrix Despite greenschist-level metamorphism, the glassy fragments still preserve original melt textures such as flow banding and vesicles ( $\mathrm{n}$ w filled with chlorite; gray). Many of the fragments display sharp crosscutting fractures, indicating that they were cool and brittle when deposited. The rock and mineral clasts represent broken basement (target) rocks; no typical volcanic textures (phenocrysts, etc.) are observed. Discrete fragments as small as $5 \mu \mathrm{m}$ across can be distinguished in the opaque matrix. Onaping Formation "Black Member,' from type locality at Onaping Falls (Highway 144, Dowling Township), northwestern corner of Sudbury structure (Canada). Sample CSF-66-36-1 (plane-polarized light).

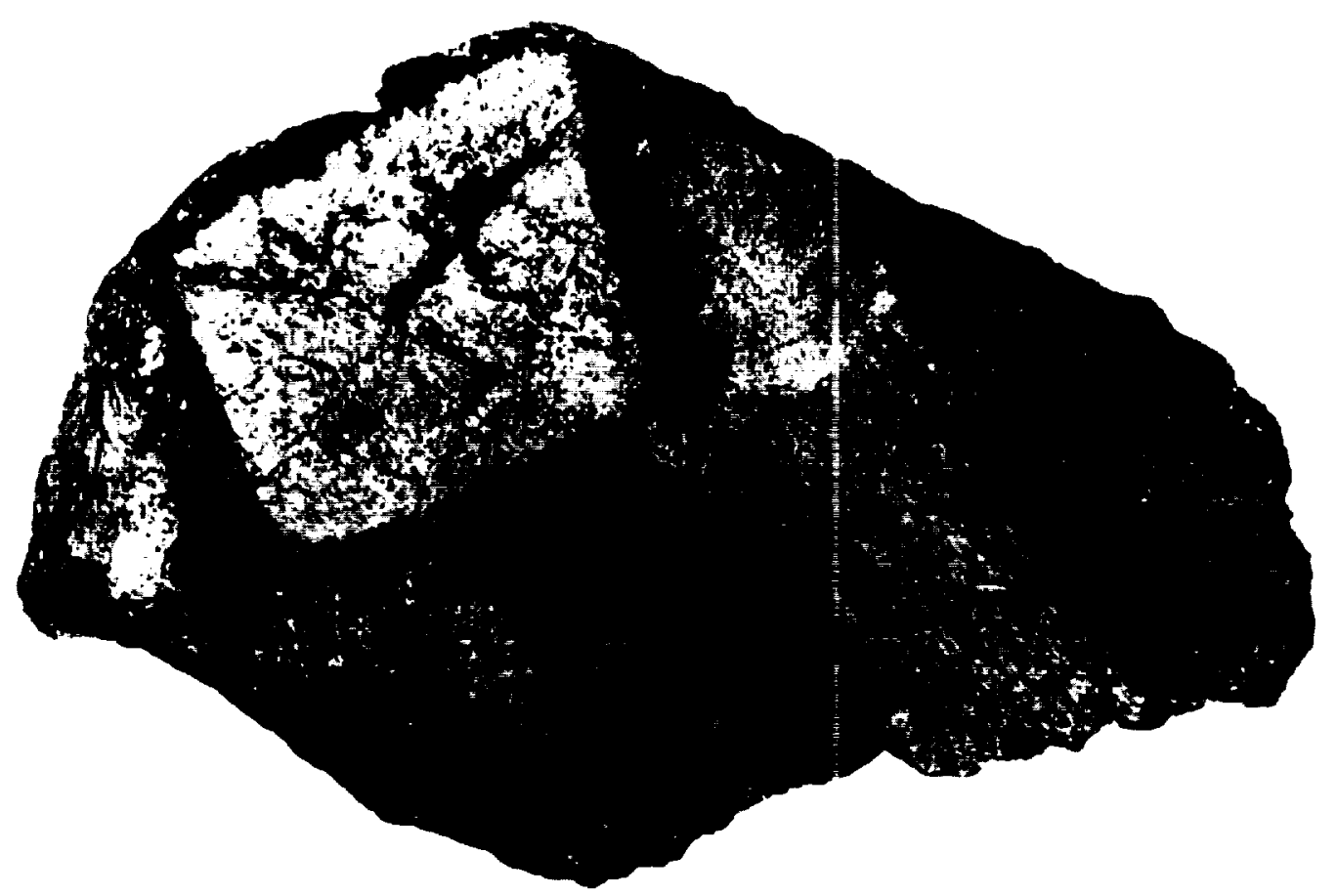

Fig. 5.16. Crater-fill breccia; suevite, "cored" inclusion. Large flow-banded frag nent (about $15 \mathrm{~cm}$ long) from a larger glassy inclusion in the suevite unit of the Ries Crater (Germany) (Bollstadt quarry). The specimen is a composite or "cored" inclusion containing a large block of shocked and fractured crystalline rock (light) surrounded by dark, flow-b inded glass. Photograph courtesy of F. Hörz. 


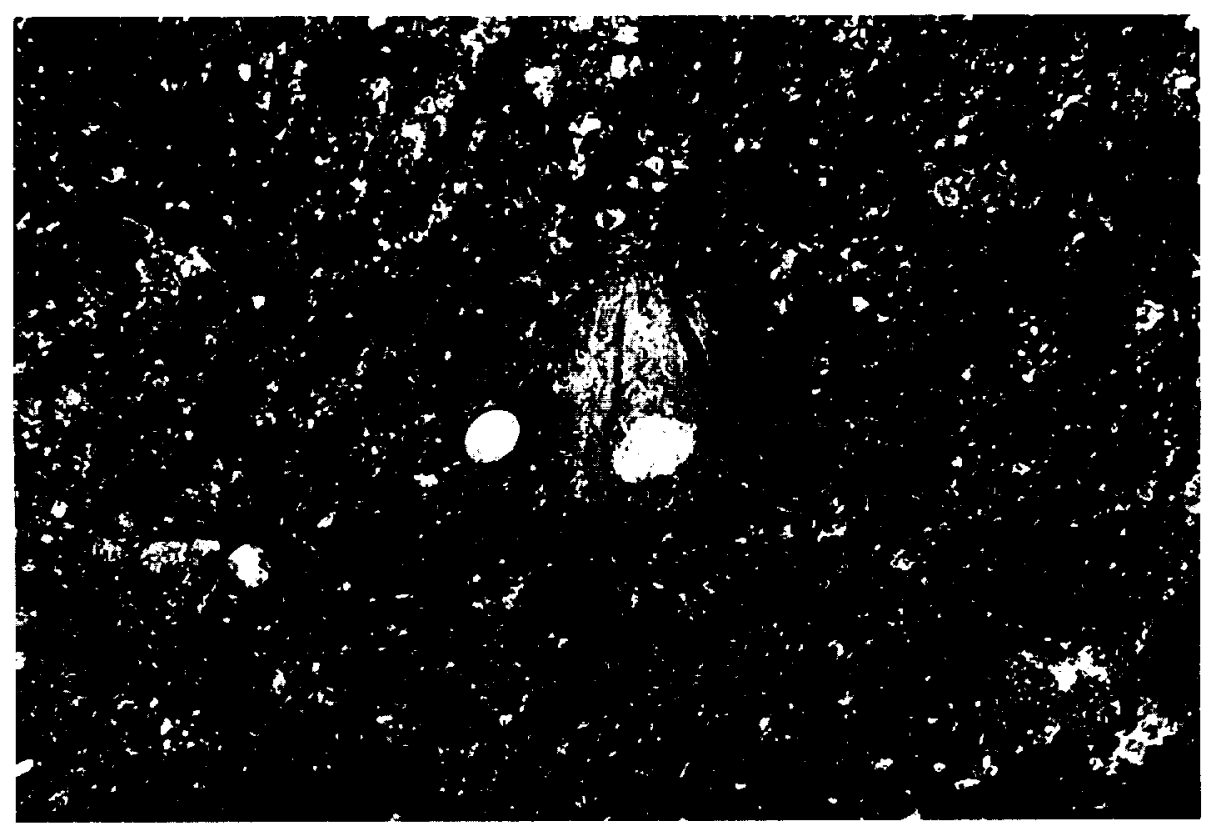

Fig. 5.17. Crater-fill breccia; suevite, "cored" inclusion. Composite (cored) inclusion in Onaping Formation "Black Member" in northwestern corner of Sudbury structure (Canada). Inclusion consists of a core fragment of crystalline granitic rock (light-colored) surrounded by flow-banded glassy material, now recrystallized. Similar inclusions are observed in fresher suevite deposits, e.g., at the Ries Crater (Germany) (see Figs. 5.12 and 5.16). A separate angular granitic fragment appears at lower right. Coin at left of inclusion is about $2 \mathrm{~cm}$ in diameter. Exposure located at "Black Member" type locality at Onaping Falls (Highway 144, Dowling Township). Photograph courtesy of J. Guy-Bray.

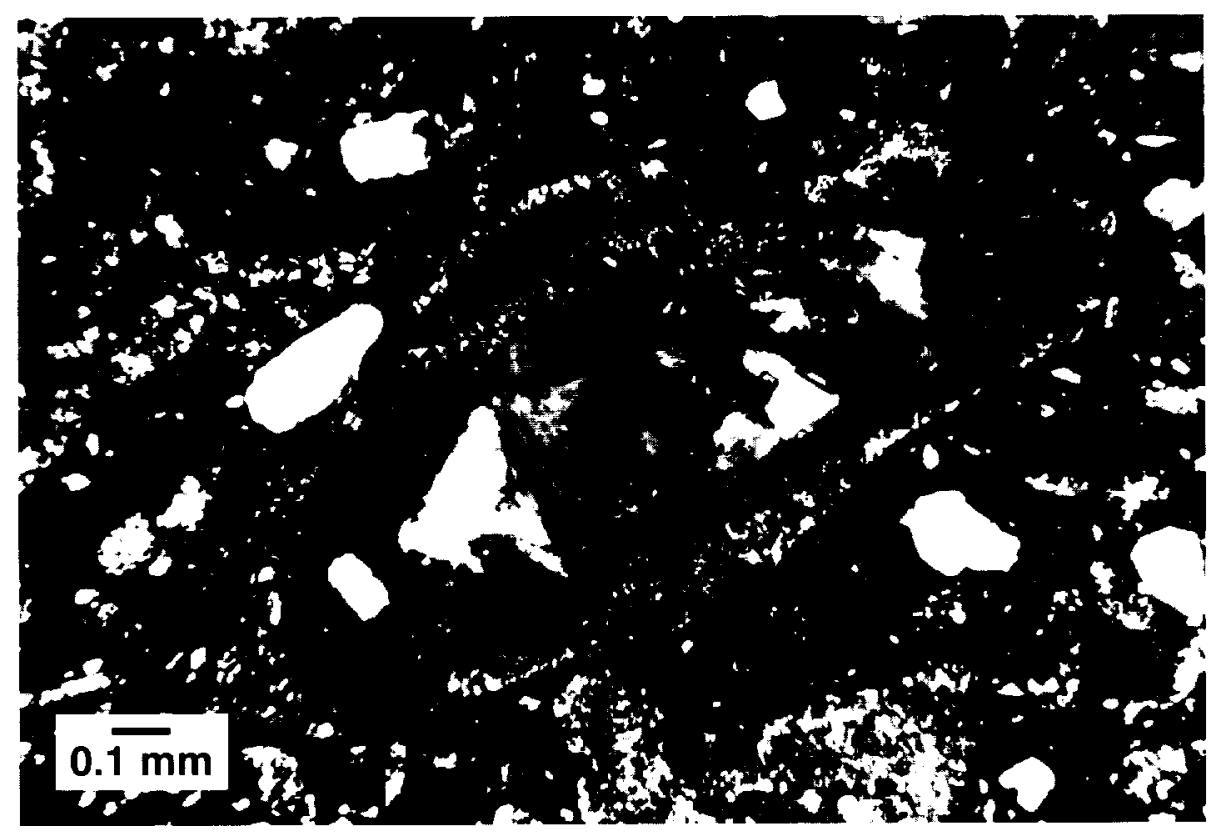

Fig. 5.18. Crater-fill breccia; suevite, "cored" inclusion. Composite rock fragment in metamorphosed suevite unit. The fragment contains a core of fine-grained granitic basement rock surrounded by a rim of microcrystalline recrystallized glass. The fragment is associated with smaller individual clasts of glassy material and rock and mineral fragments in a black, opaque, carbon-bearing matrix. Onaping Formation "Black Member," from type locality at Onaping Falls (Highwiy 144, Dowling Township), northwestern corner of Sudbury structure (Canada). Sample CSF-66-36-2 (cross-polarized light). 
ing are only rarely observed in volcanic explosion structures such as maars and diatremes, and the presence of such rim deformation provides a strong indication of an impact origin for a structure.

In a newly formed crater the rim and the surrounding region are generally covered with allogenic ejecta ejected from the growing transient crater (Melosh, 1989; Chapter 6). Two kinds of ejecta deposits can be distinguished: those deposited near the crater (proximal ejecta) and those distant from the crater (distal ejecta).

Most of the material ejected beyond the crater rim is deposited near the crater (Melosh, 1989, p. 90). In terms of crater radius $\left(\mathbf{R}_{\mathbf{c}}\right.$, the distance from the center of the crater to the final rim), approximately half the ejecta is deposited within $2 \mathrm{R}_{\mathrm{c}}$ from the center (or $1 \mathrm{R}_{\mathrm{c}}$ from the rim) to form a continuous ejecta blanket that may be tens to hundreds of meters thick, depending on the size of the crater. At greater distances, the ejecta unit becomes thinner and increasingly discontinuous; most of the ejecta (>90\%) is deposited within about $5 \mathrm{R}_{\mathrm{p}}$. (This value may serve as an arbitrary boundary between proximal and distal ejecta.) Because many of the fragments in the ejecta deposits were originally close to the impact point, they are often distinctively shocked and melted. Ejecta blankets, where they are preserved, may therefore provide the best and most accessible evidence for an impact origin of the structure.

Ejecta deposits around impact craters are not homogeneous, but are made up of distinct lithologic units derived from different regions of the transient crater and transported by different mechanisms to the site of deposition. Mixing during the ejection and deposition process is not complete, and the ejecta deposits that surround a crater contain the same diversity of rock types that are found as crater fill within the structure: lithic breccias, suevites, and impact melt rocks. In large impact structures, the ejecta deposits preserved outside the crater contain a recognizable sequence of different lithologies. The sequence at the Ries Crater (Germany) (see von Engelhardt, 1990, 1997, and references therein) contains a lower unit of polymict lithic melt-free breccia (Bunte Breccia) overlain by melt-bearing breccia (suevite). Some of the ejecta at the Ries also occurs as large (tens to hundreds of meters in size) limestone blocks ejected intact from the crater and skidded for many kilometers across the surrounding ground surface (von Engelhardt, 1990, pp. 264-265).

In impact structures formed on land, the near-surface regions are quickly removed by erosion, and the distinctive rim uplift and ejecta deposits are observed only at relatively young structures such as the Barringer Meteor Crater (Arizona) (age $50 \mathrm{ka}$ ) (Shoemaker, 1963) and the Ries Crater (Germany) (age $15 \mathrm{Ma}$ ) (von Engelhardt, 1990). At older structures (e.g., Dence, 1965, 1968), distinctively shocked rocks tend to be preserved in only two areas: in the target rocks immediately beneath the crater floor, and in the breccia and melt deposits that fill the crater itself.

\subsection{DISTAL EJECTA}

Althoug 1 most of the material (about 90 vol\%) ejected from the crater is deposited relatively close $\left(<5 \mathrm{R}_{c}\right)$ to the crater (Melish, 1989, p. 90), a significant amount (about $10 \mathrm{vol} \%) \mathrm{m}: \mathrm{y}$ travel to even greater distances $\left(>5 \mathrm{R}_{\mathrm{c}}\right.$ ) to form deposits of listal ejecta. Where an atmosphere is present, as in terrestria impact events, a combination of disruption of the atmospliere by the impact fireball, ballistic ejection from the crater, : nd subsequent atmospheric transport can distribute the : maller ejecta particles (typically $\leq 1 \mathrm{~mm}$ ) to regional or er en global distances (Alvarez et al., 1995). The resulting de oosits, usually less than a few centimeters thick, may contair distinctive evidence for impact: shocked rock and mineral fragments, distinctive chemical and isotopic signatures, anc unusual glassy objects. It has thus become possible to recc gnize debris from a given impact structure over a large area of Earth, and even to establish the existence of a major impa st event from a globally distributed ejecta layer before the s ructure itself could be located.

Althoug a few layers of distal ejecta have been identified, they have keen critical to recognizing large impact structures and $\mathrm{d} t$ termining their age. Coarse ejecta (millimeterto centimetı:r-sized fragments) from the Acraman structure (Australia) $\mathrm{D}=90 \mathrm{~km}$ ) has been recognized as a discrete layer severa centimeters thick at distances of $300-400 \mathrm{~km}$ from the si e (Gostin et al., 1986; Williams, 1986). Ejecta from the $N$.anson structure (Iowa) $(D=36 \mathrm{~km})$ has been recognized nore than $250 \mathrm{~km}$ away (Izett et al., 1993). The most striking and best-known example of distal ejecta is the thin layer o material ejected from the Chicxulub structure (Mexico) an 1 distributed worldwide to form the $\mathrm{K} / \mathrm{T}$ boundary layer (A. varez et al., 1980; papers in Sharpton and Ward, 1990, and ir Ryder et al., 1996). The occurrence in this layer of shocked ' puartz grains and small spherules of melted target rock, ac :ompanied by an anomalously high content of the element iridium (derived from the projectile), provided conclusive $\epsilon$ vidence that a large meteorite impact had occurred at th: end of the Cretaceous Period, even before the Chicxulub i mpact structure itself was identified. The layer also providerl key geochemical and geochronological evidence to demonstr ate that the Chicxulub structure was identical in age to the $\mathrm{K} / \mathrm{T}$ boundary and that it was also the source for the global ejecta layer itself.

Generall , ejecta found at greater distances from the crater displays $a$ higher level of shock effects, and much distal ejecta consis ts of small fragments of melted target rock. One peculiar and much-studied variety of distal ejecta is tektites and micrott ktites, small (centimeter- to millimeter-sized) bodies of pu re glass that have been ejected from a few impact structures and spread over areas (strewnfields) that may be thousands of kilometers in extent (see Chapter 6). 


\section{6}

\section{Impact Melts}

\subsection{FORMATION CONDITIONS}

One of the most unique features of the impact process is the virtually instantaneous melting of significant amounts of target rock, followed by the rapid distribution of this impact melt throughout the resulting crater to produce a variety of unusual crystalline and glassy igneous rocks. All impact-generated shock waves deposit some of their original energy as heat within the target rocks through which they pass. At relatively low shock pressures ( $\leq 40 \mathrm{GPa}$ ), the resulting postshock temperature rise is moderate $\left(\leq 500^{\circ} \mathrm{C}\right)$, or below the melting points of most rock-forming minerals (Table 4.2). At higher pressure ( 40-50 GPa), the higher temperatures produce significant melting, and at pressures ( $\geq 60 \mathrm{GPa}$ ) near the impact point, the shock waves deposit sufficient thermal energy to completely melt a large volume of target rock. The subsequent dynamic processes of crater formation spread this impact melt within and outside the crater as small bodies of glass in breccias and as larger bodies of crystalline igneous rock of varying size, shape, and appearance (Dence, 1971; Grieve et al., 1977, 1991b; Grieve and Cintala, 1992; Schuraytz et al., 1994). In large (D > $25 \mathrm{~km}$ ) impact structures, especially those produced in crystalline igneous and metamorphic rocks, tens to hundreds of cubic kilometers of impact melt may be produced, and impact melt units can become a significant part of the geology of the structure (Fig. 6.1).

The formation of impact melts has no counterpart in other geological processes, and many details of how impact melts are formed, moved, and emplaced are still not clear. However, some general features of the process and its geological consequences have been outlined by combining theoretical models with geological studies of impact structures (Dence, 1971; Dence et al., 1977; Grieve, 1978; Grieve et al., 1977, 1981, 1991b; Grieve and Cintala, 1992; Cintala and Grieve, 1998). During the initial stages of an impact event at typical cosmic encounter velocities, postshock temperatures $\geq 2000^{\circ} \mathrm{C}$ are produced through a large volume of target rock close to the impact point (Fig. 3.2) (O'Keefe and Abrens, 1975, 1977; Abrens and O'Keefe, 1977; Melosh, 1989, pp. 63-64 and 122-123).

These postshock temperatures are far above the normal melting points of the target rocks and their constituent minerals. As a result, when the shock wave has passed and the pressure returns to normal, spontaneous and complete melting occurs almost instantaneously throughout a large and approximately spherical volume of target rock. The shock waves that have melted the target rock also provide kinetic energy to accelerate the newly formed melt, which immediately becomes part of the overall flow and movement of target rock that opens up the transient crater (Fig. 6.2) (Dence, 1971; Grieve et al., 1981; Grieve, 1987).

A special kind of melt formation and ejection may occur during the earliest stages of contact in small regions near the interface between the projectile and the target (Fig. 3.1). In this region, extremely high shock pressures are generated, producing correspondingly high temperatures $\left(>5000^{\circ} \mathrm{C}\right)$ in the shocked material. The resulting melted and vaporized material may then be ejected as high-velocity jets, at speeds that may exceed the original impact velocity (Melosh, 1989, pp. 51-53). Depending on the amount of atmospheric resistance encountered, the jets can carry material to significant distances, forming deposits of small spherules or larger glassy bodies (Melosh and Vickery, 1991). However, such material, which may be a mixture of vaporized projectile and target rock, is relatively minor in comparison to the large volume of melt generated subsequently within the crater.

This larger melt volume, initially located near the center of the structure, is driven downward and outward toward the floor of the developing transient crater at initial velocities of a few kilometers per second (Fig. 6.2). When the melt reaches the transient crater floor, it turns and moves upward and outward along the floor (Grieve et al., 1977). At this point, the movement of the melt becomes slower and 


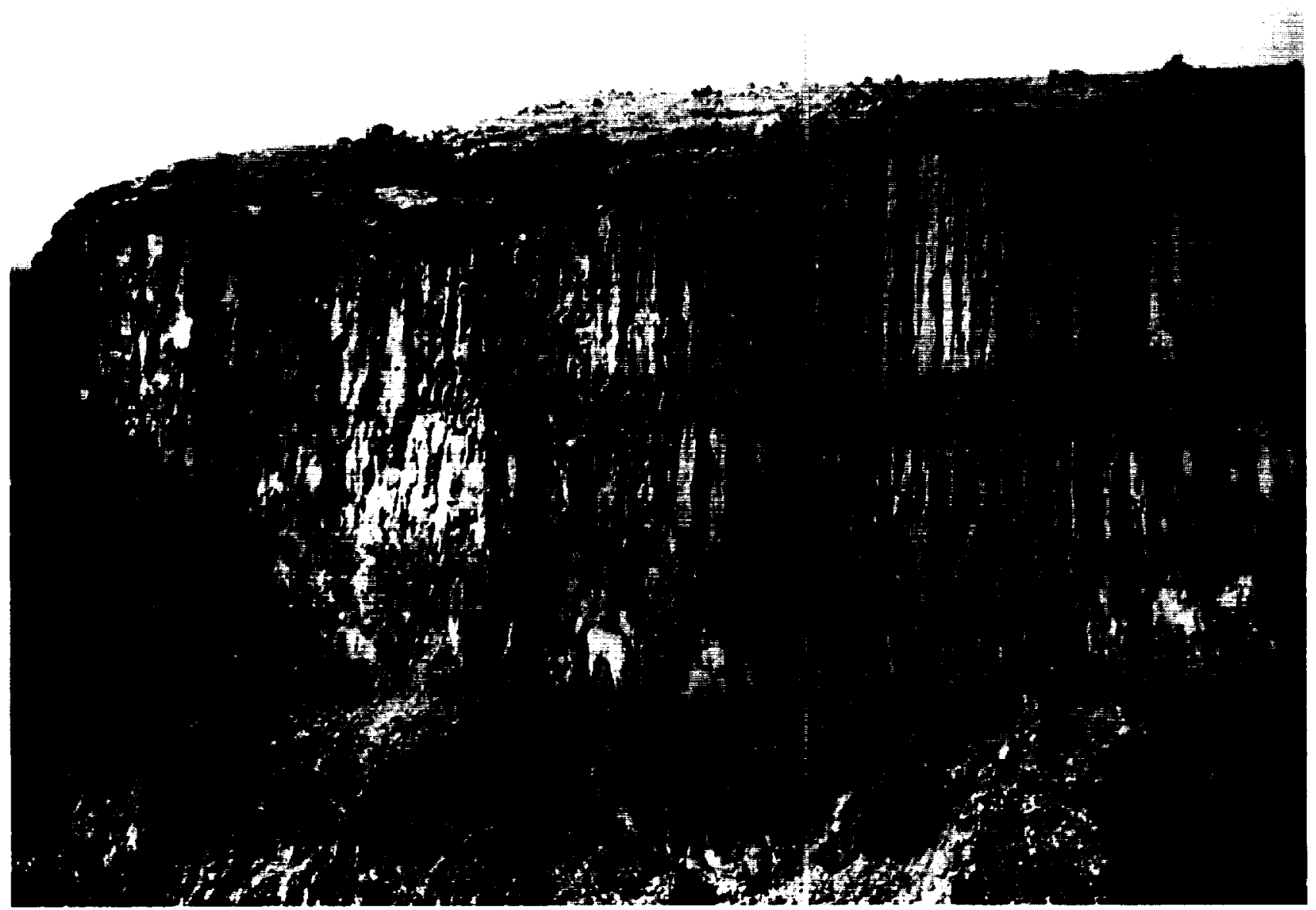

Fig. 6.1. Impact melt rock; cliff with columnar jointing. Exposed erosional rem rant of annular impact melt sheet at Mistastin Lake (Canada), forming a steep cliff about $80 \mathrm{~m}$ high. The melt unit strongly resembles e posures of normal endogenic igneous rocks and even shows two tiers of typical columnar jointing. Photograph courtesy of R. A. F. Grie te.

more complicated. The moving melt begins to incorporate cooler inclusions from the floor and wall of the transient crater. As these inclusions are assimilated, the melt cools rapidly and may subdivide into distinct units of clast-rich impact melt breccia and clast-poor impact melt (Simonds et al., $1976,1978 \mathrm{a}, \mathrm{b}$ ). Some of the outward-flowing melt might possibly reach the original ground surface, escape from the crater, and spread out over the area surrounding the crater rim like a lava flow before it solidifies. Such extrusive impact melt bodies may exist around a few well-preserved terrestrial impact structures (e.g., French et al., 1970), but the identifications so far are uncertain and such units will not be preserved in older, deeply eroded structures.

The only impact melt definitely known to be ejected from the crater occurs in small $(<50 \mathrm{~cm})$ objects composed of rock and mineral clasts in a matrix of rapidly quenched glass; these melt bodies (Fladen) form an important component of the melt-fragment breccias (suevites) deposited in and around the final crater. Most of the coherent melt layer remains within the evolving crater and finally comes to rest on top of breccias that have already partially filled the crater. Geological support for this model comes from the observed concentration of melt-rich materials in the upper part of the crater-fill treccia deposits at both large and small impact structures (Dence, 1968; Grieve, 1978; Grieve et al., 1977).

In small impact structures, e.g., Brent (Canada), most of the preserv $\mathrm{d}$ impact melt occurs as small bodies in suevites and as the matrixes of clast-rich breccias. In larger structures, wher: more melt is produced, e.g., Clearwater Lakes (Canada) and Manicouagan (Canada), the melt may also form thick coherent bodies that extend over much of the interior of the final structure (Fig. 6.1) (Dence, 1971; Grieve et al., 1977) In the past, these occurrences of apparently normal volcani : or intrusive igneous rocks were frequently cited as evidence for the internal origin of many structures now accepted as the results of meteorite impact. However, unlike normal ign: ous rocks, which originate by equilibrium melting deep wi hin the Earth and then rise slowly to the surface as molten r nagma, impact melts are produced by the rapid and comple te melting of near-surface target rocks directly beneath th : impact site itself. This different origin leaves distinctive features in the resulting impact melts, such as shock-metamorphosed inclusions, evidence of extremely high temperatur :s, unusual bulk chemical compositions, or chemical signatures from the projectile itself. It is therefore possible to dist nguish impact melts from normal igneous rocks. 


\subsection{IMPACT MELT VOLUMES AND CRATER SIZE}

Impact melt is a significant component of the rocks produced by the cratering event, especially in large impact structures. Theoretical estimates suggest that, at typical impact velocities of $15-30 \mathrm{~km} / \mathrm{s}$, as much as $40-60 \%$ of the total kinetic energy of the impacting projectile is transferred into the target rocks as thermal energy. Even though not all this energy is effective in melting the target, the volume of impact melt produced may still be 10 to $>100 \times$ the volume of the original projectile (depending mostly on the projectile's impact velocity) (O'Keefe and Abrens, 1975, 1977; Abrens and O'Keefe, 1977; Melosh, 1989, pp. 63-64 and 122-123). Additional studies (Grieve and Cintala, 1992) suggest that the volume of impact melt produced $\left(\mathrm{V}_{\mathrm{m}}\right.$, in cubic kilometers) increases expontentially with crater diameter ( $D$, in kilometers) and that the two quantities can be related by an equation of the form

$$
\mathrm{V}_{\mathrm{m} 1}=\mathrm{cD}^{\mathrm{d}}
$$

Application of theoretical and experimental cratering studies suggests approximate values of $c=0.0004$ and $D=$ 3.4 for the dataset used (Grieve and Cintala, 1992).
This relation indicates that large impact events (which form large craters) produce proportionately larger volumes of impact melt (Dence, 1971; Grieve and Cintala, 1992), but the available data (both theoretical and geological) are not precise enough for detailed estimates. Theoretical problems include significant uncertainties in various experimental parameters, as well as the difficulty of extrapolating the results of small laboratory experiments to the conditions of large impact events.

There are also several geological complications. Target rock compositions and physical properties are apparently important. Some large impact structures [e.g., Ries Crater (Germany)] contain little impact melt. This anomaly is explained (Kieffer and Simonds, 1980; Grieve and Cintala, 1992) by the observation that the target rocks in these melt-poor structures contain significant amounts of sedimentary rocks. Unlike crystalline rocks, sedimentary rocks may be both porous (e.g., sandstones) and volatile-rich (limestone, dolomites, and evaporites). Although impacts into porous rocks tend to produce proportionately more melt than impacts into denser crystalline rocks (Kieffer, 1971; Kieffer and Simonds, 1980; Stoffler, 1984), much of the melted material may form small vesicular aggregates that are ejected from the crater with a plume of expanding volatiles (Kieffer and Simonds, 1980). Crater size has another effect: Relatively more melt is ejected

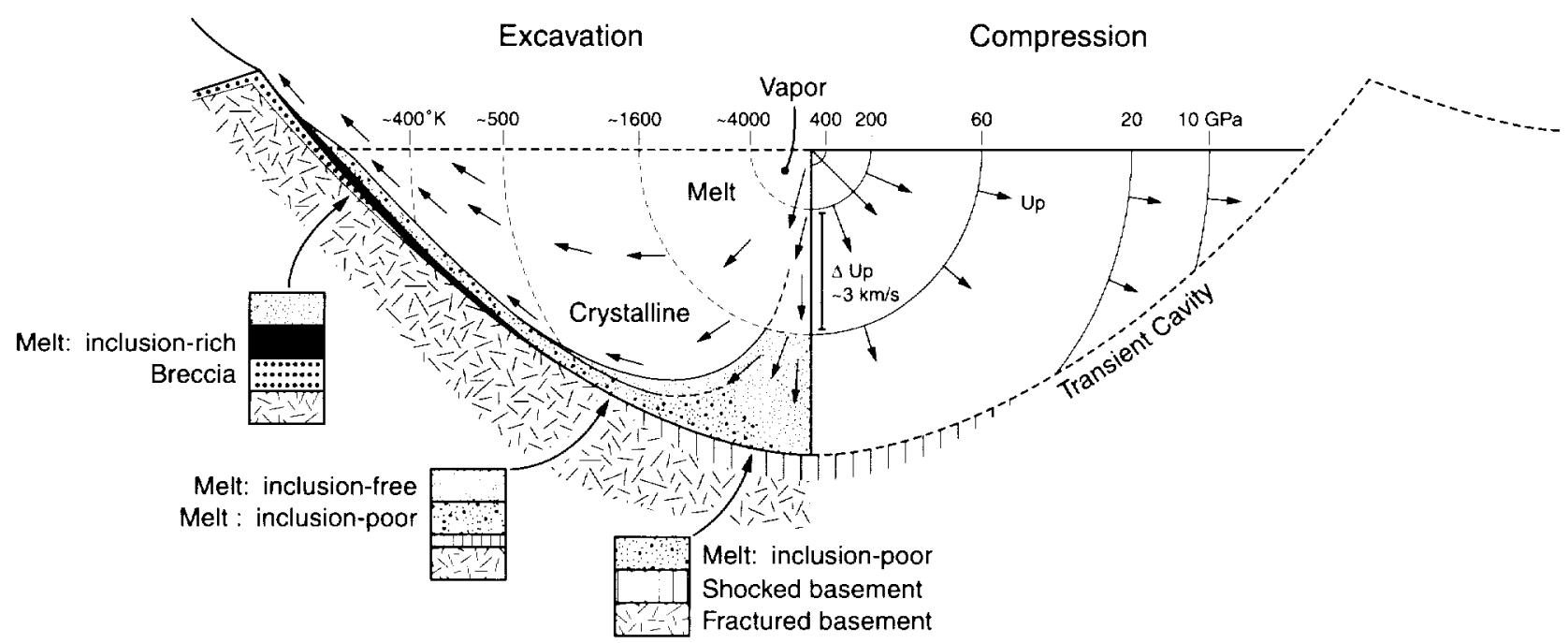

Fig. 6.2. Impact melt; formation and movement through transient crater. Cross-section diagram through a transient crater, showing formation and subsequent movement of impact melt. Concentric circles around the original impact point show isobars of peak shock pressures (right side, "Compression," in GPa) and isotherms of postshock temperatures (left side, "Excavation"). The small zone of pressures $>200 \mathrm{GPa}$ close to the impact point is briefly occupied by a mixed projectile-target vapor; the original body of impact melt forms immediately outward from this zone at pressures $>60 \mathrm{GPa}$. Kinetic energy, imparted to the melt volume by shock waves, drives the originally hemispherical volume of melt downward and outward with particle velocities $\left(U_{p}\right)>1 \mathrm{~km} / \mathrm{s}$. When the melt reaches the floor of the excavation zone, it turns and flows upward along the developing transient crater floor. During this stage, the melt can incorporate xenoliths of shocked and unshocked rocks from the crater floor and walls, and it may separate into inclusion-free, inclusion-poor, and inclusion-rich varieties. Some flowing melt may even reach the ground surface and spread out beyond the crater rim. During the subsequent crater modification stage, the melt located at high levels on the floor near the rim slumps back into the crater to form disseminated small bodies and larger layers of melt toward or at the top of the crater-fill breccias. (Modified from Grieve et al., 1977, Fig. 5.) 
from smaller craters than from larger ones, and the ejected melt is less apt to be preserved in geologically old structures. Additional geological uncertainties include (1) difficulties in estimating the original volume of eroded impact melts in older structures and (2) uncertainties in estimating melt volumes in poorly exposed structures or in buried structures explored only by drilling.

Because of these uncertainties, impact melt volumes measured in actual impact structures differ from the calculated values by factors of as much as $2-7 \times$, and calculated impact melt volumes generally exceed measured ones (Grieve and Cintala, 1992, Fig. 3). These differences are reasonable in view of the theoretical and experimental uncertainties involved, and the model is good enough for general predictions. For instance, the model clearly shows that the volume of impact melt formed in small craters (diameter $<5 \mathrm{~km}$ ) is relatively small $\left(\leq 1 \mathrm{~km}^{3}\right)$. Even so, this melt is important. It generally occurs as distinctive glass fragnents in breccias deposited in and around the crater, and these fragments are often easily identified as impact products. However, because melt volume increases even more rapidly than the cube of crater diameter, impacts of larger projectiles $(D=1-$ $10 \mathrm{~km}$ ), which produce craters $10-200 \mathrm{~km}$ across, can generate 10 to $>1000 \mathrm{~km}^{3}$ of impact melt. Such volumes are similar to those of many units of internally generated igneous rocks, and it is not surprising that many large impact structures were originally identified as the results of major endogenic igneous events.

\subsection{IMPACT MELT VARIETIES IN THE NEAR-CRATER ENVIRONMENT}

Virtually all ( $>99$ vol\%) the melt formed in an impact event is deposited within the resulting crater or within a few crater radii beyond the rim (D'nce', 1971; Grieve et al., 1977; Grieve and Cintala, 1992). In these locations, the impact melt occurs in a variety of forms: (1) discrete, small (millimeter- to centimeter-sized), irregular, generally glassy objects in suevite crater-fill breccias or in nearby ejecta deposits around the crater; (2) glassy or crystalline matrices of clast-bearing allogenic breccias (impact melt breccias) in the crater-fill deposits; (3) larger bodies of more slowly cooled igneous rock that occur as sills within the crater-fill deposits or intrude the subcrater rocks as dikes. In large structures, these latter bodies may be tens to hundreds of cubic kilometers in volume.

\subsubsection{Small Glassy Bodies}

Much of the impact melt, especially in small structures, occurs as individual discrete bodies in the allogenic breccia deposits in and immediately around the crater. In these units, the impact melt forms small, discrete, irregular bodies typically a few millimeters to about $20 \mathrm{~cm}$ in size, which may superficially resemble volcanic lapilli and bombs in size and shape. The material from the Ries Crater (Germany), which includes irregular, flattened, and aerodynamically sculptured bodies (Fla ten), is perhaps the best-known and most-studied example of this type of material (Hörz, 1965; von Engelhardt , tal., 1969; von Engelhardt and Graup, 1984; von Engelhardt, 1990, 1997). However, similar objects occur in suevite brec cias from numerous other impact structures.

These sr all melt bodies consist of rock and mineral fragments in a natrix of fresh or altered flow-banded glass. In thin sections, the rock and mineral fragments are frequently angular to harp in outline, and their shapes indicate that they are briken clasts derived from the target rocks. The fragments lso show a range of shock-metamorphic effects: fract tring, development of PDFs in quartz and feldspar, diaplectic glasses, and even incipient melting. The fragments ( ccur in a matrix of glass (often brownish in thin section) wh ch shows distinctive turbulent and heterogeneous flow structure, with compositionally different flow zones (Figs. 6.3, (.4, and 6.5).

These ir upact glass bodies also show evidence of shockproduced to mperatures far above those of conventional igneous proce ises. The most typical high-temperature indicator is the melti $2 \mathrm{~g}$ or decomposition of inclusions of refractory minerals de rived from the target rocks (particularly quartz, zircon, and sphene), for which temperatures of $>1400^{\circ}-$ $1800^{\circ} \mathrm{C}$ are equired (Figs. 6.6, 6.7, and 6.8) (El Goresy, 1965, 1968; French, 1972, pp. 23-24). The most common indicator of high temperatures in these glasses is the presence of silica glass (echatelierite), which has been formed from original quartz grains at temperatures above $1713^{\circ} \mathrm{C}$. This lechatelierite oft $n$ mixes incompletely with the other melt before cooling, pre ducing clear streaks (schlieren) of pure silica in the glass (Fig. 6.3).

Small budies of impact glass can be distinguished from normal vol anic products (e.g., obsidian, lapilli, and volcanic bombs) by their nonvolcanic features, evidence of extremely hig a temperatures (e.g., lechatelierite), and textures indicating strong disequilibrium [e.g., unabsorbed streaks or layers of pure silica (lechatelicrite) in the glass]. Because of its high forr ation temperature, the presence of lechatelierite in apparent $y$ "volcanic" glasses is an especially reliable indicator that hey are actually impact-produced melt rocks. (Lechatelierite is not found in any other natural materials except fulgurites, which are thin rube-like structures produced by the fusion of soil by lightning strikes. In particular, lechatelieri $e$ is not found in internally generated igneous rocks.) In addition, the rock and mincral inclusions in impact glassec are derived from the target rocks and not from cogenetic il,neous rocks. These inclusions are broken fragments (clasts), not phenocrysts, and a small percentage of them (typi ally $~ 1 \%$ ) display definite shock-metamorphic features: P JFs, isotropization, and high-temperature melting. Such $\mathrm{c}$ asts provide additional evidence for the impact origin of tha melt rock.

\subsubsection{Impact Melt Breccias}

Large budies of impact melt, which generally remain inside the cra er, cool more slowly and may flow for significant distances be fore solidifying (Dence, 1971; Grieve et al., 1977). 


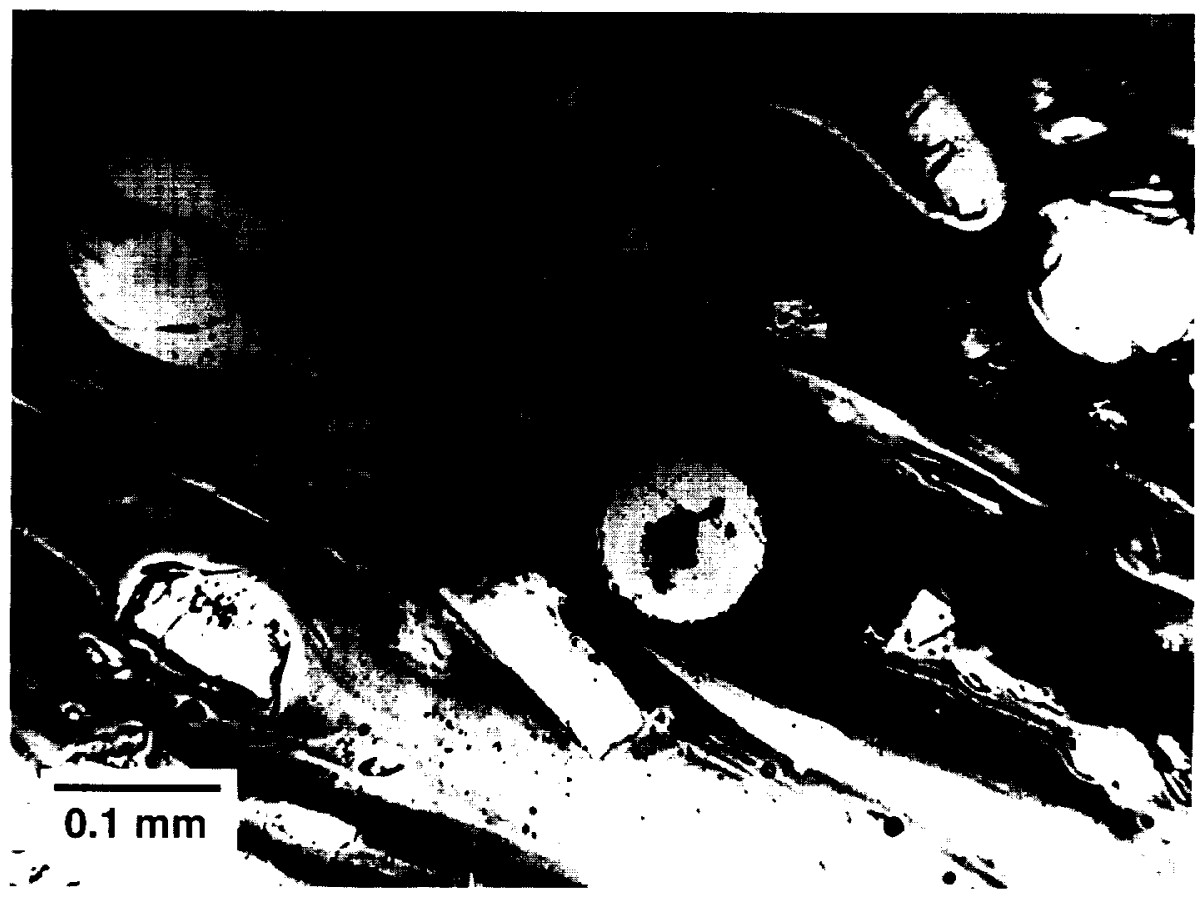

Fig. 6.3. Impact melt rock; Fladen (glass) with schlieren. Brownish, heterogeneous, flow-banded glass of granodioritic composition from glassy fragment (Fladen) in suevite breccia. The fragment contains spherical vesicles and irregular mineral fragments, mostly quartz. The matrix glass shows well-developed, locally laminar flow structure with discrete bands and streaks (scblieren) of high-silica glass (clear). Pure quartz glass (lechatelierite) also occurs as fluidal inclusions (clear; upper left), indicating shock melting of original quartz grains at temperatures above $1700^{\circ} \mathrm{C}$. From suevite in Otting quarry, Ries Crater (Germany). Photo courtesy of W. von Engelhardt (plane-polarized light).

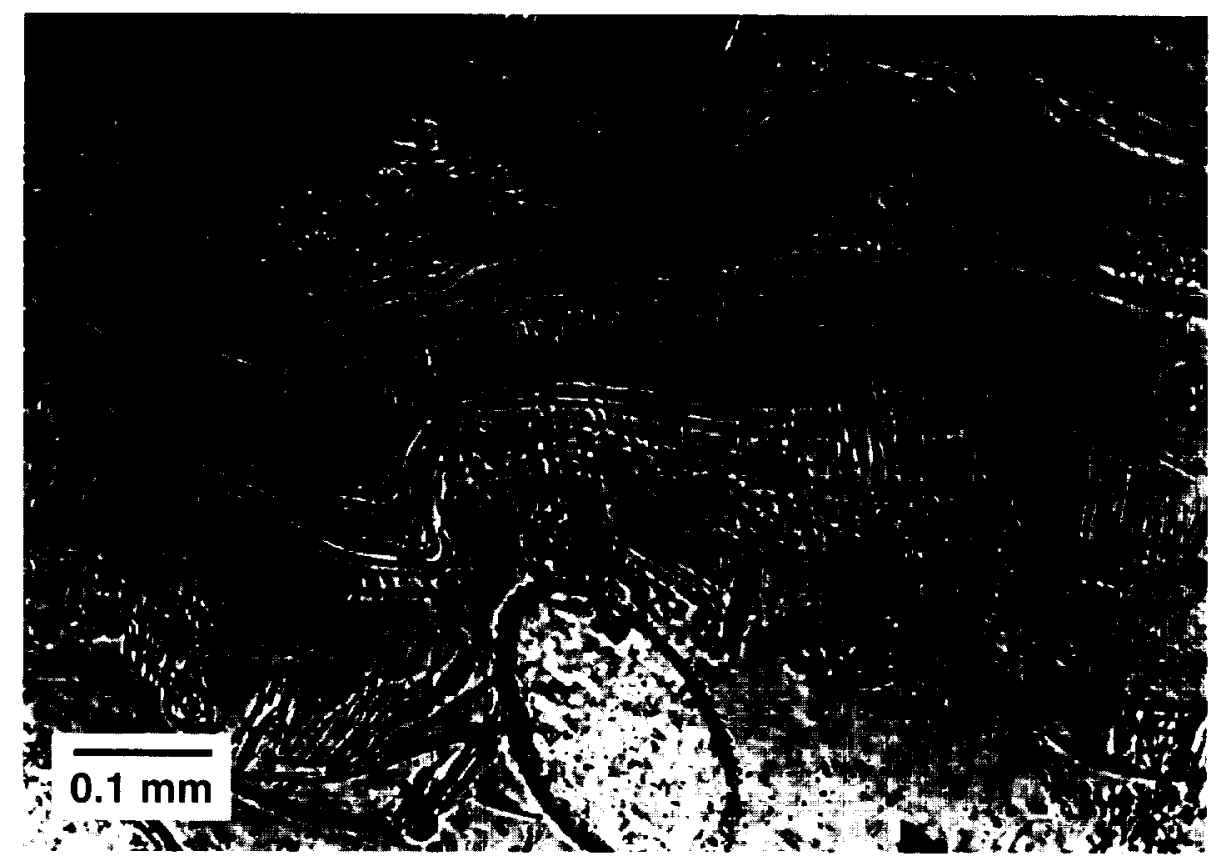

Fig. 6.4. Impact melt rock; Fladen (glass) with schlieren. Dense, heterogeneous, flow-banded glass from fragment in suevite breccia. Locally laminar flow-banding contains streaks and bands of quartz glass (lechatelierite) (clear) formed by shock melting of original quartz grains at temperatures above $1700^{\circ} \mathrm{C}$. Part of an included quartz grain (dark) appears at top, with flow-banding distorted around it. A filled vesicle (white) appears at bottom. Drill core sample from West Clearwater Lake (Canada). Photo courtesy of M. R. Dence. Sample DCW-4A-63-170.7 (plane-polarized light). 


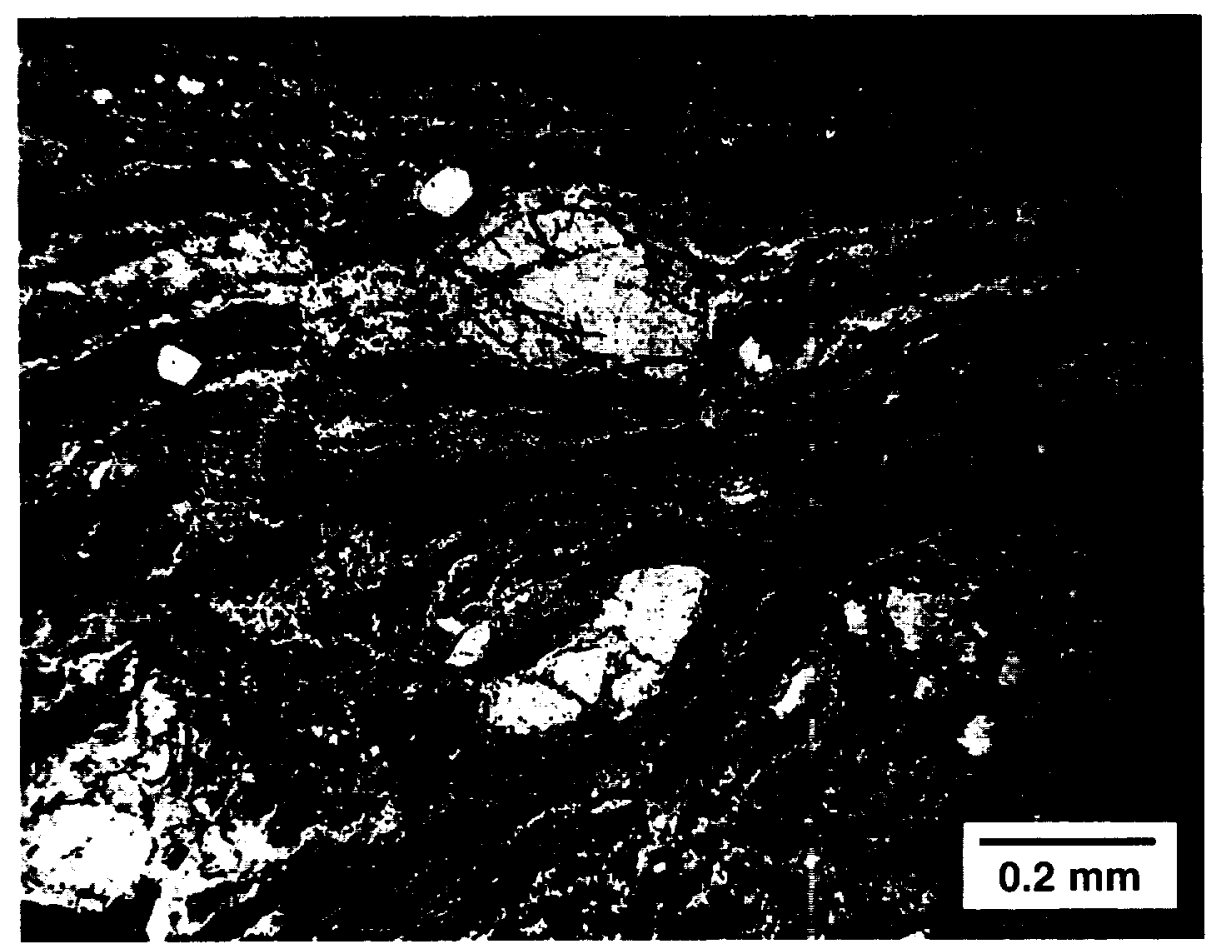

Fig. 6.5. Impact melt rock; recrystallized Fladen (glass) with flow-banding. Recry tallized glassy fragment from metamorphosed suevite breccia, containing rock and mineral clasts in heterogeneous, flow-banded recrystal lized glassy material. Despite postimpact greenschist metamorphism, original heterogeneous flow banding is still preserved by the distrit ution of secondary minerals, chiefly quartz, feldspar, chlorite, and amphibole. The mineral clasts are rounded, angular, or irregular, ar d they lack the phenocryst shapes typical of glassy volcanic rocks. Quartz clasts (c.g., at top) rarely contain preserved indistinct PD is, indicating that shock-deformation, melting, and mixing of rock fragments and melt were part of the same process. Sample from Onaping Formation, "Black Member," Sudbury (Canada). Sample CSF-67-64 (plane-polarized light).

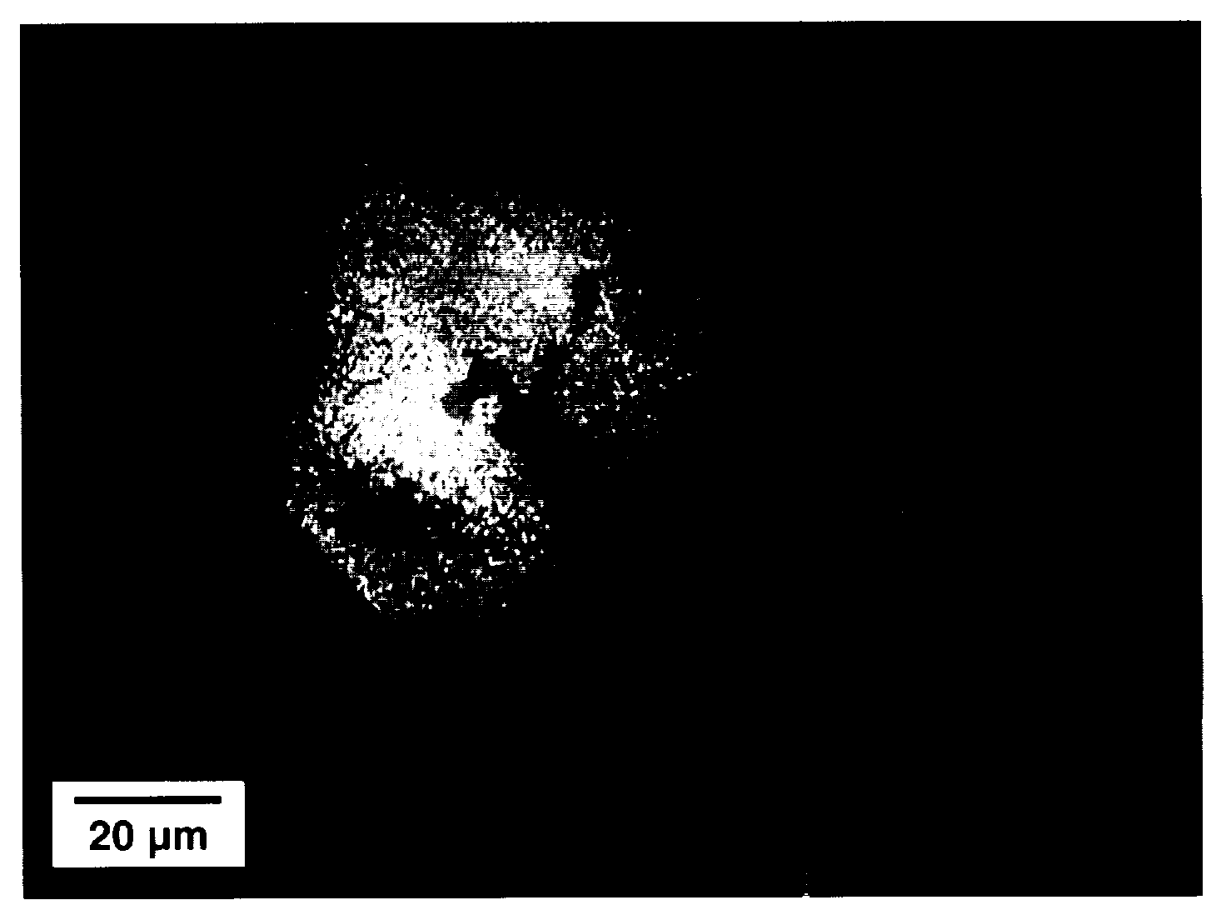

Fig. 6.6. High-temperature effects; melted (decomposed) zircon. A single grain of zircon $\left(\mathrm{ZrSiO}_{4}\right)$ from preimpact target rocks, incorporated into a frigment of high-temperature impact-melt glass ejected from the Aouelloul Crater (Mauritania). The original zircon is now melted and decomposed to a granular aggregate of the mineral baddeleyite $\left(\not{2} \mathrm{rO}_{2}\right)$ (small bright dots) and silica glass. This decomposition occurs experimentally only at temperatures above $1750^{\circ} \mathrm{C}$, and the presence of this reaction is clear evidence of high temperatures associated with meteorite impact events. Reflected light photomicrograph; courtesy of A. El Goresy. 


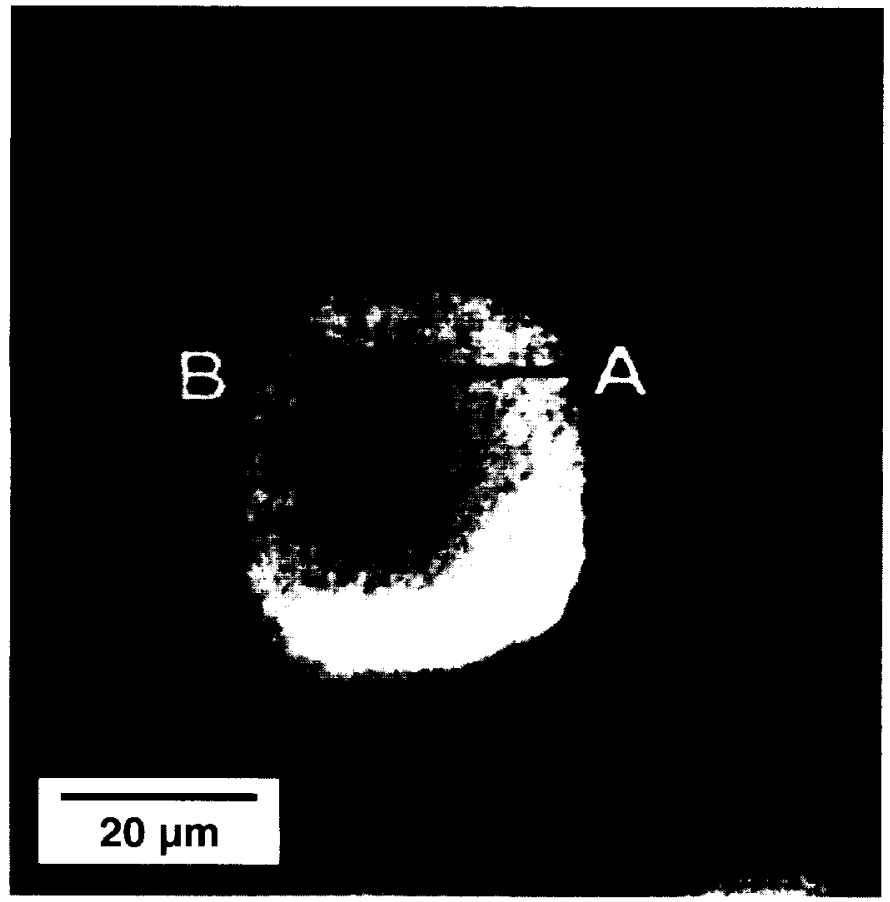

Fig. 6.7. High-temperature effects; melted (decomposed) zircon. Small rounded zircon grain, incorporated into impactmelt glass from preimpact target rocks. The rim of the grain shows partial decomposition of the zircon $\left(\mathrm{ZrSiO}_{4}\right)$ to baddeleyite $\left(\mathrm{ZrO}_{2}\right)$ (white, strongly reflecting), while the core of the grain consists of unaltered zircon (gray). From a fragment of impact glass from Möttingen, Ries Crater (Germany). Reflected light photomicrograph; courtesy of A. El Goresy.

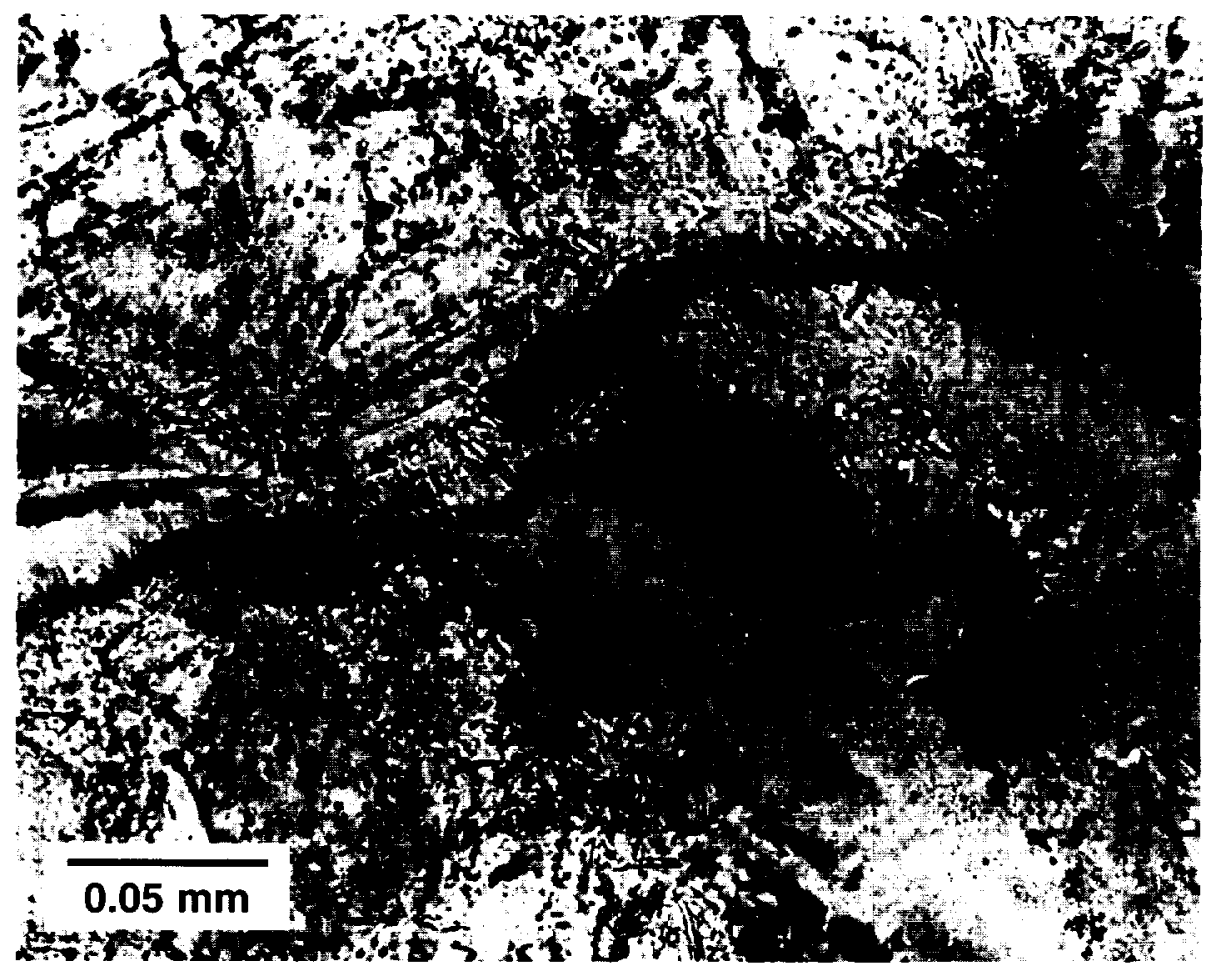

Fig. 6.8. High-temperature effects; melted sphene. Shocked and recrystallized quartzofeldspathic inclusion in metamorphosed suevite breccia. Original quartz (gray, higher relief; left) is largely unchanged. The grains are irregularly fractured and occasionally show decorated PDFs, e.g., two indistinct sets in the grain at upper left. Feldspar (clear, lower relief) is recrystallized. The clear needle-like minerals along the grain boundaries are probably secondary amphibole. Local melting and short-range flow are indicated by scattered dark flow-banded areas, possibly involving original opaque minerals. A small sphene grain (right center; arrow) (melting point $\sim 1400^{\circ} \mathrm{C}$ ) shows incipient melting, indicating unusually high localized temperatures. The right half of the grain preserves the original euhedral shape, while the left half has been converted into a spray of dark fine droplets that are being dispersed through the surrounding (plastic?) feldspar. Preservation of half the sphene grain indicates that the melting was both highly localized and rapidly quenched, as is typical for shock-metamorphic reactions. Granitic inclusion in Onaping Formation "Black Member," Sudbury (Canada). Sample CSF-67-72 (plane-polarized light). 
During movement and cooling, the melt may mix with colder rock fragments, both shocked and unshocked. Where these fragments are abundant (e.g., > 50-75 vol\% of the total rock), their introduction causes the melt to cool and solidify rapidly. The resulting rock is an impact melt breccia (or meltmatrix breccia) containing rock and mineral fragments in an igneous matrix of glassy or crystalline impact melt (Figs. 6.9 and 6.10). Impact melt breccias occur in a wide range of crater sizes and locations. They form small irregular pods and lenses a few meters to tens of meters in size, within larger units of suevites or other crater-fill breccias. They may also form the marginal zones of larger bodies of clast-poor or clast-free impact melt. In these associations, the clast-bearing impact melt breccia may grade continuously into clastpoor impact melt (Simonds et al., 1976, 1978a).

\subsubsection{Large Crystalline Bodies (Dikes and Sills)}

The formation of larger impact structures may generate several hundred to a few thousand cubic kilometers of impact melt, which collects within the crater to form large, slowly cooled, and generally crystalline bodies of igneous rock (Dence, 1971; Grieve et al., 1977; Simonds et al., 1978a,b;
Grieve et al., 1987; Schuraytz et al., 1994). These impact melt bodies occu : in two basic forms: (1) as horizontal sill-like bodies with $n$ the breccias that fill the craters, or (2) as dikelike bodies hat penetrate the basement rock beneath the crater floor.

In small impact structures $(D<5 \mathrm{~km}$ ), most of the impact melt pr sduced is distributed through the crater-fill breccias as discr ste fragments typically $<10 \mathrm{~cm}$ in size, and any bodies of $\mathrm{cr}$ stalline impact melt are correspondingly small. Examples ir clude the small pool of melt in the center of the Brent Crater (Canada) (D = 3.8 km) (Dence, 1968; Grieve, 1978) (Fig. 3.7) and the possible dikes of impact melt just outside the im of the Tenoumer Crater (Mauritania) (D = $1.9 \mathrm{~km}$ ) (Fr meb et al., 1970; Fudali, 1974).

Howeve , in larger structures, most of the impact melt forms sill-like and dike-like bodies that can be extensive (Fig. 6.1). The layers of impact melt in several structures [e.g., West Zlearwater (Canada) and Popigai (Russia)] are several hunilred meters thick and contain 80 and $1750 \mathrm{~km}^{3}$, respectively, of igneous rock (Dence, 1968; Grieve and Cintala, 1992). The well-known "Vredefort Granophyre" (formerly called the "]3ronzite Granophyre") at Vredefort (South Af-

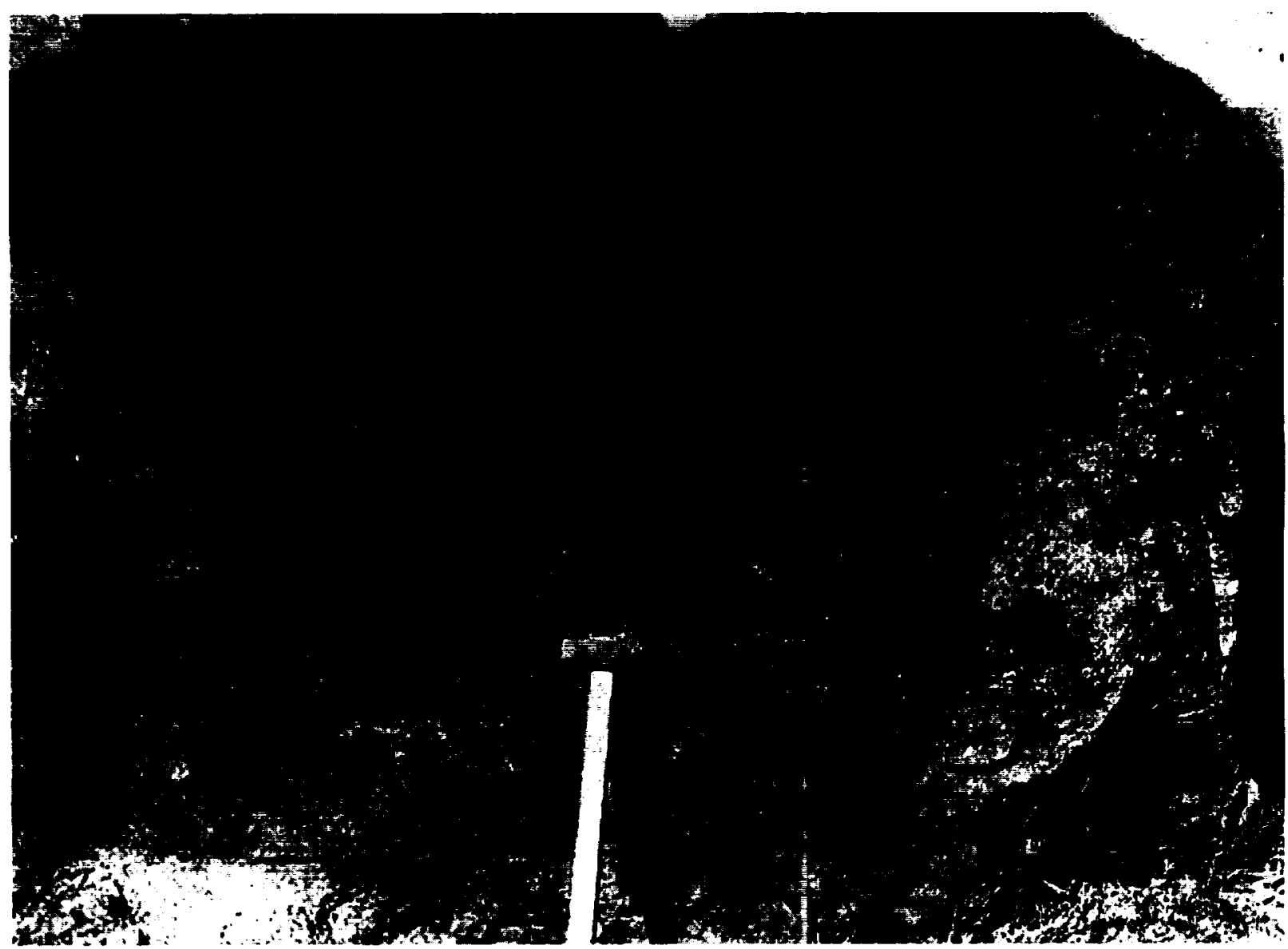

Fig. 6.9. Impact melt rock; breccia, dike. Exposure of dike of impact melt unit ("Bronzite Granophyre" or "Vredefort Granophyre") from Vredefort (South Africa) emplaced in preimpact granitic basement rocks. The like is an inclusion-rich breccia containing numerous light-colored large and small fragments (dominantly quartzite, with minor granite) in a dark, massive, coherent matrix of finely crystalline melt rock. Farm Lesutoskralal 72, near the center of the uplifted basement rocks. Photo from Nel (1927, Plate XIV). 


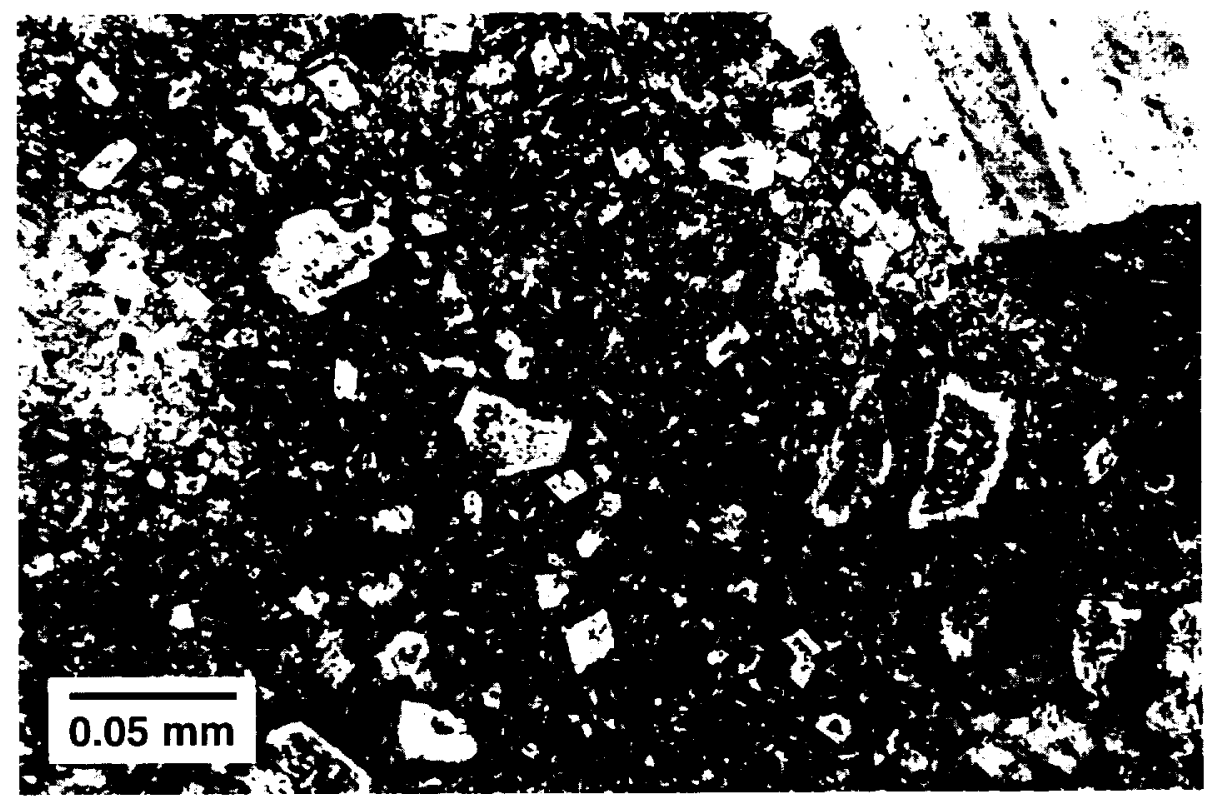

Fig. 6.10. Impact melt rock; breccia. Clast-rich melt-matrix breccia consisting of numerous mineral clasts (light-colored) (chiefly plagioclase feldspar from basement rocks), in a matrix of finely crystalline (plagioclase-pyroxene-quartz) melt. Larger plagioclase clasts show reaction rims and display partial digestion in the melt. From Mistastin Lake (Canada). Photograph courtesy of R. A. F. Grieve (plane-polarized light).

rica), a unit that is increasingly regarded as an impact melt (Dence, 1971; French and Nielsen, 1990; Therriault et al., 1996; Kocberl et al., 1996c), occurs only as small dikes in the deeply eroded basement of the structure. In this case, the presently preserved melt volume is probably only a small surviving fraction of the total impact melt $\left(10^{3}-10^{4} \mathrm{~km}^{3}\right)$ originally generated during the formation of the Vredefort structure (Fig. 6.9). Nearly all the original impact melt, which probably formed a thick sill-like unit within the original crater, has been removed by erosion.

The largest presently known body of impact melt may be the voluminous Sudbury Irruptive in the Sudbury impact structure (Canada). New geochemical and modeling studies suggest that the entire Irruptive was produced as a single body of impact melt during formation of the structure (Faggart et al., 1985; Grieve et al., 1991a; Stoffler et al., 1994; Grieve, 1994; Deutsch et al., 1995). If this view is correct, the Sudbury structure contains an impact melt body $>8000 \mathrm{~km}^{3}$ in volume, with the impact melt occurring both as the sill-like main body of the Irruptive and as a group of dikes ("offsets") that extend from the main Irruptive into the surrounding subcrater rocks (Ostermann et al., 1996; Wood and Spray, 1998).

\subsection{IMPACT MELT IN DISTAL EJECTA}

Although virtually all the melt generated in an impact event is deposited in and around the resulting crater, a very small fraction (perhaps $<0.1$ vol\%) of impact melt may be ejected from the crater as millimeter- to centimeter-sized bodies of pure melt that, chilled rapidly to glass, are deposited as part of a layer of distal ejecta hundreds or thousands of kilometers away from the impact site. Two kinds of such glassy material in distal ejecta can be conveniently distinguished: (1) spherules of fresh or altered glass, and (2) tektites and microtektites. These unusual glassy bodies, especially tektites and microtektites, have been the objects of active, intense, and frequently controversial study (for reviews see O'Keefe, 1963, 1976; papers in L. D. Pye et al., 1984 and Konta, 1988; Koeberl, 1986, 1994a). Several different types of glassy distal ejecta have been recognized, but future studies will probably produce major changes in both definitions and formation mechanisms.

At present, it is generally accepted that the formation and widespread distribution of these objects requires both intense (superheated) melting at the impact site, followed by high-velocity ejection from it, but the exact processes of melting and transport are not well understood. One possibility is that jetting of highly shocked, superheated melt occurs at the interface between the projectile and the target during the initial part of the contact/compression stage (Kieffer, 1975; Melosh, 1989, pp. 51-53; Melosh and Vickery, 1991). Other possible mechanisms may involve dispersal of subsequently shock-melted material by an expanding vapor plume from the impact site (Melosh, 1989, pp. 68-69; Alvarez et al., 1995). Any formation mechanism must explain chemical data that suggest that these glassy objects are derived from the near-surface parts of the section of target rocks at the impact site (e.g., von Engelhardt et al., 1987). It is also accepted that Earth's atmosphere must be briefly removed, or at least largely dispersed, to permit these fragile molten ob- 
jects to travel long distances without being destroyed, implying that the formation and distribution of such objects must be restricted to impact events large enough to remove (at least temporarily) the atmosphere above the impact site.

\subsubsection{Spherules}

The formation of millimeter-sized glassy spherules from shock-melted droplets of impact melt appears to be a typical process in impact events. Such spherules are especially common in samples of lunar surface materials (e.g., Taylor, 1975, pp. 67-78; Symes et al., 1998), where their abundance may reflect the peculiar conditions of the lunar environment: lack of atmosphere and the possibility of numerous impacts by small or microscopic objects. Spherules have also formed in at least some terrestrial impact events, and spherules of both glass and melted meteoritic metal have been found in young and well preserved craters like the Barringer Meteor Crater (Arizona) (Krinor, 1966, pp. 104-107 and 113-119), Wabar (Saudia Arabia) (Krinov, 1966, pp. 19-24; Mittlefehldt et al.,
1992), and Lonar (India) (Murali et al., 1987). However, spherules h ive not been widely observed in preserved impactites associated with most terrestrial impact structures, possibly because such ejected molten particles do not survive the disr aptive effects of the atmosphere, or because such particles ars quickly destroyed by weathering and erosion. A few occu rences of spherule-like objects have been described in the glassy breccias associated with impact structures (Fig. 1.11) (Graup, 1981; French, 1987). In contrast, spherules are becoming increasingly recognized as an important con ponent of the distal ejecta layer from large impact structures, and they may be found at great distances from the impact site.

The best known and most-studied spherule deposit is the distal ejecta layer (K/T boundary layer) from the Chicxulub structure (Mexico), which is distributed over distances of several thot sand kilometers from the impact site and contains a signi icant component of fresh and altered spherules of impact m slt (Montanariet al., 1983; Sharpton et al., 1992;

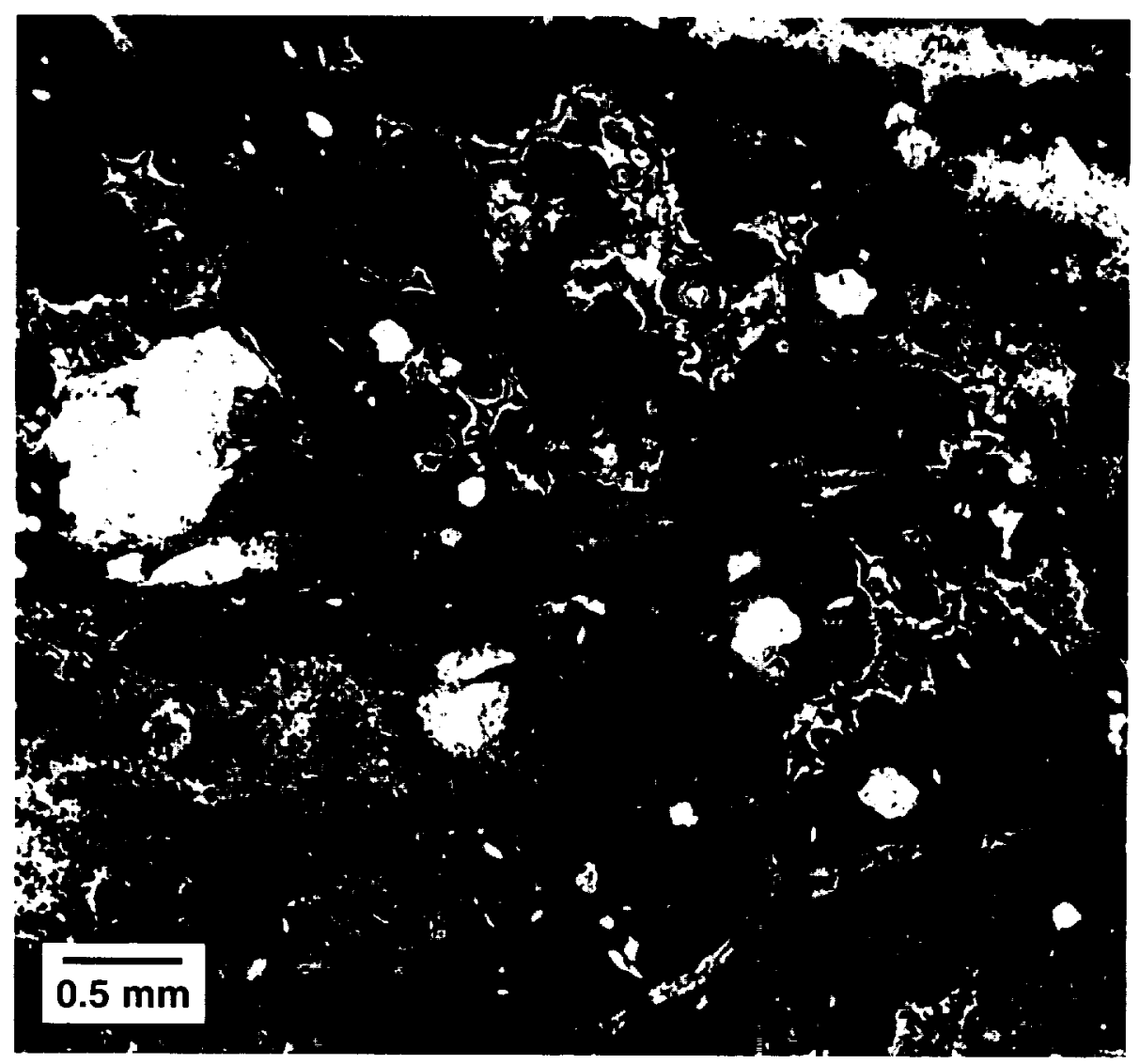

Fig. 6.11. Impact melt rock; spherulitic glass rim on rock fragment. Heterogenou mixture of recrystallized spherulitic glass and small rock and mineral fragments, forming a heterogeneous glassy rim on a larger rock tragment core. The composite inclusion occurs in a metimorphosed suevite breccia. The small rock fragments, chiefly quartz and felds ar, are generally angular and irregular in shape, and phenocryst textures typical of glassy volcanic rocks are not observed. Despite postimpa it greenschist metamorphism, original heterogeneity of the glass is preserved by the distribution of secondary minerals, chiefly quartz, felc spar, chlorite, and amphibole. The small red-brown spherical bodies frequently contain a smaller central crystal fragment, suggesting that hey were discrete droplets before being incorporated into the rim around the larger core fragment. If so, the texture may result from ac retion of glass and rock fragments during ballistic ejection. (The texture may also represent subsequent in-place devitrification or recrystallization around the mineral fragment nucleus.) Granitic rock fragment from Onaping Formation "Black Member," type locality at Onaping Falls (Highway 144, Dowling Township), northwestern corner of Sudbury structure (Canada). Sample CSF-66-50-1-D (plane-polarized light). 
Pollastro and Bohor, 1993; Bohor and Glass, 1995; papers in Sharpton and Ward, 1990 and Ryder et al., 1996). The association of these spherules with shocked quartz and an iridium anomaly establishes them as definite impact melt products, while chemical and isotopic studies have firmly established their connection to the target rocks of the Chicxulub structure (Sigurdsson et al., 1991a,b). Massive spherule layers, as much as a meter thick, have been reported from the Precambrian, but they lack any definite shockmetamorphic effects and are more problematic (Lowe and Byerly, 1986; French, 1987; Lowe et al., 1989; Simonson, 1992; Koeberl et al., 1993; Simonson and Davies, 1996; Simonson et al., 1997). Their impact origin has not been definitely established, nor have they been linked to any known impact structure.

Spherule layers have important potential for recognizing and locating other large impact structures in the future. The deposits can be detected over large areas, they can be identified as impact products, and they contain isotopic and geochemical clues that can help locate the source crater and establish its age.

\subsubsection{Tektites and Microtektites}

Tektites and microtektites are unique and long-known small glassy objects that have a long history of study and controversy (for reviews, see O'Keefe, 1963, 1976; Glass, 1984, 1990; Koeberl, 1986, 1990, 1992, 1994a). They are typically black in color, although some varieties are greenish, brownish, or grayish. The larger (centimeter-sized) tektites, which occur on land, are associated with smaller $(\leq 1 \mathrm{~mm})$ microtektites, preserved in deep-sea sediments. Although tektites and microtektites resemble volcanic glasses in form, they have several geologically unusual distinctive characteristics. They are completely glassy, with no microlites or phenocrysts. They are typically high in silica ( $>65 \mathrm{wt} \%)$, but their chemical and isotopic compositions are not volcanic and are closer to those of shales and similar sedimentary rocks. Also unlike volcanic glasses, tektites contain virtually no water $(<0.02 \mathrm{wt} \%)$, and their flow-banded structure includes particles and bands of lechatelierite, melted silica glass. A few tektites contain partly melted inclusions of shocked and unshocked mineral grains (quartz, apatite, zircon) as well as coesite (Glass and Barlow, 1979).

In the best-preserved tektite occurrence, in Southeast Asia, four types of tektite material have been recognized: (1) splash-form tektites, which are centimeter-sized objects shaped like spheres, ellipsoids, dumbbells, and other forms characteristic of isolated molten bodies; (2) ablated splash-form tektites (buttons), which display a secondary ring produced during high-specd reentry of a solidified splash-form tektite into the atmosphere; (3) Muong Nong tektites, which are generally larger $(\geq 10 \mathrm{~cm})$, irregular, and layered; and (4) microtekites, which are small $(\leq 1 \mathrm{~mm})$ spherules found as concentrations in specific layers of deepsea sediments.

Tektites and microtektites are distributed over large areas (strewnfields) of Earth's surface. Four strewnfields are known at present, distinguished by differences in location, age, and (to some extent) the characteristics of the tektites and microtektites found. The strewnfields and their ages are: (1) Australasian or southeast Asian (australites, indochinites, phillipinites), age $0.8 \mathrm{Ma}$; (2) Ivory Coast (Africa), age $\sim 1.1 \mathrm{Ma}$; (3) Central European (formerly Czechoslovakian), age 15.0 Ma; (4) North American, age $35 \mathrm{Ma}$. Both the areas and tektites masses included in the strewnfields can be large. The Australasian strewnfield covers about $50 \times$ $10^{6} \mathrm{~km}^{2}$, or about one-tenth of the area of the Earth, and it is estimated to contain $10^{8} \mathrm{~T}$ of tektite material (Glass, 1990). The North American strewnfield has an area of about $9 \times$ $10^{6} \mathrm{~km}^{2}$, and contains $10^{8}-10^{9} \mathrm{~T}$ of tektite material (Koeberl, 1989). Although large, the strewnfield masses correspond to a volume of $<1 \mathrm{~km}^{3}$ of impact melt, probably $<1-2 \%$ of the total amount of melt formed during the event.

Tektites have been controversial objects since their discovery, and both their origin and source have been hotly debated for more than a century (O'Keefe, 1963, 1976, 1994; Glass, 1990; Taylor and Koeberl, 1994). However, the current scientific consensus is that tektites and microtektites are impact melt ejected from terrestrial impact craters. An impact origin is supported by their nonvolcanic chemistry, the presence in tektites of high-pressure minerals (coesite), and features indicating unusually high temperatures (lechatelierite, decomposed zircon) (Glass and Barlow, 1979; Glass, 1990). The recent detection, in Ivory Coast tektites, of a chemical signature from an extraterrestrial projectile (Koeberl and Sbirey, 1993) provides strong independent evidence for an origin in a terrestrial impact event.

A terrestrial source for tektites has been increasingly supported by their chemical similarity to terrestrial sediments, by the presence in tektites of relict mineral inclusions (quartz, zircon, rutile, chromite, and monazite) characteristic of sedimentary rocks, and by accumulating geochemical and isotopic studies that indicate a crustal and sedimentary source. Three of the four tektite strewnfields have been linked, with varying degrees of confidence, to established impact craters of similar age (Glass, 1990; Koeberl, 1990): the Ivory Coast strewnfield to the Bosumtwi (Ghana) structure ( $D=$ $10.5 \mathrm{~km}$ ) (Koeberlet al., 1997b), the Central European field to the Ries Crater (Germany) $(\mathrm{D}=24 \mathrm{~km})$, and the North American strewnfield to the recently recognized Chesapeake Bay Crater (USA) (D = $90 \mathrm{~km}$ ) (Koeberlet al., 1996a). (This latter strewnfield was also deposited close to - but about a quarter of a million years before - a significant, although moderate, extinction event at the Eocene/Oligocene boundary.) The absence of any obvious impact structure connected to the young and widespread Australasian strewnfield is a continuing problem. Although several characteristics of the strewnfield itself suggest that the source crater is located somewhere in a relatively small region of Indochina, no candidate impact structure has yet been identified.

Despite the growing consensus on tektite origins, the mechanics of their formation and the factors that govern their distribution are still not well understood. Exactly when do tektites form during the impact process, and how are they distributed so widely? What is the relation of tektites to other types of impact melts, and especially to similar dense glasses 
found in and around certain craters? Why do tektites appear to form only in a few craters, although numerous young structures of the required minimum size (probably $\geq 10 \mathrm{~km} \mathrm{di}$ ameter, based on the diameter of the Bosumtwi Crater) are known? What are the relations of tektite-forming events to other major terrestrial changes like extinctions and magnetic reversals? It is clear that the small fraction of impact melt that produces tektites during impact events will continue to generate a large amount of discussion and research.

\subsubsection{Miscellaneous Impact Glasses}

Other types of unusual glass, located in widely different regions of the Earth, have gradually been recognized as impact melts. These glasses appear as small (generally centimeter-sized) irregular bodies that may be scattered over areas of a few square kilometers to $>100 \mathrm{~km}^{2}$. Their textures vary from dense to vesicular and slaggy, some contain mineral and rock inclusions, and colors range from blackish to pale green. These glassy objects have been relatively little studied (see papers in L. D. Pye et al., 1984 and Konta, 1988), and many questions remain about their sources, methods of formation, and possible relationships to other kinds of impact melt.

Some of these occurrences are associated with small, young impact craters. The dense, greenish Aouelloul glass is found as small (centimeter-sized) irregular bodies immediately outside the Aouelloul Crater (Mauritania) $(D=0.39 \mathrm{~km}$; age $3.1 \mathrm{Ma})$, and it appears to have been formed by complete fusion of the local sandstone (Koeberl et al., 1998). The more vesicu ar and irregular Darwin glass (age $0.75 \mathrm{Ma}$ ) is distributed (iver a wider area, but may be associated with the Darwin Créter (Australia), a small $(\mathrm{D}=1 \mathrm{~km})$ possible impact structu e (Ford, 1972; Meisel et al., 1990). In two other cases, no cendidate impact crater has yet been identified for the glas ies. The Libyan Desert glass (age $29 \mathrm{Ma}$ ) is a high-silic a ( $>95 \mathrm{wt} \%$ ), yellow-green to brownish glass found over : wide area in western Egypt (Weeks et al., 1984; Storzer and Koeberl, 1991). An impact origin is generally accepted for this glass, on the basis of the high melting temperature required for such a silica-rich composition and the presence of echatelierite and decomposed zircons in a few samples. Hiswever, a target rock of virtually pure orthoquartzite is sequired, and no source crater has yet been identified. The 1 ttle-known urengoites and other glasses from western Sib sria (Russia) also appear to be high-silica impact melts (. Jeutsch et al., 1997), but their geochemical and isotopic chi racteristics have not been matched with any known impict crater.

\subsection{RECOGNITION OF IMPACT MELT ROCKS}

Despite heir exotic origin, impact melt rocks are true igneous rock s that have formed by the cooling and crystallization of hish-temperature silicate melts, and they often

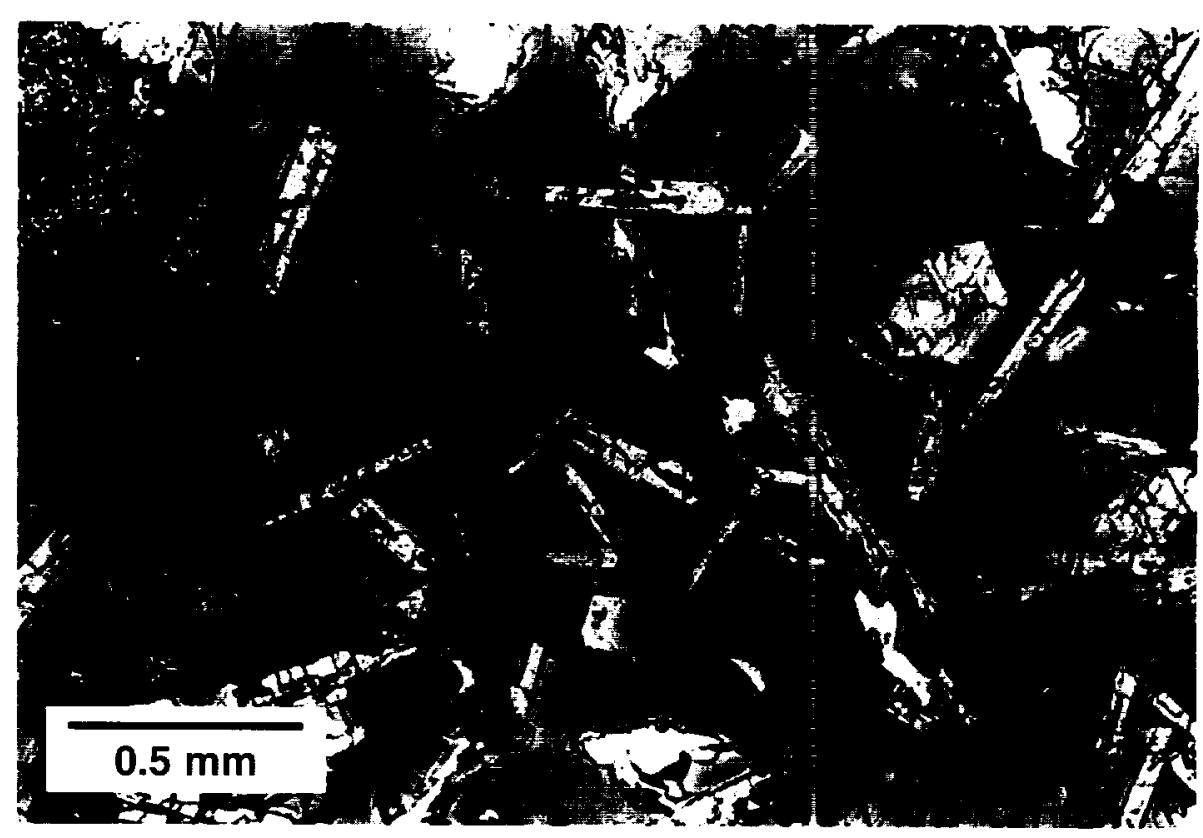

Fig.6.12. Impact melt rock; glassy, with feldspar crystals. Glassy impact melt rock with euhedral quench crystals of feldspar in a partly devitrified glassy matrix. The brownish glassy matrix shows perlitic devitrification te tures consisting of circular cracks and the growth of finer spherulitic crystals (feldspar?). This material was long considered an unusual ex trusive igneous rock ("Dellenite"). Identification as an impact melt has been based on its association with shock-metamorphosed rock: and the presence of anomalously high siderophile clements (e.g., iridium) in the melt rock itself. Sample from exposures of crater-f lling impact melt layer at Lake Dellen (Sweden). Specimen courtesy of A. Deutsch. Sample SDDe-3/4-1 (plane-polarized light). 


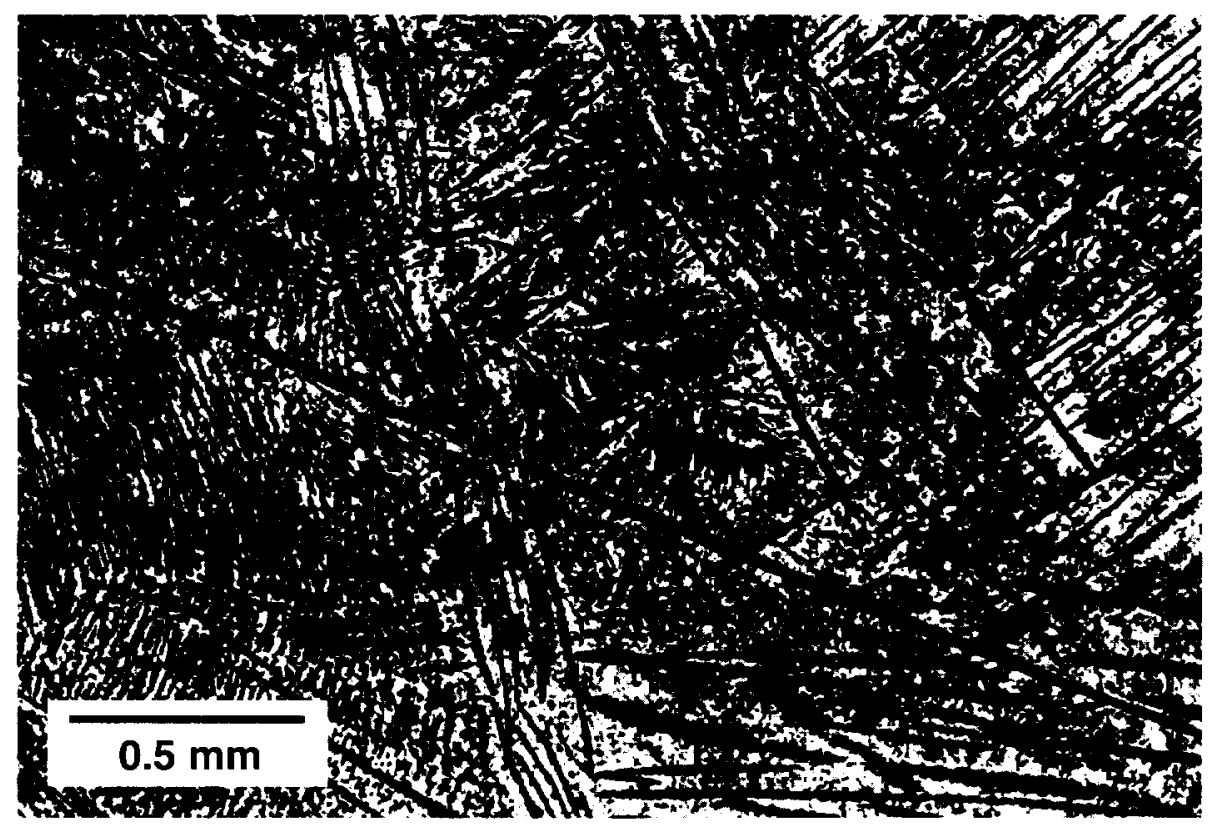

Fig. 6.13. Impact melt rock; crystalline, with pyroxene (?) quench crystals. Recrystallized glassy impact melt rock with well-developed quench textures consisting of highly elongate pyroxene(?) crystals in a fine-grained recrystallized matrix. The highly elongate strings and networks of narrow crystals are typical for rapidly cooled igneous melts formed by both conventional volcanism and impact events. Sample from the Charlevoix structure (Canada). Specimen courtesy of J. Rondot. Sample CHR-68-1 (plane-polarized light).

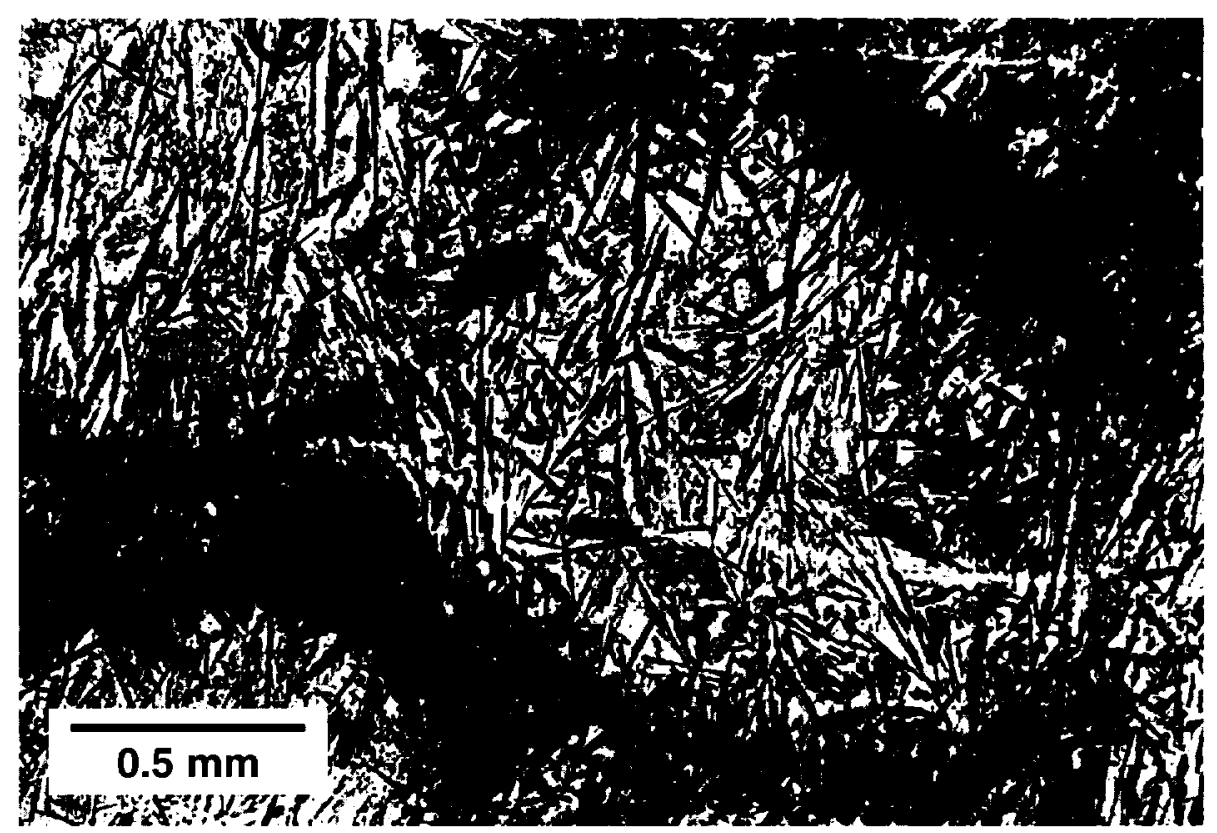

Fig. 6.14. Impact melt rock; crystalline, with pyroxene (?) quench crystals. Glassy impact melt from a 1-m-wide dike cutting metamorphosed suevite. Despite postimpact greenschist metamorphism, the rock still preserves well-developed quench textures consisting of highly elongate subparallel pyroxene(?) crystals (now possibly secondary amphibole?) in a fine-grained recrystallized matrix. Such strings and networks of elongate quench crystals are typical for rapidly cooled igneous melts formed by both conventional volcanism and impact events. In this sample, original igneous textures are preserved, together with a spherulitic texture probably produced during devitrification or recrystallization of the glassy matrix. Sample from the Onaping Formation "Black Member" at the type locality, Onaping Falls (Highway 144, Dowling Township), northwestern corner of Sudbury structure (Canada). Sample CSF-68-18 (plane-polarized light). 


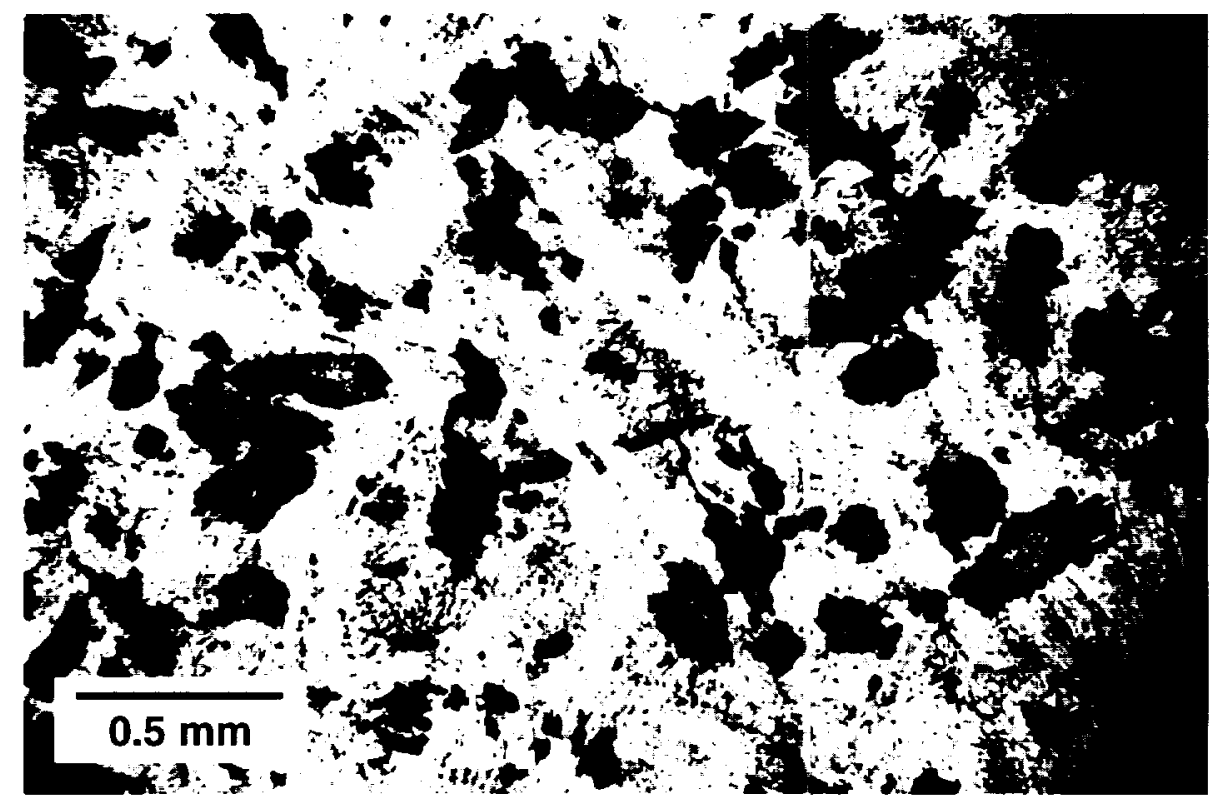

Fig. 6.15. Impact melt rock; crystalline, granular. Typical crystalline impact melt rock from a dike cutting preimpact basement granites near the center of the Vredefort structure (South Africa). This granular variety of the so-called "Bronzite Granophyre" shows a typical igneous texture, with stubby orthopyroxene crystals (gray), apparently rimmed by sec indary amphibole (dark gray), together with elongate feldspar, quartz, and minor fine-grained granophyric quartz-feldspar intergrowths (rompare with Figs. 6.16 and 6.17). Sample from dike cutting basement granite near town of Vredefort, South Africa (farm Holfontein 6 4?). Specimen courtesy of R. B. Hargraves. Sample AVH-68-2 (plane-polarized light).

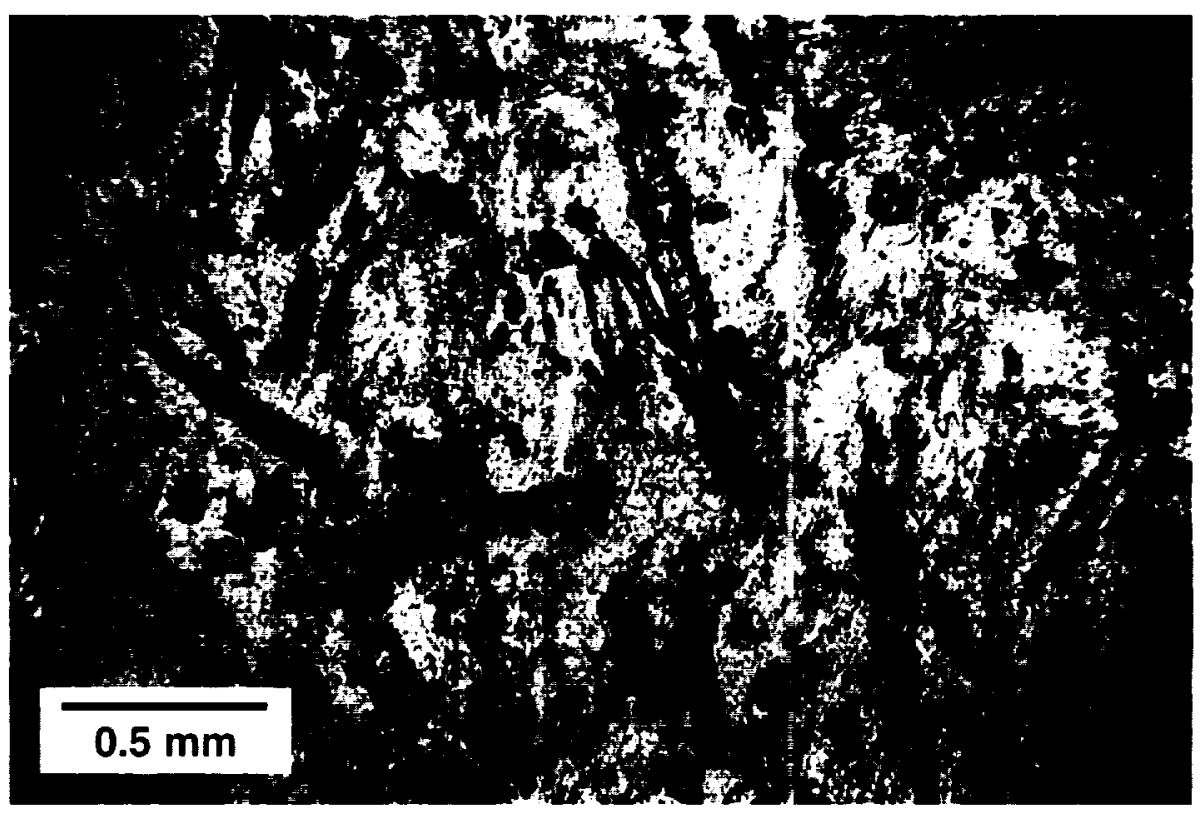

Fig. 6.16. Impact melt rock; crystalline, spherulitic. Typical crystalline impact mı lt from a dike cutting preimpact bascment granites. This spherulitic variety of "Bronzite Granophyre" shows a typical igneous texture, with large elongate orthopyroxene crystals (gray; high relief), in a groundmass of fine-grained granophyric feldspar and quartz (compare wit i Figs. 6.15 and 6.17). Sample from farm Holfontein 44, south of Vredefort, South Africa. Sample AV81-58 (plane-polarized light). 


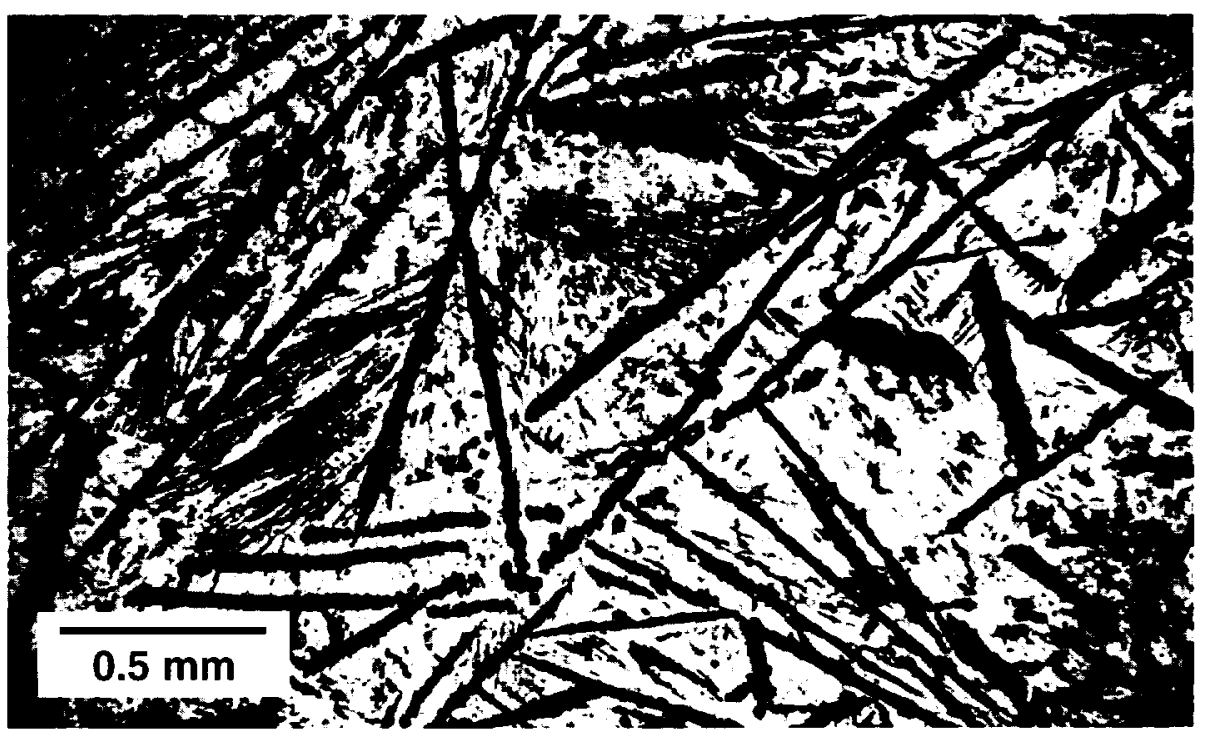

Fig. 6.17. Impact melt rock; crystalline, with quench textures. Typical crystalline impact melt from a dike cutting preimpact basement granites. This variety of "Bronzite Granophyre" shows a typical igneous texture, with highly elongate quench crystals of orthopyroxene (gray), in a fine spherulitic groundmass of intergrown feldspar and quartz (compare with Figs. 6.15 and 6.16). Sample from farm Koppieskraal, Vredefort structure (South Africa). Sample AV81-61A (plane-polarized light).

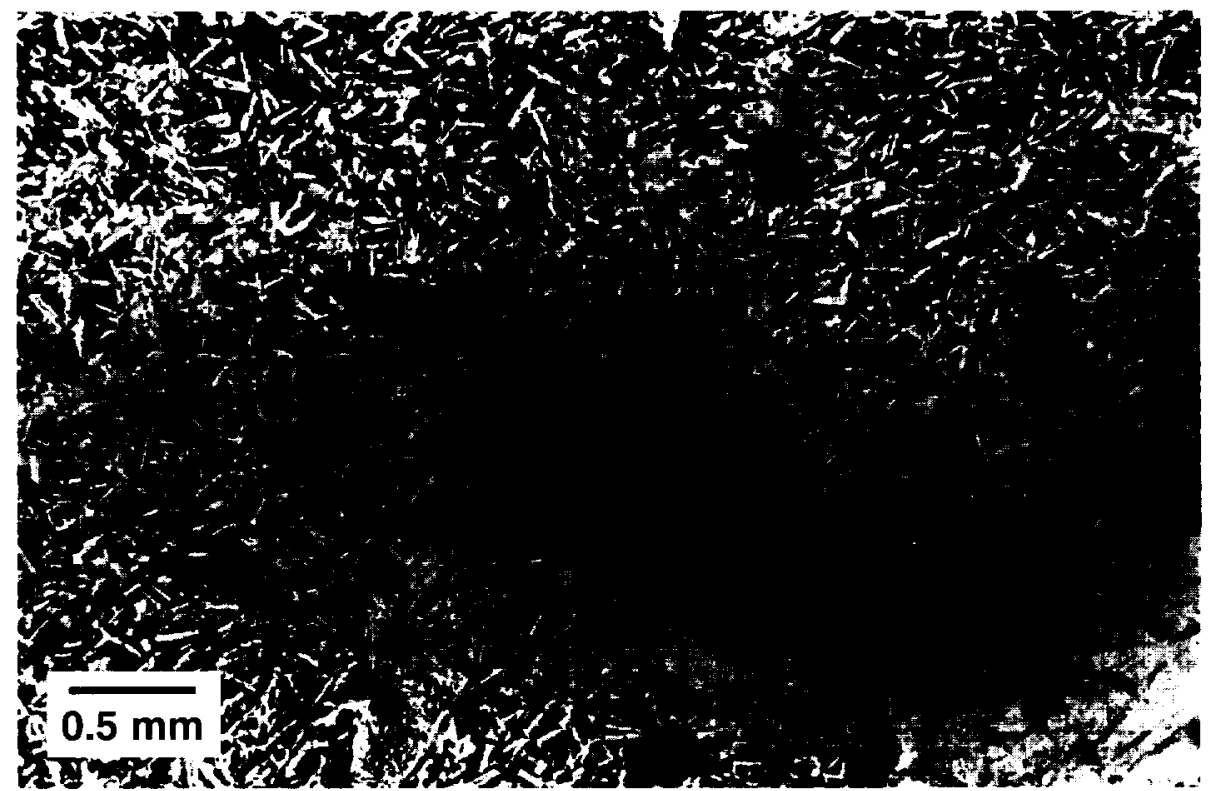

Fig. 6.18. Impact melt rock; crystalline, inclusion-poor. Well-crystallized impact melt, showing isolated clasts of plagioclase feldspar (bottom and lower right) in a fine-grained melt matrix consisting of well-crystallized plagioclase, poikilitic pyroxene, quartz, and opaque minerals. The clasts (xenocrysts) are generally partly digested, but new feldspar rims (clear) have developed on the altered cores (cloudy, gray). Sample from thick annular layer of impact melt preserved at Mistastin Lake (Canada). Photo courtesy of R. A. F. Grieve (planepolarized light). 


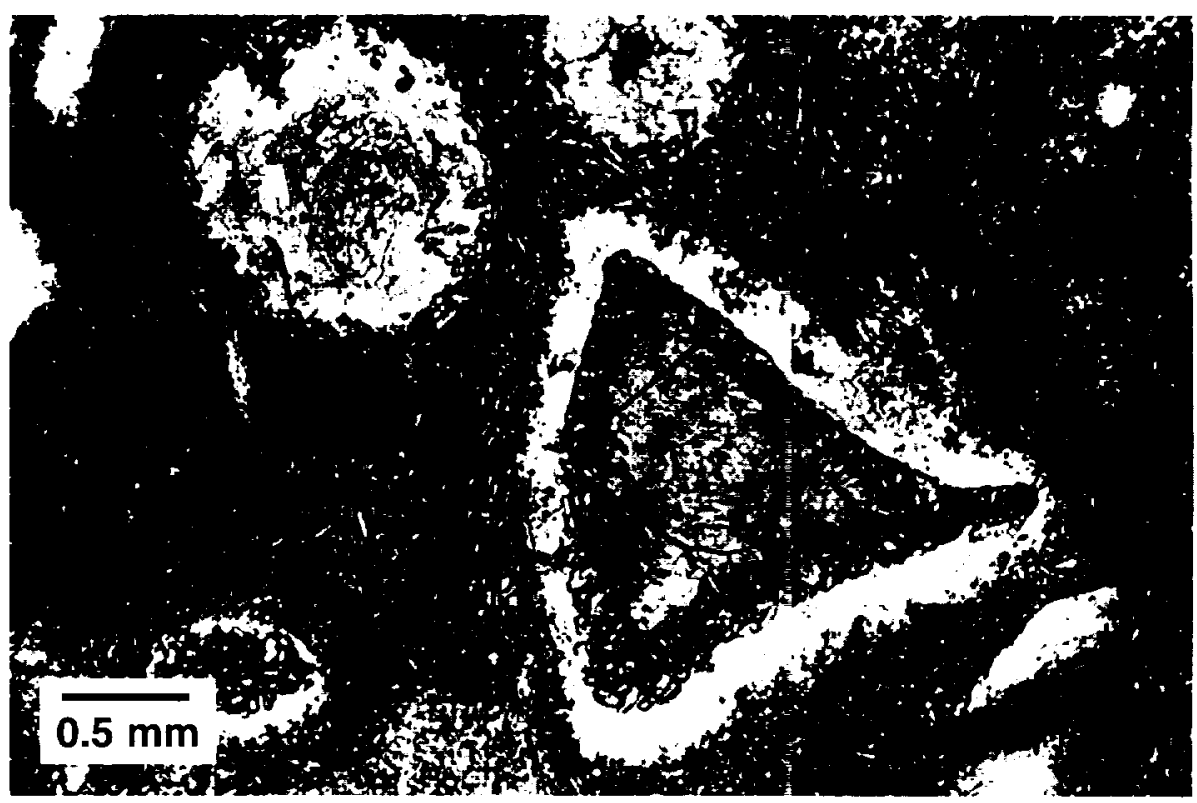

Fig. 6.19. Impact melt rock; fine-crystalline, with pyroxene coronas. Completely srystalline impact melt rock, with clasts of plagioclase and quartz in a very fine-grained matrix consisting of plagioclase, poikilitic pyroxen :, quartz, and opaque minerals. Distinctive coronas or "necklaces" of small pyroxene crystals have developed around quartz grains by reaction between the quartz xenocrysts and the melt. The triangular quartz grain shown is surrounded by a thin rim of small pyroxene crystals gray, high relief), beyond which is a rim of clear glass that has been depleted in iron and other coloring agents to form the pyroxene. Sample from thick annular layer of impact melt within the Mistastin Lake structure (Canada). Photo courtesy of R. A. F. Grieve (plane-pola ized light).

exhibit textures and mineral compositions that are identical to those of typical endogenic volcanic and intrusive rocks. Impact melt rocks may range in character from largely glassy rocks containing quench crystallites (Figs. 6.12, 6.13, and 6.14) to completely crystalline and even coarse-grained igneous rocks that may show a wide range of typical igneous textures in even small bodies (Figs. 6.15, 6.16, 6.17, and 6.18). Because of these similarities in mineralogy and texture, it may often be impossible to distinguish between an isolated specimen of impact melt and a normal igneous rock on the basis of petrographic observations alone.

The similarities between impact melt rocks and endogenic igneous rocks have been one factor in the prolonged controversies over the origin of many now-accepted impact structures. Nevertheless, several decades of field and laboratory studies have now produced some generally reliable criteria for recognizing impact melt rocks and for differentiating them from endogenic igneous rocks.

The best field evidence for the origin of an impact melt unit is an intimate association with more distinctive shockmetamorphosed rocks. Impact melt bodies that occur as dikes cutting the subcrater basement rocks may be closely associated with pseudotachylite breccias or (more convincingly) with shatter cones and microscopic shock-deformation effects in the subcrater rocks that provide definite evidence of an impact origin. Above the crater floor, impact melt bodies of various sizes are intermingled with breccias that contain distinctively shock-metamorphosed rock and mineral fragments; such an association is also clear evidence for impact.
On the : cale of individual hand specimens, the most definitive cha: acteristic of impact melts is not the igneous crystallization $t$ : xtures, but the nature and appearance of included rock and $m$ ineral clasts. These fragments are derived from the target : ocks; they do not resemble cogenetic volcanic materials. Furthermore, because the clasts are exotic (xenoliths and xeiocrysts), they may be out of equilibrium with the melt and $m$ ay develop reaction textures against it. Distinctive overgre wths of compositionally different feldspar have formed on eldspar xenocrysts in the impact melt from the Brent Cratc r (Canada) (Grieve, 1978). Another common reaction text re in impact melts is the formation of "necklaces" of small py oxene crystals against quartz clasts (Fig. 6.19). Although common in impact melts, such reaction textures also form ar sund xenocrysts in some endogenic igneous rocks and do not specifically indicate an impact origin.

More convincing, preserved target rock fragments in impact melt $\mathrm{rc}$ cks often contain definite shock features such as PDFs in qu urtz. Other textures, which reflect extremely high formation emperatures, also provide convincing evidence of impact. Feldspar xenocrysts may show unusual melting and recryst: llization textures produced at high temperatures (Ostertag ar d Stöfler, 1982; Bischoff and Stöfler, 1984). Some rapidly cooled impact melt rocks may also preserve millimeter-sized patches of lechatelierite, produced from the high-tempr rature melting of quartz grains (Figs. 6.20 and 6.21) (Freich et al., 1970; Carstens, 1975; Stöffler and Langenbors , 1994). When such bodies of lechatelierite cool, a combinat on of thermal stress and crystallization produces 


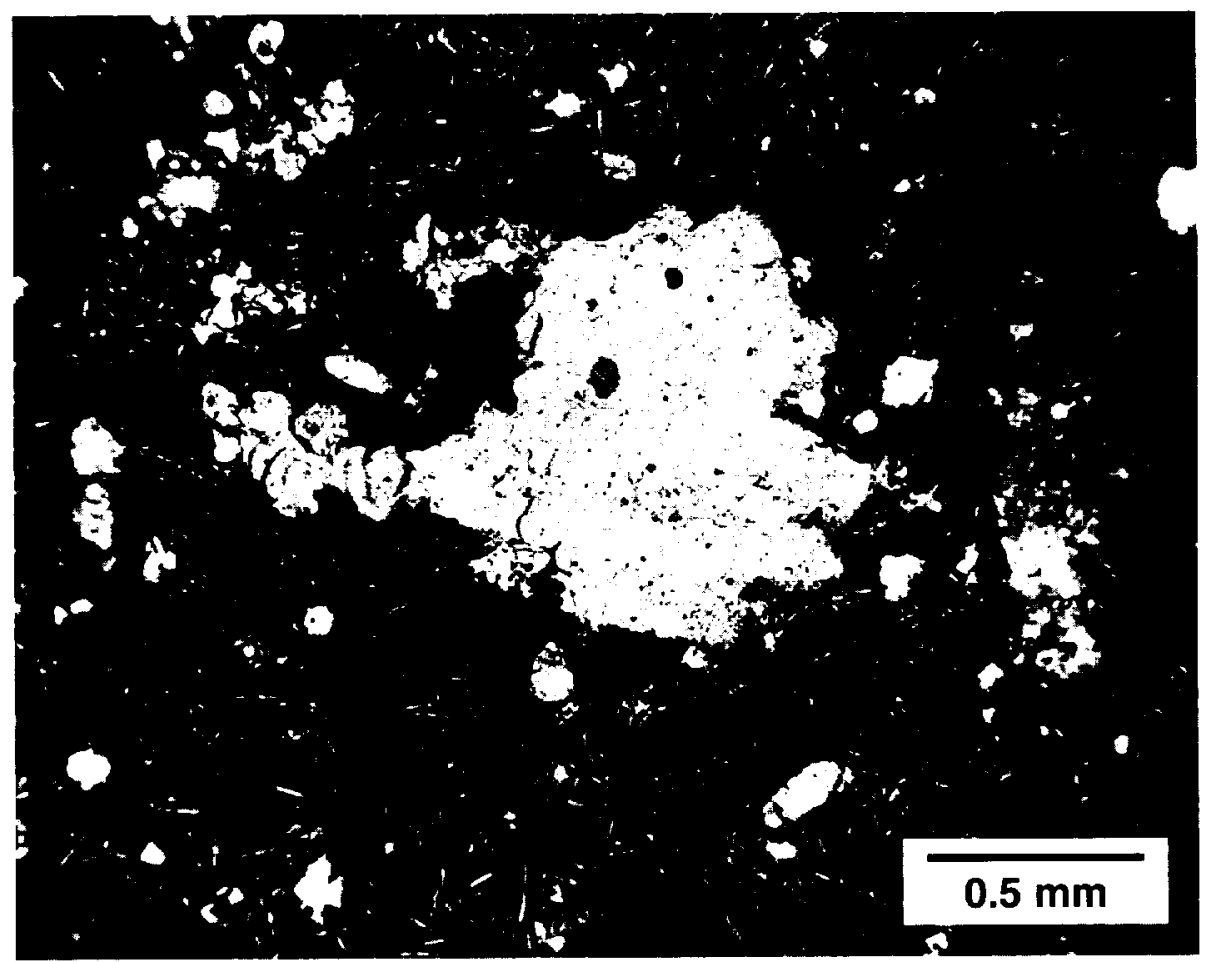

Fig. 6.20. Impact melt rock; partly crystalline, with lechatelierite. Finely crystalline impact melt rock, containing inclusions of quartz glass (lechatelierite). Irregular inclusions of clear lechatelierite (e.g., center, light gray) occur in a partly crystalline matrix consisting of pyroxene, elongate feldspar laths (white), opaque minerals, and interstitial brown glass. The contact between lechatelierite and brownish matrix glass is irregular and interpenetrating, indicating that both glasses were originally molten at the same time. The lechatelierite displays a typical crackled (Ballen) texture produced by devitrification of the silica glass to silica minerals. The lechatelierite probably originated by shock-melting of original quartz grains, at temperatures above $1700^{\circ} \mathrm{C}$, and was incorporated into the more abundant impact melt formed by the larger volume of target rock. The presence of small unaltered quartz grains (small scattered white areas) in the impact melt indicates that the lechatelierite did not form by simple in-place thermal melting in a very-high-temperature melt. Sample from a possible dike of impact melt located on the rim of Tenoumer Crater (Mauritania). Specimen courtesy of R. S. Dietz. Sample TM3-1 (plane-polarized light).

a distinctive "crackled" pattern of curved fractures in the original glass (Figs. 6.20 and 6.21). This Ballen texture is a distinctive feature of lechatelierite in impact melt rocks.

Impact melt samples that lack distinctive shock-metamorphic textures can still be identified by a variety of geochemical signatures. One test is to compare the impact melt composition with that of the target rocks. Becausc impact melts are produced predominantly from target rocks, with only a minor (usually $\leq 1 \%$ ) projectile contribution, their chemical and isotopic compositions should correspond to the average compositions of the local bedrocks. The demonstration of such compositional matches, especially when the composition cannot be easily produced by endogenic processes, is a strong (although not absolute) indication of an impact origin. Such comparisons can be more conclusive if there is a chemically or isotopically unusual component in the target rocks that can be recognized in the composition of the impact melt (French and Nielsen, 1990).

More definite evidence of an impact origin can be obtained by analyzing the impact melt for siderophile elements such as iridium, osmium, platinum, and gold. Such elements have extremely low abundances in terrestrial crustal rocks, but their abundances are much higher $(100-1000 x)$ in some meteorites. An anomalously high content of siderophile elements (especially iridium) in an impact melt indicates that the melt contains material (perhaps as much as a few percent) derived from the melted and vaporized impactor (e.g., Palme et al., 1979, 1981; Palme, 1982; Schuraytz et al., 1996). Such an iridium anomaly, identified in the $\mathrm{K} / \mathrm{T}$ boundary ejecta layer, provided the first evidence that a large meteorite impact was associated with the $\mathrm{K} / \mathrm{T}$ extinction (Alvarez et al., 1980). More recently, measurements of osmium isotopic ratios have made it possible to identify even very small amounts $(\leq 0.1 \mathrm{wt} \%)$ of the projectile in impact melt units (Koeberl and Shirey, 1993; Koeberl et al., 1996c, 1998).

The isotopic systematics of such age-dating systems as $\mathrm{Rb}-\mathrm{Sr}$ and $\mathrm{Sm}-\mathrm{Nd}$ can demonstrate that impact melt rocks have been derived from near-surface crustal rocks and not (like most normal igneous rocks) from the deep crust or mantle. Abnormally high ${ }^{87} \mathrm{Sr} /{ }^{86} \mathrm{Sr}$ ratios are a good indicator of impact melts in relatively young impact structures developed in older crustal rocks; high ratios indicate that the 
melt was produced by the melting of older and more radiogenic crustal rocks (e.g., French et al., 1970). The study of samarium and neodymium isotopic compositions of the large Sudbury (Canada) Irruptive (Faggart et al., 1985) provided the first strong indication that the entire Irruptive was an impact-me t body derived entirely by melting and mixing of the crustal tacks in which the Sudbury structure is emplaced (see also Di utsch et al., 1995; Ostermann et al., 1996).

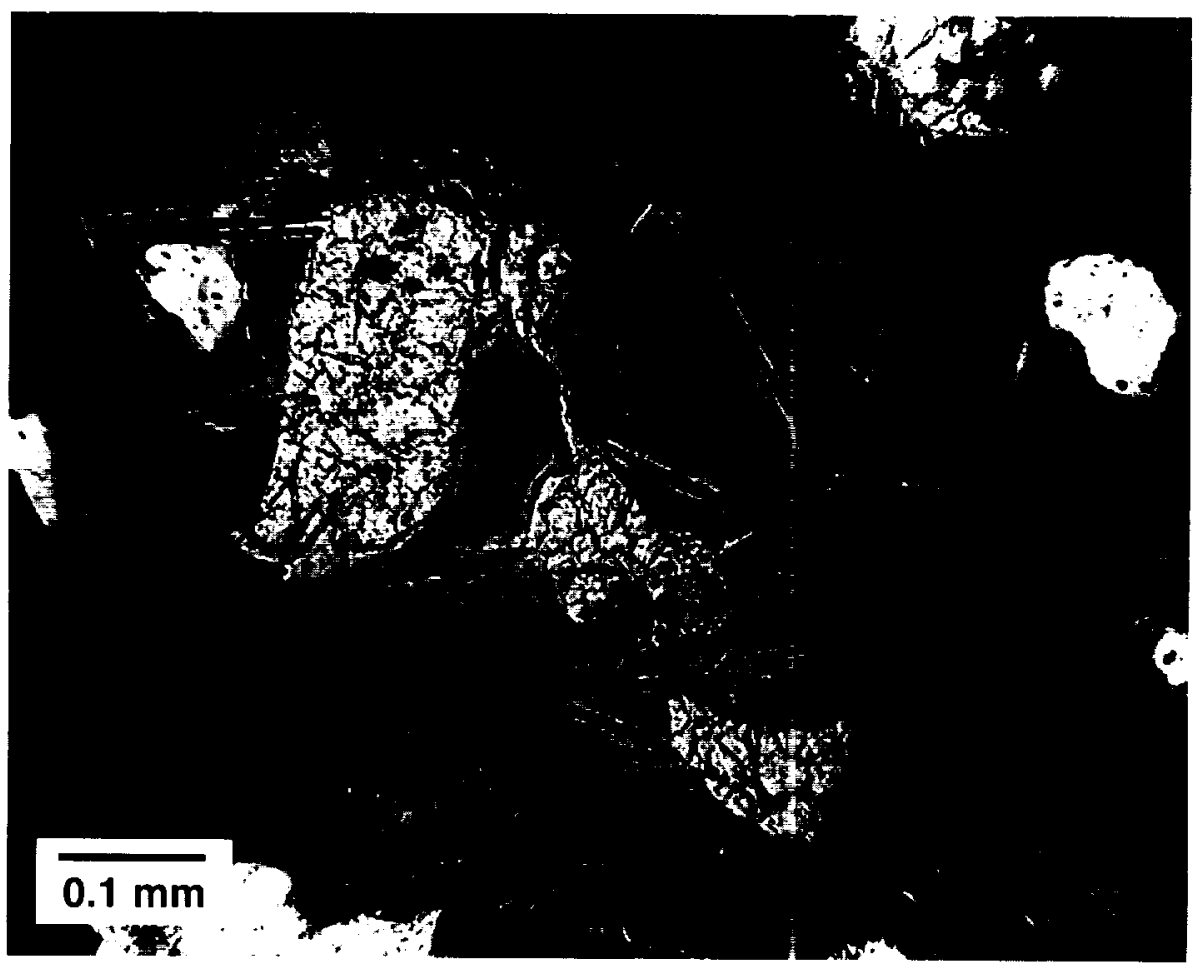

Fig. 6.21. Impact melt rock; partly crystalline, with lechatelierite. Finely crystalli ie impact melt, containing inclusions of quartz glass (lechatelicriti). Irregular inclusions of clear lechatelierite (light gray) occur in a pastly crystalline matrix containing elongate pyroxene quench crystals and clear interstitial brown glass. Contact between lechatelierite anıl brown matrix glass (central region) is irregular and interpenetrating, indicating that both glasses were originally molten at the same time. The lechatelierite displays a typical crackled (Ballen) texture produced by devitrification of the silica glass to silica minerals. The lechatelierite probably originated by shock-melting of original quartz grains, at temperatures above $1700^{\circ} \mathrm{C}$, and was incorporated into t ie more abundant impact melt derived from melting a larger volume of target rock. The presence of small unaltered quartz grains (small sc attered white arcas) in the impact melt indicates that the lechatelierite did not form by simple in-place thermal melting in a very-high-temperature melt. Sample from a possible dike of impact melt located on the rim of Tenoumer Crater (Mauritania). Specimen courtesy of R. S. Dietz. Sample TM-1-1 (plane-polarized light). 


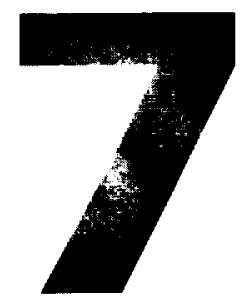

\section{How to Find Impact Structures}

\subsection{REASONS FOR THE SEARCH}

Since the 1960s, the field of meteorite impact geology has evolved far beyond the early arguments about the impact origin of a few individual geological structures. Meteorite impacts on Earth are now widely accepted as an important geological process, and one whose effects are still not fully understood. At the same time, the identification of new impact structures through the discovery of shockmetamorphic effects has become a fairly simple and routine process.

The current search for new impact structures now emphasizes the recognition, among the new discoveries, of individual structures that can provide specific information about key problems: shock-wave transmission, cratering mechanics, physical conditions of the impact environment, impactmelt formation, environmental and biological effects, and the nature of the impact flux over geologic time. The last problem is especially uncertain and controversial, chiefly because relatively few impact structures have been accurately age-dated (Bottomley et al., 1990; Deutsch and Schärer, 1994). The discovery and accurate dating of another 10-20 structures might make it possible to estimate more accurately the bombardment rate over time and to determine whether the bombardment process has been random or periodic.

For these reasons, the discovery and recognition of new terrestrial impact structures is still a critical component of future research in this field. To aid in this search, the remainder of this chapter summarizes the general properties of impact structures as they now appear on Earth, so that new candidates can be identified for detailed sampling and study (see also Appendix).

\subsection{DETECTION OF CANDIDATE IMPACT SITES}

The process of recognizing a new impact structure involves two steps: (1) detection of a candidate impact site through field studies, geophysical measurements, remote sensing, drilling programs, or (sometimes) pure accident; and (2) verification of the site as an impact structure by the discovery of shock-metamorphic effects in its rocks. (In some cases, verification can also be provided by the discovery of meteorites or a meteoritic signature - such as excess iridium - in the breccias or melt rocks associated with the structure.)

Many now-established impact structures first attracted attention because they appeared as anomalous circular features in topography or bedrock geology: lakes, rings of hills, or isolated circular areas of intense rock deformation in otherwise undeformed bedrock. A few impact structures developed in sedimentary rocks were noted because the upturned rocks of their central uplifts resembled salt domes, and the perceived economic potential promoted drilling and detailed geophysical studies. Other impact structures have been found by accident in the course of general field mapping or regional geophysical surveys. Some well-known structures [e.g., Ries Crater (Germany), Sudbury (Canada), and Vredefort (South Africa)] have been considered (often for many decades) as the sites of unusual volcanic activity or "cryptovolcanic" events. And a few structures, so deeply eroded that no circular form remains, have been recognized only by the presence of scattered patches of unusual breccias or strange "volcanic" rocks.

The increasing appreciation of extraterrestrial impacts as a mainstream geological process, and the increasing atten- 
tion given to newly recognized impact structures, has promoted more searches for new structures as well as systematic mapping of recognized structures by the sophisticated methods of remote sensing and geophysical surveys. However, the discovery and verification stages still remain separate. A candidate impact structure may be detected in many ways (field geology, remote sensing, geophysics), but verification comes only from the identification of definite impact-produced features - shock-metamorphic effects, unique geochemical signatures, or both - in its rocks. At present, there are no other geological or geophysical criteria that unambiguously distinguish impact structures from other circular features such as volcanic calderas, plutonic intrusions, or salt domes. Definite proof of impact origin requires access to the rocks. The candidate structure must first be detected somehow, then it must be sampled.

\subsubsection{Geological Features}

The first indication of a possible meteorite impact structure is frequently a distinct circular (or nearly circular) feature in the topography or bedrock geology. This circular region commonly shows distinctive and often anomalous bedrock geology in comparison to the surroundings. The region may also be the site of intense and localized deformation (fracturing, faulting, and brecciation), or it may contain unusual (or even normal-looking) volcanic or intrusive igneous rocks.

The distinctive features of impact structures vary with age and erosional history (Dence, 1972; Grieve, 1991; Grieve and Pilkington, 1996). In the few impact structures young enough and fresh enough to still preserve their original crater rims, the circular form may be striking. Original ejecta and shocked rock fragments may still be preserved on the original ground surface outside the crater, and meteorite fragments may even be found to establish the origin of the structure beyond question. In more deeply eroded structures, where the original rim and outside ejecta have been removed, the circular outcrop pattern of breccias and melt rocks that filled the original crater may still attract attention. At deeper erosion levels, where these rocks have been removed, a circular pattern of intense deformation and brecciation, accompanied in larger structures by a preserved central uplift, may still be recognizable, especially in structures formed in sedimentary rocks. In very deeply eroded structures, the circular character may still be expressed by deformed or unusual rock types (e.g., pseudotachylite) in the bedrock, even when the structure has been strongly deformed by postimpact tectonic activity [e.g., Sudbury (Canada)].

A few impact structures have been so deeply eroded that no distinctive circular feature remains. Such structures exist only as patchy remnants of unusual "volcanic" breccias and other deformed rocks, and in many cases [e.g., Rochechouart (France), Gardnos (Norway)] the shock effects (e.g., shatter cones, PDFs in quartz) were only identified in the rocks decades after the rocks themselves had been first described. The accumulated geological literature, especially papers that describe strange breccias and unusual "volcanic" rocks, may be a reward ng ground in which to search for unrecognized impact stru tures of this kind.

\subsubsection{Ge sphysical Features}

The forr uation of impact structures involves shattering and breccia ion of the rocks that already exist beneath the crater floor, followed by filling of the resulting crater by a variety of in pact-produced breccias and frequently by postimpact sed ments. These processes produce distinctive changes in $t$ te physical properties of the rocks in and around impact strur tures. These changes are expressed most notably as variati ons in the gravity and magnetic fields (Pilkington and Grieve, 1992; Grieve and Pilkington, 1996).

Gravity anomalies. Impact structures, even large ones, are relatively sh: llow, near-surface features in comparison to typical volcanic and tectonic structures. Even so, fracturing and brecciation of the target rocks beneath an impact structure extend to significant depths below the crater floor, and significant fracturing and brecciation may even be present at depths of ser eral kilometers below large structures. Evidence from some s:udies, e.g., at Ries Crater (Germany), suggests that fracturing extends to depths of about one-third the diameter of he structure (e.g., 6-8 km at Ries Crater). The fractured ro: $k$ is less dense than the unaltered target rock around the s:ructure, and the resulting density contrast may be increased by the similarly underdense fragmental breccias and sediments that fill the crater. As a result, many impact structur ss, especially bowl-shaped simple craters, exhibit a negative gr rvity anomaly that is generally circular in shape and closely roincides with the structural boundaries of the circular featu re.

Such a ne gative gravity anomaly is not a definite sign of impact, and such anomalies are absent from many established impac structures. In complex impact structures, where subcrater fra :turing and brecciation are accompanied by uplift of denses deep-seated rocks into the central part of the structure, th: normal negative gravity anomaly may be reduced or even converted to a positive anomaly, because the uplifted den: er rocks overcome the effects of fracturing and brecciation (itepto, 1990; Pilkington and Grieve, 1992; Grieve and Pilkingte $n, 1996)$.

Magnetic, momalies. Magnetic field measurements around impact struc ures have not revealed any single specific signature that zan be clearly related to the impact process (Pilkington a ad Grieve, 1992). Some impact structures show no significan: magnetic signature because of the fragmentation and mix ng of target rock during the cratering process, and they may appear only as an anomalous circular region of low or rando n magnetic signature among any regional magnetic patterns (e.g., linear anomalies) present in the surrounding preimpart bedrock (Scott et al., 1997). At other impact structures, a strong local magnetic anomaly (positive or negative) may be produced by the remanent magnetization of units of impact melt within the structure or by the uplift of more magnetic units from depth into the central uplift (Hart et al., 1995). 
Seismic studies. Seismic profiling studies are increasingly being used to determine the structural deformation present beneath large impact structures [e.g., Gosses Bluff (Australia) (Milton et al., 1972, 1996b); Montagnais (Canada) (Jansa and Pe-Piper, 1987); Chesapeake Bay (USA) (Poag, 1996, 1997); and Chicxulub (Mexico) (Morgan et al., 1997)]. These studies have revealed a pattern of subsurface deformation features that appears distinctive for such impacts, especially in the larger basin-form structures: (1) modest downward and inward displacements of the rocks along the edges of the basin; (2) structural disruption, with no coherent seismic reflectors, in a central zone that corresponds approximately to the region immediately beneath the central uplift and the original transient cavity; and (3) beneath this central zone, evidence of preserved and continuous reflectors at depth, demonstrating that the structure is shallow and has no connecting roots to the lower crust or mantle. Seismic profiles have also played an important role in demonstrating the large size and complexity of the highly deformed Sudbury (Canada) structure (Wu et al., 1994).

Despite the complexities of geophysical features and the lack of unique signatures for impact structures, geophysical measurements have been essential for the detection of impact structures that have been completely buried under layers of younger sediments. The appearance of circular anomalies in gravity or magnetic surveys has already led to the discovery of many verified subsurface impact structures, about one-third of the current known total (Grieve, 1991; Grieve and Masaitis, 1994; Grieve et al., 1995). Surprisingly large and important impact structures have been discovered in this way: Puchezh-Katunki (Russia) $(\mathrm{D}=80 \mathrm{~km})$, Chicxulub (Mexico) $(\mathrm{D} \geq 180 \mathrm{~km})$, the Chesapeake Bay Crater (USA) $(\mathrm{D}=90 \mathrm{~km}$ ), and Morokweng (South Africa) $(\mathrm{D} \geq 70 \mathrm{~km}$ ?).

Geophysical studies will continue to play a critical role in the future discovery and study of impact structures. Even though a well-defined circular geophysical anomaly can only indicate a possible impact structure, the discovery of such anomalies has frequently been followed by verification through core drilling, sample recovery, and the identification of distinctive shock effects or chemical signatures in the rocks (e.g., Corner et al., 1997; Hart et al., 1997; Koeberl et al., 1997a). The combination of geophysical field studies and subsequent core drilling is proving to be an important and effective approach for detecting and verifying new impact structures, and it is essential for detecting and exploring buried ones. Geophysical techniques also play an important and increasing role in exploring established impact structures to determine the details of their geology and formation.

\subsection{VERIFICATION OF IMPACT STRUCTURES}

The brief history of impact geology suggests that most of the new impact structures identified in the future will be noted first as some kind of anomalous circular or near-circular feature: (1) a circular or near-circular topographic or physiographic surface pattern that can be detected by some form of remote sensing such as air photography or (increasingly more common) space-based imagery; (2) a circular region of anomalous exposed bedrock, characterized by intense and localized deformation, uplift, breccia development, or by the occurrence of unusual "volcanic" rocks; or (3) a circular geophysical anomaly, most probably in the gravity or magnetic fields, associated with a surface or subsurface structural feature. Rarer candidate sites that may be deeply eroded impact structures may lack a circular signature and may appear only as scattered exposures of anomalous rocks on the ground or as descriptions in the geological literature.

Verification of an impact origin requires the discovery of unique impact-produced features. At present, the only generally accepted impact features are shatter cones, petrographic shock effects, or distinctive geochemical signatures in the rocks of the structure. Possible impact structures must therefore be sampled by means of field studies, core drilling, or examination of existing sample collections. In the field, welldeveloped and indisputable shatter cones are the best indicators of impact, because they are distinctive and widely distributed, especially in the basement rocks of deeply eroded structures. Pseudotachylite breccias in basement rocks may indicate an impact origin, especially where they occur over large areas or in thick veins (e.g., $\geq 10 \mathrm{~m}$ ), but they are not yet accepted as a unique impact indicator because similar rocks can be produced by tectonic processes.

Rock samples can provide definite evidence of impact, often by applying only the straightforward and inexpensive methods of standard petrography. Many distinctive shock effects can be identified even in small samples, such as pieces of drill core. The presence of PDFs in quartz is the most widespread, distinctive, and generally accepted petrographic shock criterion. They may occur in samples from two discrete regions in the structure: (1) in shocked-metamorphosed rock fragments in crater-fill breccias and impact melts; and (2) (more rarely) in preserved regions of shocked parautochthonous rocks just below the original crater floor, or in the central uplift, where PDFs may occur in or with shatter cones. Less common, but equally definitive, indicators of impact include diaplectic glasses (e.g., feldspar transformed to maskelynite), high-pressure mineral phases (e.g., coesite, stishovite), and lechatelierite (fused quartz) in impact melts.

In breccias or melt rocks that display no shock features, geochemical analyses may provide definite evidence of impact by identifying a signature from the projectile, either excess iridium (or other platinum-group elements) or distinctive osmium isotope ratios. Other geochemical signatures that strongly support an impact origin, but do not provide definite proof, include: (1) a match in chemical and/or isotopic compositions between the breccias and melt rocks and the target rocks in which the structure is found; and (2) isotopic signatures (e.g., $\mathrm{Sm} / \mathrm{Nd}, \mathrm{Rb} / \mathrm{Sr}$ ) in the melt rocks that indicate derivation entirely from crustal rocks (especially from crustal rocks much older than the structure itself), without any mantle-derived component. 



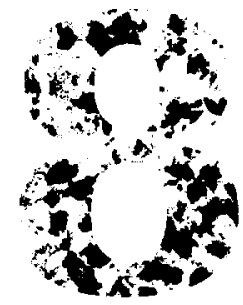

\section{What Next?}

\section{Current Problems and Future Investigations}

\subsection{IDENTIFICATION OF NEW IMPACT STRUCTURES}

Despite the apparent abundance of impact structures ( 150 now known), the terrestrial record remains both incomplete and biased, and it is essential to continue the search. The present number of known impact structures is still $\leq 25 \%$ of the total presumably still preserved on the land areas of the Earth (Trefil and Raup, 1990; Grieve, 1991). Even worse, the processes of geological destruction active on the Earth have strongly biased the observed distribution. Most known impact structures have ages of $<200 \mathrm{Ma}$, and small, easily croded structures are strongly underrepresented in the record (Grieve, 1991; Grieve and Pesonen, 1992, 1996).

The identification of more impact structures, accompanied by accurate age-dating, is essential to improve this database. With better data, we can explore some important and unanswered questions: What is the actual impact rate of various-sized extraterrestrial objects on Earth? Is the bombardment rate variable, nonrandom, or even periodic? What are the relative importances of asteroids and comets as impacting bodies? With a larger suite of impact structures, it will also be possible to identify well-preserved examples that can provide detailed information about cratering mechanics and geological effects. Finding new impact craters is also a challenge to our abilities and our imaginations: How much of the preserved impact record on Earth can we discover with the techniques we now possess, and where are the pieces of this record located?

Current searches for new impact structures are now especially active in Fennoscandia (Pesonen and Henkel, 1992; Pesonen, 1996), Africa (Koeberl, 1994b), and Australia (Glikson, 1996b; Shoemaker and Shoemaker, 1996). An important component of these searches has been the discovery of subsurface impact structures from geophysical data (Cor- ner et al., 1997; Hart et al., 1997; Gostin and Therriault, 1997). Until recently, the sea floor has been largely ignored in the search for impact structures, and only a few submarine impact structures have been identified (e.g., Jansa and Pe-Piper, 1987; Poag, 1996; Dypuik et al., 1996). The special problems of submarine impact structures are finally receiving attention. There is new interest in searching for impact structures beneath the present oceans, and scientists are beginning to explore the unusual geology of submarine impact events in a few impact structures that formed underwater but are now accessible on land (Therriault and Lindström, 1995; Lindström et al., 1996). Even so, all the submarine structures so far identified have formed on the shelf areas of adjacent continents. The deep ocean basins, which probably received about three-quarters of the projectiles that struck Earth in the last $\sim 200 \mathrm{~m} . y$., still remain to be explored, although evidence for one recent small impact in the South Pacific has been discovered (Gersonde et al., 1997). Amid this current activity on sea and land, the search for the source crater that produced the Australasian tektite strewnfield remains a prominent and nagging problem for the future.

\subsection{IMPACT EVENTS AND EXTINCTIONS}

A firm connection between one large impact event and one major biological extinction has now been solidly established between the Chicxulub structure (Mexico) and the K/T event (Alvarez et al., 1980; Sharpton et al., 1992; papers in Ryder et al., 1996; Alvarez, 1997). Research on the K/T problem has now largely turned away from debating the existence of the impact and is now focused on closer studies of the consequences. Paleontologists are studying the finer details of the extinction itself: the duration of the overall event, the relative timing of the disappearances of different spe- 
cies, and the various environmental stresses and "kill mechanisms" implied by the geological record.

At the same time, a major geological effort, involving geophysical surveys and new drilling projects (e.g., Sharpton et al., 1993, 1996b; Morgan et al., 1997), is concentrating on the Chicxulub structure itself, to determine more accurately the size of the structure, the energy released by the impact, and the amounts of volatile materials (water vapor, $\mathrm{CO}_{2}$ and $\mathrm{SO}_{2}$ ) released from melted and vaporized target materials (ocean water, limestones, and evaporites) (papers in Ryder et al., 1996; Pope et al., 1994, 1997; Yang and Abrens, 1998). These data are needed to accurately estimate the global environmental stress and to complement the paleontological studies of the extinction. In addition to its tie to the K/T extinction, the Chicxulub structure itself, because of its relative youth and immediate burial after formation, is the bestpreserved terrestrial impact structure of its size discovered to date, and the geological studies will also vield a wealth of information about the cratering mechanics and geological effects involved in such large, rare impact events.

Despite the strength of the connection between Chicxulub and the $\mathrm{K} / \mathrm{T}$ extinction, it has not yet proved possible to establish a similar firm link between an impact event and any of the half-dozen or so other major extinctions recorded in the last 700 m.y. However, there are growing indications of a link between impact events and the lesser extinction observed about 35 m.y. ago near the Eocene-Oligocene boundary (Montanari et al., 1993; Clymer et al., 1996; Langenhorst and Clymer, 1996; Glass et al., 1998). All the essential ingredients seem to be present: a significant extinction, a layer of impact debris (including microtektites) at the boundary, and two candidate impact structures in the $\geq 90-\mathrm{km}$-diameter range: Popigai (Russia) (Bottomley et al., 1997) and Chesapeake Bay (USA) (Koeberlet al., 1996a). A layer containing shocked quartz has also been found at the older (205 Ma) Triassic-Jurassic boundary, a location also characterized by a major biological extinction (Bice et al. 1992).

\subsection{DISTAL IMPACT EJECTA}

An important and unexpected resource for future studies of terrestrial impacts are the thin layers of distal ejecta that are distributed over continental to global distances from the impact site. In the past, it was considered unlikely that such thin deposits could be preserved in the geologic record, and little consideration was given to finding and identifying them. This attitude has changed drastically, chiefly as a result of studies at the $\mathrm{K} / \mathrm{T}$ boundary, where the distinctive global ejecta layer from the Chicxulub impact structure was conclusively identified even before the structure itself was located. Distal ejecta layers have also been identified from other structures, e.g., Manson (Iowa) and Acraman (Australia), and it is now generally accepted that microtektite layers also represent distal ejecta.

Although only a few distal ejecta layers from particular structures have been identified so far, the potential impor- tance of suth layers has been increased by new methods of study and cnalysis. Layers of impact-crater ejecta can now be clearly distinguished from similar sedimentary or volcanic units (e g., ash-fall beds) by the presence of such unique features as pherules, quartz PDFs, and iridium anomalies. Current ge schemical techniques are sensitive and precise enough - even if delicate and time-consuming - to extract important information about the impact event from small partic les, and it is possible, in many cases, to determine from i small sample of ejecta the age of the impact or the geocher nical characteristics of the target rock involved.

Distal ej scta layers in the sedimentary record have a large and unexplc red potential to provide critical insights into the impact histıry of the Earth (Grieve, 1997). Systematic identification of distal ejecta layers in long-duration sedimentary sections car yield independent estimates of the impact rate over geolog c time. Ejecta layers linked to known large impact structu es can improve our understanding of the crater formation frocess and the areal extent of the environmental effects. In sc me cases, it may be possible to obtain good agedates on ir pact events from the stratigraphic ages of the ejecta. Som: individual ejecta layers may also indicate the existence of insuspected and undiscovered impact structures, as was the c ise with the Chicxulub structure and for a Late Devonian is npact event recently recognized in the western USA (Leron $x$ et al., 1995).

\subsection{CARBON CHEMISTRY IN THE IMPACT ENVIRONMENT}

The unic ueness of the high-pressure shock-wave environment below the developing impact crater has long been appreciated, but there are recent indications that equally unique concitions above the impact point also produce unusual and la: ting effects. At the moment of impact, a hightemperature vapor plume, with temperatures of thousands of degrees, $x$ xpands outward and upward from the impact point (Melo:b, 1989, pp. 68-71). This plume, as it interacts with the atn osphere, plays a major role in ejecting material from the cra er to great distances (e.g., Alvarez et al., 1995). This extreme environment also produces a variety of unusual and sti 1-baffling chemical changes.

Carbon c smpounds in impactites have recently revealed a variety of :xciting and puzzling features, some of which may reflect th $\mathrm{e}$ instantaneous high-temperature environment within the $\mathrm{v}$ tpor plume. Diamonds have long been known to be a shocl-metamorphic product in carbon-bearing target rocks (e.\{., Masaitis, 1998; Masaitis et al., 1972; Koeberl et al., 1997c, , but more recent studies have discovered tiny nanodiamor ds, unrelated to preimpact target graphite, that apparently $\mathrm{f}(\mathrm{rmed}$ in the vapor phase and then were deposited in suevite breccias (Hough et al., 1995) and in ejecta at the K/T boundary (Carlisle and Braman, 1991; Hough et al., 1997).

A differer $t$ form of carbon, fullerenes, has also been discovered in terrestrial impact environments. These recently discovered "s. scer-ball" carbon molecules (e.g., the $\mathrm{C}_{60}$ mol- 
ecules called "buckyballs") have attracted attention because of their stability and unusual chemical characteristics (e.g., the ability to "cage" other atoms) (for background and details, see Aldersey-Williams, 1995). Because of their stability, it has been suggested that fullerenes could form in the outflows from high-carbon stars and could be common in both the interstellar medium and in meteorites, although fullerenes have not yet been conclusively identified in either location. However, fullerenes have been identified in the $\mathrm{K} / \mathrm{T}$ ejecta layer (Heymann et al., 1994) and in the carbonaceous Onaping Formation, an impact breccia at the Sudbury structure (Canada) (Becker et al., 1994, 1996). The presence of fullerenes in such impact-produced deposits, their possible extraterrestrial origin, and the implications of their presence for the origins of life on Earth have focused considerable multidisciplinary attention, particularly from exobiologists, on impact processes in general and Sudbury in particular.

Carbon in impact structures, and its behavior during impact events, is an area of research that currently contains a few exciting observations, enclosed in a large number of unanswered questions. Carbon is generally absent in impact structures; impactites with significant carbon contents $(>0.5 \mathrm{w} \%$ ) are known only from Sudbury (Canada) (French, 1968b; Avermann, 1994) and Gardnos (Norway) (French et al., 1997). The source(s) of this carbon has not been established; possible sources are the projectile (e.g., carbonaceous chondrite meteorites or comets), Earth's atmosphere, or yetunrecognized carbonaceous target rocks. It is also possible that the carbon has been introduced into the impactites during later metamorphism. Identifying the sources of carbon in these impactites, and distinguishing between impact-related and postimpact carbon, requires careful sampling and sophisticated analyses in the future.

The problem of carbon in the impact environment leads directly to large and longstanding questions about the origin of the solar system, the formation of planets, and the origin and history of life on Earth. Are any carbon and organic molecules present in the incoming projectile destroyed by the impact event, or can they survive to contribute to the subsequent origin of life? What does the formation and survival of diamonds and fullerenes in impact events tell us about the physical conditions in the vapor plume or the nature of Earth's atmosphere at the time of impact? Impact structures, especially those with carbonaceous impactites, preserve the results of unique natural experiments in prebiotic chemistry and the behavior of carbon compounds under extreme conditions. Interdisciplinary studies to explore these problems should be an important part of future impact studies.

\subsection{POSTIMPACT PROCESSES AND EFFECTS}

Past research on impact events has concentrated on the formation of the impact structure and its immediate effects: shock-metamorphic features, generation of impact melts, and biological extinctions. It is now recognized that the large amounts of mechanical and thermal energy depos- ited in the impact site produce longer-term effects, and there is new interest in identifying and studying impact effects that persist during the period $\left(10^{2}-10^{6} \mathrm{yr}\right)$ in which normal geological processes resume in the region affected by the impact event.

The thermal energy deposited in an impact structure as shock heating and impact-melt formation can produce hydrothermal activity and related ore deposits similar to those that result from more conventional geological processes. Such postimpact activity is frequently expressed in the secondary alteration of the impact melts themselves (Dence, 1971; Newsom et al., 1986; Mc Carville and Crossey, 1996). However, in larger structures, the combination of large volumes of melt and extensive hydrothermal circulation may produce new sedimentary deposits and associated ore bodies, e.g., the Vermillion Formation at Sudbury (Canada) (Grieve and Masaitis, 1994).

The postimpact sediments that fill some impact structures may preserve a record of the important transition between impact-related effects and postimpact geological history. At the buried Chicxulub structure (Mexico), the thick crater-fill deposits have a special importance because they may preserve the immediate postimpact history of waning impact effects and biological recovery after the K/T event. At other impact sites, crater-fill sediments may preserve the only available long-term record of postimpact geological and environmental processes that originally affected a much wider region (Beales and Lozej, 1975; Partridge et al., 1993; Grieve, 1997).

The overall shape and general geological characteristics of impact structures have been well established by extensive research, and these features can serve as important markers for determining postimpact erosion and deformation (Grieve, 1991). This knowledge is also important for identifying and reconstructing highly deformed impact structures, such as Sudbury (Canada) (Wu et al., 1994), in which the presently preserved feature may represent only a fraction of the size of the original impact structure (Therriault et al., 1997).

\subsection{PETROGENESIS OF IGNEOUS ROCKS: IMPACT MELTS}

The impact melt rocks preserved in terrestrial impact structures represent unique, important, and virtually unstudied laboratory experiments in the formation, emplacement, and crystallization of igneous rocks. Future studies of impact melts can provide unique insights into these longstanding geological problems. Impact melt bodies occur in a range of sizes, from small and rapidly cooled pods and dikes up to the huge Sudbury Irruptive with its associated ore deposits. These bodies have formed, nearly instantaneously, in a single melting event, from surrounding target rocks that can generally be sampled and characterized. The largest and best-preserved impact melt bodies are found as sills in the crater-fill deposits, and they have cooled uniformly without any addition of new magma. Their history and cooling environment can be well constrained by information about the 
crater shape and the impactite deposits associated with them. As igneous rocks, impact melts provide a degree of simplicity, information, and context that is only rarely found in endogenic igneous rocks, and study of them will provide fundamental information on all igneous rocks.

Detailed comparative studies of terrestrial impact melt rocks and endogenic igneous rocks can also improve current models for impact crater formation and impact melt generation. Is the current assumption that impact melt bodies are homogeneously mixed target rock really correct at all scales? Is there time for chemical and mineralogical differentiation in large bodies of impact melt (e.g., the Sudbury Irruptive), or do the systematic variations observed have some other cause? What can terrestrial impact melts tell us about the origin and chemistry of the very large bodies of impact melt associated with the largest lunar impact basins?

\subsection{IMPACTS AND THE EARLY EARTH}

Even the largest and oldest known terrestrial impact structures [Sudbury (Canada) and Vredefort (South Africa)] are only about 2 b.y. old and were only about $200-300 \mathrm{~km}$ in diameter when they formed. They are therefore both small and young by comparison with the earlier history of impact events in the solar system. Preserved impact features on the Moon, Mercury, and other planets exceed $1000 \mathrm{~km}$ in diameter and are $>4$ b.y. old, and the ancient and heavily cratered surfaces of the Moon and other planets show that this period was a time of intense bombardment, when impact rates were hundreds to thousands of times the present low values (Fig. 1.13) (Taylor; 1975; 1982, Chapter 3; 1992, Chapter 4; Hörzet al., 1991; Spudis, 1993).

Earth could not have escaped the heavy bombardment of extraterrestrial objects at this time, and the present scarcity of old and large terrestrial impact structures reflects the continuous geological destruction and recycling of old terrestrial rocks. We therefore face a major problem in exploring the impact history of Earth: Just when impact events become more frequent, larger, and potentially more important $(\geq 3.8 \mathrm{Ga})$, the available record of these events becomes increasingly destroyed. Are Sudbury and Vredefort the largest and oldest impact structures that we can find preserved on Earth? Or can we find the traces of larger and more ancient impact events and understand their effects?

The evidence from other planets leaves no doubt that large impacts on Earth were not only a major, but in fact the dominant, process during early geologic time ( $\geq 3.8 \mathrm{Ga})$. Comparisons with the lunar highlands (Grieve, 1980; Grieve it al., 1990) suggest that as many as 200 impact basins $\geq 1000 \mathrm{~km}$ in diameter may have formed on Earth during this period, accompanied by exponentially larger quantities of smaller structures. Plausible geological effects of these catastrophes include the formation of huge volumes of impact melts, the triggering of widespread endogenic volcanism from beneath a thin Archean crust, and the creation of early continental nuclei (Frey, 1980; Grieve, 1980; Glikson,
1993, 1996a). The effects above ground could be equally disastrous. Large impacts could blast away existing atmospheres and $t$ aen replace them with water and other volatiles carried in th e projectiles themselves. The development of life on Eart a could have followed an intermittent path in which existing life forms were destroyed by large impacts and new onts formed from the organic compounds brought in by the pro ectiles. Even in relatively recent times $(\geq 2.5 \mathrm{Ga}$ ), sporadic larşe impacts could have produced major changes in the igneou s and tectonic histories of Earth (Glikson, 1993, 1996a).

The sear h for traces of such events faces several problems. The ol 1 rocks that would preserve them are scarce and often highly metamorphosed, making it difficult to distinguish impac: effects from the results of normal geological processes (e.g., Weiblen and Schulz, 1978). A second problem is uncer ainty about what very large impact structures would look $1 \mathrm{ke}$, even if well preserved. Larger impact structures (D > 200-300 km) will generate relatively larger amounts of $\mathrm{t}$ elt, producing a wide, relatively shallow structure dominat $2 \mathrm{~d}$ by melt rather than by more familiar impactite breccias (Gri ve and Cintala, 1992; Cintala and Grieve, 1998). Such structures might easily be removed by erosion or mistaken for en logenic bodies such as sills and lopoliths. The possibility th at the well-known Bushveld Complex (South Africa) migl t be such a melt-rich impact structure (Rhodes, 1975) has so far proved to be negative (c.g., French, 1990a), but the deba e and the searches go on.

Despite $t$ lese difficulties, it may still be possible to recognize the tr ices of ancient impact events. Distinctive shock features suck as shatter cones and pseudotachylite breccias can be prese ved in even highly metamorphosed rocks, as can distinctiv e geochemical signatures (e.g., iridium anomalies) in brecc as and impact melts. It may also be possible to recognize dis tal ejecta units from ancient impact events, and such an orig $n$ has been proposed for the unusual spherule layers found in >3-b.y.-old rocks of the Barberton Mountain Land (South Africa) (Lowe and Byerly, 1986; Lowe et al., 1989) and in 2.6-b.y.-old sediments in Australia (Simonson, 1992; Simon on and Davies, 1996; Simonson et al., 1997). Definite shork-metamorphic effects have not yet been found in these sphe ule beds, and their origin is still debated (e.g., French, 1987; Koeberl et al., 1993; Koeberl and Reimold, 1995), but the mere preservation of such distinctive units in such ancient rocks is an encouraging sign for future searches.

A related yossibility, speculative and exciting, is that even thicker $(10-: 00 \mathrm{~m})$ layers of ejecta from large impact structures may be preserved among the long-studied formations of diamictites, unusual breccias currently regarded as the products of $\xi$ lacial activity or other unusual sedimentation processes (Ol erbeck et al., 1993; Rampino, 1994). These units are an imporiant target for future searches, and they should be examined anew for shock-metamorphic effects (c.g., Reimold et al. 1997b).

The incre: sing importance of meteorite impacts in Earth history, the g owing recognition of preserved impact effects in the geological record, and the ease with which impact 
events can be recognized by their shock-metamorphic effects have combined to show geologists the importance of new searches in the field. In the future, as geologists discover more ancient rocks, or as they reexamine formations discovered long ago, the possibilities of impact - and the key signatures of impact events - should be kept in mind.

During the brief history of meteorite impact geology, all past predictions about the importance of impacts and the range of their effects have turned out to be inaccurate and unimaginative underestimates. Although a lot has been learned in the last couple of decades, there is no reason to expect that today's estimates will turn out to be any more accurate. We must now do what geologists have always done when suddenly faced with ideas that are new, exciting, poorly explored, and only dimly understood. We must take the new ideas out into the field and look at the rocks again. 


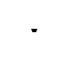




\section{Appendix}

\section{CRITERIA FOR RECOGNIZING TERRESTRIAL IMPACT STRUCTURES}

(expanded from Dence, 1972, pp. 78-79, and other sources)

\section{SURFACE FORM AND GEOLOGIC STRUCTURE}

Surface Expression and Shape:

occur in any kind of bedrock (crystalline, sediments, volcanic)

generally occur as single structures

rarely double or small multiple structures

larger structures not present as groups

generally circular

elliptical or noncircular in deformed structures

possible circular depression or definite crater

also possible circular uplifted region

may be expressed by physiographic features (e.g., topographic relief, drainage)

\section{Size and Occurrence:}

wide size range, from $<1 \mathrm{~km}$ to $>100 \mathrm{~km}$ diameter

occur in all geological terranes, bedrock (crystalline, sediments, volcanic)

only random association with other geological features

\section{Relatively shallow}

underlain by undeformed regional bedrock

unusual deformation extends less than one-third apparent diameter

Anomalous feature in regional topography, geology

unusual geology within circular area

local deformation: faulting, brecciation

unusual breccias, melt rocks within structure

serve to define structure

may be absent (deeply eroded structures)

similar breccias rarely present outside structure

deposits on or beyond rim

in structures with well-defined crater morphology

central uplift of deeper-seated rocks (in larger structures)

may form central peak or central ring

show definite stratigraphic uplift

rocks may contain distinctive shatter cones*

unique conical fractures, striated

restored apexes point inward/upward

Vague or ambiguous descriptions in previous literature deformation recognized in earlier studies (intense, sudden, localized)

conventional endogenic mechanisms not adequate

vague mechanisms proposed

unusual volcanic explosions

("cryptoexplosions")

* Indicates unique shock-metamorphic features that provide definite evidence for meteorite impact origin. 


\section{CRITERIA FOR RECOGNIZING IMPACT STRUCTURES}

\section{SURFACE FORM AND GEOLOGIC STF.UCTURE (continued)}

Brecciation: may be widespread in surface, subsurface s smples

breccia zones in bedrock below crater around rims or in central uplift areas generally in-place monomict breccias rare dike-like bodies of polymict breccia, melt unusual pseudotachylite breccias polymict breccias and melt rocks may form blanket-like, layered units (crater fill) in central regions (small structures) as annular units around central uplifts (larger st ructures)

\section{GEOPHYSICAL CHARACTF RISTICS}

\section{Gravity Signature:}

may show circular anomaly following structure typically negative (breccias and sedimentary fill) may be positive (larger structures; uplift) may also be lacking

\section{Magnetic Signature:}

no distinctive typical pattern

regional anomalies outside structure may be interru )ted, subdued, merged within structure

may be positive anomalies over specific areas

melt-bearing rocks, breccias uplifted deep-seated magnetic rocks

Seismic Characteristics:

lower seismic velocities within structure (from brecciation; presence of sedimentary fill) regional stratigraphy interrupted by structure deep seismic reflectors disrupted; chaotic patten $n$ regional structure again becomes continuous at relatively shallow depths beneath surface structure no evidence of deep roots or connections for structu re around margins, presence of concentric shallow inward faults, producing terraced rims

\section{ROCK TYPES: GENERAL CHAR ICTERISTICS}

\section{Monomict Breccias:}

abundance, distribution reflect nature of bedrock

(homogeneous/heterogeneous)

areas within bedrock below, around structure layers in units that fill structure no abnormal deformation in component clasts bulk chemical compositions are those of associated ocal bedrock no siderophile-element anomalies (iridium content: , osmium isotopes)

* Indicates unique shock-metamorphic features that provide definite evidence for meteorite impact origin. 


\section{CRITERIA FOR RECOGNIZING TERRESTRIAL IMPACT STRUCTURES}

\section{ROCK TYPES: GENERAL CHARACTERISTICS (continued)}

Polymict Breccias:

occurrence: various possible locations: intrusive dike-like bodies in bedrock irregular horizontal layers within structure

(may be transitional with melt rocks) along/outside rim of structure (ejecta)

rare: only in well-preserved structures

rock fragments: derived from local bedrock only exotic rock types rare to absent

both melt-bearing and melt-free varicties present melt-bearing: diverse types:

melt as discrete fragments; clastic matrix

melt-matrix, with bedrock clasts

melt-bearing types:

resemble endogenic volcanic breccias, e.g., ash-flow tuffs, intrusive breccias

lack typical volcanic features

no phenocrysts, cogenetic volcanic rocks

all fragments are broken bedrock clasts

may contain distinctive cored inclusions

(melt rim around bedrock clast)

breccia units appear deposited all at once

no evidence for prolonged volcanic activity

no erosional horizons observed between units

bedrock inclusions often show unusual, distinctive petrographic deformation features

bulk chemical compositions equivalent to compositions of mixed local bedrock types

siderophile-element anomalies ${ }^{*}$ may be present (iridium contents, osmium isotopes)

Melt Rocks:

occur in diverse locations

dike-like bodies in substructure bedrock

sill-like units within structure

interbedded with breccias

display range of typical igneous textures

features reflect size, cooling rate

transitional with melt-bearing breccias

included rock fragments often display unusual petrographic deformation, melting, and recrystallization textures

bulk chemical compositions equivalent to compositions of mixed local bedrock types

may show siderophile-element anomalies*

(iridium contents, osmium isotopes)

* Indicates unique shock-metamorphic features that provide definite evidence for meteorite impact origin. 


\section{CRITERIA FOR RECOGNIZING ๆ'ERRESTRIAL IMPACT STRUCTURISS}

\section{MICROSCOPIC DEFORMATION AND MIELTING FEATURES}

Found in a variety of rock types and locations in structure

(1) in-place bedrock in center of structure (rarely preserved or exposed) may be associated with shatter cones*

(2) bedrock inclusions in polymict breccias and melt rocks

Not present in rim bedrock or monomict breccia clasts

General characteristics of deformation quartzofeldspathic rocks most sensitive, best indicat urs selective: each mineral responds in isolation pervasive: generally affects each mineral grain locally variable: strong differences in deformation in tensity over small areas may be small local glassy veins, pods in rock range of effects: progressive deformation, melting progressive destruction of original fabric

Fracturing (may not be distinguishable from effects of o her geological processes) intense, closely spaced parallel sets may be shock-pr duced may be associated with definite shock-deformation eatures

Unique mineral deformation features (shock-produced) planar deformation features (PDFs) ${ }^{*}$ in quartz, feld spar multiple sets at distinct orientations may be fresh (continuous) or "decorated" (inclu ions) Brazil twins parallel to base (0001) diaplectic glasses*, c.g. maskelynite (feldspar) high-pressure mineral phases*: coesite, stishovite, diamond

Selective mineral melting* of specific minerals in rock individual minerals melt; associated minerals not aff scted melted minerals may show incipient flow, vesiculatic $n$ transitions to completely melted rock fragments, heterogeneous glasses

Unusual (high-temperature) melting effects* in rock fra rments melting, decomposition of normally refractory mine als

e.g., zircon, sphene ${ }^{*}\left(\mathrm{~T}>1400^{\circ}-1700^{\circ} \mathrm{C}\right)$ quartz $\rightarrow$ lechatelierite ${ }^{*}\left(\mathrm{~T}>1713^{\circ} \mathrm{C}\right)$ evidence of rapid quenching, disequilibrium

Unusual heterogeneous glass fragments (e.g., Fladen) mixed rock/mineral fragments in heterogeneous gla: $s$ included rock/mineral clasts show range of unusual leformation, melting effects lechatelierite ${ }^{*}$ bands, strings (schlieren) present in flc $\mathrm{w}$-banded glass strong indications of disequilibrium, rapid quenching

Deformation, melting textures: show modification or complete destruction by later )rocesses (secondary recrystallization, hydrothermal activity, n etamorphism)

*Indicates unique shock-metamorphic features that provide definite svidence for meteorite impact origin. 
Ahrens T. J. (1993) Impact erosion of terrestrial planetary atmospheres. Annu. Rev. Eartb Planet. Sci., 21, 525-555.

Ahrens T. J. and O'Keefe J. D. (1977) Equations of state and impact-induced shock-wave attenuation on the Moon. In Impact and Explosion Cratering: Planetary and Terrestrial Implications (D. J. Roddy, R. O. Pepin, and R. B. Merrill, eds.), pp. 639-656. Pergamon, New York.

Aldersey-Williams H. (1995) The Most Beautiful Molecule: The Discovery of the Buckyball. John Wiley and Sons, New York. $340 \mathrm{pp}$.

Alexopoulos J. S., Grieve R. A. F, and Robertson P. B. (1988) Microscopic lamellar deformation features in quartz: Discriminative characteristics of shock-generated varieties. Geology, 16, 796-799.

Alvarez L. W., Alvarez W., Asaro F., and Michel H. V. (1980) Extraterrestrial cause for the Cretaceous-Tertiary extinction. Science, 208, 1095-1108.

Alvarez W. (1997) T. Rex and the Crater of Doom. Princeton Univ., Princeton. $185 \mathrm{pp}$.

Alvarez W., Claeys P., and Kieffer S. W. (1995) Emplacement of Cretaceous-Tertiary boundary shocked quartz from Chicxulub crater. Science, 269, 930-935.

Arndt J., Hummel W., and Gonzalez-Cabeza I. (1982) Diaplectic labradorite glass from the Manicouagan impact crater. I. Physical properties, crystallization, structural and genetic implications. Pbys. Chem. Minerals, 8, 230-239.

Avermann M. (1994) Origin of the polymict, allochthonous breccias of the Onaping Formation, Sudbury structure, Canada. In Large Meteorite Impacts and Planetary Evolution (B. O. Dressler, R. A. F. Grieve, and V. L. Sharpton, eds.), pp. 265-274. Geol. Soc. Am. Spec. Paper 293.

Baldwin R. B. (1949) The Face of the Moon. Univ. of Chicago, Chicago. 239 pp.

Baldwin R. B. (1963) The Measure of the Moon. Univ. of Chicago, Chicago. $488 \mathrm{pp}$.

Beales F. W. and Lozej G. P. (1975) Ordovician tidalites in the unmetamorphosed sedimentary fill of the Brent Meteorite Crater, Ontario. In Tidal Deposits, $A$ Casebook of Recent Examples and Fossil Counterparts (R. N. Ginsburg, ed.), pp. 315-323. Springer-Verlag, New York.

Beals C. S., Innes M. J. S., and Rottenberg J. A. (1963) Fossil meteorite craters. In The Moon, Meteorites, and Comets (B. M. Middlehurst and G. P. Kuiper, eds.), pp. 235-284. Univ. of Chicago, Chicago.

Becker L., Bada J. L., Winans R. E., Hunt J. E., Bunch T. E., and French B.M. (1994) Fullerenes in the 1.85-billion-yearold Sudbury impact structure. Science, 265, 842-845.

Becker L., Poreda R. J., and Bada J. L. (1996) Extraterrestrial helium trapped in fullerenes in the Sudbury impact structure. Science, 272, 249-252.

Benz W., Slattery W. L., and Cameron A. G. W. (1988) Collisional stripping of Mercury's mantle. Icarus, 74, 516-528.

Bice D. M., Newton C. R., McCauley S., Reiners P. W., and McRoberts C. A. (1992) Shocked quartz at the TriassicJurassic boundary in Italy. Science, 255, 443-446.

Binzel R. P., Gehrels T., and Matthews M. S., eds. (1989) Asteroids II. Univ. of Arizona, Tucson. 1258 pp.
Bischoff A. and Stöffler D. (1984) Chemical and structural changes induced by thermal annealing of shocked feldspar inclusions in impact melt rocks from Lappajärvi Crater, Finland. Proc. Lunar Planet. Sci. Conf. 14th, in J. Geophys. Res., 89, B645B656.

Bischoff L. and Oskierski W. (1987) Fractures, pseudotachylite veins, and breccia dikes in the crater floor of the Rochechouart impact structure, SW-France, as indicators of crater-forming processes. In Research in Terrestrial Impact Structures (J. Pohl, ed.), pp. 5-29. Earth Evolution Sciences, Intl. Mono. Ser., Friedr. Vieweg and Son, Wiesbaden, Germany.

Bloss F. D. (1981) The Spindle Stage - Principles and Practice. Cambridge Univ., New York. 340 pp.

Bohor B. F. and Glass B. P. (1995) Origin and diagenesis of K/T impact spherules - From Haiti to Wyoming and beyond. Meteoritics, 30, 182-198.

Bohor B. F., Foord E. E., Modreski P. J., and Triplehorn D. M. (1984) Mineralogic evidence for an impact event at the Cretaceous-Tertiary boundary. Science, 224, 867-869.

Bohor B. F., Modreski P. J., and Foord E. E. (1987) Shocked quartz in the Cretaceous-Tertiary boundary clays: Fvidence for a global distribution. Science, 236, 705-709.

Bottke W. F. Jr., Nolan M. C., Greenberg R., and Kolvoord R. A. (1994) Collisional lifetimes and impact statistics of nearEarth asteroids. In Hazards Due to Comets and Asteroids (T. Gehrels, ed.), pp. 337-357. Univ. of Arizona, Tucson.

Bottomley R. J., York D., and Grieve R. A. F. (1990) thArgon${ }^{39}$ argon dating of impact craters. Proc. Lunar Planet. Sci. Conf. 20th, pp. 421-431.

Bottomley R., Grieve R., York D., and Masaitis V. (1997) The age of the Popigai impact event and its relation to events at the Eocene/Oligocene boundary. Nature, 388, 365-368.

Bucher W. (1963) Cryptoexplosion structures caused from without or from within the Earth? ("Astroblemes" or "Geoblemes"?). Amer.J. Sct., 261, 597-649.

Bunch T. F., Dence M. R., and Cohen A. J. (1967) Natural terrestrial maskelynite. Amer. Mineral., 52, 244-253.

Bunch T. E., Cohen A. J., and Dence M. R. (1968) Shock-induced structural disorder in plagioclase and quartz. In Shock Metamorphism of Natural Materials (B. M. French and N. M. Short, eds.), pp. 509-518. Mono Book Corp., Baltimore.

Carlisle D. B. and Braman D. R. (1991) Nanometre-size diamonds in the Cretaceous/Tertiary boundary clay of Alberta. Nature, $352,708-709$.

Carstens H. (1975) Thermal history of impact melt rocks in the Fennoscandian Shield. Contrib. Mineral. Petrol., 50, 145-155.

Carter N. L. (1965) Basal quartz deformation lamellae: A criterion for the recognition of impactites. Amer.J. Sic., 263, 786-806.

Carter N. L. (1968) Dynamic deformation of quartz. In Shock Metamorpbism of Natural Materials (B. M. French and N. M. Short, eds.), pp. 453-474. Mono Book Corp., Baltimore.

Chao E. C. T. (1967) Impact metamorphism. In Researches in Geochemistry, Vol. 2 (P. H. Abelson, ed.), pp. 204-233. John Wiley and Sons, New York.

Chao E. C. T., Shoemaker E. M., and Madsen B. M. (1960) First natural occurrence of coesite. Science, 132, 220-222. 
Chapman C. R. and Morrison D. (1989) Cosmic Catastrophes. Plenum, New York. 302 pp.

Chapman C. R. and Morrison D. (1994) Impacts on the Earth by asteroids and comets: Assessing the hazard. Nature, 367 , $33-40$.

Chyba C. F., Thomas P. J., and 'ahnle K. J. (1993) The 1908 Tunguskil explosion: Atmospheric disruption of a stony asteroid. Nature, 361, 40-44.

Chyba C. F., Owen T. C., and Ip W.-H. (1994) Impact delivery of volatiles and organic molecules to Earth. In Hazards Due to Comets and Asteroids (T. Gehrels, ed.), pp. 9-58. Univ. of Arizon, Tucson.

Cintalia M. J. and Grieve R. A. F. (1998) Scaling impact-melt and crater dimensions: Implications for the lunar cratering record. Miteoritics E Planet. Sti., 33, 889--912.

Clymer A., Bice D. M., and Montanari A. (1996) Shocked quartz from the Iate Eocene: Impact evidence from Massignano, Italy. Grology, 24, 483-486.

Comer B., Reimold W. U., Brandt D., and Koeberl C. (1997) Morokweng impact structure, Northwest Province, South Africa: Geophysical imaging and shock petrographic studies. Earth Planet. Sci. Lett., 146, 351-364.

Croft S. K. (1985) The scaling of complex craters. Proc. Lunar Planet. Sci. Conf. 15th, in J. Geophys. Res., 90, C828-C842.

Dence M. R. (1965) The extraterrestrial origin of Canadian craters. Ann. N. Y. Acad. Sci., 123, 941-969.

Dence M. R. (1968) Shock zoning at Canadian craters: Petrography and structural implications. In Shock Metamorphism of Nitural Materials (B. M. French and N. M. Short, eds.), pp. 169-184. Mono Book Corp., Baltimore.

Dence M. R. (1971) Impact melts. J. Geophys. Res., 76, 55525565.

Dence M. R. (1972) The nature and significance of terrestrial impact structures. Intl. Gool. Congr, 24th, Montral, Canada, Prot., Sett. 15, 77-89.

Dence M. R. (1973) Dimensional analysis of impact structures (abstract). Meteritics, 8, 343-344.

Dence M. R. and Robertson P. B. (1989) Shock metamorphism. In The Encylopedia of Igneous and Metamorpbic Petrology (D) R. Bowes, ed.), pp. 526-530. Van Nostrand Reinhold, New York.

Dence M. R., Innes M. J. S., and Robertson P. B. (1968) Recent geological and geophysical studies of Canadian craters. In Shoik Mitamorphism of Natural Materials (B. M. French and N. M. Short, eds.), pp. 339-362. Mono Book Corp., Baltimore.

Dence M. R., Grieve R. A. F., and Robertson P. B. (1977) Terrestrial impact structures: Principal characteristics and energy considerations. In Impact and Explosion Cratering: Planitary and Terrestrial Implications (D. J. Roddy, R. O. Pepin, and R. B. Merrill, eds.), pp. 247-275. Pergamon, New York.

Deutsch A. and Schärer U. (1994) Dating terrestrial impact events. Moteoritics, 29, 301-322.

Deutsch A., Grieve R. A. F., Avermann M., Bischoff L., Brockmeyer P., Buhl D., Lakomy R., Müller-Mohr V., Ostermann M., and Stöffler D. (1995) The Sudbury Structure (Ontario, Canada): A tectonically deformed multi-ring impact basin. Geol. Rundsch., 84, 697-709.

Deutsch A., Ostermann M., and Masaitis V. L. (1997) Geochemistry and neodymium-strontium isotope signature of tekrite-like objects from Siberia (urengoites, South Ural glass). Mitioritio \& Plant. Sit., 32, 679-686.
Dietz R. S. (1947) Meteorite impact suggested by the orientation of shater-cones at the Kentland, Indiana disturbance. $S_{c i-}$ ince, 1115, 42-43.

Dietz R. S (1959) Shatter cones in cryptoexplosion structures (meter rite impact?). J. Geol., 67, 496-505.

Dietz R. S (1963) Cryptoexplosion structures: A discussion. Amer., Sci., 261, 650-664.

Dietz R. S. (1968) Shatter cones in cryptoexplosion structures. In Sho k Metamorphism of Natural Materials (B. M. French and N M. Short, eds.), pp. 267-285. Mono Book Corp., Baltim ore.

Donofrio R R. (1997) Survey of hydrocarbon-producing impact structu res in North America: Exploration results to date and potent al for discovery in Precambrian basement rock. Oklaboma ('ool. Survey, Circ. 100, 17-29.

Dressler B. O. (1984) The effects of the Sudbury event and the intrusj in of the Sudbury Igneous Complex on the footwall rocks o the Sudbury structure. In The Geology and Ore Deposits of the sudbury Structure (E. G. Pye, A. J. Naldrett, and P. E. Giblin eds.), pp. 97-136. Ontario Geol. Survey Spec. Vol. 1.

Dressler B. (). (1990) Shock metamorphic features and their zoning and ori zntation in the Precambrian rocks of the Manicouagan structu e, Quebec, Canada. Tectonophysics, 171, 229-245.

Dressler B. J. and Sharpton V. L. (1997) Breccia formation at a comple $x$ impact crater: Slate Islands, Lake Superior, Ontario, Canad:. Tectonophysics, 275, 285-311.

Dressler B. J., Grieve R. A. F., and Sharpton V. L., eds. (1994) Large i Meteorite Impacts and Planetary Evolution. Geol. Soc. Amer. jpec. Paper 293. 348 pp.

Dressler B. 1)., Sharpton V. L., and Schuraytz B. C. (1998) Shock metam rphism and shock barometry at a complex impact structu e: Slate Islands, Canada. Contrib. Mineral. Petrol., $130,2: 5-287$.

Dypvik H., Gudlaugsson S. T., Tsikalas F., Attrep M. Jr., Ferrel R. E. J ., Krinsley D. H., Mork A., Faleide J. I., and Nagy J. (1996) Mjelnir structure: An impact crater in the Barents Sea. Gology, 24, 779-782.

El Goresy /. (1965) Baddeleyite and its significance in impact glasses. J. Geophys, Res., 70, 3453-3456.

El Goresy h. (1968) The opaque minerals in impactite glasses. In Sboce Metamorphism of Natural Materials (B. M. French and N. M. Short, eds.), pp. 531-553. Mono Book Corp., Baltim re.

Faggart B. l:. Jr., Basu A. R., and Tatsumoto M. (1985) Origin of the ? udbury Complex by meteorite impact: Neodymium isotopir evidence. Science, 230, 436-439.

Fairbairn H W. and Robson G. M. (1941) Breccia at Sudbury. Rept. Cntario Dept. Mines, 50, Part 6, 18-33.

Fcldman V. I. (1994) The conditions of shock metamorphism. In Lar e Meteorite Impacts and Planetary Evolution (B. O. Dressle:, R. A. F. Grieve, and V. L. Sharpton, eds.), pp. 121132. G :ol. Soc. Amer. Spec. Paper 293.

Fiske P. S., Hargraves R. B., Onstott T. C., Kocberl C., and Houge 1 S. B. (1994) Pseudotachylites of the Beaverhead impact structure: Geochemical, geochronological, petrographic, and field investigations. In Large Meteorite Impacts and Pl netary Evolution (B. O. Dressler, R. A. F. Grieve, and V. L. Sharpton, eds.), pp. 163-176. Geol. Soc. Amer. Spec. Pxper 293.

Ford R. J. (1972) A possible impact crater associated with Darwin Glass. iarth Planet. Sci. Lett., 16, 228-230.

Fowler C. M. R. (1993) The Solid Earth: An Introduction to Global Geophy ics. Cambridge Univ., New York. 472 pp. 
French B. M. (1968a) Shock metamorphism as a geological process. In Shock Metamorphism of Natural Materials (B. M. French and N. M. Short, eds.), pp. 1-17. Mono Book Corp., Baltimore.

French B. M. (1968b) Sudbury structure, Ontario: Some petrographic evidence for an origin by meteorite impact. In $S b o c k$ Metamorphism of Natural Materials (B. M. French and N. M. Short, eds.), pp. 383-412. Mono Book Corp., Baltimore.

French B. M. (1972) Shock-metamorphic features in the Sudbury structure, Ontario: A review. In New Developments in Sudbury Geology (J. V. Guy-Bray, ed.), pp. 19-28. Geol. Assoc. Canada Spec. Paper 10.

French B. M. (1987) Comment on "Early Archean silicate spherules of probable impact origin, South Africa and Western Australia." Geology, 15, 178-179.

French B. M. (1990a) Absence of shock-metamorphic effects in the Bushveld Complex, South Africa: Results of an intensive search. Tectonopbysics, 171, 287-301.

French B. M. (1990b) 25 years of the impact-volcanic controversy: Is there anything new under the sun or inside the Earth? Eos Trans. $A G U, 71,411-414$.

French B. M. and Nielsen R. L. (1990) Vredefort Bronzite Granophyre: Chemical evidence for origin as a meteorite impact melt. Tectonophysics, 171, 119-138.

French B. M. and Short N. M., eds. (1968) Shock Metamorphism of Natural Materials. Mono Book Corp., Baltimore. 644 pp.

French B. M., Hartung J. B., Short N. M., and Dietz R. S. (1970) Tenoumer Crater, Mauritania: Age and petrologic evidence for origin by meteorite impact. J. Geophys. Res., 75, 43964406.

French B. M., Koeberl C., Gilmour I., Shirey S. B., Dons J. A., and Naterstad J. (1997) The Gardnos impact structure, Norway: Petrology and geochemistry of target rocks and impactites. Geochim. Cosmochim. Acta, 61, 873-904.

Frey H. (1980) Crustal evolution of the early Earth: The role of major impacts. Precambrian Res., 10, 195-216.

Fudali R. F. (1974) Genesis of the melt rocks at Tenoumer Crater, Mauritania. J. Geopbys. Res., 79, 2115-2121.

Gash P.J. S. (1971) Dynamic mechanism of the formation of shatter cones. Nature Phys. Sci., 230, 32-35.

Gault D. E. (1973) Displaced mass, depth, diameter, and effects of oblique trajectories for impact craters formed in dense crystalline rocks. The Moon, 6, 32-44.

Gault D. E., Quaide W. L., and Oberbeck V. R. (1968) Impact cratering mechanics and structures. In Shock Metamorphism of Natural Materials (B. M. French and N. M. Short, eds.), pp. 87-99. Mono Book Corp., Baltimore.

Gay N. C. (1976) Spherules on shatter cone surfaces from the Vredefort structure, South Africa. Science, 194, 724-725.

Gay N. C., Comins N. R., and Simpson C. (1978) The composition of spherules and other features on shatter cone surfaces from the Vredefort structure, South Africa. Earth Planet. Sci. Lett., 41, 372-380.

Gehrels T., ed. (1994) Hazards Due to Comets and Asteroids. Univ. of Arizona, Tucson. 1300 pp.

Gersonde R., Kyte F. T., Bleil U., Diekmann B., Flores J. A., Gohl K., Grahl G., Hagen R., Kuhn G., Sierro F. J., Völker D., Abelmann A., and Bostwick J. A. (1997) Geological record and reconstruction of the late Pliocene impact of the Eltanin asteroid in the Southern Ocean. Nature, 390, 357-363.

Gibson H. M. and Spray J. G. (1998) Shock-induced melting and vaporization of shatter cone surfaces: Evidence from the
Sudbury impact structure. Meteoritics \& Planet. Sci., 33, 329336.

Glass B. P. (1984) Tektites. J. Non-Crystall. Solids, 67, 333-344.

Glass B. P. (1990) Tektites and microtektites: Key facts and inferences. Tectonophysics, 171, 393-404.

Glass B. and Barlow R. A. (1979) Mineral inclusions in Muong Nong-type indochinites: Implications concerning parent material and process of formation. Meteoritics, 14, 55-67.

Glass B. P., Koeberl C., Blum J. D., and McHugh C. M. G. (1998) Upper Eocene tektite and impact ejecta layer on the continental slope off New Jersey. Meteoritics E Planet. Si.., 33, 229-241.

Glikson A. Y. (1993) Asteroids and early Precambrian crustal evolution. Eartb-Sci. Rev., 35, 285-319.

Glikson A. Y. (1996a) Mega-impacts and mantle-melting episodes: Tests of possible correlations. AGSO J. Austral. Geol. Geophys., 16, 587-607.

Glikson A. Y., ed. (1996b) Australian impact structures. AGSOJ. Austral. Geol. Geophys., 16, 371-607.

Goltrant O., Cordier P., and Doukhan J.-C. (1991) Planar deformation features in shocked quartz: A transmission clectron microscopy investigation. Earth Planet. Sci. Lett., 106, 103-115.

Goltrant O., Leroux H., Doukhan J.-C., and Cordier P. (1992) Formation mechanisms of planar deformation features in naturally shocked quartz. Phys. Earth Planet. Inter. 74, 219-240.

Gostin V. A. and Therriault A. M. (1997) Tookoonooka, a large buried early Cretaceous impact structure in the Eromanga Basin of southwestern Queensland, Australia. Meteoritics $\mathcal{E}^{\circ}$ Planet. Sci., 32, 593-599.

Gostin V. A., Haines P. W., Jenkins R. J. F., Compston W., and Williams I. S. (1986) Impact ejecta horizon within Late Precambrian shales, Adelaide Geosyncline, South Australia. Science, 233, 198-200.

Graup G. (1981) Terrestrial chondrules, glass spherules, and accretionary lapilli from the suevite, Ries Crater, Germany. Earth Planet. Sci. Lett., 55, 407-418.

Grieve R. A. F. (1978) The melt rocks at Brent Crater, Ontario, Canada. Proc. Lunar Planet. Sci. Conf. 9th, pp. 2579-2608.

Grieve R. A. F. (1980) Impact bombardment and its role in protocontinental growth on the early Earth. Precambrian Res., 10 , $217-247$.

Grieve R. A. F. (1987) Terrestrial impact structures. Annu. Rev. Earth Planet. Sci., 15, 245-270.

Grieve R. A. F. (1990) Impact cratering on the Earth. Sci. Amer. 262, no. 4 (April 1990), 66-73.

Grieve R. A. F. (1991) Terrestrial impact: the record in the rocks. Meteoritics, 26, 175-194.

Grieve R. A. F. (1994) An impact model of the Sudbury structure. In Proceedings of the Sudbury-Noril'sk Symposium (P. C. Lightfoot and A. J. Naldrett, eds.), pp. 119-132. Ontario Geol. Survey Spec. Vol. 5.

Grieve R. A. F. (1997) Extraterrestrial impact events: The record in the rocks and the stratigraphic column. Paleogeogr., Paleodimatol, Palcoecol., 132, 5-23.

Grieve R. A. F. and Cintala M. J. (1981) A method for estimating the initial impact conditions of terrestrial cratering events, exemplified by its application to Brent crater, Ontario. Proc. Lunar Planet. Sci. 12B, pp. 1607-1621.

Grieve R. A. F. and Cintala M. J. (1992) An analysis of differential impact melt-crater scaling and implications for the terrestrial impact record. Meteoritics, 27, 526-538. 
Grieve R. A. F. and Masaitis V. L. (1994) The economic potential of terrestrial impact craters. Intl. Geol. Reve, 36, 105-151.

Grieve R. A. F. and Pesonen L. J. (1992) The terrestrial impact cratering record. Tectonophysics, 216, 1-30.

Grieve R. A. F. and Pesonen L. J. (1996) Terrestrial impact craters: Their spatial and temporal distribution and impacting bodies. Earth, Moon, Planets, 72, 357-376.

Grieve R. A. F. and Pilkington M. (1996) The signature of terrestrial impacts. AGSO J. Austral. Grol. Geophys, 16, 399420.

Grieve R. A. F. and Robertson P. B. (1976) Variations in shock deformation at the Slate Islands impact structure, Lake Superior, Canada. Contrib. Mineral. Petrol, 58, 37-49.

Grieve R. A. F. and Shoemaker E. M. (1994) The record of past impacts on Earth. In Hazards Due to Comets and Asteroids (T. Gehrels, ed.), pp. 417-462. Univ. of Arizona, Tucson.

Grieve R. A. F., Dence M. R., and Robertson P. B. (1977) Cratering process: As interpreted from the occurrence of impact melts. In Impat and Explosion Cratering: Planetary and Terrestrial Impliations (D. J. Roddy, R. O. Pepin, and R. B Merrill, eds.), pp. 791-814. Pergamon, New York.

Grieve R. A. F., Robertson P. B., and Dence M. R. (1981) Constraints on the formation of ring impact structures, based on terrestrial data. In Multi-Ring Basin. Formation and Evolution, Proc. Lunar Planet. Sci. $12 A$ (P. H. Schultz and R. B. Merrill, eds.), pp. 37-57. Pergamon, New York.

Grieve R. A. F., Reny G., Gurov E. P., and Ryabenko V. A. (1987) The melt rocks of the Boltysh impact crater, Ukraine, USSR, Contrib. Mincral. Petrol., 96, 56-62.

Grieve R. A. F, Pilkington M., and Parmentier E. (1990) Large impact basins and the early Earth (abstract). In Intl. Workshop on Meteorite Impat on the Early Earth, pr. 18-19. Perth, Australia.

Grieve R. A. F., Stöffler D., and Deutsch A. (1991a) The Sudbury Structure: Controversial or misunderstood? J. Geophys. Res., 96, 22753-22764.

Grieve R. A. F., Bottomley R. B., Bouchard M. A., Robertson P. B., Orth C. J., and Attrep M. Jr. (1991b) Impact melt rocks from New Quebec Crater, Quebec, Canada. Meteorifics, 26, 31-39.

Grieve R. A. F., Rupert J., Smith J., and Therriault A. (1995) The record of terrestrial impact cratering. GSA Today, 5, 189196.

Grieve R. A. F., Langenhorst F, and Stöfler 1). (1996) Shock metamorphism of quartz in nature and experiment: II. Significance in geoscience. Meteoritics E Planet. Sci., 31, 6-35.

Gurov E. P. and Gurova E. P. (1991) Geological Structure and Material Compositions of the Rocks of Impact Structures. Naukovia Dumka, Kiev, Ukraine, 158 pp. (In Russian.)

Guy-Bray J. V., ed. (1972) New Developments in Sudbury Geology Geol. Assoc. Canada Spec. Paper 10.124 pp.

Guy-Bray J. and Geological Staff (1966) Shatter cones at Sudbury. J. Geol., 74, 243-245.

Hargraves R. B., Cullicott C. E., Deffeyes K. S., Hougen S., Christiansen P. P., and Fiske P. S. (1990) Shatter cones and shocked rocks in southwestern Montana: The Beaverhead impact structure. Geology. 18, 832-834.

Hart R. J., Hargraves R. B., Andreoli M. A. G., Tredoux M., and Doucouré C. M. (1995) Magnetic anomaly near the center of the Vredefort structure: Implications for impactrelated magnetic signatures. Geology, 23, 277-280.

Hart R. J., Andreoli M. A. G., Tredoux M., Moser D., Ashwal L. D., Eide E. A., Webb S. J., and Brandt D. (1997) Late
Jurassic ge for the Morokweng impact structure, southern Africa. L'arth Planet. Sci. Lett., 147, 25-35.

Hartmann W K., Phillips R. J., and Taylor G. J., eds. (1986) Origin of the Mcon. Lunar and Planetary Institute, Houston. $781 \mathrm{pp}$.

Herrick R. R , Sharpton V. L., Malin M. C., Lyons S. N., and Feely K. (1997) Morphology and morphometry of impact craters. I Venus II: Geology, Geophysics, Atmosphere, and Solar Wind Eirironment (S. W. Bougher, D. M. Hunten, and R. J. Phillips, eds.), pp. 1015-1046. Univ. of Arizona, Tucson.

Heymann D, Felipe Chibante L. P., Brooks R. R., Wolbach W. S., ar d Smalley R. E. (1994) Fullerenes in the CretaceousTertiary soundary layer. Science, 265, 645-647.

Hibbard M. . (1995) Petrography to Petrogenesis. Prentice-Hall, Englewc od Cliffs. 587 pp.

Hildebrand f. R., Penfield G. T., Kring D. A., Pilkington M., Camargr -Zanoguera A., Jacobsen S. B., and Boynton W. V. (1991) ('hicxulub crater: A possible Cretaceous/Tertiary boundar : impact crater on the Yucatán Peninsula, Mexico. Geology, 19, 867-871.

Holsapple K. A. and Schmidt R. M. (1982) On the scaling of crater di nensions, 2. Impact processes. J. Geophys. Res., 87, $1849-1870$.

Holsapple K. A. and Schmidt R. M. (1987) Point source solutions and coup ling parameters in cratering mechanics. J. Geophys. Res., 92, 6350-6376.

Hörz F. (1965) Untersuchungen an Riesgläsern. Beitr. Mineral. Petrog., : 1, 621-661.

Hörz F. (196\&) Statistical measurements of deformation structures and refractive indices in experimentally shock loaded quartz. In Shock Metamorpbism of Natural Materials (B. M. French and N. .1. Short, eds.), pp. 243-253. Mono Book Corp., Baltimore

Hörz F., ed. (1971) Meteorite impact and volcanism. J. Geophys. Res., 76, 5381-5798.

Hörz F. (198.!) Ejecta of the Ries crater, Germany. In Geological Implicatims of Impacts of Large Asteroids and Comets on the Earth (L. T. Silver and P. H. Schultz, eds.), pp. 39-55. Geol. Soc. Am 2r. Spec. Paper 190.

Hörz F., Ostertag R., and Rainey D. A. (1983) Bunte Breccia of the Ries Continuous deposits of large impact craters. Rev. Geophys. Space Pbys., 21, 1667-1725.

Hörz F., Gric ve R. A. F., Heiken G., Spudis P., and Binder A. (1991) l.unar surface processes. In I.unar Sourcebook: $A$ User's $G$ ide to the Moon (G. H. Heiken, D. T. Vaniman, and B. M. Fr nch, eds.), pp. 61-120. Cambridge Univ., New York.

Hough R. M., Gilmour I., Pillinger C. T., Arden J. W., Gilkes K. W. R, Yuan J., and Milledge H. J. (1995) Diamond and silicon curbide in impact melt rock from the Ries impact crater. Nature, 378, 41-44.

Hough R. M, Gilmour I., Pillinger C. T., Langenhorst F., and Montan: ri A. (1997) Diamonds from the iridium-rich K-T boundar : layer at Arroyo el Mimbral, Tamaulipas, Mexico. Geology, 25, 1019-1022.

Howard K. A . and Offield T. W. (1968) Shatter cones at Sierra Madera, Texas. Science, 162, 261-265.

Hoyt W. G. 1987) Coon Mountain Controversies: Meter Crater and the i)evelopment of the Impact Theory. Univ. of Arizona, Tucson. $142 \mathrm{pp}$.

Izett G. A. ( .990) The Cretaceous/Tertiary boundary interval, Raton B ssin, Colorado and New Mexico, and its content of shock-matamorphosed minerals: Evidence relevant to the $\mathrm{K} / \mathrm{T}$ bot ndary impact-extinction theory. Geol. Soc. Amer. Spec. Paper 247. $100 \mathrm{pp}$. 
Izett G. A., Cobban W. A., Obradovich J. D., and Kunk M. J. (1993) The Manson impact structure: ${ }^{40} \mathrm{Ar} / 39 \mathrm{Ar}$ age and its distal impact ejecta in the Pierre Shale in southeastern South Dakota. Science, 262, 729-732.

Jansa L. F. and Pe-Piper G. (1987) Identification of an underwater extraterrestrial impact crater. Nature, 327, 612-614.

Johnson K. S. and Campbell J. A., eds. (1997) Ames structure in northwest Oklahoma and similar features: Origin and petroleum production (1995 symposium). Oklaboma Geol. Survey, Circ. 100, 396 pp.

Joreau P., French B. M., and Doukhan J.-C. (1996) A TEM investigation of shock metamorphism in quartz from the Sudbury impact structure (Canada). Earth Planet. Sci. Lett., 138, 137-143.

Kamo S. L. and Krogh T. E. (1995) Chicxulub crater source for shocked zircon crystals from the Cretaceous-Tertiary boundary layer, Saskatchewan: Evidence from new U-Pb data. Geology, 23, 281-284.

Kelley S. P. and Spray J. G. (1997) A late Triassic age for the Rochechouart impact structure, France. Meteoritics E Planet. Sci., 32, 629-636.

Kieffer S. W. (1971) Shock metamorphism of the Coconino Sandstone at Meteor Crater, Arizona. J. Geopbys. Res., 76, 5449-5473.

Kieffer S. W. (1975) Droplet chondrules. Science, 189, 333-340.

Kieffer S. W. and Simonds C. H. (1980) The role of volatiles and lithology in the impact cratering process. Rev. Geophys. Space Phys., 18, 143-181.

Kieffer S. W., Phakey P. P., and Christie J. M. (1976a) Shock processes in porous quartzite: Transmission electron microscope observations and theory. Contrib. Mineral. Petrol, 59, 41-93.

Kieffer S. W., Schaal R. B., Gibbons R., Hörz F., Milton D. J., and Dube A. (1976b) Shocked basalt from Lonar Impact Crater, India, and experimental analogues. Proc. Lunar Sii. Conf. 7th, pp. 1391-1412.

Koeberl C. (1986) Geochemistry of tektites and impact glasses. Annu. Rev. Earth Planet. Sci., 14, 323-350.

Koeberl C. (1989) New estimates of area and mass for the North American tektite strewn field. Proc. Lunar Planet. Sci. Conf. 19th, pp. 745-751.

Koeberl C. (1990) The geochemistry of tektites: An overview. Tectonophysics, 171, 405-422.

Koeberl C. (1992) Geochemistry and origin of Muong Nong-type tektites. Geochim. Cosmochim. Acta, 56, 1033-1064.

Koeberl C. (1994a) Tektite origin by hypervelocity asteroidal or cometary impact: Target rocks, source craters, and mechanisms. In Large Meteorite Impacts and Planetary Evolution (B. O. Dressler, R. A. F. Grieve, and V. L. Sharpton, eds.), pp. 133-151. Geol. Soc. Amer. Spec. Paper 293.

Koeberl C. (1994b) African meteorite impact craters: Characteristics and geological importance. J. Afr. Earth Sci, 18, 263295.

Koeberl C. and Anderson R. R., eds. (1996a) The Manson Impat Structure, Iowa: Anatomy of an Impact Crater. Geol. Soc. Amer. Spec. Paper 302. 468 pp.

Koeberl C. and Anderson R. R. (1996b) Manson and company: Impact structures in the United States. In The Manson Impact Structure, Iowa: Anatomy of an Impact Crater (C. Koeberl and R. R. Anderson, eds.), pp. 1-29. Geol. Soc. Amer. Spec. Paper 302.

Koeberl C. and Reimold W. U. (1995) Early Archean spherule beds in the Barberton Mountain Land, South Africa: No evidence for impact origin. Precambrian Res., 74, 1-33.

Koeberl C. and Shirey S. B. (1993) Detection of a meteoritic component in lvory Coast tektites with rhenium-osmium isotopes. Science, 261, 595-598.

Koeberl C., Reimold W. U., and Boer R. H. (1993) Geochemistry and mineralogy of Early Archean spherule beds, Barberton Mountain Land, South Africa: Evidence for origin by impact doubtful. Earth Planet. Sci. Lett., 119, 441-452.

Koeberl C., Poag C. W., Reimold W. U., and Brandt D. (1996a) Impact origin of the Chesapeake Bay structure and the source of the North American tektites. Science, 271, 1263-1266.

Koeberl C., Reimold W. U., Kracher A., Träxler B., Vormaier A., and Körner W. (1996b) Mineralogical, petrological, and geochemical studics of drill core samples from the Manson impact structure, Iowa. In The Manson Impact Structure, Iowa: Anatomy of an Impact Crater (C. Koeberl and R. R. Anderson, eds.), pp. 145-219. Geol. Soc. Amer. Spec. Paper 302.

Koeberl C., Reimold W. U., and Shirey S. B. (1996c) Re-Os isotope and geochemical study of the Vredefort Granophyre: Clues to the origin of the Vredefort structure. Geology, 24, 913-916.

Koeberl C., Armstrong R. A., and Reimold W. U. (1997a) Morokweng, South Africa: A large impact structure of Jurassic-Cretaceous boundary age. Geology, 25, 731-734.

Koeberl C., Bottomley R., Glass B. P., and Störzer D. (1997b) Geochemistry and age of Ivory Coast tekites and microtektites. Geochim. Cosmochim. Acta, 61, 1745-1772.

Koeberl C., Masaitis V. L., Shafranovsky G. I., Gilmour I., Langenhorst F., and Schrauder M. (1997c) Diamonds from the Popigai impact structure, Russia. Geology, 25, 967-970.

Koeberl C., Reimold W. U., and Shirey S. B. (1998) The Aouelloul crater, Mauritania: On the problem of confirming the impact origin of a small crater. Meteoritics E Planet. Sic., 33, 513-517.

Konta J., ed. (1988) Second International Conference on Natural Glasses. Charles Univ., Prague. 423 pp.

Kraut F. and French B. M. (1971) The Rochechouart meteorite impact structure, France: Preliminary geological results. J. Geophys. Res., 76, 5407-5413.

Kring D. A. (1993) The Chicxulub impact event and possible causes of K/T boundary extinctions. In Proc. First Annual Symposium of Fossils of Arizona (D. Boaz and M. Dornan, eds.), pp. 63-79. Mesa Southwest Museum and Southwest Paleontological Society, Mesa.

Kring D. A. (1997) Air blast produced by the Meteor Crater impact event and a reconstruction of the affected environment. Meteoritics E Planct. Sit., 32, 517-530.

Krinov E. L. (1966) Giant Meteorites. Pergamon, New York. $397 \mathrm{pp}$.

Krogh T. E., Davis T. W., and Corfu F. (1984) Precise U-Pb zircon and baddeleyite ages for the Sudbury area. In The Geology and Ore Deposits of the Sudbury Structure (E. G. Pye, A. J. Naldrett, and P. E. Giblin, eds.), pp. 431-446. Ontario Geol. Survey Spec. Vol. 1.

Krogh T. E., Kamo S. L., and Bohor B. F. (1993) Fingerprinting the $\mathrm{K} / \mathrm{T}$ impact site and determining the time of impact by $\mathrm{U}-\mathrm{Pb}$ dating of single shocked zircons from distal ejecta. Earth Planet. Sci. Lett., 119, 425-429.

Lambert P. (1981) Breccia dikes: Geological constraints on the formation of complex craters. In Multi-Ring Basins: Formation and Evolution, Proc. Lunar Planet. Sci. $12 A$ (P. H. Schultz and R. B. Merrill, eds.), pp. 59-78. Pergamon, New York. 
Liangenhorst F. and Clymer A. K. (1996) Characteristics of shocked quartz in late Eocene impact ejecta from Massignano (Ancona, Italy): Clues to shock conditions and source crater. Geology, 24, 487-490.

Leroux H., Reimold W. U., and Doukhan J.-C. (1994) A TEM investigation of shock metamorphism in quartz from the Vredefort dome, South Africa. Tectonophysics, 230, 223-239.

Leroux H., Warme J. E., and Doukhan J.-C. (1995) Shocked quartz in the Alamo breccia, southern Nevada: Evidence for a Devonian impact event. Geology, 23, 1003-1006.

Lightfoot P. C. and Naldrett A. J., eds. (1994) Proceedings of the Sudbury-Noril'sk symposium. Ontario Geol. Survey, Spec. Vol. $5.421 \mathrm{pp}$.

Lindström M., Sturkell E. F. F., Törnberg R., and Ormö J. (1996) The marine impact crater at Lockne, central Sweden. Geol. För. Förb. (GFF), 118, 193-206.

Love S. G. and Brownlee D. E. (1993) A direct measurement of the terrestrial mass accretion rate of cosmic dust. Science, 262, 550-553.

Lowe D. R. and Byerly G. R. (1986) Early Archean silicate spherules of probable impact origin, South Africa and Western Australia. Geology, 14, 83-86.

Lowe D. R., Byerly G. R., Asaro F., and Kyte F. J. (1989) Geological and geochemical record of 3400-million-year-old terrestrial meteorite impacts. Sience, 245, 959-962.

Manton W. L. (1965) The orientation and origin of shatter cones in the Vredefort Ring. Ann. N.Y. Acad. Sci., 123, 1017-1049.

Mark K. (1987) Mitcorite Craters. Univ. of Arizona, Tucson. $288 \mathrm{pp}$.

Martini J. E. J. (1991) The nature, distribution and genesis of the coesite and stishovite associated with the pseudotachylite of the Vredefort Dome, South Africa. Earth Planet. Sci. Lett., $103,285-300$

Masaitis V. L., ed. (1983) Strutures and Textures of Explosive Breccias and Impattites. Nedra, Leningrad (St. Petersburg). 158 pp. (In Russian.)

Masaitis V. L. (1994) Impactites from Popigai crater. In Large Meteorite Impacts and Early Planetary Evolution (B. O. Dressler, R. A. F. Grieve, and V. L. Sharpton, eds.), pp. 153162. Geol. Soc. Amer. Spec. Paper 293.

Masaitis V. L. (1998) Popigai crater: Origin and distribution of diamond-bearing impactites. Meteoritics E Planet. Sci., 33, $349-359$

Masaitis V. L., Futergendler S. I., and Gnevushev M. A. (1972) Diamonds in impactites of the Popigai meteorite crater Memoirs All-Union Mineral. Soc., Ser. 2, Part 1, 108-112. (In Russian.)

Masaitis V. L., Danilin A. N., Mashchak M. S., Raykhlin A. I., Selivanovskaya T. V., and Shadenkov Ye. M. (1980) The Geology of Astroblemes. Nedra, Leningrad (St. Petersburg). 231 pp. (In Russian.)

Maxwell D. E. (1977) Simple Z model of cratering, ejection, and the overturned flap. In Impact and Explosion Cratering: Planetary and Terrestrial Implications (D. J. Roddy, R. O. Pepin, and R. B. Merrill, eds.), pp. 1003-1008. Pergamon, New York.

McCarville P. and Crossey L. J. (1996) Post-impact hydrothermal alteration of the Manson impact structure. In The Manson Impact Struture, lowa: Anatomy of an Impact Crater (C. Koeberl and R. R. Anderson, eds.), pp. 347-376. Geol. Soc. Amer. Spec. Paper 302.

McIntyre D. B. (1968) Impact metamorphism at Clearwater Lake, Quebec. In Shock Metamorphism of Natural Materials
(B. M. J'rench and N. M. Short, eds.), pp. 363-366. Mono Book C rp., Baltimore.

McLaren D. J. and Goodfellow W. D. (1990) Geological and biologic il consequences of giant impacts. Annu. Rev. Earth Planet. 'ci., 18, 123-171.

Medenbach 1). (1985) A new microrefractometer spindle stage and its application. Fortschr. Mineral., 63, 111-133.

Meisel T., K seberl C., and Ford R. J. (1990) Geochemistry of Darwin impact glass and target rocks. Geochim. Cosmochim. Acta, 54, 1463-1474.

Melosh H. J. (1989) Impact Cratering: A Geologic Process. Oxford Univ., New York. 245 pp.

Melosh H. J (1992) Impact crater geology. In Encyclopedia of Earth Syitem Science, Vol. 2 (W. A. Nierenberg, ed.), pp. 591605. Aca demic, San Diego.

Melosh H. J. and Vickery A. M. (1989) Impact erosion of the primord al atmosphere of Mars. Nature, 338, 487-489.

Melosh H. J. and Vickery A. M. (1991) Melt droplet formation in energ tic impact events. Nature, 350, 494-497.

Milton D. J. (1977) Shatter cones - An outstanding problem in shock $m$ schanics. In Impact and Explosion Cratering: Planetary and Terrestrial Implications (D. J. Roddy, R. O. Pepin, and R. E. Merrill, eds.), pp. 703-714. Pergamon, New York.

Milton D. J., 3arlow B. C., Brett R., Brown A. R., Glikson A. Y., Manwarng E. A., Moss F. J., Sedmik E. C. E., Van Son J., and Young G. A. (1972) Gosses Bluff impact structure, Australi:. Science, 175, 1199-1207.

Milton D. J., Jlikson A. Y., and Brett R. (1996a) Gosses BluffA latest Jurassic impact structure, central Australia. Part I: Geologi al structure, stratigraphy, and origin. $A G S O J$. Austral. 1reol. Geophys., 16, 453-486.

Milton D. J., 3arlow B. C., Brown A. R., Moss F. J., Manwaring E. A., Se dmik E. C. E., Young G. A., and Van Son J. (1996b) Gosses Illuff - A latest Jurassic impact structure, central Australia. Part II: Seismic, magnetic, and gravity studies. AGSOJ. Austral. Geol. Geophys., 16, 487-527.

Mittlefehldt 1).W., See T. H., and Hörz F. (1992) Dissemination and fractionation of projectile materials in the impact melts fro n Wabar Crater, Saudi Arabia. Meteoritics, 27, 361370.

Montanari A., Hay R. L., Alvarez W., Asaro F., Michel H. V., Alvarez L. W., and Smit J. (1983) Spheroids at the Cretaceo is-Tertiary boundary are altered impact droplets of basaltic composition. Geology, 11, 668-671.

Montanari A. Asaro F., Michel H. V., and Kennett J. P. (1993) Iridium z nomalies of Late Eocene age at Massignano (Italy) and ODI' Site 689B (Maud Rise, Antarctic). Palaios, 8, 420437.

Morgan J., V/arner M. and the Chicxulub Working Group, Brittan J., Buffler R., Camargo A., Christeson G., Denton P., Hilde orand A., Hobbs R., Macintyre H., Mackenzie G., Mag tire P., Marin L., Nakamura Y., Pilkington M., Sharptor V., Snyder D., Suarez G., and Trejo A. (1997) Size and norphology of the Chicxulub impact crater. Nature, $390,472-476$.

Morrison D., shair (1992) The Spaceguard Survey: Report of the NASA International Near-Earth-Object Detection Workshop. NASA Cffice of Space Science and Applications, Solar System Explaration Division, Planetary Astronomy Program, January 25, 1992. 52 pp. + appendixes.

Muir T. L. anr. Peredery W. (1984) The Onaping Formation. In The Geole sy and Ore Deposits of the Sudbury Structure (E. G. 
Pye, A. J. Naldrett, and P. E. Giblin, eds.), pp. 139-210. Ontario Geol. Survey Spec. Vol. 1.

Müller W. F. (1969) Elektronmicroskopischer Nachweis amorpher Bereiche in stosswellenbeanspruchtem Quarz. Naturwissenschaften, 56, 279.

Murali A. V., Zolensky M. E., and Blanchard D. P. (1987) Tektitelike bodies at Lonar Crater, India: Implications for the origin of tektites. Proc. Lunar Planet. Sci. Conf. 17th, in J. Geophys. Res., 92, E729-E735.

Nel L. T. (1927) The geology of the country around Vredefort. Geol. Survey S. Afr: Spec. Publ. 6. 134 pp.

Neukum G. and Ivanov B. A. (1994) Crater size distributions and impact probabilities on Earth from lunar, terrestrial-planet, and asteroid cratering data. In Hazards Due to Comets and Asteroids (T. Gehrels, ed.), pp. 359-416. Univ. of Arizona, Tucson. 1300 pp.

Newburn R. L. Jr., Neugebauer M., and Rahe J., eds. (1991) Comets in the Post-Halley Era. Kluwer Academic, Boston. $1360 \mathrm{pp}$.

Newsom H. E., Graup G., Sewards T., and Keil K. (1986) Fluidization and hydrothermal alteration of the suevite deposit at the Ries Crater, west Germany, and implications for Mars. Proc. Lunar Planet. Sci. Conf. 17th, in J. Geopbys. Res., 91, E239-E251.

Nicolaysen L. O. and Reimold W. U., eds. (1990) Cryptoexplosions and catastrophes in the geological record, with a special focus on the Vredefort structure. Tectonopbysics, 171, pp. 1-422.

Oberbeck V. R., Marshall J. R, and Aggarwal H. (1993) Impacts, tillites, and the breakup of Gondwanaland. J. Geol, 101, $1-19$.

O'Keefe J. A., ed. (1963) Tektites. Univ of Chicago, Chicago. $228 \mathrm{pp}$.

O'Keefe J. A. (1976) Tektites and Their Origin. Elsevier, New York. 254 pp.

O'Keefe J. A. (1994) Origin of tektites. Meteoritics, 29, 73-78.

O'Keefe J. D. and Ahrens T. J. (1975) Shock effects from a large impact on the Moon. Proc. Lunar Sit. Conf. 6th, pp. 28312844.

O'Keefe J. D. and Ahrens T. J. (1977) Impact-induced energy partitioning, melting, and vaporization on terrestrial planets. Proc. Lunar Sci. Conf. 8th, pp. 3357-3374.

O'Keefe J. D. and Ahrens T. J. (1982) Cometary and meteorite swarm impact on planetary surfaces. J. Geophys. Res., 87, 66686680 .

O'Keefe J. D. and Ahrens T. J. (1993) Planetary cratering mechanics. J. Geophys. Res., 98, 17011-17028.

Ostermann M., Schärer U., and Deutsch A. (1996) Impact melt dikes in the Sudbury multi-ring basin (Canada): Implications from uranium-lead geochronology on the Foy Offset Dike. Meteoritics Eo Planet. Sci., 31, 494-501.

Ostertag R. and Stöffler D. (1982) Thermal annealing of experimentally shocked feldspar crystals. Proc. Lunar Planet. Sit. Conf. 1.3th, in J. Geophys. Res., 87, A457-A463.

Palme H. (1982) Identification of projectiles of large terrestrial impact craters and some implications for the interpretation of Ir-rich Cretaceous/Tertiary boundary layers. In Geological Implications of Impacts of Large Asteroids and Comets on the Earth (L. T. Silver and P. H. Schultz, eds.), pp. 223-233. Geol. Soc. Amer. Spec. Paper 190.

Palme H., Göbel E., and Grieve R. A. F. (1979) The distribution of volatile and siderophile elements in the impact melt of East Clearwater (Quebec). Proc. Lunar Planet. Sit. Conf. 10th, pp. 2465-2492.
Palme H., Grieve R. A. F., and Wolf R. (1981) Identification of the projectile at the Brent crater, and further considerations of projectile types at terrestrial craters. Geochim. Cosmochim. Acta, 45, 2417-2424.

Partridge T. C., Kerr S. J., Metcalfe S. E., Scott L., Talma A. S., and Vogel J. C. (1993) The Pretoria Saltpan: A 200,000 year Southern African lacustrine sequence. Paleogrogr., Palioclimatol, Paleocol., 101, 317-337.

Peredery W. V. (1972) Chemistry of fluidal glasses and melt bodies in the Onaping Formation. In New Developments in Sudbury Geology (J. V. Guy-Bray, ed.), pp. 49-59. Geol. Assoc. Canada Spec. Paper 10.

Pesonen L. J. (1996) The impact cratering record of Fennoscandia. Earth, Moon, Planets, 72, 377-393.

Pesonen L. J. and Henkel H., eds. (1992) Terrestrial impact craters and craterform structures, with a special focus on Fennoscandia. Tectonophysics, 216, 1-234.

Philpotts A. R. (1964) Origin of pseudotachylites. Amer. J. Sic., 262, 1008-1035.

Philpotts A. R. (1990) Principles of Igneous and Metamorphic Petrology. Prentice-Hall, Engelwood Cliffs. 498 pp.

Pilkington M. and Grieve R. A. F. (1992) The geophysical signature of terrestrial impact craters. Rev. Geophys., 30, 161-181.

Poag C. W. (1996) Structural outer rim of Chesapeake Bay impact crater: Seismic and bore hole evidence. Meteoritics 8 Planet. Sci., 31, 218-226.

Poag C. W. (1997) The Chesapeake Bay bolide impact: A convulsive event in Atlantic Coastal Plain evolution. Sedimentary Geol., 108, 45-90.

Pollastro R. M. and Bohor B. F. (1993) Origin and clay-mineral genesis of the Cretaceous/Tertiary boundary unit, western interior of North America. Clays Clay Min., 41, 7-25.

Pope K. O., Baines K. H., Ocampo A. C., and Ivanov B. A. (1994) Impact winter and the Cretaceous/Tertiary extinctions: Results of a Chicxulub asteroid impact model. Earth Planet. Sci. Lett., 128, 719-725.

Pope K. O., Baines K. H., Ocampo A. C., and Ivanov B. A. (1997) Energy, volatile production, and climatic effects of the Chicxulub Cretaceous/Tertiary impact. J. Geophys. Res., 102, 21645-21664.

Pye E. G., Naldrett A. J., and Giblin P. E. (1984) The geology and ore deposits of the Sudbury structure. Ontario Geol. Survey Spec. Vol. 1, 603 pp.

Pye L. D., O'Keefe J. A., and Fréchette V. D., eds. (1984) Natural Glasses: Procedings of the International Conference on Glass in Planetary and Geological Pbenomena. North-Holland, Amsterdam. $662 \mathrm{pp}$.

Rahe J., Vanysek V., and Weissman P. R. (1994) Properties of cometary nuclei. In Hazards Due to Comets and Asteroids (T. Gehrels, ed.), pp. 597-634. Univ. of Arizona, Tucson.

Rampino M. R. (1994) Tillites, diamictites, and ballistic ejects of large impacts. J. Geol., 102, 439-456.

Reiff W. (1977) The Steinheim Basin - An impact structure. In Impact and Explosion Cratering: Planetary and Terrestrial Implications (D. J. Roddy, R. O. Pepin, and R. B. Merrill, eds.), pp. 309-320. Pergamon, New York.

Reimold W.U. (1991) The geochemistry of pseudotachylites from the Vredefort Dome, South Africa. N.Jahrb. Miner. Abh., 162, 151-184.

Rcimold W. U. (1995) Pseudotachylite in impact structures Generation by friction melting and shock brecciation?: $A$ review and discussion. Eartb-Sci. $R_{e} v$, 39, 247-265. 
Reimold W. U. and Colliston W. P. (1994) Pseudotachylites of the Vredefort Dome and the surrounding Witwatersrand Basin, South Africa. In Large Meteorite Impacts and Planetary Evolution (B. O. Dressler, R. A. F. Grieve, and V. L. Sharpton, eds.), pp. 177-196. Geol. Soc. Amer. Spec. Paper 293.

Reimold W. U. and Gibson R. L. (1996) Geology and evolution of the Vredefort impact structure, South Africa. J. Afr. Earth Sic., 23, 125-182.

Reimold W. U., Oskierski W., and Huth J. (1987) The pseudotachylite from Champagnac in the Rochechouart meteorite crater, France. Proc. Lunar Planet. Sci. Conf. 17th, in J. Goophys. Re's. 92, E737-E748.

Reimold W. U., Koeberl C., and Brandt D. (1997a) Suevite at the Roter Kamm crater, Namibia. Meteoritics E Planet Sci., $32,431-437$.

Reimold W. U., von Brunn V., and Koeber] C. (1997b) Are diamictites impact ejecta? - No supporting evidence from South African Dwyka Group diamictite. J. Geol., 105, 517530.

Rhodes R. (1975) New evidence for impact origin of the Bushveld Complex, South Africa, Geology, 3, 549-554.

Robertion P. B. (1975) Zones of shock metamorphism at the Charlevoix impact structure, Quebec. Geol. Soc. Amer. Bull., $86,1630-1638$.

Robertson P. B. and Grieve R. A. F. (1977) Shock attenuation at terrestrial impact structures. In Impact and Explosion Cratering: Planetary and Terrestrial Implications (D. J. Roddy, R. O. Pepin, and R. B. Merrill, eds.), pp. 687-702. Pergamon, New York.

Robertson P. B., Dence M. R., and Vos M. A. (1968) Deformation in rock-forming minerals from Canadian craters. In Shock Mitamorphism of Natural Materials (B. M. French and N. M. Short, eds.), pp. 433-452. Mono Book Corp., Baltimore.

Roddy D. J. (1968) The Flynn Creck crater, Tennessee. In Shock Mitamorphism of Natural Materials (B. M. French and N. M. Short, eds.), pp. 291-322. Mono Book Corp., Baltimore

Roddy D. J. (1978) Pre-impact geologic conditions, physical properties, energy calculations, meteorite and initial crater dimensions and orientations of joints, faults and walls at Meteor Crater, Arizona. Proc. Lunar Planet. Sci. Conf. 9th, pp. 3891-3930.

Roddy D. J. and Davis L. K. (1977) Shatter cones formed in largescile experimental explosion craters. In Impact and Explosion Cratering: Planetary and Terrestrial Implications (D. J. Roddy, R. O. Pepin, and R. B. Merrill, eds.), pp. 715-750. Pergamon, New York.

Roddy D. J., Boyce J. M., Colton G. W., and Dial A. L. Jr. (1975) Meteor Crater, Arizona, rim drilling with thickness, structural uplift, diameter, depth, volume, and mass-balance calculations. Proc. Lunar Sci. Conf. 6th, pp. 2621-2644.

Roddy D. J., Pepin R. O., and Merrill R. B., eds. (1977) Impact and Explosion Cratering: Planetary and Tirrestrial Implications. Pergatmon, New York. 1301 pp.

Ryder G., Fastovsky D., and Gartner S., eds. (1996) The CretaceousTertiary Event and Other Catastrophes in Earth History. Geol. Soc. Amer. Spec. Paper 307. 569 pp.

Schatal R. B. and Horz F. (1977) Shock metamorphism of lunar and terrestrial basalts. Proi. Lunar Sci. Conf. 8th, pp. 16971729.

Schultz P. H. and Merrill R. B., eds. (1981) Multi-Ring Basins: Formation and Evolution, Proc. Lunar Planet. Sci. $12 \mathrm{~A}$. Pergamon, New York. $295 \mathrm{pp}$.
Schuraytz B. C., Sharpton V. L., and Marín L. E. (1994) Petrology of impict-melt rocks at the Chicxulub multiring basin, Yucatár , Mexico. Geology, 22, 868-872.

Schuraytz B C., Lindstrom D. J., Marin L. E., Martinez R. R., Mittlef :hldt D. W., Sharpton V. L., and Wentworth S. J. (1996) Iridium metal in Chicxulub impact melt: Forensic chemisi ry on the K-T smoking gun. Science, 271, 1573-1576.

Scott R. G., Pilkington M., and Tanczyk E. I. (1997) Magnetic investigations of the West Hawk, Deep Bay and Clearwater impact structures, Canada. Metcoritics \& Planet. Sci., 32, 293-303.

Shand S. J. 1916) The pseudotachylyte of Parijs (Orange Free State) : nd its relation to "trap-shotten gneiss" and "flinty crush-r sck." Quart. J. Geol. Soc. London, 72, 198-221.

Sharpton V. L. and Grieve R. A. F. (1990) Meteorite impact, cryptoe plosion, and shock metamorphism: A perspective on the evic ence at the K/T boundary. In Global Catastrophes in Earth 11istory: An Interdisciplinary Conference on Impacts, Volcanism, and Mass Mortality (V. L. Sharpton and P. D. Ward, e ds.), pp. 301-318. Geol. Soc. Amer. Spec. Paper 247.

Sharpton V. L. and Ward P. D., eds. (1990) Global Catastrophes in Earth listory: An Interdisciplinary Conference on Impacts, Volcanis n, and Mass Mortality. Geol. Soc. Amer. Spec. Paper 247. $631 \mathrm{pp}$.

Sharpton V L., Dalrymple G. B., Marin L. E., Ryder G., Schuray tz B. C., and Urrutia-Fucugauchi J. (1992) New links betweer the Chicxulub impact structure and the Cretaceous/ Tertiary boundary. Nature, 359, 819-821.

Sharpton V. L., Burke K., Camargo-Zanoguera A., Hall S. A., Lee D. S., Marín L. E., Suárez-Reynoso G., QuezadaMuñet n J. M., Spudis P. D., and Urrutia-Fucugauchi J. (1993) Zhicxulub multiring impact basin: Size and other charact ristics derived from gravity analyses. Science, 261, 1564-1567.

Sharpton V. L., Dressler B. O., Herrick R. R., Schneiders B., and Scrtt J. (1996a) New constraints on the Slate Islands impact : tructure, Ontario, Canada. Geology, 24, 851-854.

Sharpton V. L., Marin L. E., Carney J. L., Lee S., Ryder G., Schuraytz B. C., Sikora P., and Spudis P. D. (1996b) A model if the Chicxulub impact basin based on evaluation of geop. iysical data, well logs, and drill core samples. In The Cretacecus-Tertiary Event and Other Catastrophes in Eartb History (G. Ryder, D. Fastovsky, and S. Gartner, eds.), pp. 55-"4. Geol. Soc. Amer. Spec. Paper 307.

Shoemaker J:. M. (1963) Impact mechanics at Meteor Crater, Arizon I. In The Moon, Meteorites, and Comets (B. M. Middlelıurst and G. P. Kuiper, eds.), pp. 301-336. Univ. of Chicagc, Chicago.

Shoemaker I:. M. (1977) Why study impact craters? In Impact and Exylosion Cratering: Planetary and Terrestrial Implications (L. J. Roddy, R. O. Pepin, and R. B. Merrill, eds.), pp. 1-10. Pergamon, New York.

Shoemaker F . M. and Chao E. C. T. (1961) New evidence for the impact c rigin of the Ries Basin, Bavaria, Germany. J. Geophys. Res., 66, 3371-3378.

Shoemaker I. M. and Hackman R. J. (1962) Stratigraphic basis for a lun ir time scale. In The Moon: Proceedings of Symposium No. 14 o the International Astronomical Union (Z. Kopal and Z. K. Mikhailov, eds.), pp. 289-300. Academic, New York.

Shoemaker F. M. and Shoemaker C. S. (1996) The Proterozoic impact record of Australia. AGSO J. Austral. Geol. Geophys., 16, 379-398. 
Shoemaker E. M., Hackman R. J., and Eggleton R. E. (1963) Interplanetary correlation of geologic time. Adv. Astronatut. Sci., 8, 70-89.

Sibson R. H. (1975) Generation of pseudotachylyte by ancient seismic faulting. Geopbys. J. Roy. Astron. Soc., 43, 775-794.

Sigurdsson H., D'Hondt S., Arthur M. A., Bralower T. J., Zachos J. C., van Fossen M., and Channell J. E. T. (1991a) Glass from the Cretaceous/Tertiary boundary in Haiti. Nature, $349,482-487$.

Sigurdsson H., Bonté Ph., Turpin L., Chaussidon M., Metrich N., Steinberg M., Pradel Ph., and D'Hondt S. (1991b) Geochemical constraints on source region of Cretaceous/Tertiary impact glasses. Nature, 353, 839-842.

Silver L. T. and Schultz P. H., eds. (1982) Geological Implications of Impacts of Large Asteroids and Comets on the Earth. Geol. Soc. Amer. Spec. Paper 190. 528 pp.

Simonds C. H., Warner J. L., Phinney W. C., and McGee P. E. (1976) Thermal model for impact breccia lithification: Manicouagan and the Moon. Proc. Lunar Sci. Conf. 7th, pp. 25092528 .

Simonds C. H., Floran R. J., McGee P. E., Phinney W. C., and Warner J. L. (1978a) Petrogenesis of melt rocks, Manicouagan impact structure, Quebec. J. Geophys. Res., 83, 27732788 .

Simonds C. H., Phinney W. C., McGee P. E., and Cochran A. (1978b) West Clearwater, Quebec, impact structure, Part I: Field geology, structure and bulk chemistry. Proc. Lumar Planet. Si. Conf. 9th, pp. 2633-2658.

Simonson B. M. (1992) Geological evidence for a strewn field of impact spherules in the early Precambrian Hamersley Basin of Western Australia. Geol. Soc. Amer. Bull., 104, 829-839.

Simonson B. M. and Davies D. (1996) PGEs and quartz grains in a resedimented Late Archean impact horizon in the Hamersley Group of Western Australia (abstract). In Lunar and Planetary Science XXVII, pp. 1203-1204. Lunar and Planetary Institute, Houston.

Simonson B. M., Beukes N. J., and Hassler S. (1997) Discovery of a Neoarchean impact spherule horizon in the Transvaal Supergroup of South Africa and possible correlations to the Hamersley Basin of Western Australia (abstract). In Lunar and Planetary Science XXVIII, pp. 1323-1324. Lunar and Planetary Institute, Houston.

Speers E. C. (1957) The age relation and origin of common Sudbury breccia. J. Geol., 65, 497-514.

Spencer J. R. and Mitton J., eds. (1995) The Great Comet Crash: The Impact of Comet Shoemaker-Levy 9 on Jupiter. Cambridge Univ., New York. 118 pp.

Spray J. G. (1995) Pseudotachylyte controversy: Fact or friction? Geology, 23, 1119-1122.

Spray J. G. (1997) Superfaults. Geology, 25, 579-582.

Spray J. G. and Thompson L. M. (1995) Friction melt distribution in multi-ring impact basins. Nature, 373, 130-132.

Spray J. G., Kelley S. P., and Reimold W. U. (1995) Laser probe argon-40/argon-39 dating of coesite- and stishovite-bearing pseudotachylites and the age of the Vredefort impact event. Meteoritics, 30, 335-343.

Spudis P. D. (1993) The Geology of Multi-Ring Impact Basins: The Moon and Other Planets. Cambridge Univ., New York. 263 pp.

Stähle V. (1973) Cordierite glass formed by shock in a cordieritegarnet-gneiss from the Ries crater, Germany. Earth Planet. Sci. Lett., 18, 385-390.
Stepto D. (1990) The geology and gravity field in the central core of the Vredefort structure. Tectonophysics, 171, 75-103.

Stöfler D. (1966) Zones of impact metamorphism in the crystalline rocks at the Nördlinger Ries Crater. Contrib. Mineral. Petrol, $12,15-24$.

Stöffler D. (1967) Deformation und Umwandlung von Plagioklas durch Stosswellen in den Gesteinen der Nördlinger Ries. Contrib. Mineral. Petrol., 16, 51-83.

Stöffler D. (1971) Progressive metamorphism and classification of shocked and brecciated crystalline rocks at impact craters. J. Geophys. Res., 76, 5541-5551.

Stöffler D. (1972) Deformation and transformation of rockforming minerals by natural and experimental shock processes: I. Behavior of minerals under shock compression. Fortschr. Mineral., 49, 50-113.

Stöffler D. (1974) Deformation and transformation of rockforming minerals by natural and experimental shock processes: II. Physical properties of shocked minerals. Fortschr. Mineral., 51, 256-289.

Stöfller D. (1984) Glasses formed by hypervelocity impact. $J$. Non-Crystall. Solids, 67, 465-502.

Stöffler D. and Grieve R. A. F. (1994) Classification and nomenclature of impact metamorphic rocks: A proposal to the IUGS Subcommission on the Systematics of Metamorphic Rocks (abstract). In European Sci. Foundation Second Intl. Workshop on "Impact Cratering and the Evolution of Planet Earth": The Identification and Characterization of Impacts, Ostersund, Sweden.

Stöfler D. and Grieve R. A. F. (1996) IUGS classification and nomenclature of impact metamorphic rocks: Towards a final proposal (abstract). In Intl. Workshop, Postojna 96: The Role of Impact Processes in the Geological and Biological Evolution of Planet Earth (K. Drobne, S. Gorican, and B. Kotnik, eds.), pp. 89-90. Ljubljana.

Stöfler D. and Langenhorst F. (1994) Shock metamorphism of quartz in nature and experiment: I. Basic observation and theory. Meteoritics, 29, 155-181.

Stöffler D., Knöll H.-D., and Maerz U. (1979) Terrestrial and lunar impact breccias and the classification of lunar highland rocks. Proc. Lunar Planet. Sci. Conf. 10th, pp. 639-675.

Stöfler D., Bischoff L., Oskierski W., and Wiest B. (1988) Structural deformation, breccia formation, and shock metamorphism in the basement of complex terrestrial impact craters: implications for the cratering process. In Deep Drilling in Crystalline Bedrock, Vol. 1: The Deep Gas Drilling in the Siljan Impact Structure, Sweden and Astroblemes (A. Bodén and K. G. Eriksson, eds.), pp. 277-297. Springer-Verlag, New York.

Stöffler D., Deutsch A., Avermann M., Bischoff L., Brockmeyer P., Buhl D., Lakomy R., and Müller-Mohr V. (1994) The formation of the Sudbury structure, Canada: Toward a unified impact model. In Large Meteorite Impacts and Planetary Evolution (B. O. Dressler, R. A. F. Grieve, and V. L. Sharpton, eds.), pp. 303-318. Geol. Soc. Amer. Spec. Paper 293.

Storzer D. and Koeberl C. (1991) Uranium and zirconium enrichments in Libyan Desert Glass: Zircon, baddeleyite and high temperature history of the glass (abstract). In Lumar and Planetary Science XXII, pp. 1345-1346. Lunar and Planetary Institute, Houston.

Symes S. J. K., Sears D. W. G., Akridge D. G., Huang S., and Benoit P. H. (1998) The crystalline lunar spherules: Their formation and implications for the origin of meteoritic chondrules. Meteoritics E Planet. Sci., 33, 13-29. 
Taylor G. J., Warren P., Ryder G., Delano J., Pieters C., and Lofgren G. (1991) Lunar rocks. In Lunar Sourcebook: A User's Guide to the Moon (G. H. Heiken, D. T. Vaniman, and B. M. French, eds.), pp. 183-284. Cambridge Univ., New York.

Taylor S. R. (1975) Lunar Sicince: A Post-Apollo View. Pergamon, New York. 372 pp.

Taylor S. R. (1982) Planctary Scinee: A Lunar Perspective. Lunar and Planetary Institute, Houston. $481 \mathrm{pp}$.

Taylor S. R. (1992) Solar System Evolution: A New Perspective. Cimbridge Univ, New York. 307 pp.

Taylor S. R. and Koeberl C. (1994) The origin of tektites: Comment on a paper by J. A. O'Keefe. Meteoritics, 29, 739-742.

Therriault A. M. and Lindström M. (1995) Planar deformation features in quartz grains from the resurge deposit of the Lockne structure, Sweden. Meteoritics, 30, 700-703.

Therriault A. M., Reimold W. U., and Reid A. M. (1996) Field relations and petrography of the Vredefort Granophyre. $S$. Afr. J. Giol., 99, 1-21.

Therriault A. M., Grieve R. A. F., and Reimold W. U. (1997) Original size of the Vredefort Structure: Implications for the geological evolution of the Witwatersrand Basin. Meteoritics E Planet. Sci., 32, 71-77.

Thompson L. M. and Spray J. G. (1994) Pseudotachylitic rock distribution and genesis within the Sudbury impact structure. In Large Meteorite Impacts and Planetary Evolution (B. O. Dressler, R. A. F. Grieve, and V. L. Sharpton, eds.), pp. 275-287. Geol. Soc. Amer. Spec. Paper 293.

Trefil J. S. and Raup D. M. (1990) Crater taphonomy and bombardment rates in the Phanerozoic. J. Geol., 98, 385-398.

Turtle E. P. and Pierazzo E. (1998) Constraints on the size of the Vredefort impact crater from numerical modeling. Mitioritics Es Plantt. Sit, 33, 483-490.

Verschuur G. L. (1996) Impact' The Threat of Comets and Asteroids. Oxford Univ., New York. 237 pp.

von Engelhardt W. (1990) Distribution, petrography and shock metamorphism of the ejectia of the Ries crater in Germany A revicw. Tectonophysics, 171, 259-273.

von Engelhardt W. (1997) Suevite breccia of the Ries impact crater, Germany: Petrography, chemistry, and shock metamorphism of erystalline rock clasts. Miteoritics E Planet. Sci., 32, 545554.

von Engelhardt W. and Bertsch W. (1969) Shock induced planar deformation features in quartz from the Ries Crater, Germany. Contrib. Mineral. Petrol., 20, 203-234.

von Engelhardt W. and Graup G. (1984) Suevite of the Ries Crater, Germany: Source rocks and implications for cratering mechanics. Giol. Runtsch., 73, 447-481. von Engelhar lt W. and Stöffler D. (1965) Spaltflächen im Quarz als Anzeichen für Einschläge grosser Meteoriten. Naturwissensct, aften, 17, 489-490.

von Engelhar lt W. and Stöfler D. (1968) Stages of shock metamorphisı in crystalline rocks of the Ries Basin, Germany. In Shock Metamorphism of Natural Materials (B. M. French and N. 11. Short, eds.), pp. 159-168. Mono Book Corp., Baltimor:.

von Engelha dt W., Stoffler D., and Schneider W. (1969) Petrolog sche Untersuchungen im Ries. Geol. Bavar., 61, 229-295

von Engelharc r W., Luft E., Arndt J., Schock H., and Weiskirchner W. (198:) Origin of moldavites. Geobim. Carmochim. Acta., $51,1425-1443$

Weaver K. F. (1986) Meteorites: Invaders from space. National Geograph C, 170, No. 3 (September 1986), pp. 390-418.

Weeks R. A., Underwood J. R. Jr., and Giegengack R. (1984) Libyan I lesert Glass: A review. J. Non-Crystall. Solids, 67, 593-619

Weiblen P. W. and Schulz K. J. (1978) Is there any record of meteorite impact in the Archean rocks of North America? Proc. Lun ar Planet. Sci. Conf. 9th, pp. 2749-2771.

Wilhelms D. ¿. (1993) To a Rocky Moon: A Geologist's History of Lunar Exploration. Univ of Arizona, Tucson. $477 \mathrm{pp}$.

Wilhelms D. E., McCauley J. F., and Trask N. J. (1987) The geologic istory of the Moon. U.S. Geol. Survey Prof. Paper 1348. $30^{\circ} \mathrm{pp}$.

Wilkening L. L., ed. (1982) Comets. Univ. of Arizona, Tucson. $766 \mathrm{pp}$.

Williams G. E. (1986) The Acraman impact structure: Source of ejecta in ate Precambrian shales, South Australia. Science, 233, 200-203.

Wilshire H. C., Offield T. W., Howard K. A., and Cummings D. (1972 Geology of the Sierra Madera cryptoexplosion structure, Pecos County, Texas. U.S. Geol. Survey Prof. Paper 599-H. 4: pp.

Wood C. R. ald Spray J. G. (1998) Origin and emplacement of offset dyk es in the Sudbury impact structure: Constraints from Hes . Meteoritics E Planet. Sci., 33, 337-347.

Wu J., Milkere t B., and Boerner D. (1994) Timing constraints on deformati on history of the Sudbury impact structure. Can.J. Earth Si. 31, 1654-1660.

Yang W. and A hrens T. J. (1998) Shock vaporization of anhydrite and globa effects of the K/T bolide. Earth Planet. Sci. Lett. $156,125-140$. 
NOTES 
NOTES 